\title{
Auswertemethoden für die zeitaufgelöste Fluoreszenzspektroskopie
}

\author{
DISSERTATION \\ zur Erlangung des Doktorgrades \\ der Mathematisch-Naturwissenschaftlichen Fakultäten \\ der Georg-August-Universität zu Göttingen
}

vorgelegt von

Uwe Heinz Bünting

aus Sande

Göttingen 1999 
Habe nun, ach! Spektroskopie, Computerei und PLS, Und leider auch Chemie! Durchaus studiert, mit heißem Bemühn. Da stehe ich nun, ich armer Thor! Und bin so klug als wie zuvor.

(frei nach Goethe) 


\section{Publikationen}

1. D.A. Coley und U. Bünting. The Identification of Complex Objects from NMR Images by Genetic Algorithm. IEE Digest, 193, S. 91-96, 1994.

2. P. Karlitschek, U. Bünting, T. Nörthemann, G. Hillrichs. Fluorometric detection of water pollutants with a fiber coupled solid-state UV-Laser. In: Laser methods for biological and environmental applications. SPIE-Proceedings, 2965, S. 88-96, 1996.

3. U. Bünting, P. Karlitschek. Mathematical model for optimum fibre optic probe design and characterisation. Spectrochimica Acta A, 54, S. 1369-1374, 1998.

4. P. Karlitschek, F. Lewitzka, U. Bünting, M. Niederkrüger, G. Marowsky. Detection of aromatic pollutants in the environment by using $U V$-laser-induced fluorescence. Applied Physics B, 67, S. 497-504, 1998.

5. U. Bünting, P. Karlitschek, F. Lewitzka, G. Marowsky, M. Niederkrüger. Environmental monitoring using micro-optical sensors. In: Micro System Technologies 98, H. Reichel, E. Obermeier (Editoren), VDE Verlag Berlin, S. 219$224,1998$.

6. G. Marowsky, U. Bünting Laserlicht im Leitungswasser. In: Neue Zürcher Zeitung, 27.2.1997.

7. U. Bünting, F. Lewitzka, P. Karlitschek. Mathematical Model of a LaserInduced Fluorescence Fiber-Opitc Sensor Head for Trace Detection of Pollutants in Soil. Applied Spectroscopy, 53, S. 49-56, 1999.

8. F. Lewitzka, P. Karlitschek, U. Bünting, M. Niederkrüger, G. Marowsky. Quantitative analysis of aromatic molecules in water by laser induced fluorescence spectroscopy and multivariate calibration techniques. SPIE-Proceedings, 3821 (im Druck), 1999. 


\section{Inhaltsverzeichnis}

1. Einleitung 2

2. Physikalische Grundlagen 4

2.1 Spektroskopie an Aromaten . . . . . . . . . . . . . . . . . . 4

2.2 Lichtleitung in Wellenleitern . . . . . . . . . . . . . . . 10

$\begin{array}{lr}\text { 3. Meßsystem } & \mathbf{1 3}\end{array}$

3.1 Der Laser . . . . . . . . . . . . . . . . . . . . . . . . . . . 14

3.2 Detektor . . . . . . . . . . . . . . . . 15

3.3 Der optische Sensor . . . . . . . . . . . . . . . . . . . . 18

3.4 Elektronik und Software . . . . . . . . . . . . . . . . . . . 18

3.5 Meßdaten und Aufnahmeparameter . . . . . . . . . . . . . . . . . 19

3.6 Gesamtspezifikation . . . . . . . . . . . . . . . . . . . . 21

3.7 Das PMT-System . . . . . . . . . . . . . . . . . 21

4. Modellierung der Optrodengeometrie 22

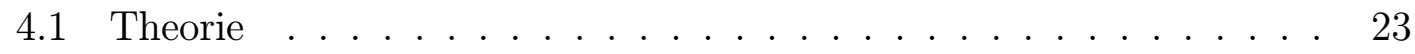

4.1 .1 Die Parameter . . . . . . . . . . . . . . . . . 23

4.1.2 Berechnung der Energiedichtefunktion $\rho(\vec{r}) \ldots \ldots . . . . .26$

4.1.3 Berechnung der Wahrscheinlichkeitsfunktion $h(\vec{r}) \ldots 26$

4.1.4 Berechnung des Beobachtungsgebietes $T$. . . . . . . . . 30

4.2 Rechnungen und Ergebnisse . . . . . . . . . . . . . . . . . 32

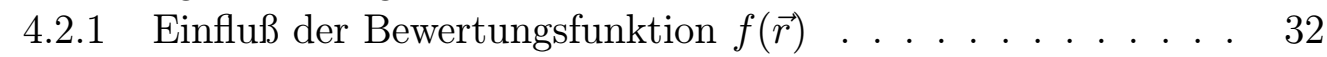

4.2.2 Einfluß der numerischen Apertur der Fasern . . . . . . . . . 36

4.2.3 Der Drehwinkel der Nachweisfaser $\varphi$. . . . . . . . . . 36

4.3 Diskussion . . . . . . . . . . . . . . . . . . . . 38

5. Messungen $\quad \mathbf{4 2}$

5.1 Künstliche Laborproben . . . . . . . . . . . . . . . . . . . . . . . . . . 42

5.2 Gewässerproben . . . . . . . . . . . . . . . . . . . . . . . . . 43

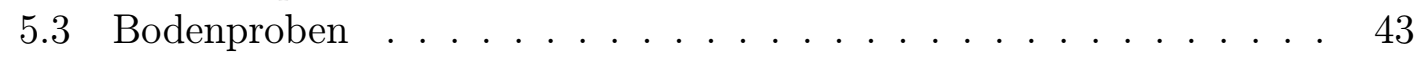

6. Bausteine für die Analyse zeitaufgelöster Spektren $\mathbf{4 5}$

6.1 Datenvorbereitung und -reduktion . . . . . . . . . . . . . . . 46

6.1.1 Dispersionskorrektur . . . . . . . . . . . . . . . 46

6.1.2 Entfaltung der Gerätefunktion . . . . . . . . . . . . . . . 48

6.1.3 Datenreduktion entlang der Wellenlängenachse . . . . . . . . 49

6.2 Techniken zur Matrixzerlegung . . . . . . . . . . . . . . . 52

6.2.1 Integration über die Zeitachse . . . . . . . . . . . . 53

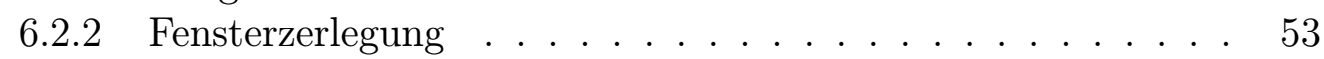

6.2.3 Abstrakte Faktorzerlegung (AFD) . . . . . . . . . 53 
6.3 Multivariate Kalibration . . . . . . . . . . . . . . . . . . . . 55

6.3.1 Multiple Lineare Regression (OLS) . . . . . . . . . . . . . 57

6.3.2 Hauptkomponentenregression (PCR) . . . . . . . . . . 58

6.3.3 Partial Least Squares Regression (PLS) . . . . . . . . . . . . 60

6.3.4 Bestimmung signifikanter Faktoren . . . . . . . . . . . 64

7. Optimierung und Vergleich verschiedener Auswertemethoden 65

7.1 Überblick . . . . . . . . . . . . . . . . . . . . . . 65

7.2 Untersuchungen zur Matrixzerlegung . . . . . . . . . . . . 67

$7.2 .1 \quad$ FT-AFD . . . . . . . . . . . . . . . 68

$7.2 .2 \quad$ NNFD und IS . . . . . . . . . . . . . . . . . . . . . 69

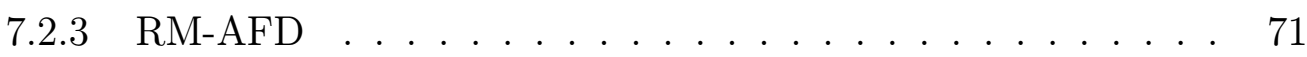

7.2 .4 PEM-AFD . . . . . . . . . . . . . . . . . 74

$7.2 .5 \quad \mathrm{C}-\mathrm{AFD} \ldots \ldots \ldots \ldots \ldots$

7.2 .6 Fensterzerlegung . . . . . . . . . . . . . . . 84

7.3 Untersuchungen zur Kalibration . . . . . . . . . . . . . . . . 84

7.4 Nachweisgrenzen . . . . . . . . . . . . . . . . . . . . . . 88

7.5 Querempfindlichkeiten ... . . . . . . . . . . 88

7.6 Diskussion der Ergebnisse . . . . . . . . . . . . . . . . 92

8. Umweltproben und Feldversuche $\quad 93$

8.1 Tankstellenunfall . . . . . . . . . . . . . . . . . . . . . . . 93

8.2 Xylol-Verschmutzungen . . . . . . . . . . . . . . . . . . . . 94

8.3 Feuerwehreinsatz Leineverschmutzung . . . . . . . . . . . . . . . . 94

8.4 Tracerversuch Potsdamer Havel (Mai 98) . . . . . . . . . . . . . . . . . 95

8.4.1 Havel bei Phöben (4. Mai 98) . . . . . . . . . . . . . . 97

8.4.2 Havel „Tiefer See“ bei Potsdam (5. Mai 98) . . . . . . . . . 97

8.5 Tracerversuch Elbe bei Dresden (April 99) . . . . . . . . . . . . . . 101

8.5.1 Erstellung des Kalibrationsmodells für die Tracersubstanz . 101

8.5.2 Durchführung der Messungen . . . . . . . . . . . . . . . 102

8.5.3 Ergebnisse . . . . . . . . . . . . . . . . 105

8.6 Diskussion der Ergebnisse . . . . . . . . . . . . . . . 107

$\begin{array}{ll}\text { 9. Zusammenfassung und Ausblick } & \mathbf{1 1 0}\end{array}$

A. Anhang 112

A.1 Symbole und allgemeine Abkürzungen . . . . . . . . . . . . . . . 112

A.1.1 Mathematische Symbole . . . . . . . . . . . . . 112

A.1.2 Allgemeine Abkürzungen . . . . . . . . . . . . . . . 113

A.2 Abkürzungen und Eigenschaften der Schadstoffe . . . . . . . . . . . 114

A.3 Das Meßprogramm FAP-CONTROL . . . . . . . . . . . . 116

A.4 Eigenschaften der Datensätze DS1 bis DS8 . . . . . . . . . . . . . 117

A.5 Spektren . . . . . . . . . . . . . . . . . . . . 119 
Abbildungsverzeichnis 132

Tabellenverzeichnis 135

Literaturverzeichnis 136

Index 150 


\section{Einleitung}

Das Thema Umweltverschmutzung und Umweltschutz ist von großem öffentlichen Interesse. Um Umweltverschmutzungen wirksam erkennen und bekämpfen zu können, sind leistungsfähige Methoden zum Schadstoffnachweis notwendig. Dabei spielt nicht nur die Analysegenauigkeit sondern vor allem auch die Analysegeschwindigkeit eine wichtige Rolle. Ein weiterer wichtiger Aspekt sind die Analysekosten, die der Untersuchung einer Schadstoffausbreitung oder einer kontinuierlichen Schadstoffüberwachung (z.B. bei der Trinkwassergewinnung) im Wege stehen können.

Zum jetzigen Zeitpunkt werden zur Schadstoffbestimmung nahezu ausschließlich naßchemische Verfahren eingesetzt. Dazu werden an der zu untersuchenden Stelle Proben entnommen, die Schadstoffe mit Lösungsmitteln extrahiert und - z.B. mit chromatographischen Verfahren - analysiert [1]-[5]. Dieser Vorgang nimmt einige Stunden in Anspruch und ist mit erheblichen Kosten verbunden.

Während die Genauigkeit der bisher verwendeten Verfahren zum Schadstoffnachweis nur wenige Wünsche offen läßt, sind die Kosten einer Analyse so hoch und die Analysegeschwindigkeit für viele Anwendungen derart niedrig, daß eine große Anzahl an sich notwendiger Schadstoffuntersuchungen nicht durchgeführt werden. Zudem fällt bei vielen naßchemischen Analysen eine nicht unerhebliche Menge Sondermüll an. Dabei ist besonders bei der Untersuchung der Schadstoffausbreitung die wiederholte genaue Aufspaltung nach den verschiedenen Bestandteilen der Verschmutzung weder notwendig noch sinnvoll.

Analysedauer und -kosten können mit Hilfe der zeitaufgelösten LIF-Spektroskopie (LIF: Laser Induced Fluorescence) für einen bedeutenden Teil der Umweltschadstoffe drastisch reduziert werden. Dies sind vor allem Verschmutzungen mit umweltrelevanten Kohlenwasserstoffen, z.B. durch Mineralölkontaminationen oder Verbrennungsrückstände. Die spektroskopische Analyse wird dadurch ermöglicht, daß Kohlenwasserstoffverschmutzungen sehr oft fluoreszierende Bestandteile enthalten. Da mit einem mobilen in-situ-fähigen Laserspektrometer die Messungen direkt vor Ort vorgenommen werden können, entfallen Probenahme und -aufbereitung. Vor allem dadurch reduziert sich die Analysedauer gegenüber der klassischen Analytik von Stunden in den Bereich von Sekunden pro Messung. Selbst wenn mit einem solchen Laserspektrometer eine differenzierte Analyse nicht möglich sein sollte, kann an Hand des fingerprint-Verfahrens die Ausbreitung einer Verschmutzung schnell und einfach bestimmt werden.

Die Anwendungsmöglichkeiten für ein solches LIF-Spektrometer sind vielfältig und bedeutend. In der Bundesrepublik Deutschland existieren schätzungsweise 20 bis 30000 Altlastflächen [6, 7], d.h. es besteht der begründete oder bewiesene Verdacht, daß von diesen Flächen Gefahren für Mensch und Umwelt ausgehen [8]. Für die Auffindung und räumliche Abgrenzung von Altlasten und die Kontrolle des Sanierungsverlaufes ist eine schnelle und zuverlässige Analyse notwendig.

Auch bei akuten Verschmutzungen, wie z.B. bei Unfällen oder kriminellen Umweltverschmutzungen, ist häufig eine schnelle Schadstoffanalyse notwendig, um die 
negativen Folgen der Verschmutzung durch gezielte Maßnahmen möglichst klein zu halten und ggf. den Verursacher festzustellen.

Ziel der vorliegenden Arbeit war zum einen die Entwicklung eines Sensorkopfes (Optrode) für die Bodenanalytik, um ein ursprünglich nur für die Wasseranalytik entwickeltes Laserfluorimeter auch auf dieses Einsatzgebiet zu erweitern. Zweitens sollten bestehende und ggf. neue Auswertemethoden für die Meßdaten (zeitaufgelöste Fluoreszenzspektren) untersucht und entwickelt werden und auf Basis dieser Ergebnisse ein Meß- und Auswerteprogramm für dieses Laserspektrometer erstellt werden. Drittens sollte das System auf seine Labor- und Feldtauglichkeit untersucht und optimiert werden. 


\section{Physikalische Grundlagen}

In diesem Kapitel werden kurz die wichtigsten Grundlagen der Fluoreszenzspektroskopie an aromatischen Kohlenwasserstoffen und die Grundlagen der Lichtleitung in Glasfasern beschrieben. Für eine ausführliche Diskussion der Fluoreszenzspektroskopie sei vor allem auf die Standardwerke von BIRKs [9] und BECKER [10] sowie ferner auf die Monographien [11]-[14] verwiesen.

\subsection{Fluoreszenzspektroskopie an aromatischen Kohlenwasserstoffen}

Eine besonders wichtige Gruppe organischer Schadstoffe sind die polyzyklischen aromatischen Kohlenwasserstoffe (PAK), die die größte bekannte singuläre Klasse chemischer Karzinogene bilden ${ }^{1}$ [20, 21, 22]. Der Eintrag der PAK durch Industrie, allgemeine Verbrennungsprozesse [23], Unfälle (z.B. Tankerunfälle) [24, 25] und weniger offensichtliche Weise an dünnen Grenzschichten (Ölfilme, Stahlhärtung etc.) [26] führt zu einer derart starken Belastung, daß die PAK mittlerweile in annähernd jeder natürlichen Wasser- oder Bodenprobe nachweisbar sind [27, 28, 29]. Dabei werden z.T. Konzentrationen erreicht, die den Trinkwassergrenzwert um mehr als das zehnfache übersteigen (Rhein bei Koblenz: 3, $1 \mu \mathrm{g} / 1$ PAK Summenwert 1974; TVO-Grenzwert: 0,2 $\mu \mathrm{g} / \mathrm{l}$ ) [30]. Der natürliche Eintrag der PAK in die Biosphäre kann hingegen vernachlässigt werden [30].

Zum laserspektroskopischen Nachweis von PAK existieren bereits eine Reihe von Arbeiten [31]-[52]. Allerdings sind bisher kaum gebrauchsfertige Laserspektrometer für den mobilen Einsatz vorhanden (vergleiche Abschnitt 3.1). In den letzten Jahren wurde in der Arbeitsgruppe Umweltmeßtechnik im Laser-Laboratorium Göttingen e.V. (LLG) ein zeitauflösendes Laserspektrometer auf Basis eines diodengepumpten Festkörperlasers für den Nachweis von fluoreszierenden Schadstoffen, v.a. von PAK, in Wasser entwickelt $[46,53,54,55]$. Zu Beginn dieser Arbeit war die Fertigstellung des Prototypen noch nicht abgeschlossen.

\section{Physik der aromatischen Kohlenwasserstoffe}

Verbindungen, die das Kohlenstoff-Grundgerüst des Benzols enthalten, werden als aromatische Kohlenwasserstoffe (Arene) bezeichnet. Benzol (siehe Abb. 2.1), eine der 217 denkbaren Verbindungen mit der Summenformel $\mathrm{C}_{6} \mathrm{H}_{6}$, ist aus sechs funktionell gleichwertigen CH-Gruppen aufgebaut, wobei sowohl die Kohlenstoff- als auch die Wasserstoffatome in einem gleichseitigen planaren Sechseck angeordnet sind. Die ringförmige Struktur des Benzols ist erstmals 1865 von KEKuLÉ mit abwechselnden Doppel- und Einfachbindungen zwischen den C-Atomen vorgeschlagen

1 Die Grundlagen zum Verständnis der Karzinogenität der PAK werden in [15]-[19] behandelt. 
worden (siehe Abb. 2.1).<smiles></smiles>

Abbildung 2.1: Strukturformel des Benzols nach Kekulé. Um die delokalisierten $\pi$ Elektronen anzudeuten, wird heute häufig ein eingeschriebener Kreis verwendet.

Mit dem Auftreten des Benzolrings in einer chemischen Verbindung sind eine Reihe von Eigenschaften verbunden, aus denen bereits Kekulé selbst folgerte, daß die Bindungen im Benzolring nicht fixiert sein können. Erst quantenmechanische Untersuchungen von E. HüCKEL und L. PAUling in den 30er Jahren führten $\mathrm{zu}$ einer befriedigenden Beschreibung des Benzols, wonach ein delokalisiertes $\pi$ Elektronensystem den ganzen Ring umfaßt $[56,57]$. Die sechs $\pi$-Elektronen sind demnach gleichmäßig um den ganzen Ring verteilt, so daß alle $\mathrm{C}-\mathrm{C}$-Bindungen völlig gleichartig sind. Dieses $\pi$-Elektronensystem bewirkt neben den typischen Eigenschaften aromatischer Verbindungen die Fluoreszenz durch einen $\pi^{*} \rightarrow \pi$ Übergang, die einen fluoreszenspektroskopischen Nachweis ermöglicht. Oft wird als Formel für Benzol ein Sechseck mit einem eingeschriebenen Kreis verwendet, der die delokalisierten $\pi$-Elektronen symbolisiert.

Unter den kondensierten aromatischen Ringsystemen oder polyzyklischen aromatischen Kohlenwasserstoffen (PAK) versteht man Moleküle mit mindestens zwei aromatischen Kohlenstoffringen, die gemeinsame C-Atome aufweisen. Bekannte Vertreter sind das Naphthalin und das Anthracen (Abb. 2.2). Bei diesen Molekülen sind die $\pi$-Elektronen über das gesamte Molekül verteilt, eine Beschreibung durch einzelne Kreise in den Ringen wäre hier irreführend. Man verwendet daher meist die Schreibweise entsprechend der „Kekulé-Formel“, wobei der zweite Strich einer Doppelbindung jeweils für zwei delokalisierte $\pi$-Elektronen steht $[56,58]$. Wie beim Benzol ist auch für die PAK wieder ein $\pi^{*} \rightarrow \pi$ Übergang für die Fluoreszenzeigenschaften verantwortlich.

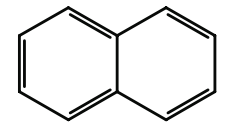

(a)

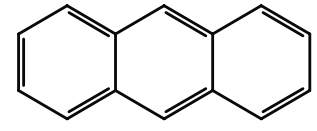

(b)

Abbildung 2.2: Die Strukturformeln für (a) Naphthalin und (b) Anthracen. 


\section{Definition der Fluoreszenz}

Manche Stoffe absorbieren Licht und emittieren einen Teil der Energie in Form von Lumineszenzlicht. Zur Unterscheidung von elektrisch oder chemisch angeregter Lumineszenz wird auch von Photolumineszenz gesprochen. Jede Photolumineszenz besitzt eine zeitliche Trägheit. Diese Verzögerung liegt in der Größenordnung von Nanosekunden bis Sekunden und wird meist als exponentielles Abklingen der Lumineszenzintensität nach Aussetzen der Anregung beobachtet. In diesem Fall wird die Zeit $\tau$, in der die Intensität auf 1/e (37\%) abgefallen ist, als Abklingdauer oder Lebensdauer bezeichnet.

Läßt sich der Abfall der Intensität $I(t)$ nicht durch eine einfach-exponentielle Funktion beschreiben, so wird die Abklingdauer mit Hilfe der allgemeineren Gleichung

$$
\tau=\frac{\int_{0}^{\infty} I(t) t d t}{\int_{0}^{\infty} I(t) d t}
$$

definiert [59].

Photolumineszenz ist der Oberbegriff für Fluoreszenz und Phosphoreszenz. Noch über die 50er Jahre dieses Jahrhunderts hinaus wurde die Fluoreszenz von der Phosphoreszenz an Hand der Abklingdauer unterschieden. Photolumineszenz wurde als Fluoreszenz bezeichnet, wenn die Abklingdauer unterhalb von $10^{-4}$ Sekunden lag [59]. Hat man eine genaue Kenntnis über die Elektronenstruktur des betreffenden Moleküls, so kann diese etwas willkürliche Trennung durch eine genauere von G. Lewis und M. Kasha 1944 vorgeschlagene Definition ersetzt werden [60]. Danach liegt bei einem Interkombinationsübergang zwischen zwei Termen verschiedener Multiplizität (z.B. Triplett $\rightarrow$ Singlett) eine Phosphoreszenz und sonst eine Fluoreszenz vor $[59,61]$. Der $\pi^{*} \rightarrow \pi$ Übergang der aromatischen Kohlenwasserstoffe findet zwischen zwei Termen gleicher Multiplizität statt.

\section{Das Lambert-Beersche Gesetz}

Das Lambert-Beersche Gesetz ist die Grundlage aller Auswertemethoden, die in dieser Arbeit behandelt werden. Der Anteil des Anregungslichts, der durch einen fluoreszierenden Stoff (Fluorophor) absorbiert wird, läßt sich mit Hilfe diese Gesetzes berechnen. Hierbei ist das Absorptionsvermögen proportional zur Konzentration, wobei die Proportionalitätskonstante, der molare Absorptionskoeffizient, eine wellenlängenabhängige Stoffkonstante ist.

Die Intensität des in ein Volumenelement der Länge $l$ eintretenden Lichts sei mit $I_{0}$ bezeichnet, die Intensität des aus diesem Volumen austretenden Lichts mit $I$. Die differentielle Intensitätsabnahme $\mathrm{d} I$ ist der Intensität $I(x)$ und der durchstrahlten Schichtdicke $\mathrm{d} x$ proportional [62]:

$$
-\mathrm{d} I=k \cdot I(x) \cdot \mathrm{d} x .
$$




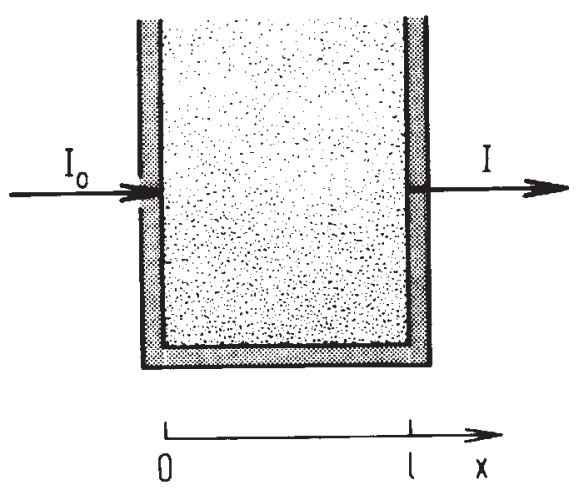

Abbildung 2.3: Zur Ableitung des Lambert-Beerschen Gesetzes.

Eine Integration zwischen 0 und 1 liefert

$$
\frac{I}{I_{0}}=e^{-k \cdot l}
$$

Das Verhältnis $I_{0} / I$ wird auch als Transmissionsvermögen $T$ und $\log _{10}(1 / T)$ als dekadisches Absorptionsvermögen A bezeichnet:

$$
A=\log _{10} \frac{I_{0}}{I}=a \cdot l,
$$

wobei a der lineare dekadische Absorptionskoeffizient ist. 1852 hat BEER für eine Lösung mit völlig transparentem Lösungsmittel den Zusammenhang

$$
a=\epsilon \cdot c
$$

gefunden, wobei $c$ die molare Konzentration des lichtschwächenden Stoffes und $\epsilon$ der molare dekadische Absorptionskoeffizient ist. Faßt man die Gleichungen (2.4) und (2.5) zusammen, erhält man das Lambert-Beersche Gesetz:

$$
A=\log _{10} \frac{I_{0}}{I}=\epsilon \cdot c \cdot l .
$$

In der Literatur werden als Einheiten dabei häufig Liter $/(\mathrm{Mol} \cdot \mathrm{cm})$ für $\epsilon$ und $\mathrm{Mol} / \mathrm{Li}-$ ter für $c$ verwendet $[61,62]$.

\section{Lineares Mischungsmodell}

Das Lambert-Beersche Gesetz ist Grundlage des linearen Mischungsmodells, das auch in der deutschsprachigen Literatur häufig mit dem englischen Begriff LinearMixture-Model (LMM) bezeichnet wird. Das LMM ist Grundlage für alle in dieser Arbeit verwendeten Analysemethoden. 
Das LMM beschreibt das zeitaufgelöste Fluoreszenzspektrum $\mathbf{M} \in \mathbb{R}^{Z \times W}$ mit $Z$ Zeiten und $W$ Wellenlängen eines Multikomponentengemisches als lineare Summe der Fluoreszenzspektren der einzelnen Komponenten $\mathbf{S}_{j} \in \mathbb{R}^{Z \times W}$ (bequemerweise auf die Konzentration 1 skaliert), solange die Konzentration $c_{j}$ der Analyten in dem Mischspektrum unterhalb eines Schwellenwertes liegen:

$$
\mathbf{M}=\sum_{j=1}^{J} c_{j} \mathbf{S}_{j}+\mathbf{E} .
$$

Die Residuen E enthalten die Rauscheffekte und eine eventuelle Hintergrundfluoreszenz. Der Schwellenwert für $c_{j}$ ist abhängig vom Analyt, liegt aber typischerweise im Prozent- oder Promillebereich [59]. Die Konzentrationen der Schadstoffe, deren Analyse hier von Belang sind, liegen fast immer im sub-ppm Bereich, so daß diese Voraussetzung hier erfüllt ist. Die Spektren $\mathbf{S}_{j}$ werden als Einheitsspektren bezeichnet und bilden eine orthogonale Basis [63]. Sollten zwei Spektren nicht orthogonal sein, so ist eine spektroskopische Unterscheidung der zugehörigen Analyten prinzipiell nicht möglich und es wird nur eines der beiden Spektren in die Basis mit aufgenommen.

\section{Energiezustände}

Wenn ein Molekül ein Photon der Frequenz $\nu$ absorbiert, so muß es als Folge dieses Prozesses in einen angeregten Energiezustand übergehen.

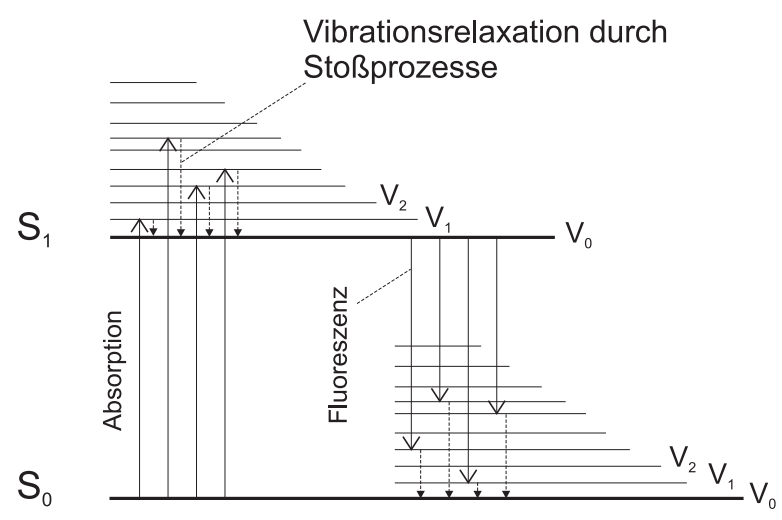

Abbildung 2.4: Jablonski-Diagramm. Dargestellt sind nur die Elektronenzustände $\mathrm{S}_{0}$ und $\mathrm{S}_{1}$ sowie einige Vibrationszustände.

Mit Hilfe eines Jablonski-Diagramms (Abb. 2.4) lassen sich die zur Fluoreszenz führenden Energieübergänge anschaulich darstellen: Bei Raumtemperatur befinden sich fast alle Moleküle im untersten Vibrationszustand $V_{0}$ des Elektronengrundzustands $S_{0}$. Durch Absorption eines Photons mit ausreichend großer Energie findet ein Übergang in einen der vielen Rotations- und Vibrationszustände des ersten 
angeregten Elektronenzustands $S_{1}$ statt. In kondensierter Materie geht das Molekül durch Wechselwirkung mit umgebenden Molekülen in etwa $10^{-12}$ Sekunden strahlungslos in den niedrigsten Vibrationszustand $V_{0}$ des ersten angeregten Elektronenzustands über (Vibrationsrelaxation). Eine mittlere Zeit später verläßt das Molekül unter Abgabe eines Photons diesen Zustand, um in einen der Vibrationszustände von $S_{0}$ zu gelangen, von wo es wieder strahlungslos nach $V_{0}$ relaxiert. Diese Zeit ist molekülabhängig und liegt meist zwischen $10^{-10}$ und $10^{-5}$ Sekunden.

Sowohl für die Absorption als auch für die Emission werden die Wahrscheinlichkeiten, mit denen bestimmte Vibrationszustände eingenommen werden, durch das FranCK-CONDON-Prinzip bestimmt, dem folgende Überlegung zu Grunde liegt: Die Änderung des Elektronenzustandes erfolgt viel schneller als die Änderung des Ortes, während eines in Abb. 2.5 dargestellten Übergangs ändert sich also fast nur die Energie; der Ort dagegen nur sehr wenig. Bei der Absorption definiert die Energie des absorbierten Photons den Vibrationszustand, in den das Molekül von $\left(S_{0}, V_{0}\right)$ ausgehend versetzt wird. Die Absorptionswahrscheinlichkeit hängt dabei vom Quadrat der Wellenfunktionen der beiden Zustände ab. Haben beide am gleichen Ort ein Maximum, so wird die Übergangswahrscheinlichkeit hoch sein; fällt das Maximum des Grundzustands mit einem Minimum des angeregten Zustands zusammen, ist die Übergangswahrscheinlichkeit i.a. kleiner. So ergibt sich ein wellenlängenabhängiges Absorptionsspektrum. Das Emissionsspektrum ergibt sich analog aus den Übergangswahrscheinlichkeiten zwischen dem $\left(S_{1}, V_{0}\right)$-Zustand und den Vibrationszuständen $\left(S_{0}, V_{i}\right)$.

Aromatische Moleküle erlauben eine Vielzahl von Rotations- und Vibrationszuständen. Für eine wäßrige Umgebung sind die Energiedifferenzen im Rahmen von $0,1 \mathrm{eV}$ zwischen zwei Vibrationszuständen noch aufösbar, für die Differenzen zwischen zwei Rotationszuständen, die etwa zwischen 0,01 und 0,001 eV liegen, ist dies bei Raumtemperatur nicht mehr der Fall. Es ergibt sich ein kontinuierliches Absorptions- und Emissionsspektrum.

Typische Anregungsenergien für aromatische Moleküle liegen zwischen 3 und $5 \mathrm{eV}$, das entspricht Wellenlängen zwischen 400 und $250 \mathrm{~nm}$. Dabei läßt sich ein Zusammenhang zwischen der Molekülgröße und der Anregungsenergie beobachten: Je kleiner das Molekül ist, desto höher muß die Anregungsenergie liegen. Bereits im vorherigen Abschnitt wurde erwähnt, daß die $\pi$-Elektronen für das Fluoreszenzverhalten der aromatischen Moleküle verantwortlich sind. Genauer sind es Übergänge zwischen dem höchsten besetzten (bindenden) $\pi$-Orbital (HOMO, von engl. highest occupied molecule orbital) und dem niedrigsten unbesetzten (antibindenden) $\pi^{*}$ Orbital (LUMO, lowest unoccupied MO), die zur Fluoreszenz führen. In einer vereinfachten Darstellung lassen sich die $\pi$-Elektronen der konjugierten aromatischen Systeme ähnlich wie das Elektronengas in Metallen durch ein eindimensionales Gas in einem Potentialtopf darstellen. Die Länge des Potentials entspricht dabei der Länge des konjugierten Systems, im Falle der PAK beispielsweise der längsten Diagonale über das Molekül. An diesem Modell wird deutlich, warum die Anregungsenergie mit zunehmender Molekülgröße kleiner wird: Die Abstände zwischen 


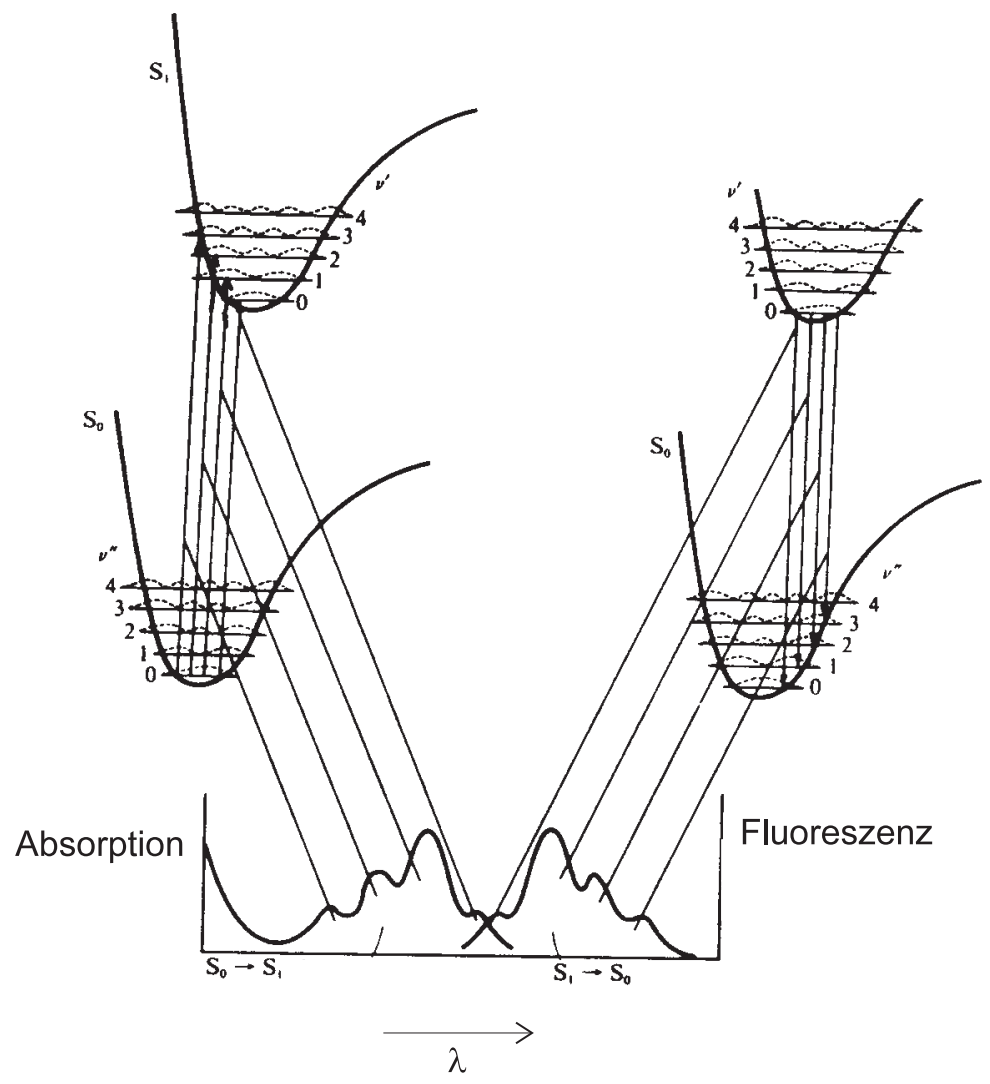

Abbildung 2.5: Zur Erläuterung des Franck-Condon-Prinzips.

den Energieeigenwerten für ein Elektron im Potentialtopf nehmen mit zunehmender Länge dieses Topfes ab [64, 65, 66, 67].

\subsection{Lichtleitung in Wellenleitern}

Für den Feldeinsatz der LIF-Sensorik ist die Führung des Laserlichts vom Laser zum Meßort und die des Fluoreszenzlichts vom Meßort zum Detektor mittels Glasfasern von entscheidender Bedeutung. Solche Lichtleitfasern bestehen aus einem Kernmaterial mit dem Brechungsindex $n_{1}$ und einem umgebenden Mantelmaterial mit Brechzahl $n_{2}<n_{1}$. Durch den geringeren Brechungsindex des Mantels wird an der Grenzschicht zwischen Kern und Mantel Totalreflexion ermöglicht (siehe Abb. 2.6).

Die Bedingung für die Totalreflexion ist, daß der Winkel zwischen dem Lichtstrahl und der Senkrechten zur Grenzfläche größer oder gleich dem Grenzwinkel $\alpha_{0}$ 


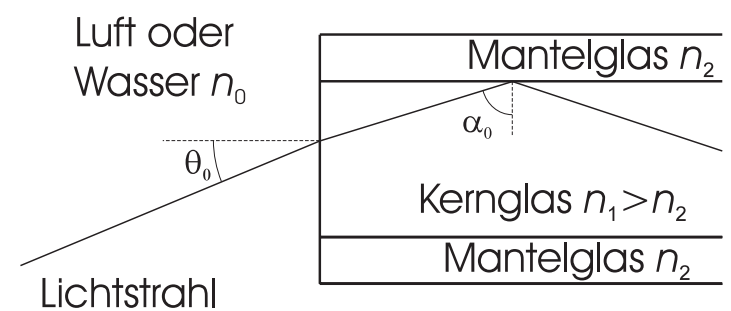

Abbildung 2.6: Schematischer Aufbau eines Lichtwellenleiters.

ist, wobei sich der Grenzwinkel durch

$$
\sin \alpha_{0}=\frac{n_{2}}{n_{1}}
$$

berechnet. Tritt ein Lichtstrahl unter dem Winkel $\theta$ zur Faserachse aus dem umgebenden Medium mit der Brechzahl $n_{0}$ in die Faser ein, so wird er an der Stirnfläche der Faser entsprechend dem Snelliusschen Brechungsgesetz [68] gebrochen, das hier in der Form

$$
\frac{\cos \alpha}{\sin \theta}=\frac{n_{0}}{n_{1}}
$$

aufgeschrieben sei, mit dem Winkel $\alpha$ zwischen Lichtstrahl und der Senkrechten zur Faserachse.

Damit ergibt sich aus den drei Brechzahlen des Kerns, des Mantels und des umgebenden Mediums der maximale Winkel $\theta_{\max }$, unter dem ein Lichtstrahl in eine Lichtleitfaser eingekoppelt werden kann:

$$
\begin{aligned}
\sin \theta_{\text {max }} & =\frac{n_{1}}{n_{0}} \cdot \cos \alpha_{0} \\
& =\frac{n_{1}}{n_{0}} \cdot \sqrt{1-\sin ^{2} \alpha_{0}} \\
& =\frac{1}{n_{0}} \cdot \sqrt{n_{1}^{2}-n_{2}^{2}} .
\end{aligned}
$$

$\theta_{\max }$ wird als Akzeptanzwinkel des Lichtleiters bezeichnet. Häufig wird an Stelle dieses Winkels die Numerische Apertur

$$
N A=\sin \theta_{\max }
$$

einer Faser angegeben. Da die Brechzahlen wellenlängenabhängig sind, hängt der Akzeptanzwinkel nicht nur vom umgebenden Medium sondern auch von der Wellenlänge des Lichts ab, das in die Faser eingekoppelt wird. Abbildung (2.7) zeigt den wellenlängenabhängige Brechungsindex für Quarz (siehe auch Abschnitt (6.1.1)).

Lichtleiter aus Glas weisen typischerweise oberhalb von etwa $300 \mathrm{~nm}$ eine tolerable Transparenz auf. Für kürzere Wellenlängen kommt es zu zunehmenden 


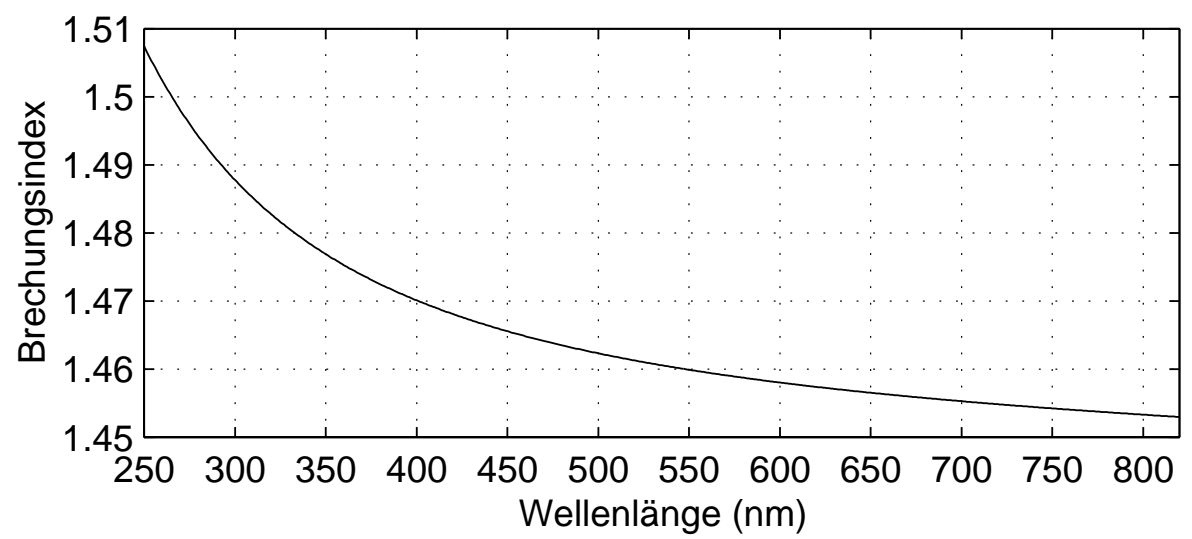

Abbildung 2.7: Wellenlängenabhäniger Brechungsindex von Quarzglas.

Transmissionsverlusten, die neben der Wellenlänge auch von der Energie des transmittierten Lichtpulses abhängt. In diesem Bereich kommen für die zeitaufgelöste LIF-Sensorik aufgrund der hohen Lichtenergien nur noch Quarzglasfasern in Frage. Quarzglas $\left(\mathrm{SiO}_{2}\right)$ ist im Grunde eine Flüssigkeit mit extrem hoher Viskosität. Dadurch sind im Gegensatz zu kristallinem Quarz die optischen und mechanischen Eigenschaften isotrop, d.h. in alle Raumrichtungen gleich. Um für den Kern und für den Mantel einer Faser Quarzglas verwenden zu können, wird der Brechungsindex durch geeignete Dotierung verändert [69].

Für die Transmission von UV-Licht hoher Intensität kommt derzeit nur ein Fasertyp in Frage. Dabei handelt es sich um multimode Stufenindex-Fasern mit reinem Quarzglas als Kernmaterial und Fluor-dotiertem Quarzglas als Mantelmaterial ( Fdoped cladding) [70]. Auf diese Weise kann der UV-Bereich ab ca. 250-260 nm für die Lichtleitung erschlossen werden. Alle Dotierungen des Kerns führen im UV zu höheren Transmissionsverlusten. Deshalb eignen sich u.a. Gradientenindex-Fasern nicht für UV-Anwendungen. Die Numerische Apertur der für diese Arbeit verwendeten $F$-doped Quarz-Lichtleiter liegt für $n_{0}=1$ (Luft) und ultraviolettes Licht $(\lambda=300 \mathrm{~nm})$ bei 0.22 , entsprechend einem Akzeptanzwinkel von 12.7 . Für Wasser mit $n_{0}=1.33$ als umgebendes Medium reduziert sich der Akzeptanzwinkel auf $9.5^{\circ}$.

Die Transmission von Hochleistungs-UV-Laserpulsen in Quarzfasern wird ausführlich von P. KARLITSCHEK behandelt [55]. Die Wellenlängenlimitierung ist in erste Linie auf die Bildung von Farbzentren zurückzuführen, siehe dazu [71]-[81]. Daneben gibt es eine Reihe von Arbeiten zur Transmission von Excimerlaser-Pulsen (u.a. [82]-[86]) sowie einige Arbeiten zur Transmission von frequenzvervielfachten Nd:YAG-Laserpulsen (266 und $355 \mathrm{~nm}$ ) [87]-[90]. Zur Herstellung von Glasfasern siehe die Referenzen [91, 92, 93]. Der Einfluß von Wasserstoff in Fasern wird u.a. behandelt in [94]-[97]. 


\section{Meßsystem}

Für diese Arbeit wurde ein zeitauflösendes Laserspektrometer verwendet, das in den letzten Jahren ${ }^{1}$ für den Schadstoffnachweis in Wasser entwickelt wurde [46, 53, 98, 99]. Das Meßsystem, projektiert zum mobilen Nachweis von aromatischen Kohlenwasserstoffen, hat die folgenden Eigenschaften:

- eine Zeitauflösung im Bereich weniger Nanosekunden mit einem Meßbereich von mehreren hundert Nanosekunden,

- eine spektrale Auflösung von wenigen Nanometer mit einem Meßbereich von etwa 260 bis $600 \mathrm{~nm}$,

- eine hohe Nachweisempfindlichkeit bei gleichzeitig hoher Signaldynamik,

- Meßzeiten pro Spektrum um eine Minute oder weniger und

- ein kompakter, robuster und batteriebetriebener Aufbau für den mobilen Einsatz.

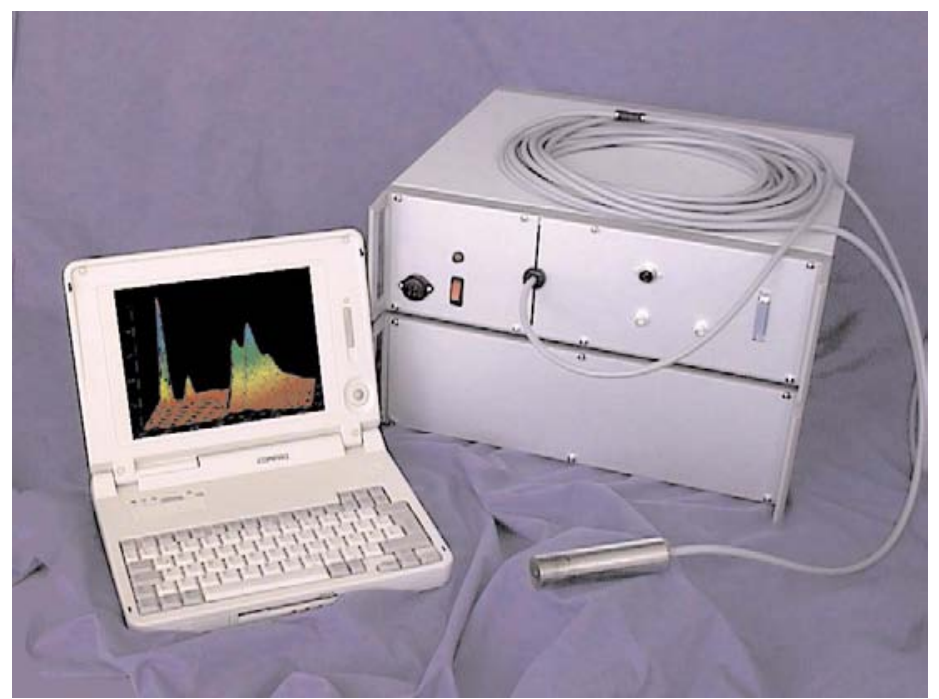

Abbildung 3.1: Ein Foto des CCD-Laserfluorimeters mit Steuerungscomputer. Der Laser nimmt das untere Gehäuse ein, die Nachweiseinheit mit der Elektronik befindet sich im oberen Gehäuse.

Das Meßsystem (siehe Abb. 3.1) besteht im wesentlichen aus vier Teilen: Anregungslaser, Glasfaserkabel mit Optrode (Sensorkopf), Nachweiseinheit (aufgebaut als optischer Vielkanalanalysator) und Steuerelektronik (siehe Abb. 3.2). Der Laser erzeugt Lichtpulse mit einer Wellenlänge von wahlweise 266, 355 oder $532 \mathrm{~nm}$ und

1 von G. Hillrichs, P. Karlitschek, T. Nörthemann, F. Lewitzka, M. Niederkrüger und dem Autor, Arbeitsgruppe Umweltmeßtechnik, Laser-Laboratorium Göttingen e.V. 
einer Pulslänge zwischen 7 und 8 ns. Die Pulse werden in eine Lichtleitfaser eingekoppelt und in die zu untersuchende Wasserprobe geleitet. Im Wasser befindliche Schadstoffe werden durch das Licht zur Fluoreszenz angeregt. Weitere Lichtleiter führen das Fluoreszenzlicht von der Probe zum Detektor, in dem es spektral zerlegt und zeitaufgelöst nachgewiesen wird.

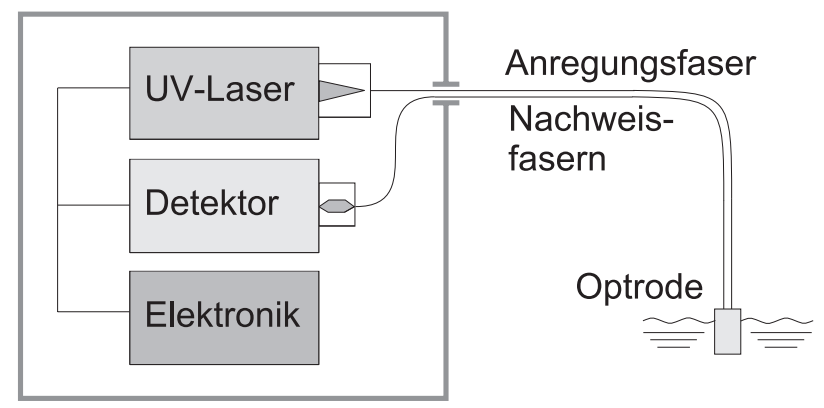

Abbildung 3.2: Schematischer Aufbau des Meßsystems. Die UV-Laserpulse werden durch eine Glasfaser zur Probe geführt. Das Fluoreszenzlicht der Schadstoffe wird mittels weiterer Glasfasern aufgesammelt und zum Detektor geleitet.

Vor Einkopplung in die Anregungsfaser wird ein kleiner Teil der Laserenergie mit Hilfe von Strahlteilern auf zwei Photodioden geleitet. Die erste Photodiode dient der zeitlichen Triggerung des Bildverstärkers der Nachweiseinheit, die zweite als Energiemonitor.

\subsection{Der Laser}

Um eine zeitaufgelöste Spektroskopie zur Trennung der PAK-Fluoreszenzen untereinander und von der Hintergrundfluoreszenz zu ermöglichen, ist ein gepulster UV-Laser mit Nanosekunden-Pulsdauer nötig [100, 51]. Im interessierenden Wellenlängenbereich sind das v.a. Excimerlaser bei 248 und $308 \mathrm{~nm}$ und der Stickstofflaser bei $337 \mathrm{~nm}$. Darüber hinaus ist die Erzeugung von UV-Laserpulsen durch Frequenzkonversion von Farbstoff- oder Festkörperlaserpulsen mittels nichtlinearer Prozesse möglich. Die meisten Untersuchungen zur LIF-Spektroskopie zum Nachweis von aromatischen Kohlenwasserstoffen, wurden mit Stickstofflasern durchgeführt [33, 34, 35, 36, 42, 43, 47, 101]. Frequenzverdoppelte Farbstofflasersysteme und KrF-Excimerlaser wurden bislang nur im Labor eingesetzt [37, 38, 39, 46]. Ebenso wurden Nd:YAG-Laser mit Frequenzkonversion bisher hauptsächlich für den Laboreinsatz herangezogen [31, 32, 39, 40, 102, 103]. LIEBERMAN berichtet von einem Nd:YAG-System, das für Feldmessungen auf einem LKW montiert war [104].

Durch neue Entwicklungen auf dem Gebiet der Diodenlaser ist es möglich gewor- 
den, Diodenlaser-gepumpte Festkörperlaser zu konstruieren [105, 106, 107]. Diese besitzen eine hohe elektro-optische Konversionseffizienz, lange Lebensdauer und Robustheit und lassen sich infolge des guten Strahlprofils gut frequenzkonvertieren. Auf der Basis dieser Technologie wurde von P. KARLITSCHEK ein Diodenlasergepumpter Nd:YAG-Laser entwickelt $[55,108]$. Durch Verzicht auf Wasserkühlung und Netzanschluß ist der Laser gut für den Feldeinsatz geeignet. Da die Laserpulse wahlweise verdoppelt, verdreifacht oder vervierfacht werden können [109, 110], stehen drei Anregungswellenlängen zur Verfügung (532, 355 und $266 \mathrm{~nm})$. Von besonderer Bedeutung für die PAK-Analytik ist die Wellenlänge $266 \mathrm{~nm}$, da hier viele der interessierenden Analyten eine gute Absorption zeigen und zugleich eine Fasertransmission gerade noch tolerabel ist. Bereits bei der Wellenlänge $248 \mathrm{~nm}$ des Excimerlasers beträgt die relative Transmission bei 15 Meter Glasfaserkabel nur noch etwa 15\% (266 nm: 30\%) [55]. Die Wellenlänge $532 \mathrm{~nm}$ ist für den Einsatz bei Tracerversuchen (siehe Abschnitt (8.5)) von Bedeutung. Die Anregungswellenlänge $355 \mathrm{~nm}$ steht für weitere Analyten zur Verfügung, wurde für diese Arbeit allerdings nicht verwendet.

Einer der wesentlichen Probleme bei der Entwicklung des Lasers war die Anforderung, mit einem vergleichsweise einfachen gütegeschaltetem Laser Pulslängen unter $10 \mathrm{~ns} z u$ erreichen, was eine Reihe von Problemen aufwarf [111, 112, 113]. Durch Wahl geeigneter Optiken (siehe Abb. 3.3) war es möglich, die Resonatorlänge des Lasers auf $55 \mathrm{~mm}$ zu verkürzen. Dadurch konnte eine Pulsdauer von $8 \mathrm{~ns}$ (532 nm) bzw. $7 \mathrm{~ns}$ (355 und $266 \mathrm{~nm}$ ) erreicht werden. Als aktiver Güteschalter wurde eine KDD`P-Pockelszelle mit 99\%-iger Deuterierung und Brewster-Fenstern verwendet. Die maximalen Pulsenergien liegen bei $800 \mu \mathrm{J}(532 \mathrm{~nm}), 150 \mu \mathrm{J}(355 \mathrm{~nm})$ und $100 \mu \mathrm{J}$ $(266 \mathrm{~nm})$.

\subsection{Detektor}

Der Detektor wurde als zeitaufösender Vielkanalanalysator aufgebaut, bestehend aus einem holographischen Gitter, einem Bildverstärker, einer Ankopplungsoptik und einer CCD-Kamera (siehe Abb. 3.4).

Die das Fluoreszenzlicht transportierenden Nachweisfasern sind vor einem auswechselbaren Spalt angeordnet. Verwendet wurden Spaltgrößen von 100 und 250 $\mu \mathrm{m}$. Zwischen Spalt und Fasern befindet sich zudem ein Filter zur Verringerung des Signals auf der Anregunsgwellenlänge. Für die UV-Wellenlängen wurden hier Kantenfilter verwendet, für $532 \mathrm{~nm}$ wurde ein holographischer 532-nm-Notch-Filter eingesetzt.

Im Spektrograph ${ }^{2}$ wird das Licht über einen Spiegel auf ein holographisches

2 CP140-103, Jobin Yvon Instruments S.A. GmbH, Grasbrunn. 


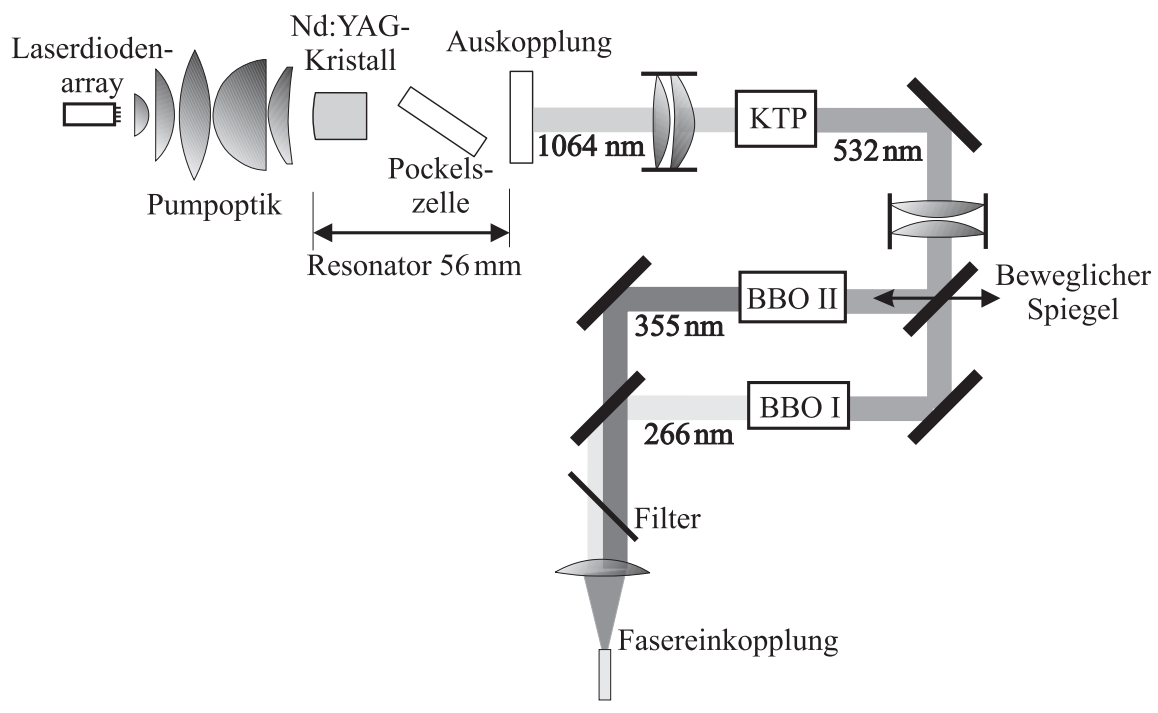

Abbildung 3.3: Schematische Darstellung des Diodenlaser-gepumpten Nd:YAG-Lasers. KTP: nichtlinearer Kristall zur Erzeugung der zweiten Harmonischen durch Frequenzverdopplung. BBO I: dito, zur Erzeugung der vierten Harmonischen. BBO II: Kristall zur Erzeugung der dritten Harmonischen durch Frequenzmischung.

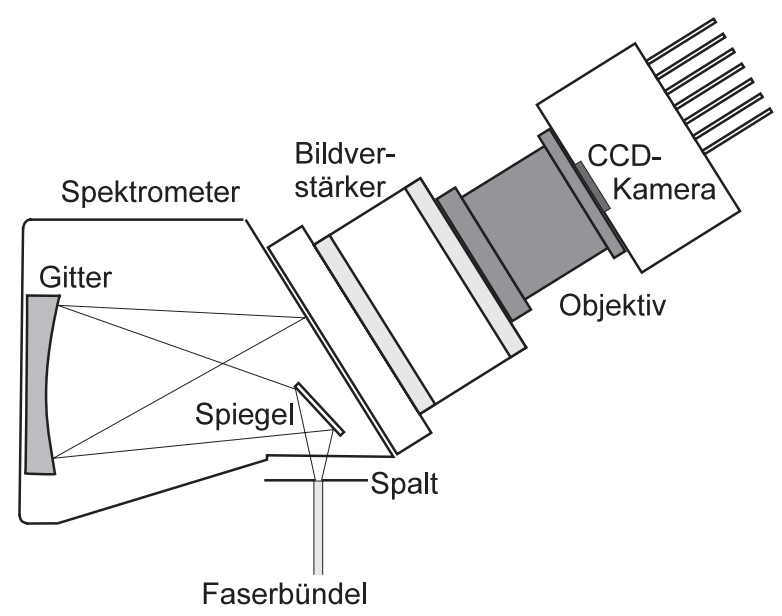

Abbildung 3.4: Der Vielkanalanalysator. Ein Spektrograph wurde als Polychromator verwendet. Ein Bildverstärker hat neben der empfindlichkeitssteigernden Aufgabe die Funktion, durch das Setzen von Zeitfenstern die Zeitauflösung zu ermöglichen. Eine gekühlte CCD-Kamera registriert das spektral zerlegte Licht.

Gitter geführt ${ }^{3}$. Das Öffnungsverhältnis erlaubt die direkte Einkopplung der Licht-

3 astigmatisch-korrigiertes holographisches Flat-Field Gitter; Brennweite $=140 \mathrm{~mm}$, Gitterkonstante $=285 \mathrm{l} / \mathrm{mm}$, Arbeitsbereich $=190-800 \mathrm{~nm}$, Dispersion $=24.2 \mathrm{~nm} / \mathrm{mm}$, Öffnungsverhältnis $=\mathrm{f} / 2$, Bildfeldlänge $=25.20 \mathrm{~mm}$. 
leiter, deren Öffnungskegel vollständig auf die Fokusebene abgebildet werden.

In der Fokusebene des Spektrographen befindet sich hinter einem Quarzfenster die Photokathode ${ }^{4}$ des Bildverstärkers ${ }^{5}$. Die Photokathode ist ab 5 ns pulsbar und arbeitet in einem Spektralbereich von 180 bis $800 \mathrm{~nm}$. Mit Hilfe der gepulsten Photokathode wird die erforderliche Zeitaufösung erreicht (siehe Abb. 3.5). Der Verstärkungsfaktor (gain) bei maximaler Beschleunigungsspannung beträgt $1: 10000$.

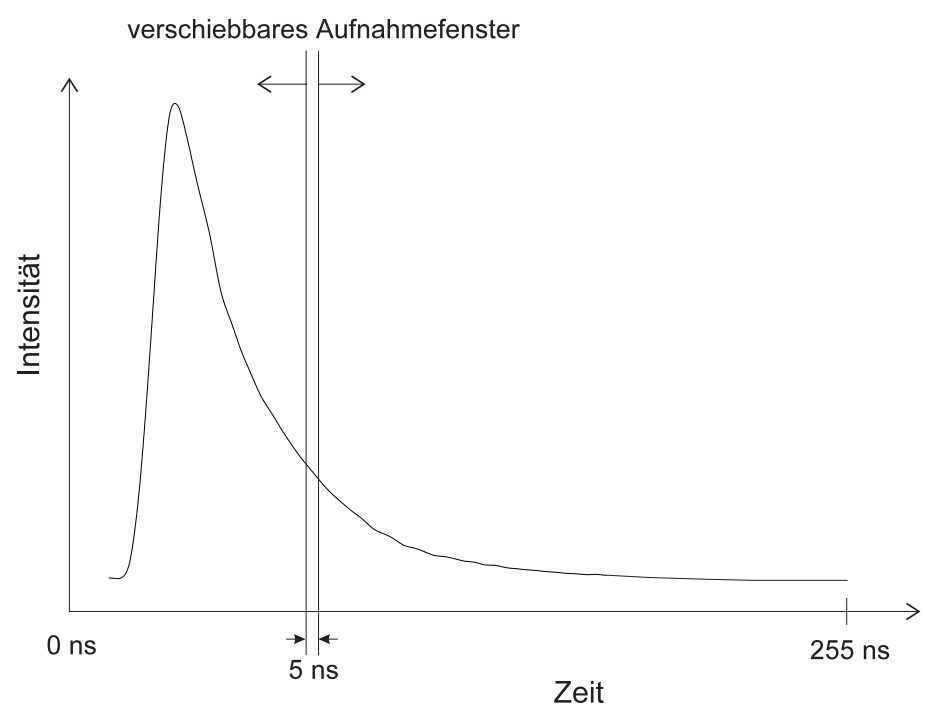

Abbildung 3.5: Der Bildverstärker kann im gepulsten Betrieb verschiebbare Zeitfenster setzen. Dadurch wird eine zeitaufgelöste Messung möglich.

Der Bildverstärker ist durch ein Objektiv ${ }^{6}$ mit der CCD-Kamera ${ }^{7}$ verbunden, das mit der maximal geöffneten Blende verwendet wird. Die CCD-Kamera wird zur Verminderung des Dunkelrauschens durch ein Peltier-Element gekühlt und zur Verminderung des Ausleserauschens in der Slow-Scan-Technik ausgelesen. Der CCDChip besteht aus einer Matrix mit 512x64 Kanälen. Die vier vertikal angeordneten Nachweisfasern werden auf die 64 vertikalen Kanäle abgebildet, die von der Kamera bereits intern während des Auslesens integriert werden. Die Kamera wird extern mit $500 \mathrm{kHz}$ getaktet, was eine maximale Auslesefrequenz von $155 \mathrm{~Hz}$ ermöglicht.

Der Chip deckt mit 512 Kanälen einen spektralen Bereich von $275 \mathrm{~nm}$ Breite ab (z.B. 260 bis $535 \mathrm{~nm}$ ), die spektrale Aufösung der CCD-Kamera liegt demnach bei etwa $0.5 \mathrm{~nm}$ und ist etwas höher als die des Bildverstärkers mit $0.8 \mathrm{~nm}$. Das

4 S20 Photokathode, Hamamatsu Photonics Deutschland GmbH, Herrsching.

$5 \quad M C P$, PCO Computer Optics GmbH, Kelheim.

6 Nikkor $50 \mathrm{~mm}, \mathrm{f} / 1,2$, Nikon GmbH, Düsseldorf.

7 CCD-C5809-0906, Hamamatsu. 
analoge Signal der Kamera hat laut Spezifikation einen Abstand zwischen Signalund Rauschpegel von 1:23 000, entsprechend einer Auflösung von 14.5 Bit.

\subsection{Der optische Sensor}

Der Teil des Sensors, aus dem das Anregungslicht austritt und in dessen unmittelbarer Nähe die Fluoreszenz stattfindet, wird als Sensorkopf oder Optrode bezeichnet. Das Kunstwort Optrode (von optische Elektrode) geht auf LüBBERS und OpITZ (1975) zurück [101].

Die Optimierung der Optrode für den Schadstoffnachweis in Wasser wurde bereits in [54] beschrieben. In Kapitel 4 wird ein allgemeineres Modell zur Berechnung und Charakterisierung von Optrodendesigns behandelt. Die hier gezeigte Geometrie war das Ergebnis der früheren Untersuchungen. Sowohl die ältere, nur für die Wasseranalytik konzipierte, als auch die neuere Optrode, die sowohl für Wasser als auch für Böden eingesetzt werden kann, wurden für die Messungen dieser Arbeit verwendet. Die Optroden mit den Lichtleiterkabeln wurden von der Firma Prinz Optics $^{8}$ nach vorgegebenen Spezifikationen gefertigt. Vier UV-Fasern aus Quarz mit einem Kerndurchmesser von $400 \mu \mathrm{m}$ und einer Numerischen Apertur von 0.22 gruppieren sich um eine $600 \mu \mathrm{m}$ Quarzfaser (siehe Abb. 3.6).

\subsection{Elektronik und Software}

Die Ansteuerung der Einzelkomponenten erfordert eine hohe zeitliche Präzision im Nanosekundenbereich. Eine Photodiode registriert den Anregungslaserpuls zwischen Laser und Einkopplung in die Anregungsfaser. Zwei programmierbare digitale Delay-Generatoren ${ }^{9}$ verzögern das Signal der Photodiode und steuern das Zeitfenster des Bildverstärkers. Die benötigte Vorlaufzeit der Steuerungseinheit liegt bei 90 ns, d.h. das Zeitfenster kann frühestens 90 ns nach Registrierung des Laserpulses geöffnet werden. Diese Vorlaufzeit wird durch die Laufzeit des Lichtes in dem $15 \mathrm{~m}$ langen Sensorkabel (135 ns) ausreichend kompensiert. Eine Elektronik auf Basis eines 16-Bit AD-Wandlers konvertiert das analoge Signal (0..10 V) in ein digitales Signal, das bis zum Abruf durch einen PC in einem $512 \mathrm{~KB}$ Zwischenspeicher abgelegt wird.

Das Meßprogramm, mit dem CCD- und PMT-System gesteuert werden, wurde vom Autor für das Betriebssystem Microsoft Windows $95 / 98^{\mathrm{TM}}$ in den Programmiersprachen $\mathrm{C}++$ und Delphi ${ }^{10}$ entwickelt. Eine ausführliche Darstellung des Meßprogrammes findet sich im Anhang (A.3).

8 Prinz Optics GmbH, Stromberg.

9 AD9501, Analog Devices, Stuttgart.

10 Borland $\mathrm{C}++$, Vers. 4.52 und Borland Delphi, Vers. 2.01. 


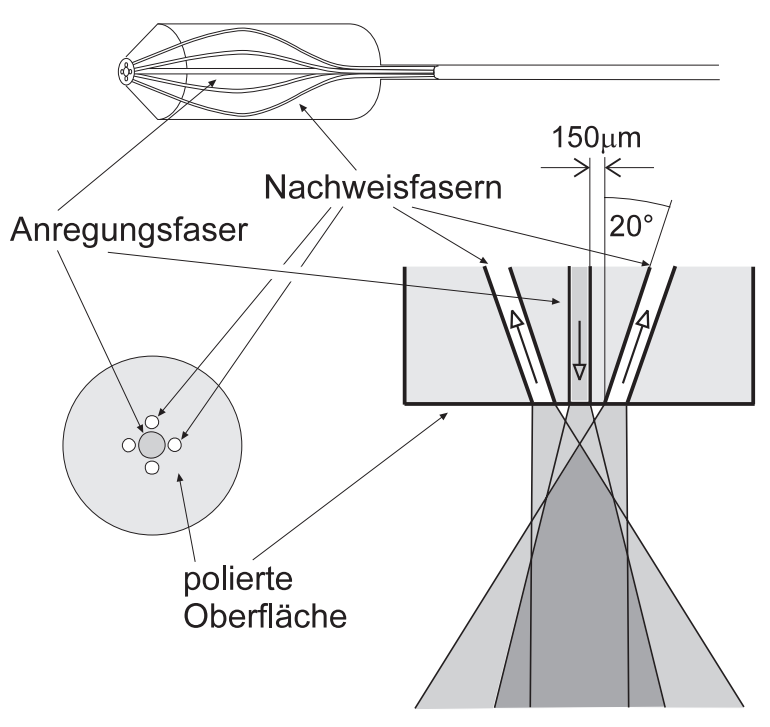

Abbildung 3.6: Die ältere Optrode, die nur für die Wasseranalytik eingesetzt werden kann. Vier Nachweisfasern gruppieren sich symmetrisch um eine Anregungsfaser. Der Winkel zwischen der als Anregungsfaser verwendeten $600 \mu \mathrm{m}$-Faser und den $400 \mu \mathrm{m}$ Nachweisfasern beträgt $20^{\circ}$. Die Länge der Fasern von der Optrode bis zum Laser bzw. Detektor liegt bei $15 \mathrm{~m}$. Die neuere Optrode ist in Abb. (4.1) auf Seite 24 zu sehen.

\subsection{Meßdaten und Aufnahmeparameter}

Vielkanalanalysatoren werden üblicherweise zur Aufzeichnung von „integralen“ 2DSpektren verwendet, wobei sich die Bezeichnung auf eine Integration über die Zeit bezieht. Ein 2D-Spektrum enthält die Signalintensität als Funktion der Wellenlänge.

Durch kleine Zeitfenster und der Aufzeichnung einer Folge von 2D-Spektren läßt sich ein zeitaufgelöstes 3D-Spektrum erzeugen. In dieser Arbeit wurde mit Zeitfenstern von $5 \mathrm{~ns}$ und einer Folge von $Z$ 2D-Spektren gearbeitet $(Z=50 \ldots 200)$, die mit den 512 Kanälen der CCD-Kamera eine Datenmatrix mit $512 \times Z$ Elementen ergaben. Der Versatz der einzelnen Zeitfenster und damit der zeitliche Abstand zwischen den einzelnen 2D-Spektren wurde zwischen einer und drei Nanosekunden gewählt. Abbildung 3.7 zeigt als Beispiel das zeitaufgelöste Spektrum von Acenaphthen und Pyren in Wasser.

Um das Signalrauschen zu verringern, wurde über eine Anzahl von Spektren gemittelt (typischerweise zwischen 7 und 60). Die Zahl der notwendigen Laserpulse ergibt sich aus dem Produkt der Anzahl der Mittelungen und der Anzahl der 2D-Spektren. Bei der Aufzeichnung können die einzelnen Zeitfenster sowohl sequentiell als auch wahlfrei aufeinander folgen. Bei sequentiellen Fenstern werden alle Einzelspektren eines 2D-Spektrums in einem Zug aufgenommen. Anschließend 


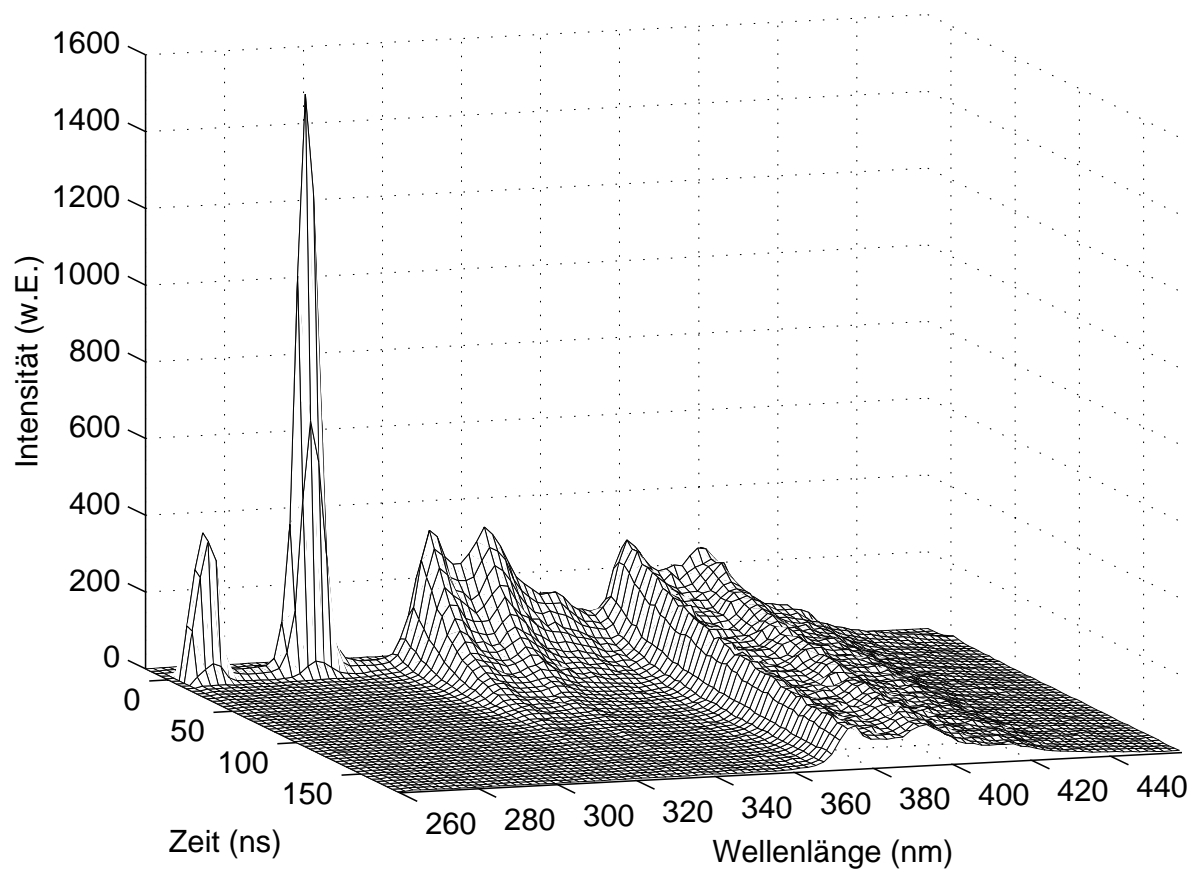

Abbildung 3.7: Das zeitaufgelöste Spektrum einer Wasserprobe mit 10 ppb Acenaphthen $(300-360 \mathrm{~nm})$ und $10 \mathrm{ppb}$ Pyren $(360-440 \mathrm{~nm})$. Bei $266 \mathrm{~nm}$ ist das Signal des elastisch gestreuten Fluoreszenzlichtes und bei $294 \mathrm{~nm}$ das Ramansignal des Wassers zu sehen.

wird die Position des Fensters um den zeitlichen Versatz erhöht und die nächsten Einzelspektren aufgenommen. Bei wahlfreien Fenstern ist die Reihenfolge aller Einzelspektren zufällig. Wahlfreie Aufnahmefenster führen zu einer deutlich höheren Aufnahmezeit, da die Elektronik für jeden Laserpuls auf ein neues Zeitfenster eingestellt werden muß. Untersuchungen von M. NIEDERKRÜGER und dem Autor haben gezeigt, daß die Verwendung von sequentiellen Fenstern gleichwertig mit der Verwendung wahlfreier Fenster ist, wenn die gesamte Aufnahmezeit in der Größenordnung einer Minute bleibt [114].

\section{Kalibrierung}

Die spektrale Kalibrierung wurde mit Hilfe einer Quecksilberdampf-Lampe durchgeführt und mit den bekannten Wellenlängen des elastisch und Raman-gestreuten Lichtes in Wasser überprüft. Die zeitliche Kalibrierung geschah relativ zum gemessenen Maximum des Anregungssignals. Der zeitliche Ausschnitt wurde so gewählt, daß das erste Aufnahmefenster des 3D-Spektrums den Beginn des Anregungssignals registriert. Die Photodiode zur Energiemessung wurde mit Hilfe eines Energiemeßgerätes $^{11}$ für den Bereich $10 . .70 \mu \mathrm{J}$ kalibriert.

11 Universal Radiometer RM 6600 mit Probenkopf RJP-735, Polytec, Waldbronn. 


\subsection{Gesamtspezifikation}

Das spektrale Aufösungsvermögen des Gesamtsystems ist durch die Spaltbreite an der Faserauskopplung gegeben und beträgt bei Verwendung des 250- $\mu \mathrm{m}$-Spalts $6 \mathrm{~nm}$ und mit dem 100- $\mu \mathrm{m}$-Spalt $2.5 \mathrm{~nm}$. Die Ungenauigkeit der Zeitfenster liegt bei $\pm 0.5 \mathrm{~ns}$ und ergibt sich aus dem Fehler der zur Triggerung verwendeten Photodiode, der Ungenauigkeit der Delaygeneratoren und dem Fehler des Bildverstärkers. Die Zeitfenster können in einem Bereich von 0 bis $506 \mathrm{~ns}$ in Schritten von 1 ns gesetzt werden. Das minimale Zeitfenster hat eine Breite von $5 \mathrm{~ns}$, die maximale Breite beträgt $255 \mathrm{~ns}$.

Die Maximalfrequenz, mit der Einzelspektren erfaßt werden können, wird durch den Laser, die Verarbeitungsgeschwindigkeit des AD-Wandlers und des Steuerungscomputers auf $60 \mathrm{~Hz}$ begrenzt. Die Meßzeit für ein typisches zeitaufgelöstes Spektrum (30 Mittlungen pro Zeitscheibe, 50 Zeitscheiben) liegt bei ca. 40 Sekunden.

\subsection{Das PMT-System}

Wenige Monate vor Niederschrift dieser Arbeit wurde ein zweites Meßsystem fertiggestellt, das PMT-Spektrometer (PMT: Photo Multiplier Tube). Das PMT-System ist deutlich kleiner, leichter und preiswerter als das CCD-System. Da keine in dieser Arbeit verwendeten Daten mit dem neuen System aufgezeichnet wurden, soll dies hier allerdings nur kurz angesprochen werden. Wenn nicht explizit anders erwähnt, bezieht sich diese Arbeit daher auf das CCD-Meßsystem.

Das neue System verwendet einen Monochromator zur Wahl einer bestimmten Wellenlänge und einen Photomultiplier (PMT) zum zeitaufgelösten Nachweis des Fluoreszenzlichtes. Der Laser ist eine Weiterentwicklung des Lasers des CCDSystems und kommt dank transversalem Pumpen mit nur zwei anstelle von vier Laserdiodenarrays aus. Während im CCD-System mit einem Laserpuls das spektrale Verhalten der Fluoreszenz zu einem wählbaren Zeitpunkt beobachtet wird (zeitsequentieller Nachweis), wird im PMT-System das zeitliche Verhalten der Fluoreszenz auf einer wählbaren Wellenlänge aufgezeichnet (wellenlängensequentieller Nachweis). Trotz erheblicher Unterschiede in der Technik liefern beide Systeme bei Wahl entsprechender Aufnahmeparameter vergleichbare zeitaufgelöste Spektren. Alle Methoden zur Datenauswertung können daher sowohl für das CCD-System als auch für das PMT-System angewendet werden. 


\section{Modellierung der Optrodengeometrie}

Teil der Entwicklung des Laserfluorimeters war die Optimierung der Optrode (von optische Elektrode, der Sensorkopf). Obwohl die meisten in dieser Arbeit vorgestellten Versuche mit Schadstoffen in Wasser durchgeführt wurden, ist das Meßsystem auch für die Schadstoffmessung in Böden konzipiert. Die Optrode für Messungen in Wasser [54] ist dafür ungeeignet. Im folgenden wird die mathematische Modellierung und Optimierung einer Optrode für Messungen in bzw. auf Bodenproben vorgestellt.

Durch die Implementierung des Modells als Computerprogramm war es möglich, diverse Parameter der Optrodengeometrie sowie verschiedene in Frage kommende Materialien für die optischen Komponenten mittels Simulation zu untersuchen. Dazu zählen die Durchmesser der optischen Fasern und deren numerische Apertur, Anzahl und räumliche Orientierung der Fasern und weitere optische Komponenten. Besonderheiten wie schräg angeschliffene Faserenden wurden ebenso berücksichtigt.

Bei den Berechnungen wurden typischerweise zwei Parameter variiert und die jeweils verbleibenden Parameter konstant gehalten. Die Ergebnisse wurden graphisch dargestellt.

Zur Optimierung eines Optrodendesigns mittels mathematischer Modellierung existieren nur eine vergleichsweise geringe Anzahl von Publikationen [34],[115][124]. Allerdings berücksichtigen die Modellierungen entweder kein bewertetes Beobachtungsvolumen oder das Modell verwendet geometrische Symmetrien, die bei dieser Aufgabenstellung nicht anwendbar waren (z.B. Rotationssymmetrie). So schreibt dann auch PAnne ([125], S. 99): „Obwohl von einer Reihe von Autoren der Versuch unternommen wurde, eine simplifizierte parallele Anordnung von Beobachtungs- und Anregungsfaser mathematisch zu beschreiben ..., konnte für die gewinkelte Faseranordnung bisher kein befriedigender Ansatz gefunden werden.".

Das vorgestellte mathematische Modell ist nicht auf Optroden für undurchsichtige Proben wie Böden begrenzt, bei dem das Nachweisgebiet in einer Ebene liegt. Auch die Untersuchung und Optimierung von Optroden für Flüssigkeiten oder Gas ist damit möglich. Es stellt somit eine erhebliche Erweiterung des Modells aus [54] dar.

Um ein optimales - oder doch zumindest ein „gutes“ - Optrodendesign bestimmen zu können, müssen verschiedene Designs verglichen werden. Dazu ist ein Wert nötig, der die Qualität oder die Leistungsfähigkeit einer Optrode beschreibt. Die Aufgabe der Optrode ist es, im Rahmen gewisser Vorgaben möglichst viel des optischen Signals, des Fluoreszenzlichtes der Schadstoffe, zu empfangen und zum Detektor zu übertragen. Als Hauptqualitätsmerkmal wird daher die Optrodeneffizienz $C E$ (von collection efficiency) als die Menge des Fluoreszenzlichtes definiert, die eine Optrode bei vorgegebener Anregungslichtstärke „sammelt“. Die Nachweisebene wird dabei als so dicht mit Fluorophoren besetzt angenommen, daß jedes Anregungsphoton zu einem Fluoreszenzphoton führt.

$C E$ ist eine Funktion des Designs, d.h. der geometrischen Parameter und der 
Materialparameter einer Optrode. Durch Änderung der Parameter ändert sich der Wert von $C E$, der Einfluß der einzelnen Parameter und der Parameter untereinander kann untersucht und quantifiziert werden. Die Parameterkombination mit dem höchsten $C E$-Wert wird als optimal angenommen.

Wesentliches Element bei der Berechnung von $C E$ ist die Bewertungsfunktion $f(\vec{r})$ (Gleichung (4.2)), die den Einfluß eines Punktes ${ }^{1} \vec{r}$ auf der Nachweisebene dem Teil der kontaminierten Bodenprobe, in dem die Fluoreszenzphotonen emittiert werden - zur Summe des gesamten empfangenen Fluoreszenzlichtes beschreibt. Diese Funktion besteht aus zwei Faktoren: (1) Der Intensität des Anregungslichtes an diesem Punkt und (2) der Wahrscheinlichkeit des von diesem Punkt emittierten Photons, die Nachweisfaser zu erreichen und in dieser zum Detektor geführt zu werden. Die Theorie und die programmtechnische Umsetzung für den zweiten Faktor wird vergleichsweise kompliziert durch refraktive Elemente zwischen der Nachweisoberfläche und der Nachweisfaser (ein Schutzfenster und ein Luftspalt) sowie durch einen schrägen Anschliff der Fasern. Neben den Brechungen an allen Oberflächen muß eine mögliche Totalreflexion bei Übergängen aus optisch dichteren zu optisch dünneren Medien berücksichtigt werden.

\subsection{Theorie}

\subsubsection{Die Parameter}

Die grundsätzliche Geometrie der Optrode ist in Abbildung (4.1) gezeigt. Die zu optimierenden Parameter sind die Winkel $\gamma$ zwischen den Fasern und der z-Achse, Position $\vec{c}$ und räumliche Orientierung $\vec{a}$ der Fasern und die Stärke $z_{\text {win }}$ des Schutzfensters und dessen Brechungsindex (der durch unterschiedliche Materialien variiert werden kann).

Zusätzlich ist zu erwarten, daß für eine gekippte Anregungsfaser (d.h. $\gamma_{E F} \neq 0$ ) die optimalen Kippwinkel $\gamma_{D F}$ und die Drehwinkel $\varphi$ der Fasern um die z-Achse (Abb. (4.2)) von den Winkeln $\omega$ der Nachweisfasern in der x-y-Ebene abhängig sind. Mit anderen Worten: Die optimalen Werte für die Winkel $\gamma_{D F}$ und $\varphi$ müssen für jede Nachweisfaser einzeln bestimmt werden.

Neben einem möglichst hohen $C E$-Wert soll die gesuchte (optimale) Geometrie für die Optrode einige technische und praktische Voraussetzungen erfüllen. Dazu zählt ein durch die Art der Herstellung vorgegebener Minimalabstand $d$ zwischen den Fasern von etwa $150 \mu \mathrm{m}$, kommerziell erhältliche Faserdurchmesser für UVfähige Fasern (z.B. 200, 400 oder $600 \mu \mathrm{m}$ ) und ein vertretbarer Herstellungspreis.

1 Punkte seien hier durch Vektoren (z.B. $\vec{r} \in \mathbb{R}^{3}$ ) beschrieben, wodurch sich einige Gleichungen kompakter schreiben lassen. Die Vektorelemente $\left(r_{x}, r_{y}, r_{z}\right)$ sind dabei die Koordinaten des Punktes im Euklidischen Raum $\mathbb{R}^{3}$. 


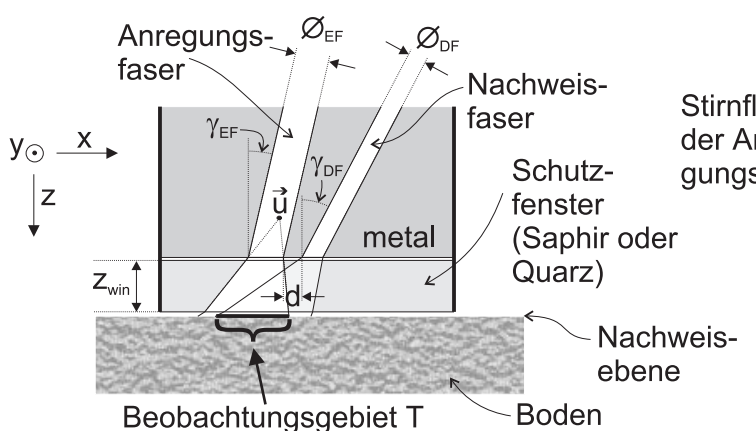

(a)

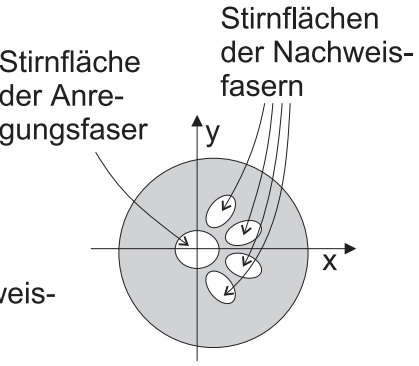

(b)

Abbildung 4.1: Die Geometrie der Optrode für Feststoffmessungen (a) von der Seite mit einer eingezeichneten Nachweisfaser und (b) von unten mit vier Nachweisfasern. Das Beobachtungsgebiet $T$ ist die Schnittmenge des von der Anregungsfaser beleuchteten Gebietes mit dem Akzeptanzkegel der Nachweisfasern.

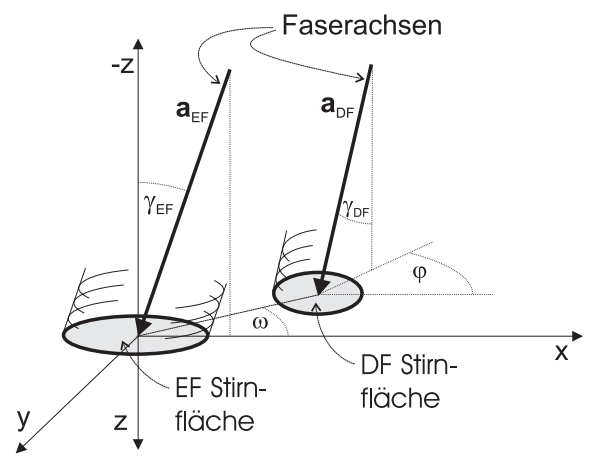

Abbildung 4.2: Zur Definition der Winkel $\omega$ und $\varphi$ der Nachweisfaser.

Die Energie des Anregungslasers von maximal $100 \mu \mathrm{J}$ pro Puls legt einen Durchmesser für die Anregungsfaser von mindestens $\varnothing_{E F}=600 \mu \mathrm{m}$ nahe [89] (EF $=$ excitation fiber, $\mathrm{DF}=$ detection fiber). Die Größe des Eingangsspaltes des Detektors von $(250 \times 1600 \mu \mathrm{m})$ beschränkt die Anzahl der Nachweisfasern auf $3\left(\varnothing_{D F}=600 \mu \mathrm{m}\right)$, $4\left(\varnothing_{D F}=400 \mu \mathrm{m}\right)$ oder $7\left(\varnothing_{D F}=200 \mu \mathrm{m}\right)$. Die minimale Stärke $z_{w i n}$ des Schutzfensters sollte aus Stabilitätsgründen zwischen 500 und $800 \mu \mathrm{m}$ liegen, abhängig vom verwendeten Material (in Frage kommen v.a. Saphir oder Quarz).

Sind diese Anforderungen erfüllt, so ist das entscheidende Vergleichskriterium verschiedener Designs die Optrodeneffizienz $C E$ (siehe Gleichung (4.1)). Der $C E$ Wert eines Designs mit mehreren Nachweisfasern kann als die Summe der $C E$ Werte entsprechender Designs mit jeweils einer Nachweisfaser berechnet werden. Die Berechnungen können also auf ein EF-DF-Paar reduziert werden.

Für die Rechnungen wird das Beobachtungsgebiet in kleine Einheitsquadrate aufgeteilt. Jedes dieser Quadrate wird mit Hilfe der Funktion $f: \mathbb{R}^{3} \rightarrow \mathbb{R}_{0}^{+}$ent- 
Tabelle 4.1: Symbole und Funktionen, die für die mathematische Modellierung der Bodenoptrode verwendet wurden.

\begin{tabular}{r|l}
$E F$ & excitation fiber, Anregungsfaser \\
$D F$ & detection fiber, Nachweisfaser \\
$C E$ & collection efficiency, Optrodeneffizienz \\
$N A$ & Numerische Apertur \\
$B$ & Teilgebiet der Stirnfläche einer Nachweisfaser \\
$\vec{b}$ & Punkt auf einer Faserstirnfläche \\
$\vec{b}^{r i m}$ & Punkt auf dem Rand einer Faserstirnfläche \\
$T$ & Beobachtungsgebiet in der Nachweisebene \\
$\emptyset_{E F}, \emptyset_{D F}$ & Durchmesser von Anregungs- und Nachweisfaser(n) \\
$z_{w i n}$ & Dicke bzw. Stärke des Schutzfensters, z-Position der Nachweisebene \\
$n_{w i n}$ & Brechungsindex des Schutzfenstermaterials \\
$d$ & Abstand zwischen EF und DF \\
$\vec{a}_{E F}, \vec{a}_{D F}$ & Achsen von EF und DF \\
$\vec{c}_{E F}, \vec{c}_{D F}$ & Schnittpunkt von Faserachsen und x-y-Ebene bei $z=0$ \\
$\vec{e}_{x}, \vec{e}_{y}, \vec{e}_{z}$ & Einheitsvektoren \\
$\varepsilon$ & Integrationsschrittweite \\
$\gamma_{E F}, \gamma_{D F}$ & Kippwinkel (Winkel zwischen z-Achse und Faserachse) \\
$\varphi$ & Drehwinkel einer Nachweisfaser um die z-Achse \\
$\omega$ & Positionswinkel einer Nachweisfaser, abhängig von $\vec{c}_{D F}$ \\
$\theta$ & Akzeptanzwinkel einer Faser außerhalb der Faser, abhängig von NA \\
$\theta_{i n}$ & und dem Brechungsindex des umgebenen Mediums \\
$\mathrm{d}(\vec{v}, \vec{w})$ & Akzeptanzwinkel innerhalb einer Faser \\
$\angle(\vec{v}, \vec{w})$ & Winkel zwischen den Vektoren $\vec{v}$ und $\vec{w}$ \\
$\vec{v} \times \vec{w}$ & Kreuzprodukt zwischen den Vektoren $\vec{v}$ und $\vec{w}$ \\
&
\end{tabular}

sprechend dem Beitrag dieses Quadrates zur Gesamtsumme des vom Detektor empfangenen Fluoreszenzlichtes bewertet. $C E$ läßt sich dann definieren als:

$$
C E=s_{C E} \int_{-\infty}^{\infty} \int_{-\infty}^{\infty} f(\vec{r}(x, y)) \mathrm{d} x \mathrm{~d} y
$$

wobei $x$ und $y$ die entsprechenden Komponenten des Vektors $\vec{r}$ (mit $r_{z}=z_{\text {win }}$ ) sind. $s_{C E}$ ist eine Konstante zur Skalierung von $C E$ auf "handliche" Werte.

Der Wert innerhalb von $T$ hängt von zwei Faktoren ab: (1) der Energiedichte des Anregungslichtes $\rho(\vec{r})$ am Punkt $\vec{r}$ und (2) der Wahrscheinlichkeit $h(\vec{r})$ eines Photons, von diesem Punkt aus innerhalb des Akzeptanzwinkels $\theta$ die Stirnfläche der Nachweisfaser zu treffen:

$$
f(\vec{r})=\rho(\vec{r}) h(\vec{r})
$$


Für das Gebiet auf der Nachweisebene außerhalb der Schnittmenge $T$ von Anregungs- und Nachweiskegel (siehe Abb. 4.1) ist einer dieser beiden Faktoren und damit $f$ gleich Null.

\subsubsection{Berechnung der Energiedichtefunktion $\rho(\vec{r})$}

Versuche mit den verwendeten Fasern haben gezeigt, daß für nicht zu große Kippwinkel der Anregungsfaser $\left(\gamma_{E F} \leq 30^{\circ}\right)$ die Energiedichte an $\vec{r}$ durch die Funktion:

$$
\rho(\vec{r})=\left\{\begin{array}{lll}
E_{0} \vec{u}^{2}|\vec{r}-\vec{u}|^{-2} & : & \text { wenn } \vec{r} \in T_{E F} \\
0 & : & \text { sonst }
\end{array}\right.
$$

angenähert werden kann [126], wobei $E_{0}$ die Anregungsenergie, $T_{E F}$ die beleuchtete Fläche auf der Nachweisebene und $\vec{u}$ die (gedachte) Spitze des Anregungslichtkegels ist (siehe Abb. 4.1):

$$
\vec{u}=\vec{c}_{E F}-\frac{\frac{1}{2} \varnothing_{E F}}{(\tan \theta)} \frac{\vec{a}_{E F}}{\left|\vec{a}_{E F}\right|} .
$$

\subsubsection{Berechnung der Wahrscheinlichkeitsfunktion $h(\vec{r})$}

Die Berechnung von $h(\vec{r})$ besteht aus zwei Schritten: Im ersten Schritt wird die Fläche $B$ auf der Stirnfläche der Nachweisfaser berechnet, die ein Fluoreszenzphoton vom Punkt $\vec{r}$ kommend unter Einhaltung des Akzeptanzwinkels erreichen kann. Genauer:

(i) Die Fläche B ist vollständig Teil der Stirnfläche der Nachweisfaser.

(ii) Eine Transmission in die Faser ist für von $\vec{r}$ kommende Photonen für jeden Punkt in $B$ möglich, auch dann, wenn sich zwischen Schutzfenster und Nachweisfaser ein kleiner Luftspalt befindet (Berücksichtigung von möglicher Totalreflexion).

(iii) Nach allen Brechungsvorgängen ist der Winkel zwischen den Lichtstrahlen in der Faser und der Faserachse nicht größer als der Akzeptanzwinkel $\theta_{\text {in }}$ der Faser.

Im zweiten Schritt wird $\beta(\vec{r})$ berechnet, der Raumwinkel, unter dem die Fläche $B$ vom Punkt $\vec{r}$ aus gesehen erscheint. Die Wahrscheinlichkeitsfunktion ist dann:

$$
h(\vec{r})=\frac{\beta(\vec{r})}{4 \pi} .
$$




\section{Schritt Eins: Berechnung der Fläche $B$}

Definition: Es sei valid $(\vec{b}, \vec{r})$ eine boolsche Funktion, die das Ergebnis WAHR hat, wenn der Punkt $\vec{b}$ innerhalb von $B$ liegt, d.h. für $\vec{b}$ sind die Bedingungen (i) bis (iii) erfüllt. Andernfalls sei der Wert von valid $(\vec{b}, \vec{r})$ FALSCH. Die Ansätze, die obigen drei Kriterien für zwei gegebene Punkte $\vec{b}$ und $\vec{r}$ zu überprüfen, werden kurz diskutiert.

Für (i) wird ein Vektor $\vec{v}$ definiert:

$$
\begin{aligned}
& v_{x}=\left\{\begin{array}{lll}
1 & : & \text { wenn } a_{D F, x}=a_{D F, y}=0, \\
a_{D F, x} & : & \text { sonst }
\end{array}\right. \\
& v_{y}=a_{D F, y} \\
& v_{z}=0
\end{aligned}
$$

wobei $\vec{a}_{D F}$ die Achse der Nachweisfaser ist. Mit $\vec{v}$ läßt sich die große Halbachse der elliptischen Fläche der schräg angeschliffenen Stirnfläche der Nachweisfaser durch

$$
\vec{r}_{a}=\frac{\frac{1}{2} \emptyset_{D F}}{\cos \left(\gamma_{D F}\right)} \frac{\vec{v}}{|\vec{v}|}
$$

und die kleine Halbachse durch

$$
\vec{r}_{b}=\frac{1}{2} \emptyset_{D F} \frac{\vec{w}}{|\vec{w}|}
$$

berechnen, wobei $\vec{w}=\vec{e}_{z} \times \vec{r}_{a}$ ist (mit dem Kreuzprodukt $\times$ ). Die Brennpunkte der Ellipse sind:

$$
\vec{f}_{ \pm}=\vec{c}_{D F} \pm \sqrt{\left|\vec{r}_{a}\right|^{2}-\left|\vec{r}_{b}\right|^{2}} \frac{\vec{r}_{a}}{\left|\vec{r}_{a}\right|}
$$

und die Bedingung (i) ist erfüllt, wenn die Relation

$$
\mathrm{d}\left(\overrightarrow{f_{+}}, \vec{b}\right)+\mathrm{d}\left(\overrightarrow{f_{-}}, \vec{b}\right) \leq 2\left|\vec{r}_{a}\right|
$$

zutrifft.

Zum Test der Bedingung (ii) und (iii) ist eine Gleichung erforderlich, die die Brechung von Licht beschreibt [127]:

$$
\overrightarrow{s^{\prime}}=\frac{n}{n^{\prime}} \vec{s}-\vec{e}\left(\frac{n}{n^{\prime}} \vec{e} \cdot \vec{s}-\sqrt{1-\left(\frac{n}{n^{\prime}}\right)^{2}(1-\vec{e} \cdot \vec{s})}\right)
$$

mit $\vec{s}(|\vec{s}|=1)$ dem zu brechenden Strahl, $\overrightarrow{s^{\prime}}$ dem gebrochenen Strahl, $n$ und $n^{\prime}$ den Brechungsindizes vor und hinter der brechenden Ebene und $\vec{e}$ dem Einheitsvektor senkrecht zur brechenden Ebene mit $0 \leq \vec{e} \cdot \vec{s} \leq 1$. Wird der Ausdruck unter 
der Wurzel negativ, findet eine Totalreflexion des Strahls statt. Demnach ist die Bedingung (ii) erfüllt, wenn der Ausdruck

$$
\left(\frac{n}{n^{\prime}}\right)^{2}(1-\vec{e} \cdot \vec{s}) \leq 1
$$

für $\vec{s}=\frac{\vec{b}-\vec{r}}{|\vec{b}-\vec{r}|}, \vec{e}=-\vec{e}_{z}$ und $n=n_{w i n}$ wahr ist. Zur Berücksichtigung des Luftspaltes zwischen Schutzfenster und Nachweisfaser muß zum Test auf Totalreflexion der Brechungsindex von Luft $\left(n^{\prime}=1.0\right)$ verwendet werden.

Findet keine Totalreflexion statt, wird der gebrochene Strahl $\overrightarrow{s^{\prime}}$ nach Gleichung (4.10) mit $n^{\prime}=1.49$ berechnet, dem mittleren Brechungsindex von Quarz für UVLicht im Bereich 266 bis $330 \mathrm{~nm}$ [128]. Bedingung (iii) ist dann erfüllt, wenn die Gleichung

$$
\angle\left(\overrightarrow{s^{\prime}}, \vec{a}_{D F}\right) \leq \theta_{\text {in }}
$$

wahr ist, wobei $\angle$ der Winkel zwischen den beiden Vektoren ist.

Um die Fläche $B$ zu bestimmen, wird ein Gitter durch die Punktmenge $B_{p}^{\prime}$ definiert:

$$
\begin{aligned}
B_{p}^{\prime}=\left\{\vec{v} \in B_{p}^{\prime} \mid \quad\right. & v_{x} \geq c_{x}-\left|\vec{r}_{a}\right| ; v_{x} \leq c_{x}+\left|\vec{r}_{a}\right| ; \\
& v_{y} \geq c_{y}-\left|\vec{r}_{a}\right| ; v_{y} \leq c_{y}+\left|\vec{r}_{a}\right| ; \\
& \left.v_{z}=c_{z} ; \mathrm{d}(\vec{v}, \vec{w}) \geq \varepsilon_{B} \text { für alle } \vec{w} \in B_{p}^{\prime}\right\}
\end{aligned}
$$

mit der großen Halbachse der Stirnfläche der Nachweisfaser $\vec{r}_{a}$ von Gleichung (4.6). Mit Hilfe der oben eingeführten Funktion valid $(\vec{b}, \vec{r})$ wird die Punktmenge $B_{p}^{\prime}$ auf die Punktmenge $B_{p}$ reduziert, durch welche die Fläche $B$ mit der Auflösung $\varepsilon_{B}$ beschrieben wird ${ }^{2}$ :

$$
B_{p}=\left\{\vec{b} \in B_{p}^{\prime} \mid \operatorname{valid}(\vec{b}, \vec{r})=\mathrm{WAHR}\right\}
$$

\section{Schritt Zwei: Projektion der Fläche $B$ auf eine Einheitskugel und Be- rechnung des Raumwinkels $\beta(\vec{r})$}

Lemma. Die Fläche B ist nicht konkav.

Beweis (durch Widerspruch): Wäre $B$ konkav, dann gäbe es drei Punkte $\vec{b}_{1}, \vec{b}_{2} \in B$ und $\overrightarrow{b^{\prime}} \notin B$, mit $\overrightarrow{b^{\prime}}$ auf der Verbindungslinie zwischen $\vec{b}_{1}$ und $\vec{b}_{2}$ und nach Definition $\operatorname{valid}\left(\vec{b}_{1}, \vec{r}\right)=\operatorname{valid}\left(\vec{b}_{2}, \vec{r}\right)=$ WAHR und valid $\left(\overrightarrow{b^{\prime}}, \vec{r}\right)=$ FALSCH. Dies ist nicht möglich, da alle drei Bedingungen (i) bis (iii) auch für $\overrightarrow{b^{\prime}}$ erfüllt sein müssen, wenn sie es auch für $\vec{b}_{1}, \vec{b}_{2}$ sind: (i) ist erfüllt, da eine Ellipse konvex ist, (ii) und (iii) sind erfüllt, da $\angle\left(\vec{a}_{D F}, \overrightarrow{b^{\prime}}-\vec{r}\right) \leq \max \left\{\angle\left(\vec{a}_{D F}, \overrightarrow{b_{1}}-\vec{r}\right), \angle\left(\vec{a}_{D F}, \overrightarrow{b_{2}}-\vec{r}\right)\right\}$.

2 Die Beschreibung einiger der modellierten Objekte durch Punktmengen wurde gewählt, wenn dadurch eine einfachere Handhabung und höhere Flexibilität der Tranformationen im Raum möglich wurde. Rechenaufwand und Genauigkeit wurden durch Wahl einer entsprechenden Größe von $\varepsilon_{B}$ in akzeptablen Größenordnungen gehalten. 
Definition. Die „Einhüllende“ einer Menge von Punkten $B_{p}$ in einer Ebene ist die (endliche) Folge $\left(\vec{b}_{i}\right)_{i=1 . . N_{\text {out }}}, \vec{b}_{i} \in B_{p}$, wobei für jede Gerade durch die Paare $\left(\vec{b}_{i}, \vec{b}_{i+1}\right),\left(i=1 . . N_{\text {out }}-1\right)$ alle Punkte aus $B_{p}$ auf der gleichen Seite oder auf der Gerade liegen (siehe Abb. 4.3).

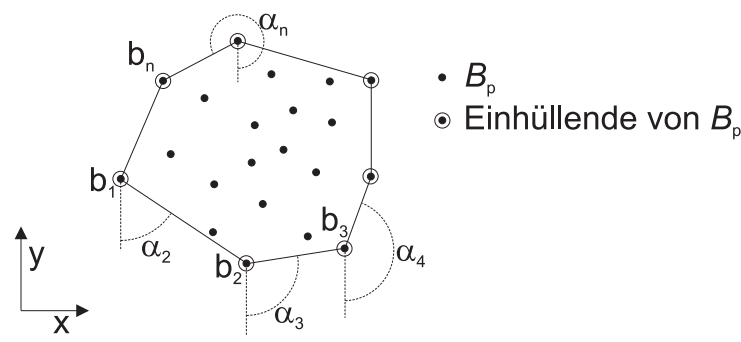

Abbildung 4.3: Die Einhüllende einer Punktmenge. Der Winkel $\alpha_{i}$ ist monoton zunehmend von Punkt zu Punkt.

Um die Einhüllende einer Punktmenge $B_{p}$ zu bestimmten, wird bei dem Punkt mit dem kleinsten x-Wert begonnen und als $\vec{b}_{1}$ der Serie genommen. Der $n$-te Punkt $(n \geq 2)$ wird mit Hilfe von Punkt $\vec{b}_{n-1}$ berechnet. Für jeden Punkt $\vec{b} \in B$, der nicht bereits Teil der Einhüllenden ist, wird der Winkel

$$
\alpha(\vec{b})=\left\{\begin{array}{lll}
\angle\left(\vec{b}-\vec{b}_{n-1},-\vec{e}_{y}\right) & : & \text { wenn } b_{x}-b_{n-1, x}>0, \\
2 \pi-\angle\left(\vec{b}-\vec{b}_{n-1},-\vec{e}_{y}\right) & : & \text { sonst }
\end{array}\right.
$$

berechnet. Der kleinste dieser Winkel mit $\alpha(\vec{b}) \geq \alpha_{n-1}$ wird als $\alpha_{n}$ bezeichnet (mit $\left.\alpha_{1}=0\right)$ und der zugehörige Punkt ist $\vec{b}_{n}$. Die Folge ist vollständig für $\vec{b}_{n}=\vec{b}_{1}$, wobei dann $N_{\text {ein }}:=n$ gesetzt wird. Abschließend wird der „Schwerpunkt" $\vec{b}_{0}$ der Folge definiert $\left(\vec{b}_{0}\right.$ ist nicht Teil der Einhüllenden, diese Indizierung erleichtert aber einige Gleichungen):

$$
\vec{b}_{0}=\frac{1}{N_{\text {ein }}} \sum_{i=1}^{N_{\text {ein }}} \vec{b}_{i}
$$

Aus dem Lemma folgt, daß die Einhüllende $\left(\vec{b}_{i}\right)_{i=1 \ldots N_{e i n}}$ von $B_{p}$ ausreichend für die Beschreibung der Fläche $B$ ist. Die Transformation

$$
{\overrightarrow{b^{\prime}}}_{i}=\frac{\vec{b}_{i}-\vec{r}}{\left|\overrightarrow{b_{i}}-\vec{r}\right|}, \quad i=0 . . N_{e i n},
$$

projiziert die Punkte $\left(\vec{b}_{i}\right)$ (und den Schwerpunkt) auf die Einheitskugel um $\vec{r}$ und transformiert den Koordinatenursprung auf $\vec{r}$. Die resultierenden Punkte $\left(\overrightarrow{b^{\prime}}{ }_{i}\right)$ repräsentieren die Projektion der Fläche $B$ auf der Einheitskugel als sphärisches Polygon. Mit dem projizierten Schwerpunkt kann dieses Polygon als eine Menge von sphärischen Dreiecken $\left({\overrightarrow{b^{\prime}}}_{0},{\overrightarrow{b^{\prime}}}_{i},{\overrightarrow{b^{\prime}}}_{i+1}\right),\left(i=1 . . N_{\text {ein }}-1\right)$ betrachtet werden. Der 
gesuchte Raumwinkel $\beta(\vec{r})$ ist die Oberfläche der projizierten Fläche $B$, berechnet als die Summe der Flächeninhalte dieser Dreiecke [129]:

$$
\beta(\vec{r})=\sum_{i=1}^{N_{\text {ein }}-1} 4 \tan ^{-1}\left(\tan \left(\frac{s_{i}}{2}\right) \tan \left(\frac{s_{i}-a_{i}}{2}\right) \tan \left(\frac{s_{i}-b_{i}}{2}\right) \tan \left(\frac{s_{i}-c_{i}}{2}\right)\right)^{1 / 2}
$$

mit

$$
\begin{aligned}
a_{i} & =\angle\left({\overrightarrow{b^{\prime}}}_{0},{\overrightarrow{b^{\prime}}}_{i}\right), \\
b_{i} & =\angle\left({\overrightarrow{b^{\prime}}}_{0},{\overrightarrow{b^{\prime}}}_{i+1}\right), \\
c_{i} & =\angle\left({\overrightarrow{b^{\prime}}}_{i},{\overrightarrow{b^{\prime}}}_{i+1}\right) \\
s_{i} & =\frac{1}{2}\left(a_{i}+b_{i}+c_{i}\right) .
\end{aligned} \quad \text { und }
$$

\subsubsection{Berechnung des Beobachtungsgebietes $T$}

Außerhalb von $T$ ist die Bewertungsfunktion $f$ gleich Null. Um die Integration über $f$ zur Berechnung von $C E$ (Gleichung (4.2)) auf den Bereich innerhalb von $T$ $\mathrm{zu}$ beschränken, werden zwei boolsche Funktionen in_cone $e_{\mathrm{EF} / \mathrm{DF}}(\vec{r})$ verwendet. Je nachdem, ob die Funktion für Anregungs- oder Nachweisfaser Verwendung findet, wird die Funktion als in_cone $e_{\mathrm{EF}}$ oder in_cone if $_{\text {in }}$ geschrieben.

Definition: Die Funktion in cone $_{\mathrm{EF} / \mathrm{DF}}(\vec{r})$ hat den Wert WAHR, wenn $\vec{r}$ in $T_{E F / D F}$ liegt und andernfalls FALSCH.

Der Übersicht halber wird hier für kurze Zeit auf den Subskript $E F / D F$ verzichtet, da folgende Überlegungen für Anregungs- und Nachweisfaser gleichermaßen gelten. Entsprechend zu der Beschreibung der Fläche $B$ durch eine Punktmenge wird der Anregungs- bzw. Akzeptorkegel einer Glasfaser durch eine Menge von Lichtstrahlen beschrieben. Mit Hilfe von $\vec{r}_{a}$ und $\vec{r}_{b}$, der großen und der kleinen Halbachse der Faserstirnfläche (Gleichungen (4.6) und (4.7), die für die Anregungsfaser analog zur Nachweisfaser aufgestellt werden), wird eine Folge von $N_{s}$ Vektoren erzeugt, die vom Mittelpunkt der Faserstirnfläche aus den Rand der Stirnfläche beschreiben:

$$
\vec{r}_{k}=\vec{r}_{a} \cos \left(2 \pi(k-1) / N_{s}\right)+\vec{r}_{b} \sin \left(2 \pi(k-1) / N_{s}\right), \quad k=1 . . N_{s} .
$$

Durch Verbindung dieser Vektoren mit der Faserachse $\vec{a}$ entsteht eine Folge von Lichtstrahlen zur Beschreibung eines Faserkegels:

$$
\vec{s}_{k}=\vec{a}+|\vec{a}| \tan \left(\theta_{i n}\right) \frac{\vec{r}_{k}}{\left|\vec{r}_{k}\right|}, \quad k=1 . . . N_{s}
$$

Durch eine Verkettung von Brechungen wird der Lichtweg durch die verschiedenen Brechungsebenen zwischen Glasfaser und Nachweisebene modelliert. Zwischen dem Inneren der Glasfaser und der Nachweisebene finden drei Brechungen statt: Faserinneres $\rightarrow$ Luft $\rightarrow$ Schutzfenster $\rightarrow$ Nachweisebene. Die Brechungen werden 
anhand Gleichung (4.10) nacheinander berechnet und resultieren in den Strahlen $\left(\overrightarrow{s^{\prime}} k\right)$, die auf $s_{k, z}^{\prime}=z_{\text {win }}$ skaliert werden.

Um das ganze Volumen eines Faserkegels mit Strahlen zu „füllen“, werden die Strahlen $\left({\overrightarrow{s^{\prime}}}_{k}\right)$ an eine Folge von Punkten $\left(\vec{b}_{i}^{r i m}\right)_{i=1 . . N_{r i m}}$ auf dem Rand der Faserstirnfläche gehängt ${ }^{3}$ :

$$
\left(\vec{b}_{i}^{r i m}\right)=\vec{c}+\vec{r}_{a} \cos \left(2 \pi(i-1) / N_{\text {rim }}\right)+\vec{r}_{b} \sin \left(2 \pi(i-1) / N_{\text {rim }}\right), i=1 . . N_{\text {rim }}
$$

Die Schnittmenge des Kegels und der Nachweisebene wird wieder durch eine Punktmenge beschrieben:

$$
T_{E F / D F}=\left\{\vec{t}_{i, k} \in \mathbb{R}^{3} \mid \vec{t}_{i, k}=\vec{b}_{i}^{r i m}+\vec{s}_{k}^{\prime} ; i=1 . . N_{\text {rim }}, k=1 . . N_{s}\right\} .
$$

Auf diese Weise lassen sich der Anregungskegel $T_{E F}$ und der Nachweiskegel $T_{D F}$ berechnen. Es seien $\left(\vec{t}_{l, E F / D F}\right)_{l=1 . . N_{t}}$ die Einhüllenden der Punktmengen $T_{E F / D F}$ und $\vec{t}_{0, E F / D F}$ entsprechend wieder die Schwerpunkte der Punktmengen. Da diese Punkte alle in der Nachweisebene liegen, gilt $t_{l, z}=r_{z}=z_{\text {win }}$.

Die Funktion in_cone $e_{E F / D F}(\vec{r})$ entscheidet, ob $\vec{r}$ in der Fläche $T_{E F / D F}$ liegt, indem die Geraden durch $\left(\vec{t}_{l}, \vec{t}_{l+1}\right),\left(l=1 . . N_{t}-1\right)$ gebildet werden. Wenn für jede dieser Geraden der Punkt $\vec{r}$ auf der gleichen Seite der Gerade wie der Schwerpunkt $\overrightarrow{t_{0}}$ liegt, so hat in_cone $E F / D F$ den Wert WAHR, andernfalls FALSCH.

Mit dem Gitter

$$
\begin{aligned}
T_{p}^{\prime}=\left\{\vec{t} \in \mathbb{R}^{3} \mid\right. & t_{x} \geq \min \left\{{\overrightarrow{t^{\prime}}}_{x} \in \mathbb{R} \mid \overrightarrow{t^{\prime}} \in T_{D F} \cup T_{E F}\right\} ; \\
& t_{x} \leq \max \left\{{\overrightarrow{t^{\prime}}}_{x} \in \mathbb{R} \mid \overrightarrow{t^{\prime}} \in T_{D F} \cup T_{E F}\right\} ; \\
& t_{y} \geq \min \left\{{\overrightarrow{t^{\prime}}}_{y} \in \mathbb{R} \mid \overrightarrow{t^{\prime}} \in T_{D F} \cup T_{E F}\right\} ; \\
& t_{y} \leq \max \left\{{\overrightarrow{t^{\prime}}}_{y} \in \mathbb{R} \mid \overrightarrow{t^{\prime}} \in T_{D F} \cup T_{E F}\right\} ; \\
t_{z} & \left.=z_{w i n} ; \mathrm{d}(\vec{t}, \vec{v}) \geq \varepsilon_{T} \text { für alle } \vec{v} \in T_{p}^{\prime}\right\}
\end{aligned}
$$

wird das effektive Beobachtungsgebiet $T$ durch die Punktmenge

$$
T_{p}=\left\{\vec{t} \in T_{p}^{\prime} \mid \text { in_cone }_{\mathrm{EF}}(\vec{t})=\mathrm{WAHR} ; \text { in_cone }_{\mathrm{DF}}(\vec{t})=\mathrm{WAHR}\right\} .
$$

mit der Auflösung $\varepsilon_{T}$ beschrieben. Gleichung (4.1) läßt sich damit durch

$$
C E=s_{C E} \sum_{T_{p}} f(\vec{t}), \quad \vec{t} \in T_{p}
$$

ersetzen.

3 Während die Punkte $\vec{r}_{k}$ aus Gleichung (4.19) relativ zum Mittelpunkt der Faserstirnfläche den Rand der Faser beschreiben, enthalten die Punkte $\left(\vec{b}_{i}^{\text {rim }}\right)$ durch Aufnahme der Faserposition $\vec{c}$ absolute Koordinaten. 


\subsection{Rechnungen und Ergebnisse}

Mit Hilfe des obigen Modells wurden die Optrodeneffizienzen $C E$ für diverse Optrodendesigns berechnet. Die Skalierung $s_{C E}$ von $C E$ ist für den Vergleich verschiedener Optrodendesigns unerheblich, so lange sie in allen Rechnungen gleich oder doch zumindest vergleichbar ist. Sie wurde hier aus Bequemlichkeit derart gewählt, daß die vorkommenden $C E$-Werte in etwa im Bereich zwischen 0 und 1000 liegen.

Wenn nicht anders erwähnt, wurden folgende Standardwerte verwendet: $\varepsilon=$ $10 \mu \mathrm{m}, \varnothing_{E F}=600 \mu \mathrm{m}, \varnothing_{D F}=400 \mu \mathrm{m}, N A$ (beide Fasern) $=0.22, \gamma_{E F}=10^{\circ}$, $c_{D F, y}=0, c_{D F, z}=0, \varphi=0^{\circ}$ und $\omega=0^{\circ}$.

Das Computerprogramm für die Berechnungen wurde in $\mathrm{C}++$ implementiert und ist eine direkte Umsetzung der obigen Gleichungen.

\subsubsection{Einfluß der Bewertungsfunktion $f(\vec{r})$}

Zur graphischen Darstellung der Bewertungsfunktion wurde $f(\vec{r})$ (Gleichung (4.2)) in der Nachweisebene für zwei verschiedene Stärken des Schutzfensters berechnet (Abbildungen (4.4) und (4.5)). Zur besseren Orientierung wurde der Umriß von Anregungs- und Nachweiskegel eingezeichnet.

Beide Abbildungen zeigen, daß der Einfluß von verschiedenen Bereichen des Beobachtungsgebietes $T$ deutlich unterschiedlich ist. Kleine Werte im linken Teil der Schnittmenge von Anregungs- und Nachweiskegel werden im wesentlichen durch eine reduzierte Fähigkeit der Nachweisfaser verursacht, Photonen von diesem Teil unter Einhaltung des Akzeptanzwinkels zu transportieren. Anders ausgedrückt, in diesen Bereichen ist die Wahrscheinlichkeitsfunktion $h(\vec{r})$ (Gleichung (4.5)) klein, da die Winkelbedingung (iii) (Glg. (4.12)) nur für einen kleinen Teil der Stirnfläche der Nachweisfaser (beschrieben durch $B_{p}^{\prime}$ ) erfüllt ist. In beiden Abbildungen ist auf der linken Seite eine Abflachung des Nachweiskegels zu erkennen, die für größere Kippwinkel $\gamma_{D F}$ stärker wird (siehe Abb. (4.5), in dem auch der Nachweiskegel für $\gamma_{D F}=42^{\circ}$ skizziert ist). Dieser Effekt entsteht durch Totalreflexion der Photonen an der Oberfläche zwischen dem Schutzfenster und dem schmalen Luftspalte vor der Faserstirnfläche. Photonen, die von zu weit links kommen, können die Nachweisfaser nicht erreichen.

\section{Einfluß des Schutzfensters}

In Abbildung (4.6) ist die Größe der unbewerteten Beobachtungsfläche $T$ als Funktion des Kippwinkels $\gamma_{D F}$ und der Stärke eines Quarz-Schutzfensters $z_{\text {win }}$ gezeigt. Wie nicht anders zu erwarten, steigt $T$ mit zunehmendem $z_{w i n}$. Wieder ist der Effekt der Totalreflexion zu erkennen: Für Werte von $\gamma_{D F}$ größer als etwa $53^{\circ}$ erreicht kein Fluoreszenzlicht mehr die Nachweisfaser.

Diese Abbildung zeigt im Vergleich mit Abbildung (4.7) den Unterschied zwischen bewerteter und unbewerteter Beobachtungsfläche. Deutlich zu erkennen ist, 


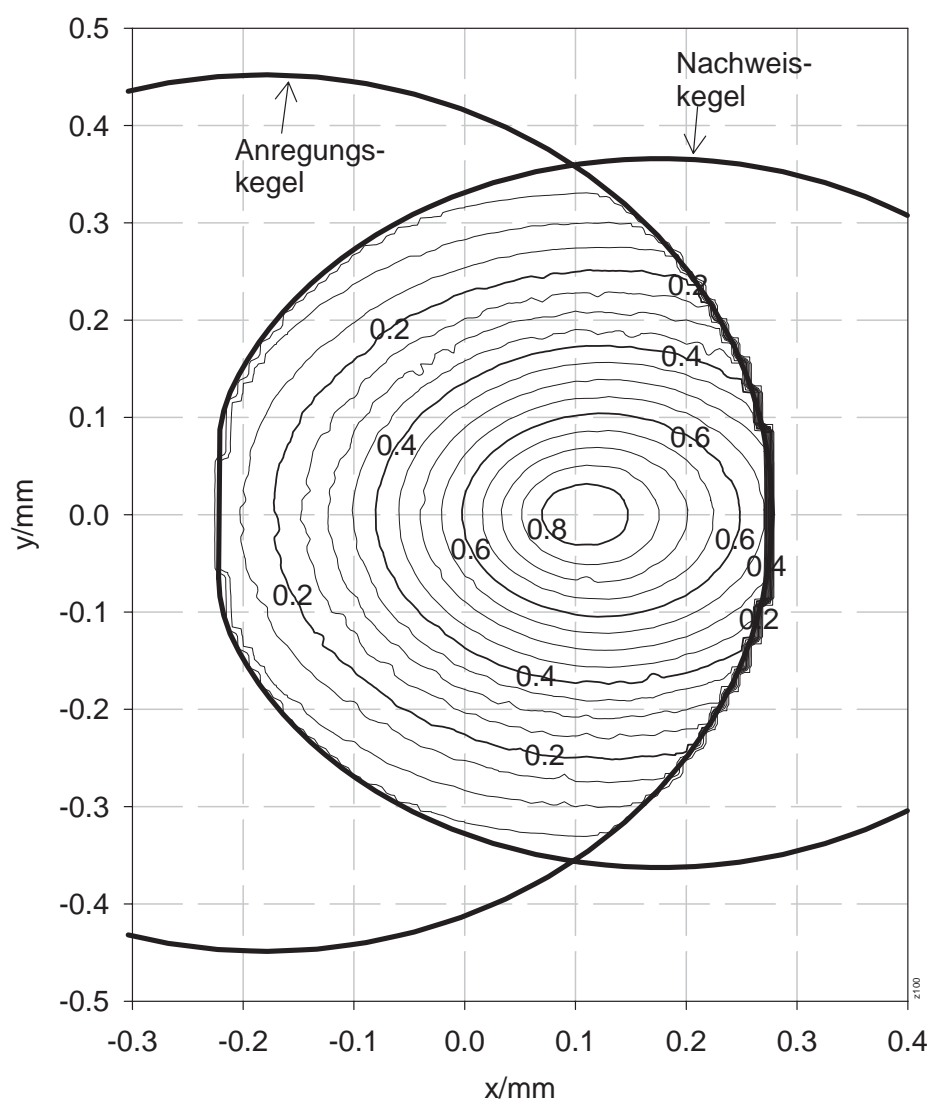

Abbildung 4.4: Die Bewertungsfunktion für eine Schutzfensterstärke von $z_{\text {win }}=1 \mathrm{~mm}$. Weitere Parameter: $\gamma_{D F}=34^{\circ}$; x-Position der Nachweisfaser: $c_{D F, x}=0.8 \mathrm{~mm}$, dadurch Abstand der Fasern $d=250 \mu \mathrm{m}$; Brechungsindex der Nachweisfaser: $n_{\text {win }}=1.49$ (Quarz).

daß die Betrachtung der unbewerteten Beobachtungsfläche (wie z.B. bei CHONG [116]) für die Effizienzbewertungen nicht ausreichend ist. In Abbildung (4.7) ist für die gleiche Parameterauswahl anstelle der unbewerteten Fläche $T$ die Optrodeneffizienz $C E$ zu sehen, die sich auch als bewertete Beobachtungsfläche auffassen läßt. Die Form des Graphen in dieser Abbildung unterscheidet sich stark von der Form der unbewerteten Fläche $T$.

Mit optimalem Kippwinkel $\gamma_{D F}$ von etwa $35^{\circ}$ ergibt sich eine optimale Stärke des Schutzfensters um $z_{w i n}=1.1 \mathrm{~mm}$. Abbildung (4.8) zeigt die gleiche Rechnung für ein Schutzfenster aus Saphir, das einen deutlich höheren Brechungsindex aufweist (für UV-Licht: 1.8 an Stelle von 1.49). Die Kegel der Fasern werden dadurch deutlich schmaler. Das resultiert in einem größeren Optimalwert für $z_{\text {win }}$ und in einer nur etwa halb so hohen maximalen Optrodeneffizienz. 


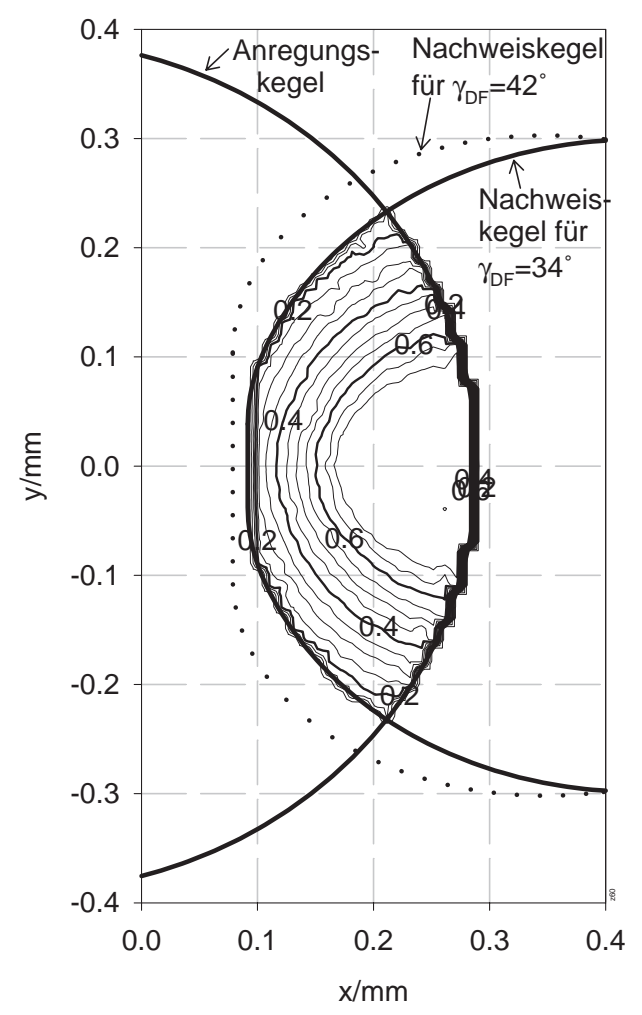

Abbildung 4.5: Die Bewertungsfunktion für eine Schutzfensterstärke von $z_{\text {win }}=$ $0.6 \mathrm{~mm}$. Zusätzlich ist der Nachweiskegel für $\gamma_{D F}=42^{\circ}$ eingezeichnet, um den Einfluß der Totalreflexion zu demonstrieren. Die anderen Parameter wurden wie in Abb. (4.4) gewählt.

\section{Untersuchung der Kippwinkel $\gamma_{E F}$ und $\gamma_{D F}$}

Der Einfluß der Kippwinkel von Anregungs- und Nachweisfaser ist in Abbildung (4.9) für ein Schutzfenster aus Quarz gezeigt. Aus der Anordnung der Fasern (Abb. (4.1)) folgt, daß für kleine Rotationswinkel $\varphi$ und sinnvolle Abstände zwischen den Fasern $d$ der Kippwinkel der Anregungsfaser nicht größer als der Kippwinkel der Nachweisfaser sein kann (vergleiche die Abbildungen (4.1) und (4.2)). Dieser verbotene Bereich ist in der Abbildung (4.9) grau unterlegt.

Mit den Ergebnissen dieser Rechnung können für den Kippwinkel der Anregungsfaser neben der Optrodeneffizienz noch weitere wünschenswerte Eigenschaften einer Optrodengeometrie berücksichtigt werden. Insbesondere sollte die Menge des von der Beobachtungsebene in die Nachweisfaser gestreuten und reflektierten Lichtes möglichst klein sein. Mit einem Öffnungswinkel des Lichtkegels der Anregungsfaser zwischen 7 und $9^{\circ}$ (abhängig vom Brechungsindex des Schutzfensters) kann dies recht effektiv durch einen Kippwinkel der Anregungfaser von $\gamma_{E F} \geq 9^{\circ}$ erreicht werden. Berücksichtigt man den Luftspalt zwischen Schutzfenster und Faser, ist $\gamma_{E F}=10^{\circ}$ ein sinnvoller Wert. Für diesen Winkel beträgt der $C E$-Wert 850, ledig- 


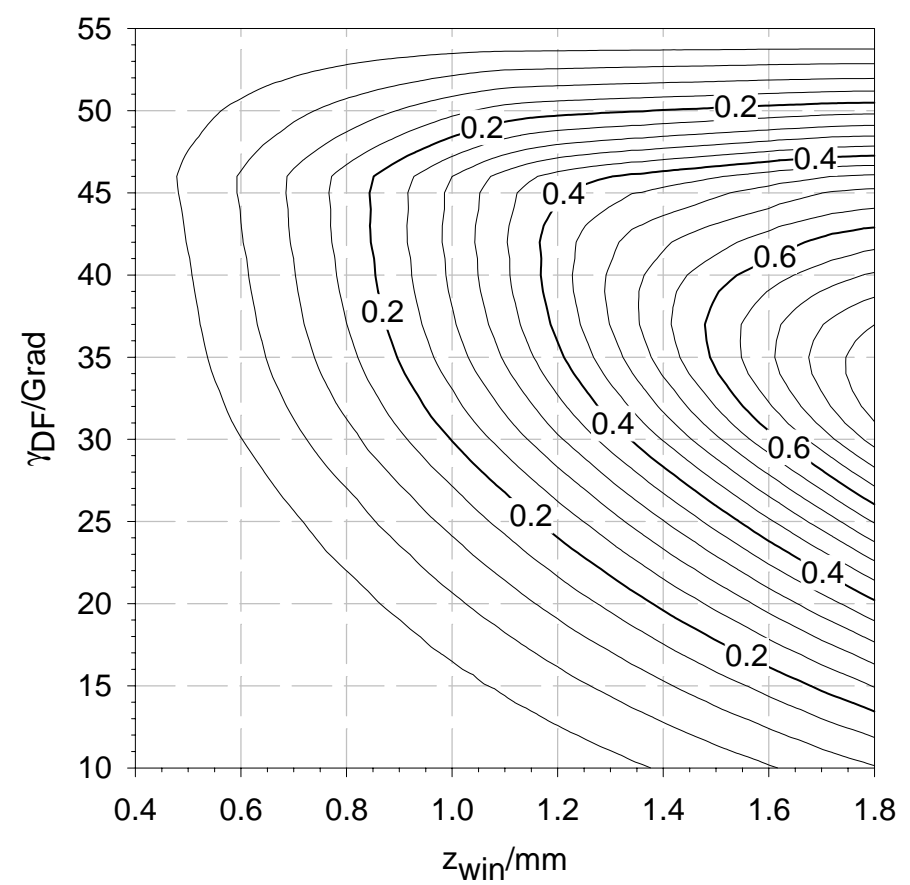

Abbildung 4.6: Die unbewertete Beobachtungsfläche $T$ in $\mathrm{mm}^{2}$ für ein QuarzSchutzfenster $\left(n_{w i n}=1.49\right)$ als Funktion von Fensterstärke $z_{w i n}$ und Kippwinkel $\gamma_{D F}$. Andere Parameter: $c_{D F, x}=0.8 \mathrm{~mm}, \varepsilon=20 \mu \mathrm{m}$.

lich 15\% niedriger als im Optimum, das bei einem für Reflexionen sehr ungünstigen Winkel von $-10^{\circ}$ liegt.

\section{Faserabstand}

In Abbildung (4.10) wird der Einfluß des Abstandes zwischen den Fasern $d$ untersucht. $d$ ist eine Funktion der Faserposition $\vec{c}_{D F}\left(\vec{c}_{E F}=0\right)$ und hängt zudem vom Kippwinkel ab, da die große Halbachse der Stirnfläche der Nachweisfaser mit zunehmendem $\gamma_{D F}$ größer wird. Die tatsächliche Variable bei den Berechnungen war dann auch nicht $d$ sondern die x-Komponente von $\vec{c}_{D F}$. Als zweite Variable wurde wieder der Kippwinkel der Nachweisfaser verwendet. Der minimale Abstand zwischen den Fasern hängt von der Art der Herstellung ab. Bei Verwendung üblicher mechanischer Herstellungsverfahren beträgt der Minimalabstand zwischen den Fasern etwa $150 \mu \mathrm{m}$, der Bereich unterhalb dieser Grenze ist wieder grau unterlegt. Kleinere Abstände ließen sich mit Hilfe der Mikrosystemtechnik erreichen, sind allerdings nicht notwendig, da daß Maximum von $C E$ auch mit $d=150 \mu \mathrm{m}$ fast erreicht wird. 


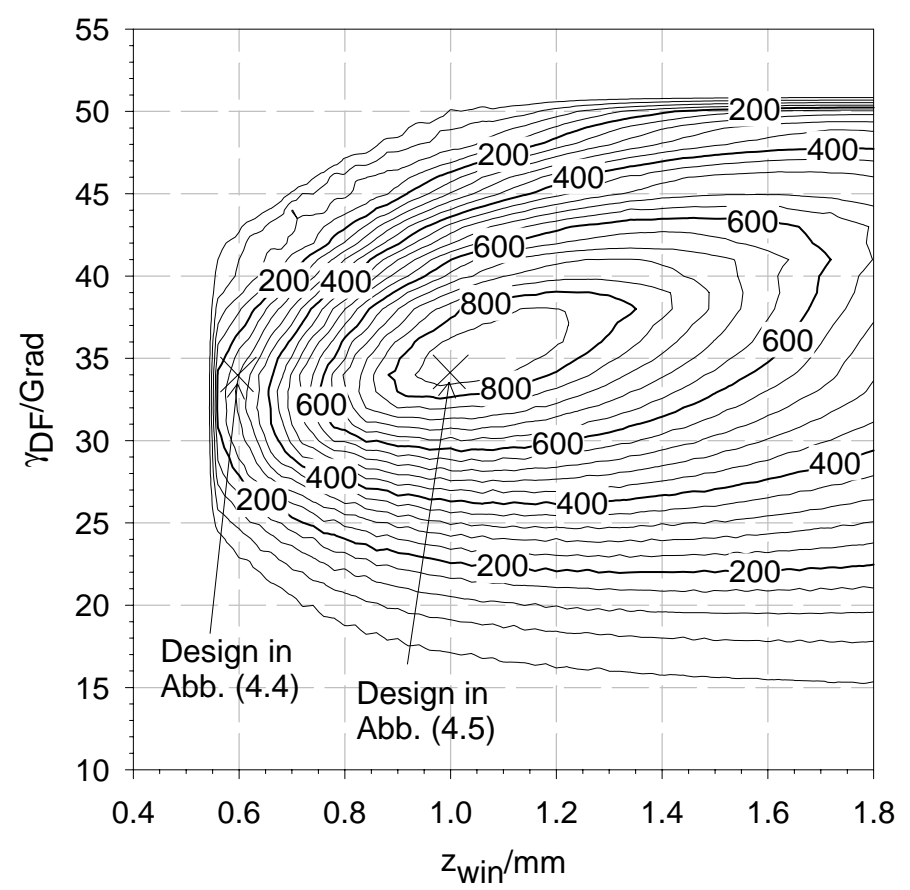

Abbildung 4.7: Optrodeneffizienz $C E$ als Funktion von Fensterstärke $z_{w i n}$ eines QuarzSchutzfensters $\left(n_{\text {win }}=1.49\right)$ und Kippwinkel $\gamma_{D F}$ mit den gleichen Parametern wie in Abb. (4.6). Zusätzlich sind die Designs der Abbildungen (4.4) und (4.5) gezeigt.

\subsubsection{Einfluß der numerischen Apertur der Fasern}

Die numerische Apertur $N A$ hat einen großen Einfluß auf die Optrodeneffizienz $C E$. Obwohl dieser Parameter für diese spezielle Anwendung auf $N A=0.22$ vorgegeben war, da letztlich nur Quarz-Quarz-Fasern die hohen Anforderungen an die UVEigenschaften der Glasfasern erfüllten [55], ist es von theoretischem Interesse, den Einfluß dieses Parameters zu untersuchen. Neben der Optrodeneffizienz wird in Abbildung (4.11) noch die Größe des Beobachtungsgebietes $T$ und die Größe des von einer Anregungsfaser mit $\gamma_{E F}=0^{\circ}$ beleuchteten Gebietes als Funktion der numerischen Apertur gezeigt. Um den Vergleich zu erleichtern, wurden die drei Graphen auf $N A=0.1$ genormt.

Es ist interessant festzustellen, daß $C E$ mit zunehmender $N A$ deutlich stärker ansteigt als $T$. Wie weiter oben diskutiert, läßt sich dieser Effekt durch einen starken Beitrag des Bereiches von $T$ erklären, der nahe bei der Nachweisfaser liegt.

\subsubsection{Der Drehwinkel der Nachweisfaser $\varphi$}

Die vorhergehenden Berechnungen wurden mit dem Zentrum der Nachweisfaser auf der $\mathrm{x}$-Achse durchgeführt $\left(c_{D F, y}=0\right)$, wodurch auch Positionswinkel $\omega$ und Drehwinkel $\phi$ auf Null festgelegt waren. Der Positionswinkel $\omega$ ist der Win- 


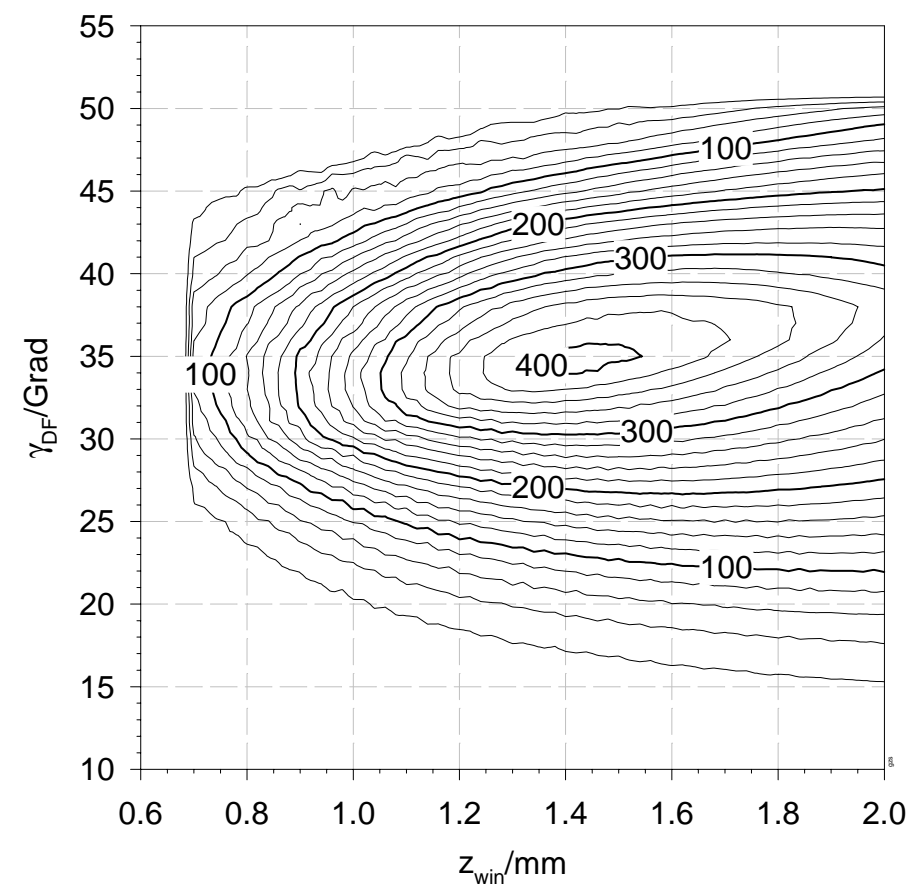

Abbildung 4.8: Optrodeneffizienz $C E$ als Funktion von Fensterstärke $z_{w i n}$ eines Saphir-Schutzfensters $\left(n_{\text {win }}=1.8\right)$ und Kippwinkel $\gamma_{D F}$ mit den gleichen Parametern wie in Abb. (4.6). Die maximale Optrodeneffizienz ist nur etwa halb so hoch wie mit einem Schutzfenster aus Quarz.

kel zwischen der x-Achse und der Verbindungsgeraden der Faserzentren $(\omega=$ $\left.\tan ^{-1} c_{D F, y} / c_{D F, x}\right)$ und der Drehwinkel $\varphi$ ist der Winkel zwischen der x-Achse und der Ebene, die von der Achse der Nachweisfaser und der z-Achse aufgespannt wird (vergleiche Abb. (4.2)). Sind beide Winkel gleich, so gibt es (außerhalb der Faser) einen Schnittpunkt von Faserachse und z-Achse. Für Nachweisfasern, deren Stirnmittelpunkte in der Nähe der x-Achse liegen, sind auch die optimalen Werte für $\varphi_{D F}$ und $\omega$ nahe beieinander. Für Nachweisfasern, die deutlich von der x-Achse entfernt sind (z.B. die oberste und unterste Nachweisfaser in Abb. (4.1)(b)) ist der Unterschied für die Optimalwerte signifikant.

Die Positionen der Nachweisfasern, wie in Abbildung (4.1(b)) gezeigt, sind für $\gamma_{E F}=10^{\circ}, \gamma_{D F}=34^{\circ}$, Faserdurchmesser von 600 und $400 \mu \mathrm{m}$ für Anregungs- und Nachweisfasern und einen Abstand der Fasern von $d=150 \mu \mathrm{m}$ :

\begin{tabular}{c|cr} 
Positionsvektor & x-Wert & \multicolumn{1}{c}{ y-Wert } \\
\hline$\vec{c}_{D F}^{1}$ & $0.724 \mathrm{~mm}$ & $0.325 \mathrm{~mm}$ \\
$\vec{c}_{D F}^{2}$ & $0.239 \mathrm{~mm}$ & $0.757 \mathrm{~mm}$ \\
$\vec{c}_{D F}^{3}$ & $0.724 \mathrm{~mm}$ & $-0.325 \mathrm{~mm}$ \\
$\vec{c}_{D F}^{4}$ & $0.239 \mathrm{~mm}$ & $-0.757 \mathrm{~mm}$
\end{tabular}




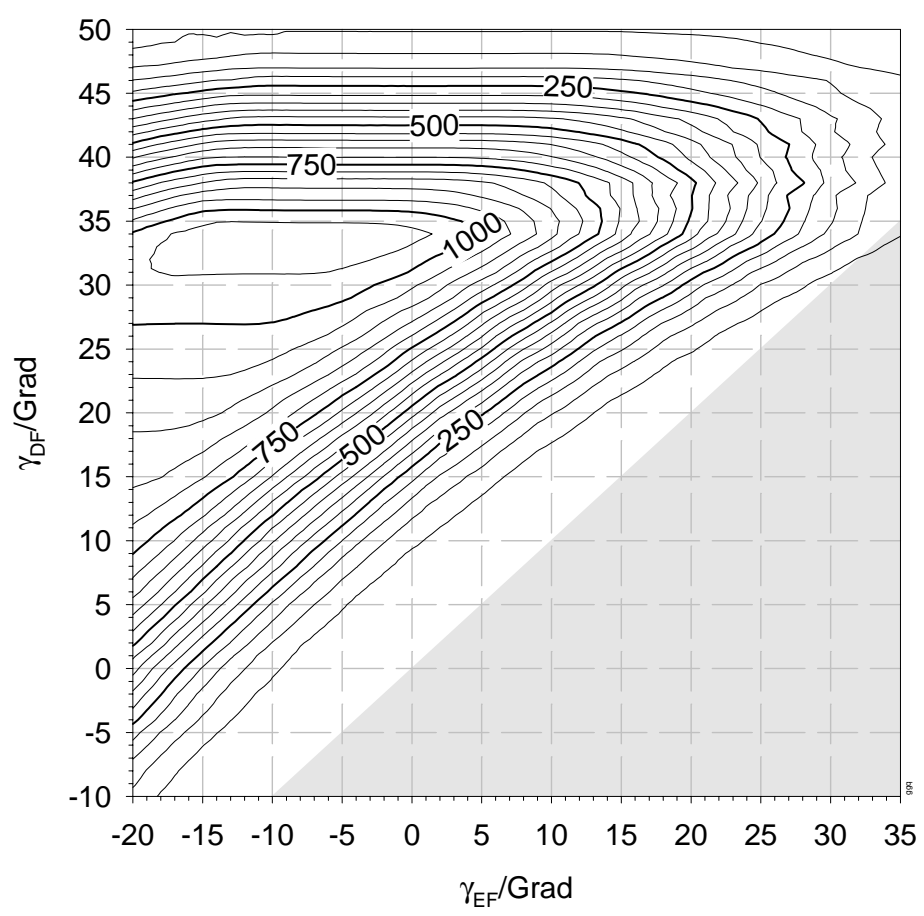

Abbildung 4.9: $\quad C E$ als Funktion der Kippwinkel $\gamma_{E F}$ und $\gamma_{D F}$ von Anregungs- und Nachweisfaser. Der Bereich, in dem sich die Fasern überschneiden würden, ist grau unterlegt. Andere Parameter: $c_{D F, x}=0.8 \mathrm{~mm}, z_{\text {win }}=1.0 \mathrm{~mm}, n_{\text {win }}=1.49, \varepsilon=20 \mu \mathrm{m}$ und $\varphi=0^{\circ}$.

Dabei wurden die Fasern nahe der $\mathrm{x}$-Achse mit 1 und 3 gekennzeichnet, die mit einem größeren Abstand zur x-Achse mit 2 und 4. Der Wert der Positionswinkel der Fasern 2 und 4 berechnet sich demnach zu $\omega= \pm 72.5^{\circ}$.

Abbildung (4.12) zeigt die Optrodeneffizienz als Funktion des Drehwinkels $\varphi_{D F}$ und des Kippwinkels $\gamma_{D F}$ der Nachweisfasern 2 und 4. Der optimale Drehwinkel für diese Fasern zeigt sich demnach als etwa $10^{\circ}$ kleiner als der Positionswinkel $\omega=72.5^{\circ}$.

\subsection{Diskussion}

Ein interessantes Ergebnis ist eine oft beobachtete Plateau-Ausbildung im Bereich des Maximums der Optrodeneffizienz mit starken Gradienten außerhalb der Plateaus. Daher ist bei Kenntnis der Maxima ein exaktes Einhalten mancher Optimalparameter nicht notwendig, wodurch sich Vorteile bei der Herstellung einer Optrode ergeben. Dafür ist die Kenntnis über das Verhalten der Optrodeneffizienz bei Veränderung dieser Parameter von großer Bedeutung, da in zu großer Entfernung vom Parameteroptimum die Effizienz rapide sinkt.

Glücklicherweise befindet sich das Optimum der Parameter entweder in oder in 


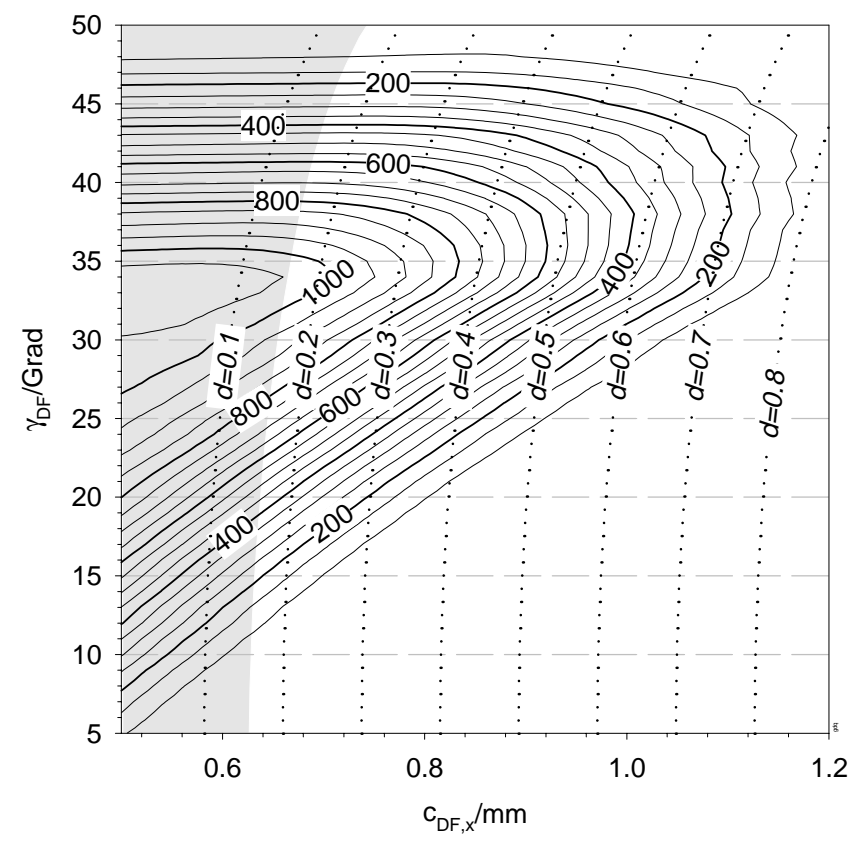

Abbildung 4.10: $C E$ als Funktion von Position $\vec{c}_{D F}$ und Kippwinkel $\gamma_{D F}$ der Nachweisfaser. Der Abstand der Fasern $d$ ist eine einfache trigonometrische Funktion dieser beiden Werte und ist ebenfalls eingezeichnet. Der graue Bereich ist mit normalen Herstellungsmethoden nicht erreichbar. Andere Parameter: $z_{\text {win }}=1.0 \mathrm{~mm}, n_{\text {win }}=1.49$ und $\varepsilon=20 \mu \mathrm{m}$.

der Nähe der durch die Herstellung vorgegebenen Grenzen. Die optimale Stärke eines Schutzfensters zwischen Nachweisebene und Fasern liegt nach den Berechnung für Quarz zwischen 1.0 und $1.2 \mathrm{~mm}$, was problemlos erreicht werden kann. Der optimale Kippwinkel der Anregungsfaser $\gamma_{E F}$ ist negativ, aber die vorteilhafte Geometrie mit einem positiven Winkel von $\gamma_{E F}=10^{\circ}$ zur Verringerung von Reflexions- und Streulicht liegt noch am Rande des Optimum-Plateaus. Ebenso ist der erreichbare Minimalabstand zwischen den Fasern dicht am theoretischen Optimum.

Die Berechnungen ergaben, daß ein Quarzfenster durch seinen geringeren Brechungsindex zu einer etwa doppelt so hohen Optrodeneffizienz im Vergleich zu einem Saphirfenster führt. Der Vorteil von Saphir gegenüber Quarz - die höhere Kratzfestigkeit des Saphirs - wird also mit einer verringerten Sensorempfindlichkeit bezahlt. Die Schutzfenster wurden daraufhin auswechselbar gestaltet. Dadurch kann je nach Anwendung ein Quarz- oder ein Saphirfenster verwendet werden.

Ein Optimalwert zieht sich durchgängig durch alle Berechnungen, der Kippwinkel der Anregungsfaser von $\gamma_{E F}=34^{\circ}$. Dieser Wert ist einer der wichtigsten Parameter für die Optrode.

Die optimalen Drehwinkel $\varphi_{D F}$ sind für große Positionswinkel $\left(\omega=72.5^{\circ}\right)$ deut- 


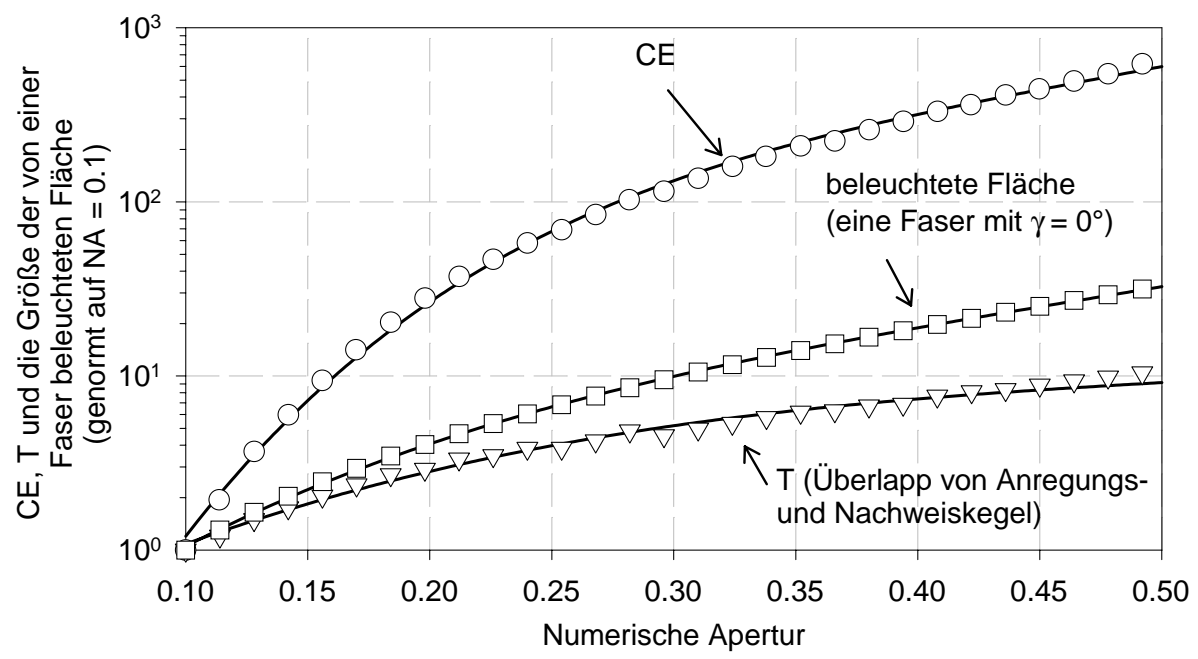

Abbildung 4.11: Optrodeneffizienz $C E$, unbewertetes Beobachtungsgebiet $T$ und Größe der durch eine Anregungsfaser mit $\gamma_{E F}=0^{\circ}$ beleuchteten Fläche $\left(T_{E F}\right)$ als Funktion der numerischen Apertur NA. Die drei Funktionen wurden auf $N A=0.1$ genormt, d.h. $C E$ hat hier ausnahmsweise eine andere Skalierung Andere Parameter: $\gamma_{D F}=34^{\circ}$ (für $C E$ and $T$ ), $c_{D F, x}=0.8 \mathrm{~mm} \Leftrightarrow d=250 \mu \mathrm{m}, z_{\text {win }}=1.0 \mathrm{~mm}, n_{\text {win }}=1.49$ und $\varepsilon=20 \mu \mathrm{m}$.

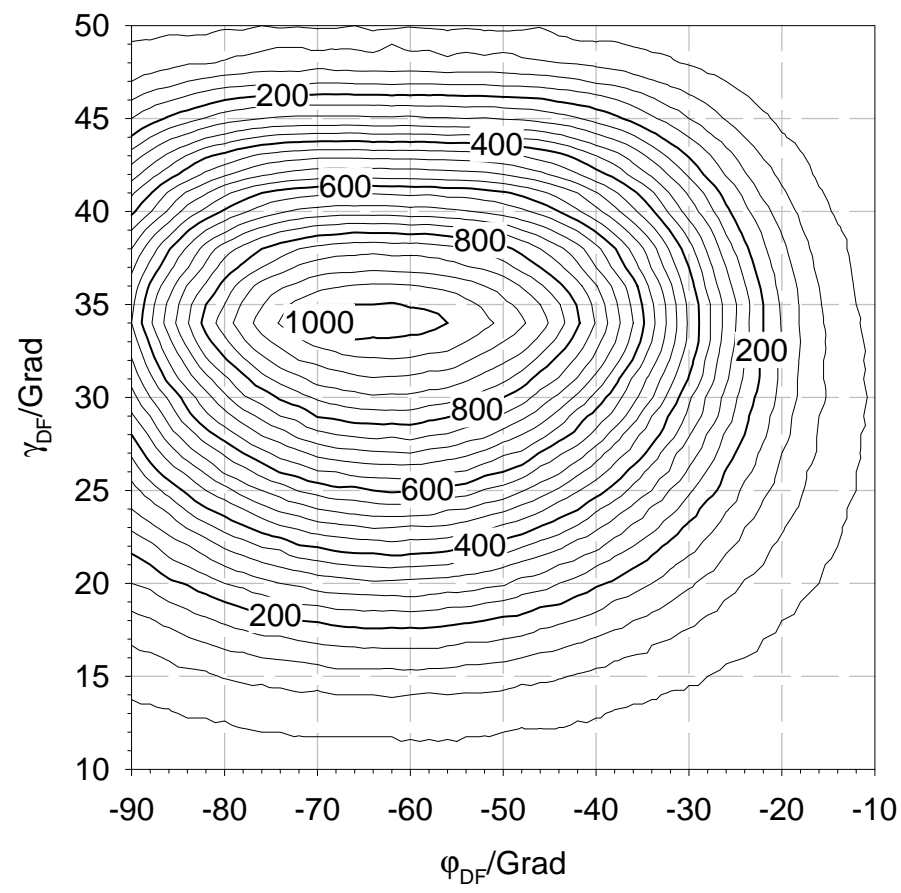

Abbildung 4.12: Optrodeneffizienz $C E$ als Funktion von Drehwinkel $\varphi$ und Kippwinkel $\gamma_{D F}$. Erklärungen siehe Text. Andere Parameter: $c_{D F, x}=0.8 \mathrm{~mm}, z_{\text {win }}=1.0 \mathrm{~mm}, n_{\text {win }}=$ 1.49 und $\varepsilon=20 \mu \mathrm{m}$. 
lich von $\omega$ verschieden. Aus Gründen der einfacheren Herstellung (höhere Symmetrie) für Positions- und Drehwinkel kann allerdings auch der gleiche Wert gewählt werden, da sich für $\varphi=72.5^{\circ}$ die Optrodeneffizienz dadurch um weniger als $5 \%$ reduziert. Interessant und erfreulich ist die Tatsache, daß der optimale Kippwinkel $\gamma_{D F}$ auch für große Positionswinkel in der Nähe von $34^{\circ}$ liegt.

Zudem konnte ein starker Einfluß der numerischen Apertur auf die Optrodeneffizienz berechnet werden. Wäre es möglich, Glasfasern mit einer höheren Apertur zu verwenden, würde sich die Effizienz der Optrode drastisch erhöhen.

Die auf Basis dieser Berechnung angefertigten Optroden ${ }^{4}$ wurde mit folgenden Parametern realisiert:

Durchmesser der Fasern:

$\varnothing_{E F}=600 \mu \mathrm{m}$ und $\varnothing_{D F}=400 \mu \mathrm{m}$

Kippwinkel der Fasern:

$\gamma_{E F}=10^{\circ}$ und $\gamma_{D F}=34^{\circ}$

Abstand der Fasern:

$d=150 \mu \mathrm{m}$

Stärke des Quarz-Schutzfensters: $z_{\text {win }}=1.0 \mathrm{~mm}$

Stärke des Saphir-Schutzfensters: $z_{\text {win }}=1.5 \mathrm{~mm}$

4 durch die Firma Prinz Optics GmbH, Stromberg. 


\section{Messungen}

Für die Erstellung und Untersuchung von Auswertemethoden wurden eine größere Anzahl von Spektren benötigt. Da nur wenige Proben mit natürlichen Kontaminationen zur Verfügung standen, wurden im Labor mehrere hundert künstlich kontaminierte Wasserproben hergestellt.

\subsection{Künstliche Laborproben}

Als künstliche Laborproben werden hier Proben bezeichnet, die mit destilliertem Wasser im Labor gezielt mit Schadstoffen kontaminiert wurden. Die künstlichen Laborproben wurden in Zusammenarbeit mit M. NIEDERKRÜGER erstellt und vermessen, der die verschiedenen Einflußparameter bei der Aufzeichnung von Fluoreszenzspektren künstlicher Proben (z.B. Oberflächenadsorption an Glasoberflächen, Einfluß von Lösungsmitteln, Photostabilität) ausführlich untersucht hat [114].

Die Laborproben wurden direkt im Untersuchungsgefäß ${ }^{1}$ angesetzt. Dazu wurde mit einer Mikroliterpipette ${ }^{2}$ ein definiertes Volumen einer $10 \mathrm{ng} / \mathrm{l}$ Stammlösung $^{3}$ in das vorgelegte Volumen destillierten Wassers ${ }^{4}$ pipettiert und die Lösung mit einem Magnetrührer ${ }^{5}$ durchmischt und/oder kurzzeitig (5 Minuten) in einem Ultraschallbad $^{6}$ beschallt. Die Pipetten wurden auf gravimetrischem Wege entsprechend der Bedienungsanleitung volumenkalibriert.

Die Lösungen wurde unter Fremdlichtausschluß bei Raumtemperatur unter mäßigem Rühren $(10 \mathrm{~Hz})$ mit dem Magnetrührer vermessen.

Nach der Messung wurde die Optrode mit Methanol und destilliertem Wasser gespült und mit einem feinen Laborwischtuch ${ }^{7}$ gereinigt. Die Untersuchungsgefäße wurden zur Reinigung mit Aceton für 15 Minuten im Ultraschallbad beschallt und anschließend mit handelsüblichem Spülmittel, destilliertem Wasser und Methanol gespült und im Trockenschrank bei $130^{\circ} \mathrm{C}$ getrocknet. Die Magnetrührstäbe wurden ebenfalls mit Aceton, Wasser und Methanol gereinigt.

1 Bechergläser mit 50, 80 und $100 \mathrm{ml}$ aus Duran Glas, ISO 3819, Schott.

2 Eppendorfpipetten: (a) Reference Variabel, 10-100 $\mu \mathrm{g} / \mathrm{l}$, mit Standardtips gelb, $100 \mu \mathrm{g} / \mathrm{l}$ und (b) Veripette 4810, 0.5-10 $\mu \mathrm{g} / 1$ mit Standardtips weiß, $10 \mu \mathrm{g} / \mathrm{l}$, Eppendorf-Netheler-Hinz GmbH, Hamburg-Eppendorf.

3 PAK-Stammlösungen zu $10 \mathrm{ng} / \mathrm{l}$ in Acetonitril, Dr. Ehrensdorfer GmbH, Augsburg.

4 genauer: demineralsiertes Wasser, das zusätzlich durch vier Filter bzw. Ionentauscher $(1 \times$ Milligard, $2 \times$ Ionex, $1 \times$ Organex) eines Milli- $Q$ Wassersystems der Firma Millipor S.A. Molsheim, Frankreich, von verbliebenen Metallionen und organischen Substanzen gereinigt wurde.

5 Magnetrührer Icamag RCT, Janke \& Kunkel GmbH, Staufen; Magnetrührstäbe mit PFTEÜberzug, neoLab MIGGE Laborbedarf-Vetriebs GmbH, Heidelberg.

6 Ultraschallbad Sonorflex RK 100 H, Bandelin, Berlin.

7 Kimwipes Lite 200, Kimberley-Clark. 


\subsection{Gewässerproben}

Es wurden aus diversen deutschen Gewässern (u.a. aus Nordsee, Ems-Jade-Kanal, Leine, Luther (Göttingen), Weende (Göttingen), Havel, Elbe, Rhein) mit einem Eimer Wasserproben genommen und in Laborflaschen ${ }^{8}$ nach Göttingen transportiert. Dort wurden die Wasserproben in der Laborflasche 10 Minuten mit dem Ultraschallbad beschallt und anschließend mit dem CCD-Laserfluorimeter vermessen. Die für diese Arbeit verwendeten Spektren finden sich im Anhang (A.10). Etwa einhundert der natürlichen Wasserproben wurden nach der Messung wie in Abschnitt (5.1) beschrieben mit PAK kontaminiert und erneut vermessen, um PAK-Kontaminationen in natürlichen Gewässern zu simulieren.

\subsection{Bodenproben}

In Zusammenarbeit mit der Universität Erlangen wurde von F. LEWITZKA und M. NiEDERKRÜGER der Nachweis von Mineralölkohlenwasserstoffen (MKW) in Böden untersucht [130]. Als Meßkopf wurde die in Kapitel 4 behandelte Optrode eingesetzt.

Die kontaminierten Bodenproben wurde in einem standardisierten Verfahren aus einem Oberboden (Ah-Horizont) der Uni Erlangen und drei verschiedenen Mineralölen hergestellt (Dieselkraftstoff, Windsor-Rohöl und der OSO-Fraktion, einem Zwischenprodukt bei der Erdölraffination). Zur Herstellung der Proben wurde das Öl in n-Pentan gelöst und mit 10 Gramm des Bodens in einem Rundkolben verrührt. Nach mehreren Stunden wurde das Pentan unter Wasserstrahlvakuum mit Hilfe eines Rotationsverdampfers abgezogen. Dieses Verfahren stellt zum einen sicher, daß die Schadstoffe weitgehend homogen im Boden verteilt sind und zum anderen ist durch das schnelle Abtrennen des Pentans gewährleistet, daß die natürliche Bodenfeuchtigkeit erhalten bleibt. Durch Wahl unterschiedlicher Ölmengen wurden verschiedene Schadstoffkonzentrationen eingestellt.

Für die Messungen mit dem Fluorimeter wurde ein Teil des kontaminierten Bodens in eine Petrischale gefüllt und der Meßkopf leicht aufgedrückt. Die Messungen wurden jeweils viermal wiederholt, wobei immer an einer anderen Stelle des Bodens gemessen wurde.

Da nicht genug Daten für eine multivariate Kalibration zur Verfügung standen, wurden die Daten eines Spektrums im gesamten Zeitbereich und im Wellenlängenbereich zwischen $315 \mathrm{~nm}$ und $505 \mathrm{~nm}$ integriert. Der von starkem Streulicht dominierte Bereich ist damit weitgehend ausgeklammert. Die so erhaltenen integralen Fluoreszenzintensitäten wurden gegen die MKW-Konzentrationen aufgetragen (Abb. (5.1)). Es sind jeweils die Mittelwerte aus 4 Messungen aufgetragen, der eingezeichnete Fehlerbalken entspricht der Standardabweichung. Bei der Berechnung

8 Laborflaschen 250 und $500 \mathrm{ml}$ aus Duran Glas, ISO 4796, Schott. 
der Regressionsgerade wurde mit dem Kehrwert der Standardabweichung gewichtet. Die Nachweisgrenze für MKW in Böden wurde mit diesen Kalibrationsgraphiken und einer kritischen Betrachtung der Spektren auf 1000 bis 2000 ppm abgeschätzt (je nach Art der Kontamination) [130]. Da zum Zeitpunkt der Messungen das Laserfluorimeter noch nicht mit dem Kantenfilter zur Abschwächung der Streulichtsignale ausgestattet war, kann davon ausgegangen werden, daß die Nachweisgrenze mit Kantenfilter im Bereich einiger hundert ppm MKW liegt. Zum Vergleich: der Interventionswert für MKW-belastete Böden beträgt nach der „Holländischen Liste" 5000 ppm [131].
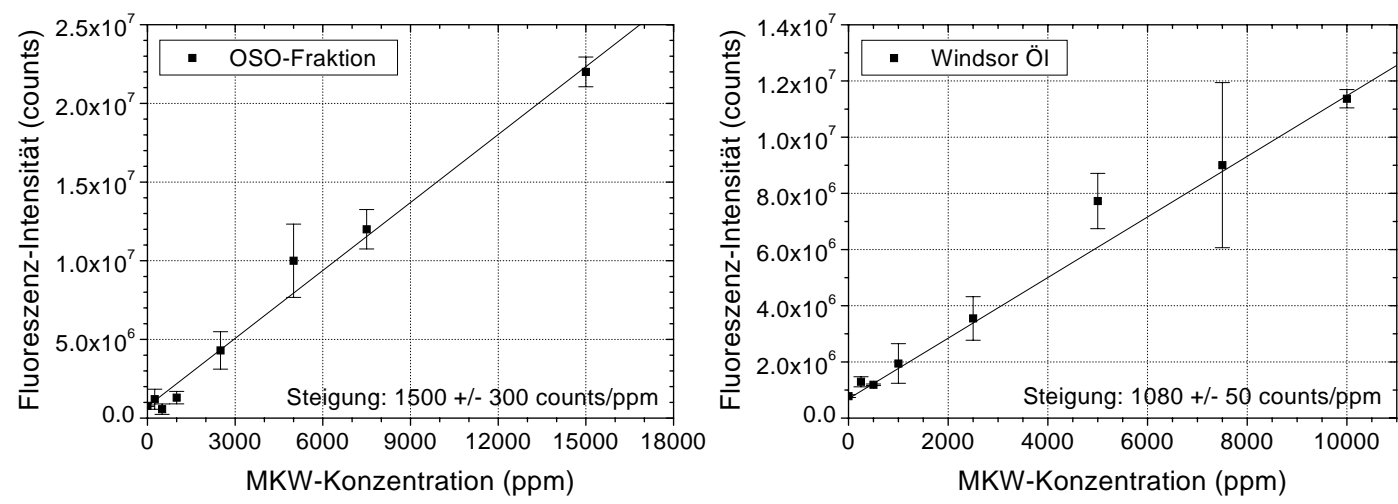

Abbildung 5.1: Bodenkalibrationen mit OSO-Fraktion und Windsor-Öl 


\section{Bausteine für die Analyse zeitaufgelöster Spektren}

In dieser Arbeit wurden mehrere Auswerteverfahren entwickelt, die sich grundsätzlich aus drei Teilen zusammensetzten:

1. Aufbereitung der Rohdaten, u.a. zur Rauschreduktion und Verkleinerung der Datenmenge (Datenvorbereitung),

2. Zerlegung der Matrizen von zeitaufgelösten Spektren in Vektoren (Matrixzerlegung) und

3. Erstellung eines multivariaten Kalibrationsmodells durch Regression mit Hilfe eines größeren Satzes solcher Vektoren oder Anwendung eines bestehenden Kalibrationsmodells zur Vorhersage von Analytkonzentrationen (Erstellung bzw. Anwendung des Kalibrationsmodells).

Schritt zwei und drei sind in Abbildung 6.1 dargestellt. Für die sinnvolle Anwendung eines Kalibrationsmodells müssen Datenvorbereitung und Matrixzerlegung bei der Vorhersage identisch mit denen sein, die bei der Erstellung des Modells angewendet wurden.

(a) Kalibration:

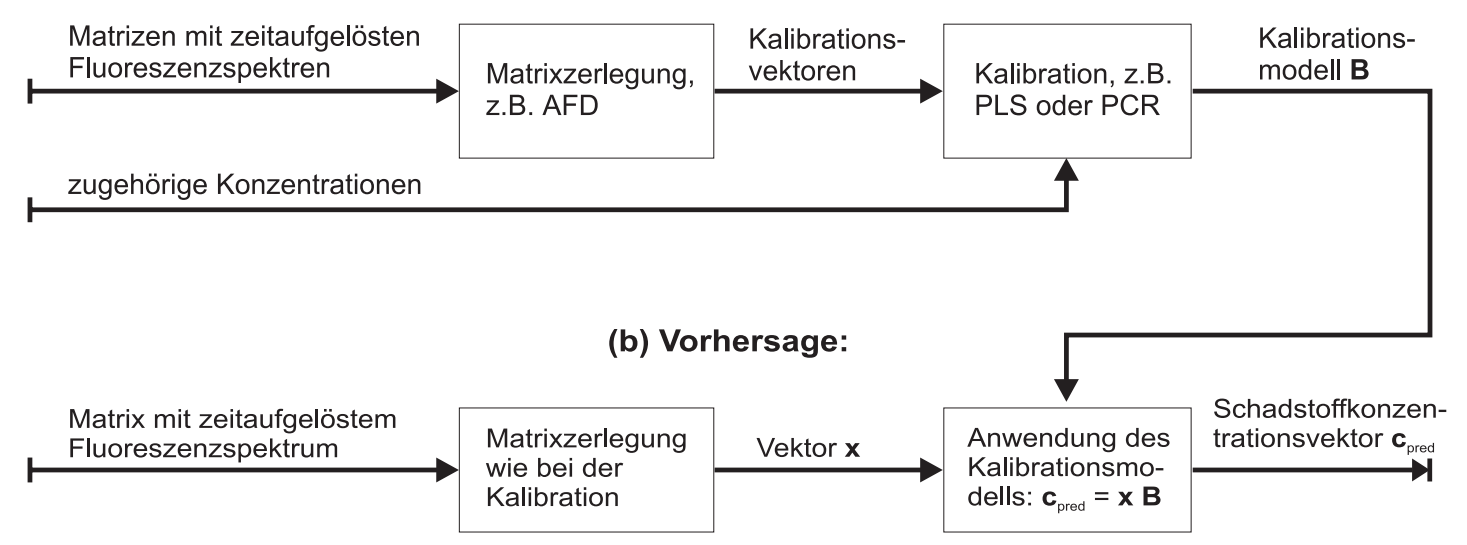

Abbildung 6.1: Blockdiagramm mit den wesentlichen Elementen eines KalibrationsValidationszyklusses. Vor der Matrixzerlegung findet ggf. eine Datenaufbereitung und/oder eine Datenreduktion statt.

Verschiedene Möglichkeiten zur Bearbeitung dieser Schritte werden in diesem Kapitel vorgestellt. Während die Datenreduktion entlang der Wellenlängenachse unabhängig von der nachfolgenden Auswertemethode ist und sich im Wesentlichen nach Geräteparametern wie der spektralen Auflösung richtet, ist die Datenreduktion entlang der Zeitachse eng mit der Datenanalyse verknüpft. Aus diesem Grund 
wird hier die spektrale Datenkompression noch der Datenaufbereitung zugerechnet und die temporale Datenreduktion dem Abschnitt über die Zerlegung der zeitaufgelösten Matrizen in Vektoren.

\subsection{Datenvorbereitung und -reduktion}

\subsubsection{Dispersionskorrektur}

Um die Analyse zeitaufgelöster Fluoreszenzspektren von der speziellen Meßapparatur, mit der die Spektren aufgezeichnet werden, zu entkoppeln, kann nach der Aufnahme der zeitaufgelösten Spektren eine Dispersionskorrektur durchgeführt werden. Die Dispersion des in dieser Arbeit diskutierten Meßsystems wird beim Durchgang des Lichtes durch die Glasfasern verursacht. Eine Dispersionskorrektur empfiehlt sich demnach insbesondere dann, wenn zur Aufnahme der Spektren verschiedene Glasfaserkabel mit unterschiedlichen Längen verwendet werden oder die Gleichzeitigkeit der Signale innerhalb einer Zeitscheibe des Spektrums gewährleistet sein soll.

Während die intermodale Dispersion, die zeitliche Verbreiterung eines Signals in einer Glasfaser durch unterschiedlich gewinkelte Lichtwege, für Faserlängen unter 100 Meter vernachlässigt werden kann ([125], S. 186), führt die wellenlängenabhängige zeitliche Verschiebung durch intramodale Dispersion (Materialdispersion) zu einer signifikanten Verzerrung der zeitlichen Struktur der zeitaufgelösten Spektren (siehe Abb. (6.2)).

Die Laufzeit der Signale für das Quarzglas der verwendeten Lichtleiter berechnet sich nach $[132,133]$ :

$$
\mathrm{T}(\lambda)=\frac{\mathrm{L}}{\mathrm{v}_{\mathrm{g}}(\lambda)}
$$

(siehe Abb. (6.3)) mit L der einfachen Länge des Lichtleiters und der Gruppengeschwindigkeit

$$
\mathrm{v}_{\mathrm{g}}(\lambda)=\frac{c}{n(\lambda)}\left(1+\frac{\lambda}{n(\lambda)} \frac{\mathrm{d} n}{\mathrm{~d} \lambda}(\lambda)\right)
$$

eines Lichtpulses in der Faser. Dabei ist $c$ ist die Vakuumlichtgeschwindigkeit und $n(\lambda)$ der wellenlängenabhängige Brechungsindex des Quarzglases. Dieser läßt sich gut mit Hilfe der von MALiTson [128] gefundenen Beziehung

$$
n_{\text {quarz }}^{2}=\frac{0.696166 \lambda^{2}}{\lambda^{2}-0.00467915}+\frac{0.407943 \lambda^{2}}{\lambda^{2}-0.0135121}+\frac{0.897479 \lambda^{2}}{\lambda^{2}-97.9340}+1
$$

(mit $\lambda$ in $\mu \mathrm{m}$ ) beschreiben.

Mit einer Bezugswellenlänge, z.B. der Anregungswellenlänge $\lambda_{0}=266 \mathrm{~nm}$, läßt sich die zeitliche Verschiebung der Signale dann durch die Gleichung

$$
\Delta \mathrm{T}(\lambda)=\mathrm{T}(\lambda)-\mathrm{T}\left(\lambda_{0}\right)
$$




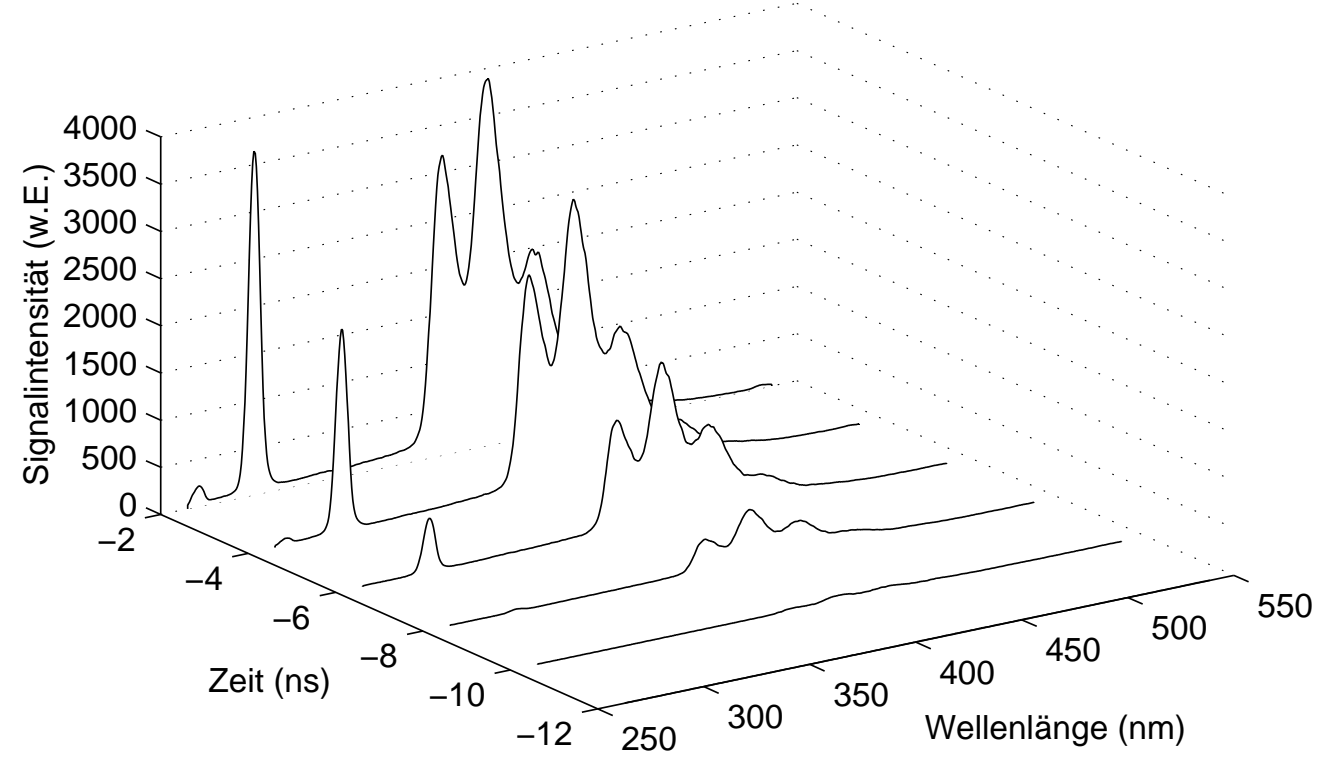

Abbildung 6.2: Der Anstieg von Raman-Streusignal und Anthracen-Fluoreszenz im Bereich 12 bis 2 Nanosekunden vor dem Maximum der Anregung $(\mathrm{t}=0 \mathrm{~ns}$ bezogen auf die Wellenlänge $294 \mathrm{~nm}$ ). Durch intramodale Dispersion in der Glasfaser erreicht das langwellige Fluoreszenzsignal den Detektor früher als das kurzwellige Ramansignal. Am deutlichsten ist das zum Zeitpunkt $\mathrm{t}=-8 \mathrm{~ns}$ zu sehen.

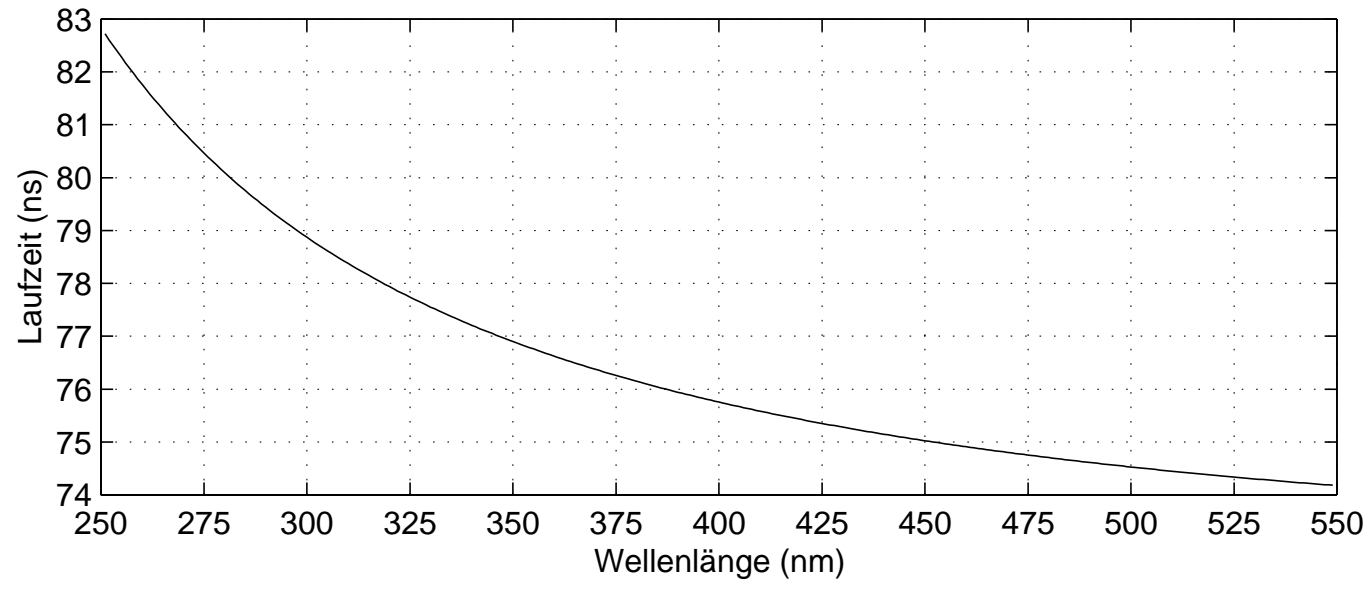

Abbildung 6.3: Wellenlängenabhängige Laufzeit eines Lichtpulses in einer $15 \mathrm{~m}$ langen Quarz-Glasfaser.

berechnen, die direkt zur Dispersionskorrektur verwendet werden kann. 


\subsubsection{Entfaltung der Gerätefunktion}

Nach der Dispersionskorrektur kann eine Entfaltung des Zeitverhaltens der Fluoreszenz und der Gerätefunktion durchgeführt werden.

Für den Zeitbereich, in der die Anregung durch den Laserpuls noch nicht abgeschlossen ist, stellt das gemessene Fluoreszenzsignal $f(t)$ eine Faltung aus Gerätefunktion $g(t)$ und Fluoreszenz-Impulsantwort, der Exponentialfunktion $e(t)$ dar [134]:

$$
f(t)=(e * g)(t)=\int_{-\infty}^{\infty} e(\tau) g(t-\tau) \mathrm{d} \tau .
$$

Befinden sich mehrere Fluorophore in der Probe, so ist $e(t)$ die Summe der Impulsantwort-Exponentialfunktionen. Die Umkehrung der Faltung, die Entfaltung oder Dekonvolution, läßt sich mit Hilfe von Fouriertransformationen durchführen. Die Fouriertransformierte sei hier, einer allgemeinen Konvention folgend, mit einem Großbuchstaben bezeichnet:

$$
X(\nu)=\frac{1}{\sqrt{2 \pi}} \int_{-\infty}^{\infty} x(t) e^{-i \nu t} \mathrm{~d} t .
$$

Für die Transformierten $F(\nu), E(\nu)$ und $G(\nu)$ der Signale $f(t), e(t)$ und $g(t)$ gilt der Faltungssatz (z.B. [134]):

$$
f(t)=(e * g)(t) \Leftrightarrow F(\nu)=E(\nu) G(\nu) .
$$

Sind nur die Signale $f(t)$ und $g(t)$ bekannt, so läßt sich für den Bereich, in dem $G(\nu) \neq 0$ gilt, $E(\nu)$ durch

$$
E(\nu)=\frac{F(\nu)}{G(\nu)}
$$

errechnen. Eine Rücktransformation

$$
e(t)=\frac{1}{\sqrt{2 \pi}} \int_{-\infty}^{\infty} E(\nu) e^{i \nu t} \mathrm{~d} \nu
$$

liefert das entfaltete Signal $e(t)$.

Da die Signale in Form von diskreten Werten vorliegen, bietet sich für die praktische Durchführung der Fouriertransformationen die diskrete Fouriertransformation (DFT) [135, 136] bzw. die mathematisch gleichwertige Fast Fourier Transform (FFT) [137] an. Dabei ist auf Periodizität der Funktionen zu achten. Dazu können z.B. die ersten und die letzten Werte der Signale stetig aneinander angenähert werden.

Als Gerätefunktion $g(t)$ kann das tatsächlich gemessene Anregungssignal oder das Ramansignal verwendet werden (siehe Abb. 6.4). Untersuchungen zur Korrelation der elastisch und Raman-gestreuten Signale haben gezeigt, daß beide Signale vergleichbar gute Gerätefunktionen darstellen [54]. 


\subsubsection{Datenreduktion entlang der Wellenlängenachse}

Wenn bei einem Spektrometer der spektrale Abstand zwischen zwei benachbarten Kanälen kleiner ist als die spektrale Aufösung, läßt sich die Datenmenge entlang der Wellenlängen ohne wesentlichen Informationsverlust reduzieren.

Dazu wird im ersten Schritt das 2D-Spektrum einer Zeitscheibe geglättet, um Rauscheffekte zu vermindern. Die in dieser Arbeit hauptsächlich verwendete Methode nutzt eine digitale Fouriertransformation. Das Spektrum wird mit Hilfe einer FFT transformiert, die Anzahl der Fourier-Koeffizienten wird reduziert (durch Nullsetzen der mittleren Koeffizienten [138]) und die restlichen Koeffizienten werden rücktransformiert. Auch hier ist wieder auf die Periodizität der Funktionen zu achten. An Stelle der Fouriertransformation sind je nach Art des Spektrums auch andere Transformationen denkbar, wie z.B. die Hadamard- oder die WaveletTransformation. Andere Methoden der Rauschreduktion sind Tiefpaßfilter [139] oder polynomiale Approximationen.

Die Abbildung (6.5) zeigt die Datenreduktion des Spektrums des EPA-Standardgemisches durch Fouriertransformation. In Abbildung (6.6) sind die zugehörigen Residuen (Orginal abzüglich rücktransformiertes Spektrum) gezeigt.

Im zweiten Schritt wird das geglättete Spektrum „gesampelt“, d.h. an vorgegebenen Stützstellen wird die Signalintensität bestimmt. Bei einer polynomialen Approximation kann hier direkt der Funktionswert an der Stützstelle genommen

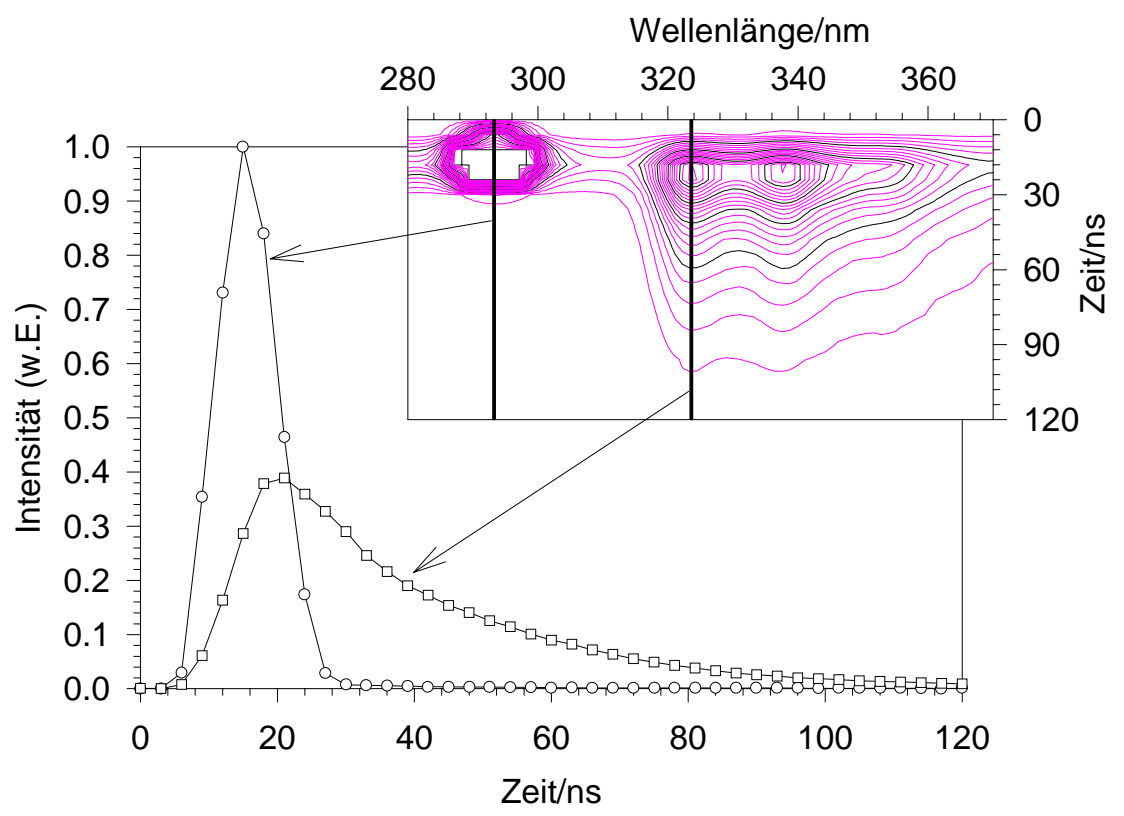

Abbildung 6.4: Raman- (bei $294 \mathrm{~nm}$ ) und Fluoreszenzsignal von $10 \mathrm{ppb}$ Acenaphthen in dest. Wasser. Das Ramansignal kann direkt als Gerätefunktion für eine digitale Entfaltung verwendet werden. 

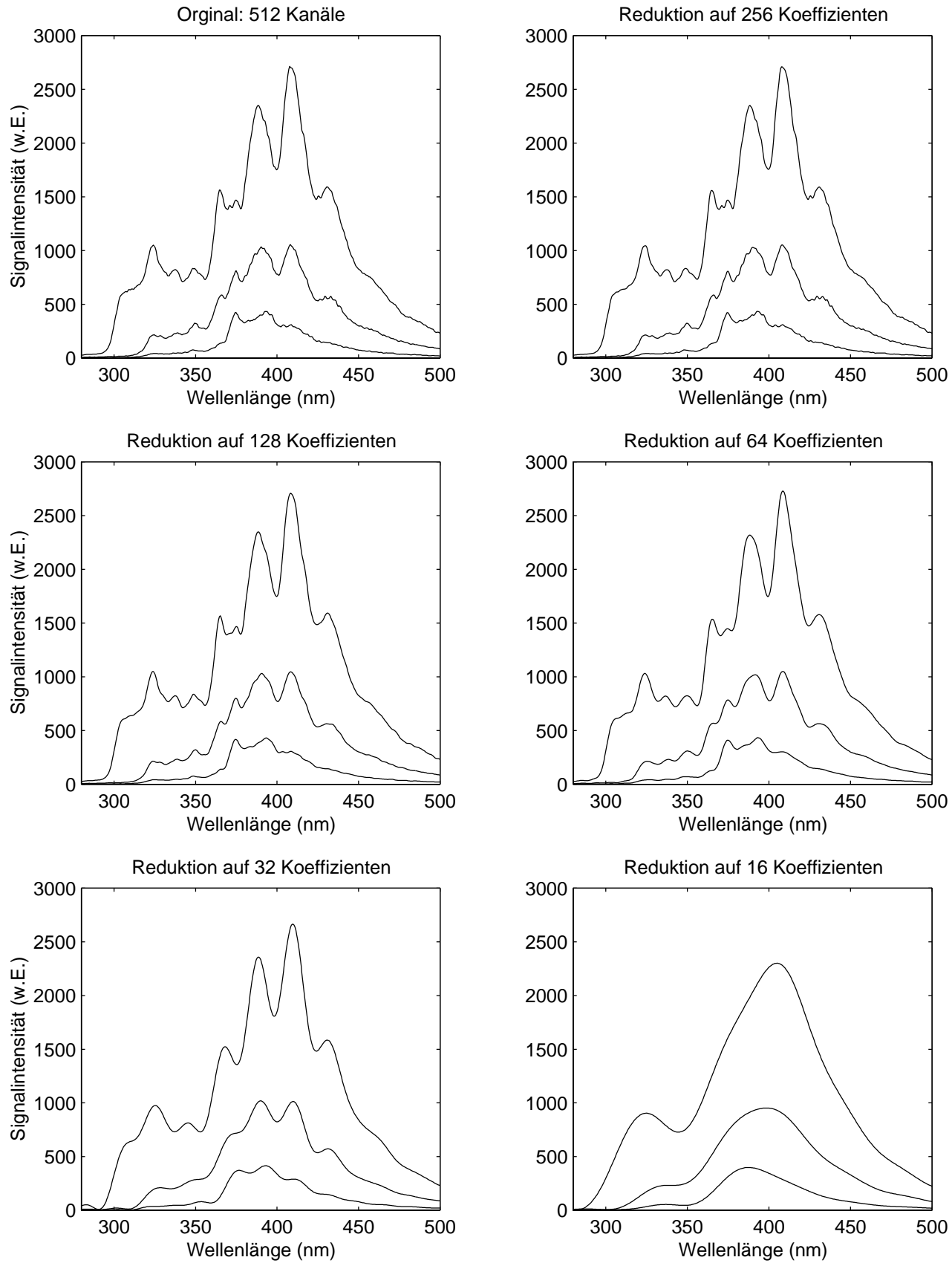

Abbildung 6.5: Datenreduktion durch Fouriertransformation. Links oben sind drei Zeitscheiben aus dem zeitaufgelösten Spektrum des EPA-PAK-Standardgemisches gezeigt (20, 50 und 100 ns nach Maximum der Anregung). Mit Hilfe der Fouriertransformation wurde die Datenmenge von 512 (reellen) Zahlen schrittweise auf 256, 128, 64, 32 und 16 reelle Fourier-Koeffizienten reduziert. Geeignet scheinen vor allem die Reduktionen auf 128 und 64 Koeffizienten zu sein. 

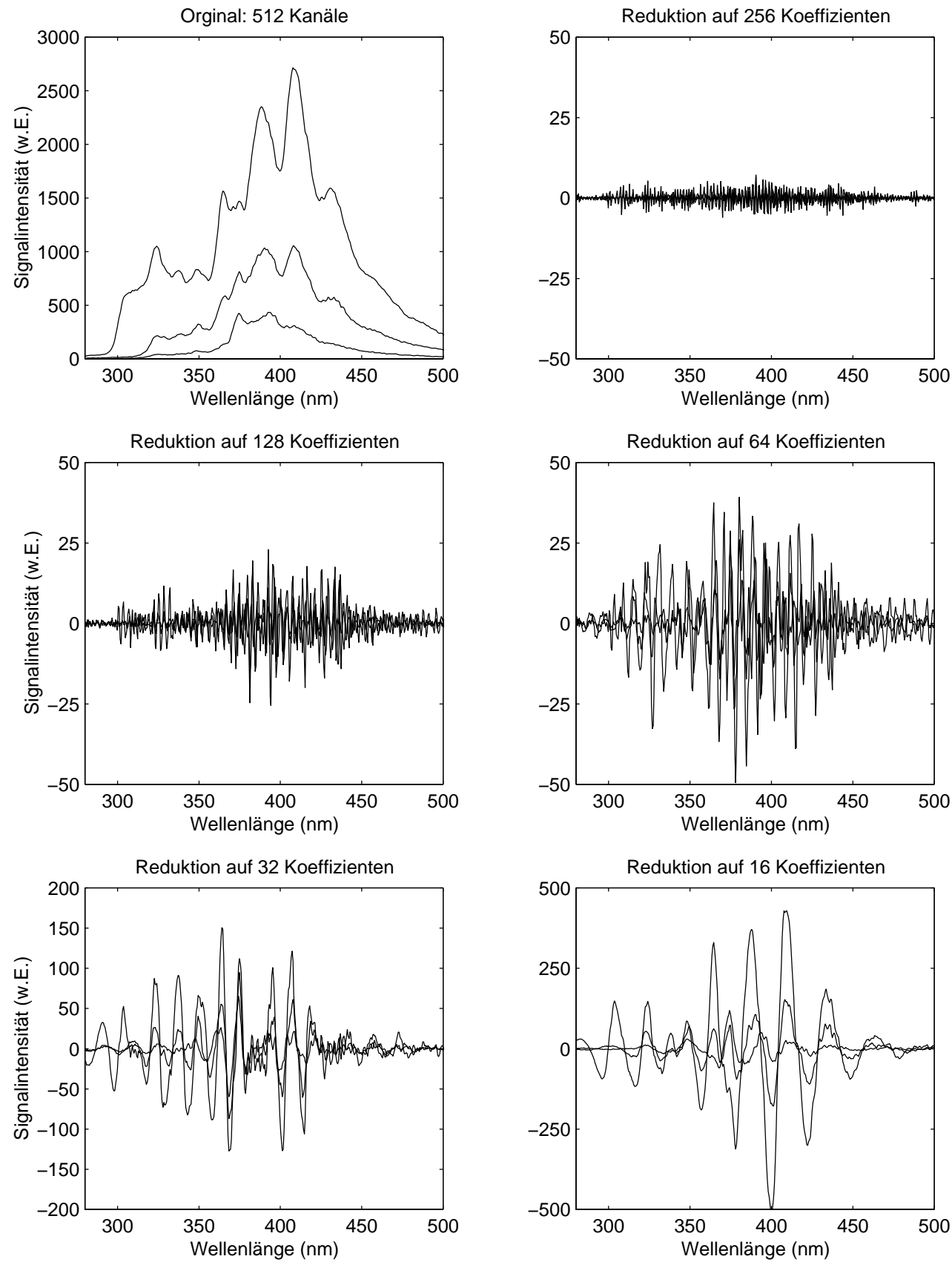

Abbildung 6.6: Residuen der Datenreduktion durch Fouriertransformation. Links oben sind wieder die drei Zeitscheiben aus dem EPA-Spektrum gezeigt (vergl. Abb. (6.5)). Die anderen Graphiken zeigen die Residuen zwischen diesem Orginal und den rücktransformierten Funktionen. 
werden, bei einer digitalen Vorgabe des geglätteten Spektrums sollte, wenn eine neue Stützstelle nicht exakt mit einer alten übereinstimmt, zwischen den alten Stützstellen gewichtet interpoliert werden. Ein typischer Abstand zwischen zwei neuen Stützstellen ist die halbe spektrale Auflösung des Spektrometers.

Bei dem Meßsystem, mit dem die Daten für diese Arbeit aufgenommen wurden, lag die spektrale Aufösung bei etwa $5 \mathrm{~nm}$, das entspricht einem Filter mit der Filterbreite von \pm 4 Kanälen des Detektors. Beschränkt man sich nach Anwendung der Fourierglättung oder des Tiefpaßfilters beim Sampling auf jeden 4. Kanal, so reduziert sich die Wellenlängeninformation von 512 auf 128 Werte.

Neben diesen Methoden, die einheitlich auf den ganzen Bereich des Spektrums angewendet werden, können zusätzlich Elemente der Datenmatrix ausgelassen werden, die bekanntermaßen wenige oder keine verwertbaren Informationen enthalten.

\subsection{Techniken zur Matrixzerlegung}

Die meisten klassischen Methoden zur Auswertung von spektroskopischen Daten, vor allem auch die multivariaten Methoden, erfordern die Organisation der Daten einer Messung in Form von Vektoren. Um diese Methoden dennoch verwenden zu können, müssen die Matrizen der zeitaufgelösten Spektren (Signalintensität in Abhängigkeit von Wellenlänge und Zeit) in Vektoren umgewandelt werden. Im einfachsten Fall werden die einzelnen Zeilen (oder Spalten) der Matrizen zu einem Vektor hintereinander gehängt. Da die multivariaten Methoden zur Kalibration aber mit einem ganzen Satz von Spektren gleichzeitig arbeiten müssen, bei dem die Vektoren (aus $\mathbb{R}^{K}$ ) der einzelnen $I$ Messungen zu einer Kalibrationsmatrix $\mathbf{X} \in \mathbb{R}^{I \times K}$ zusammengefaßt werden, wird ohne vorherige Datenreduktion bei z.B. $I=500$ Spektren, $W=512$ Wellenlängen und $Z=100$ Zeiten ein solcher Kalibrationsdatensatz mit $K=W Z$ geradezu gigantisch groß.

Um die Kalibrationsmatrix zu verkleinern, sind als 1. Stufe datenreduzierende Umformungen sinnvoll, wie sie im vorherigen Abschnitt besprochen wurden. Insbesondere ist eine Reduktion entlang der Wellenlängenachse empfehlenswert. Als 2. Stufe läßt sich z.B. mit einer geeigneten Faktorzerlegung die Datenmenge in Richtung der Zeitachse drastisch reduzieren. Aber auch andere Methoden zur Reduktion der Daten entlang der Zeitachse können bei manchen Daten sinnvoll sein. Die verbleibenden Werte, gleichsam die Essenz der zeitaufgelösten Spektren, sind dann für die Bearbeitung mit multivariaten Methoden geeignet.

Die Verwendung einer Vielzahl von verschiedenen Buchstaben zur Bezeichnung von Matrizen, Indizes und Konstanten ist bei dieser Thematik unvermeidlich. Soweit möglich, wurden die Konventionen der einschlägigen Literatur übernommen, vor allem die von MARTEns [140]. Zur Orientierung findet sich auf Seite 112 ein Symbolverzeichnis. 


\subsubsection{Integration über die Zeitachse}

Der wohl einfachste Weg der zeitlichen Datenreduktion ist eine simple Addition der einzelnen Zeitscheiben eines Spektrums. Das Resultat entspricht dann einem klassischen nicht-zeitaufgelöstem 2D-Spektrum ${ }^{1}$. Obwohl hier die zeitliche Information verloren geht, kann auch diese Methode wertvolle Dienste leisten, vor allem, wenn die Abklingzeit des zu detektierenden Stoffes unterhalb oder im Bereich der zeitlichen Systemauflösung liegt.

\subsubsection{Fensterzerlegung}

Anstelle einer Integration über den ganzen Zeitbereich können auch mehrere Integrationen über jeweils nur einen Teil des Zeitbereiches treten, die Fensterzerlegung, bei der die Zeitscheiben in vorgegebenen Zeitbereichen addiert werden. Das entspricht einer Messung mit wenigen breiten Zeitscheiben, bei drei Zeitfenstern beispielsweise eines Anregungsfensters, in dem die Signale während der Anregung mit dem Laserpuls integriert werden und einem „frühen" und einem „späten“ Zeitfenster nach dieser Anregung (siehe Abb. 6.7). Die Fensterzerlegung wurde für die zeitaufgelöste Laserspektroskopie bereits von ScHADE et.al. angewendet $[35,47,45]$.

Die so gewonnenen 2D-Spektren werden zu einem Vektor aneinander gehängt und erlauben auf diese Weise die weitere Bearbeitung mit multivariaten Methoden. Bei dieser Zerlegung fallen als optimierbare Parameter die Anzahl, Position und Breite der Zeitfenster an. Unter Verwendung einer Bewertungsfunktion für die Qualität einer Zerlegung läßt sich diese Optimierung automatisieren.

\subsubsection{Abstrakte Faktorzerlegung (AFD)}

Bei der Zerlegung des zeitaufgelösten Spektrums $\mathbf{M} \in \mathbb{R}^{W \times Z}$ mit Hilfe der abstrakten Faktorzerlegung wird die Matrix $\mathbf{M}$ durch das Produkt aus einer Matrix mit den spektralen Informationen $\mathbf{S} \in \mathbb{R}^{W \times N_{\tau}}$ und einer Matrix mit den zeitlichen Informationen $\mathbf{Z} \in \mathbb{R}^{N_{\tau} \times Z}$ dargestellt:

$$
\mathbf{M}=\mathbf{S Z}+\mathbf{E}
$$

Die Matrix E enthält die Residuen des Modells, die durch die Zerlegung nicht erfaßt werden, im Idealfall also nur das Rauschen des Signals. Zur besseren Orientierung

1 Die Bezeichnung 2D-Spektrum für Spektren der Form „Fluoreszenzintensität als Funktion der Wellenlänge“ und 3D-Spektren für „Intensität als Funktion von Wellenlänge und Zeit“ stammt aus der analytischen Chemie und bezieht sich auf die typische Art der Darstellung solcher Spektren. 

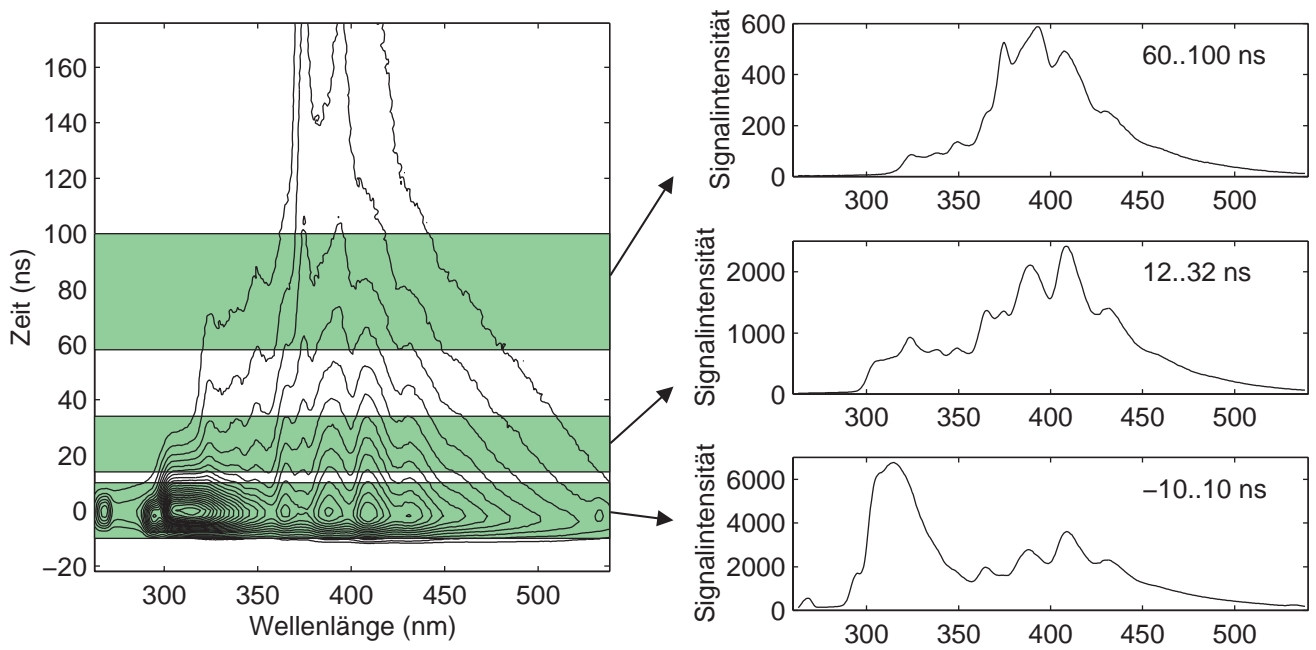

Abbildung 6.7: Zerlegung des zeitaufgelösten Fluoreszenzspektrums des EPA-PAKStandardgemisches (16 PAK à $10 \mathrm{ppb}$ ) in drei 2D-Spektren durch Integration über drei Zeitfenster.

werden solche Matrixgleichungen manchmal auch in folgender Form dargestellt:

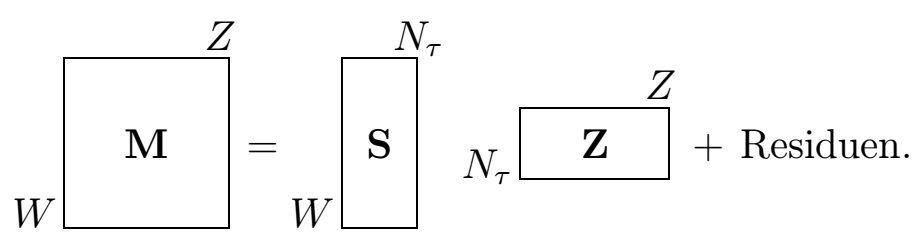

$N_{\tau}$ ist eine noch zu bestimmende Zahl, die deutlich kleiner als $W$ oder $Z$ ist. Das in $\mathbf{Z}$ enthaltene zeitliche Verhalten wird bei einer Kinetik 1. Ordnung, von der hier ausgegangen werden kann, durch ein exponentielles Gesetz beschrieben. Bei Vorgabe von $N_{\tau}$ Abklingzeiten $\tau_{1} \ldots \tau_{N_{\tau}}$ wird die Matrix $\mathbf{Z}$ durch die Faltung mit der als Vektor gegebenen Gerätefunktion $\mathbf{g}=\left(g_{1}, \ldots, g_{Z}\right)$ (vgl. Gleichung (6.5)) und den zu den Abklingzeiten gehörenden exponentiellen Abklingkurven berechnet:

$$
Z_{n z}=g_{z} * \exp \left(-z \Delta t_{0} / \tau_{n}\right)
$$

$Z_{n z}$ ist das Element in der Zeile $n$ und Spalte $z$ der Matrix Z. Der Index $z$ bezeichnet die jeweilige Zeitscheibe und $\Delta t_{0}$ ist der Abstand zweier Zeitscheiben.

Alternativ kann auf die Faltung mit der Gerätefunktion auch verzichtet werden, wenn die Dispersionskorrektur bereits durchgeführt wurde und nur der Teil des zeitaufgelösten Spektrums M betrachtet wird, für den die Fluoreszenzanregung (der Laserpuls) bereits vollständig abgeklungen ist. Es können auf diese Weise dann allerdings nur Substanzen erfaßt werden, deren Fluoreszenzlebensdauer ausreichend 
groß ist, also mindestens in der Größenordnung der zeitlichen Länge des Laserpulses liegt.

Für eine bestimmte Matrix $\mathbf{Z}$ wird die zugehörige spektrale Matrix $\mathbf{S}$ mit Hilfe der Pseudoinversen (auch generalisierte Inverse genannt) $\mathbf{Z}^{\dagger}$ von $\mathbf{Z}$ berechnet:

$$
\mathbf{S}=\mathbf{M} \mathbf{Z}^{\dagger}
$$

Eine Möglichkeit zur Berechnung der Pseudoinversen ist:

$$
\mathbf{Z}^{\dagger}=\mathbf{Z}^{T}\left(\mathbf{Z} \mathbf{Z}^{T}\right)^{-1}
$$

Zur Unterscheidung von den noch zu behandelnden NNFD-Spektren, bei der die Spektren $\mathbf{S}$ nicht negativ werden können, werden Spektren, die nach dieser Gleichung berechnet werden, als ANFD-Spektren bezeichnet (ANFD: allow negative factor decomposition). Zur Gewinnung des Kalibrationsvektors werden die einzelnen Spalten von $\mathbf{S}$ wie schon bei der Fensterzerlegung aneinander gehängt.

Der Begriff abstrakte Faktorzerlegung (AFD: abstract factor decomposition) beruht darauf, daß die gewählten Abklingzeiten $\tau_{n}$ nicht den bekannten Abklingzeiten der gesuchten Analyten entsprechen. Auch sind die Spektren in der Matrix S nicht die Fluoreszenzspektren von Reinstoffen. Das abstrakte Spektrum zu der Abklingzeit $\tau_{n}$ stellt vielmehr eine - nicht notwendigerweise lineare - Überlagerung der Spektren dar, deren Abklingzeiten in der Nähe von $\tau_{n}$ liegen.

Da bei der AFD bewußt darauf verzichtet wird, Spektren realer Analyten aus der Matrix $\mathrm{M}$ zu erhalten, kann $N_{\tau}$ deutlich kleiner als die Anzahl der gesuchten Analyten sein. In jedem abstrakten Spektrum können Informationen über mehrere Fluorophore vorhanden sein.

\subsection{Multivariate Kalibration}

Ziel der multivariaten Kalibration ist die Vorhersage von Variablen $\mathbf{y} \in \mathbb{R}^{J}$ durch andere Variablen $\mathbf{x} \in \mathbb{R}^{K}$, wobei $\mathbf{x}$ und $\mathbf{y}$ hier per Definition Zeilenvektoren sind. Häufig handelt es sich bei $\mathbf{y}$ um die Meßwerte von Interesse und bei $\mathbf{x}$ um Ersatzvariablen, die Information über $\mathbf{y}$ enthalten, aber einfacher, schneller oder billiger zu bestimmen sind. So kann es sich bei $\mathbf{x}$ um das 2D-Fluoreszenzspektrum (bestehend aus $K$ Kanälen) einer Probe und bei y um die Konzentrationen der $J$ Fluorophore in der Probe handeln.

In den meisten chemometrischen Anwendungen reicht erstaunlicherweise ein lineares Modell aus [140, 141] und $\mathbf{y}$ läßt sich hinreichend genau durch

$$
\mathbf{y}=\mathbf{x B}
$$

berechnen, wobei $\mathbf{B} \in \mathbb{R}^{K \times J}$ die Koeffizientenmatrix des linearen Modells ist. Selbst für Problemstellungen, in denen ein nichtlineares Verhalten bekannterweise 
vorhanden ist, ist es möglich, daß ein lineares Modell bessere Ergebnisse in der Vorhersage liefert als ein entsprechend nichtlineares [142, 143]. Tatsächlich hat der lineare Ansatz in der Fluoreszenzspektroskopie im untersuchten Konzentrationsbereich auch seine theoretische Rechtfertigung, das Linear Mixture Model (siehe Abschnitt (2.1)). Demnach stellt das Fluoreszenzspektrum eines Multikomponentengemisches die lineare Summe der einzelnen Spektren dar.

Die Aufgabe der multivariaten Regression besteht in der Bestimmung der Koeffizientenmatrix B aus Gleichung (6.14). Dazu wird ein Lerndatensatz benötigt, bei dem zu $I$ gemessenen Variablen $\mathbf{x}_{1} \quad . \quad \mathbf{x}_{I}$ die zugehörigen Vektoren $\mathbf{y}_{1} \quad . . \mathbf{y}_{I}$ bekannt sind. Die $\mathbf{x}_{i}$ bilden die Zeilen einer Matrix $\mathbf{X}$ (Regressormatrix), die $\mathbf{y}_{i}$ entsprechend die Zeilen einer Matrix Y (Regressandenmatrix).

In der Matrixversion der Gleichung (6.14) werden diese Matrizen dann durch

$$
\mathbf{Y}=\mathbf{X B}+\text { Residuen }
$$

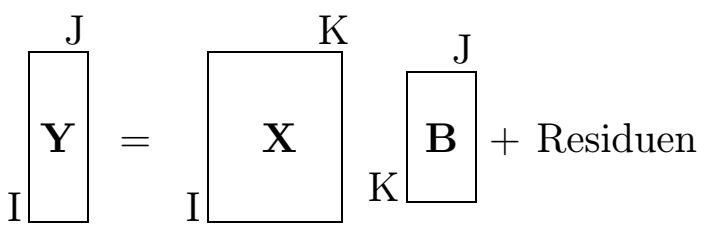

verbunden. Die Residuen enthalten den Anteil der Regressandenmatrix, der durch das lineare Modell nicht erfaßt wird.

Die drei in der Chemometrie vornehmlich benutzten Regressionsmethoden für die Kalibration sind OLS (ordinary least squares regression), PCR (principle component regression) und PLS (partial least squares regression). Dabei haben sich PCR und PLS in einer Vielzahl von Anwendungen als besonders leistungsfähig bewiesen (z.B. PCR: [144, 145, 146], PLS: [147, 148, 149]). Alle drei Kalibrationen werden im Abschnitt (7.3) experimentell untersucht.

In der Literatur findet sich häufig auch die Verwendung und Diskussion von PCR und PLS gemeinsam (z.B. $[150,151,152])$. Als Konsequenz haben sich mehrere Autoren um einen prinzipiellen Vergleich von PLS und PCR sowohl vom Standpunkt der Simulation (z.B. [153]) als auch aus theoretischer Sicht $([154,155])$ bemüht.

PCR und PLS zählen, anders als bei der OLS, zu den faktoriellen Methoden. Die Faktoranalyse wurde am Anfang des 20. Jahrhunderts in der Psychologie eingeführt. Als Begründer dieser Methode gelten PEARSON (1901) und SPEARMAN (1904) [156, 157]. Da die Methoden der Faktoranalyse ursprünglich in der Verhaltenspsychologie und der Biologie eingesetzt wurden, ergeben sich vor allem in der Anpassung der Terminologie Probleme bei der Übertragung und Anwendung auf chemisch-physikalische Fragestellungen. So steht der Begriff Faktor in keinem Zusammenhang zur rein mathematischen Deutung des Wortes als Multiplikator ${ }^{2}$.

2 Ursprünglich sollten genetische Faktoren mit physikalisch meßbaren Eigenschaften verknüpft werden [158]. Hotelling hat bereits 1903 vorgeschlagen, den Begriff Faktor durch Komponente zu ersetzen [159], diese Konvention hat sich aber nicht durchgesetzt. 
Bei der Faktoranalyse wird versucht, den (vielen) gemessenen Daten (wenige) gemeinsame Faktoren zuzuordnen. Diese Faktoren sollen Eigenschaften beschreiben, die nicht direkt meßbar sind. Es ist zwar möglich, daß die Anzahl der verwendeten Faktoren ebenso groß ist wie die Anzahl der gemessenen Daten, besonders in der Spektroskopie ist das aber die seltene Ausnahme. Daher liegt die Anzahl der verwendeten Faktoren meist deutlich unter der Anzahl der Rohdaten. Die Wahl der Faktorenzahl ist eine der wichtigsten Entscheidungen für die erfolgreiche Anwendung der Faktorenanalyse (siehe Abschnitt (6.3.4)). Die restlichen, nicht verwendeten Faktoren beschreiben im Idealfall dann lediglich das Rauschen des Systems oder andere nicht interessierende Eigenschaften der Proben.

PLS und PCR gehen im Grenzfall (maximale Anzahl von Faktoren) in die OLS über. In [141] wird von einer statistischen Arbeit berichtet, in der gezeigt wird, wie sich die drei Methoden OLS, PCR und PLS kontinuierlich in eine parametrische Familie von Regressionsmethoden einbetten lassen [160]. Für den Parameterwert Null erhält man demnach OLS, für Eins PLS und schließlich für Unendlich PCR. Alle dazwischen liegenden Parameterwerte werden als Kompromiß zwischen den drei Varianten gedeutet.

\subsubsection{Multiple Lineare Regression (OLS)}

Bei der (multiplen) linearen Regression (OLS - ordinary least squares regression) wird die Koeffizientenmatrix $\mathbf{B}$ durch Inversion von $\mathbf{X}$ berechnet [161, 162]. Für OLS finden sich auch öfter die Bezeichnungen CLS (classical least square regression) oder MLR (multiple linear regression). Da die Matrix $\mathbf{X}$ in der Regel nicht quadratisch ist, müssen die Regressionskoeffizienten $\mathbf{B}$ über die generalisierte Inverse $\mathbf{X}^{\dagger}$ (siehe Gleichung (6.13)) von $\mathbf{X}$ bestimmt werden:

$$
\mathbf{B}=\mathbf{X}^{\dagger} \mathbf{Y}
$$

Diese Lösung ist allerdings nur für unkorrelierte Variablen $\mathbf{x}$ befriedigend. Zusätzlich wird für B eine „gute“ mathematische Konditionierung gefordert, beschrieben durch die Konditionszahl $\operatorname{cond}_{q}(\mathbf{B})=\|\mathbf{B}\| \cdot\left\|\mathbf{B}^{-1}\right\|$. Ist $\mathbf{B}$ nicht quadratisch, wird die Konditionierung durch $\operatorname{cond}(\mathbf{B})=\left[\operatorname{cond}_{q}\left(\mathbf{B}^{T} \mathbf{B}\right)\right]^{1 / 2}$ berechnet. Kommt die Konditionierung oder ihr Kehrwert in die Nähe der Rechengenauigkeit, ist das System schlecht konditioniert und die Lösung unbrauchbar [163].

Zur Lösung des Gleichungssystems (6.16) bietet sich als Alternative zu Gleichung (6.13) z.B. die Singulärwertzerlegung (SVD -Singular Value Decomposition) an [125].

\section{OLS und das lineare Mischungsmodell}

Werden die Vektoren $\mathbf{x}$ durch eine lineare Matrixzerlegung aus den zeitaufgelösten Fluoreszenzspektren gewonnen, so läßt sich die Gleichung (2.7) des lineare Mi- 
schungsmodells (Abschnitt (2.1)) auch in Matrixform schreiben:

$$
\mathbf{x}=\mathbf{y K}+\mathbf{e},
$$

wobei $\mathbf{y}$ der Vektor mit den zu $\mathbf{x}$ gehörenden Konzentrationen, $\mathbf{K}$ die Matrix der Basisvektoren (skaliert auf die Konzentration 1) und e der Vektor mit den nicht durch das Modell beschriebenen Residuen ist. Die least-squares-Lösung dieser Gleichung ist:

$$
\mathbf{y}=\mathbf{x K}^{\dagger}
$$

Die OLS ist also für eine lineare Matrixzerlegung die direkte Umsetzung des linearen Mischungsmodells (vergleiche Gleichungen (6.15) und (6.16) mit $\mathbf{B}=\mathbf{K}^{\dagger}$ und $\mathbf{Y}=$ Einheitsmatrix).

\subsubsection{Hauptkomponentenregression (PCR)}

Bei dem OLS-Verfahren treten Probleme auf, wenn die Rohdaten korreliert sind, was häufig der Fall ist. Ein Ausweg bietet die Hauptkomponentenregression (PCR - Principal Component Regression), bei der eine vorgeschaltete Datenreduktion durch eine Hauptkomponentenanalyse (PCA) solche Korrelationen beseitigt.

\section{Hauptkomponentenanalyse (PCA)}

Die Hauptkomponentenanalyse (PCA - Principal Component Analysis) ist eine Methode der Datenumformung von korrelierten Variablen, die einerseits zur Visualisierung der inneren Struktur eines Datensatzes herangezogen wird und andererseits neue statistische Variablen, die Faktorenwerte, mit günstigen Eigenschaften für nachgeschaltete Analysen liefert [159, 164, 165, 166]. Für die Problemstellung dieser Arbeit wird sie als eine Methode zur Datenreduktion und als Vorstufe zur Hauptkomponentenregression (PCR) vorgestellt.

In der PCA wird von einer Rohdatenmatrix $\mathbf{X} \in \mathbb{R}^{I \times K}$ ausgegangen, in deren Spalten $K$ verschiedene Meßwerte (Variablen) einer Probe und in den Zeilen $I$ verschiedene Proben (Objekte) angeordnet sind. Hauptkomponenten sind gewichtete Linearkombinationen der rohen Variablen. Die erste Hauptkomponente (PC1) wird derart gebildet, so daß die Varianz der Faktorenwerte der neu erzeugten $I$ „künstlichen“ Variablen, maximal ist. Die 2. Hauptkomponente (PC2) erschließt die nächstgroße Varianz bei gleichzeitiger Orthogonalität zu PC1. Entsprechend werden die weiteren Hauptkomponenten gebildet. Zur rechnerischen Bestimmung der Hauptkomponenten geht man zunächst von der Kovarianzmatrix $\mathbf{K} \in \mathbf{R}^{K \times K}$ der Matrix $\mathbf{X}$ aus:

$$
\mathbf{K}=\frac{\mathbf{X}^{T} \mathbf{X}}{n-1}
$$

Für diese Matrix werden die Eigenvektoren $\mathbf{v}_{\mathbf{1}} . . \mathbf{v}_{\mathbf{K}}$ und Eigenwerte $\lambda_{1} . . \lambda_{K}$ bestimmt. Die Eigenvektoren werden als Spalten der Eigenvektormatrix $\mathbf{V}$ und die 
Eigenwerte als Diagonalelemente der Eigenwertmatrix $\boldsymbol{\Lambda}$ zusammengefaßt. Die Faktorenwerte sind das Matrixprodukt aus $\mathbf{X}$ und $\mathbf{V}$ :

$$
\mathbf{T}=\mathbf{X V}
$$

Die Hauptkomponenten sind die Linearkombinationen, mit denen die Faktorenwerte gebildet werden.

Liegen $\mathbf{T}$ und $\mathbf{V}$ vor, ist natürlich auch die Umkehrung möglich:

$$
\mathbf{X}=\mathbf{T V}^{T} \text {. }
$$

Der Sinn dieser Operationen liegt darin, daß man sich nun auf wenige Hauptkomponenten beschränkt und damit die Matrix X entsprechend Gleichung (6.21) nur bis auf einen Fehler $\mathbf{E}=\mathbf{X}-\mathbf{T V}^{T}$ (Residuenmatrix) annähert [167, 168]. Der Informationsgehalt über die Rohdaten ist in der ersten Hauptkomponente, gebildet durch den Eigenvektor mit dem höchsten Eigenwert, in der Regel am höchsten. Die Varianz, und damit der Informationsgehalt der Faktorenwerte, wird mit abnehmendem Eigenwert kleiner. Tatsächlich sind die Eigenwerte proportional zur Varianz der korrespondierenden Faktorenwerte. Auf die Bestimmung der Zahl signifikanter Hauptkomponenten wird in Abschnitt (6.3.4) eingegangen.

\section{Regression}

Eine Hauptkomponentenregression von $J$ verschiedenen y-Variablen ist äquivalent zu $J$ Hauptkomponentenregressionen auf jeweils eine y-Variable [140]. Daher reicht es, sich auf den Fall einer y-Variable zu konzentrieren, d.h. in Gleichung (6.15) werden an Stelle der Matrizen $\mathbf{Y}$ und $\mathbf{B}$ die Vektoren $\mathbf{y} \in \mathbb{R}^{I}$ und $\mathbf{b} \in \mathbb{R}^{K}$ verwendet.

Der Name Hauptkomponentenregression beruht darauf, daß bei der PCR aus den Rohdaten X im ersten Schritt durch eine Hauptkomponentenanalyse (PCA) Gewichte $\mathbf{P}$ für die $\mathbf{x}$-Werte gewonnen werden (in der PCA meist mit dem Buchstaben $\mathbf{V}$ bezeichnet), mit deren Hilfe sich Faktoren $\mathbf{T}$ zur Beschreibung von $\mathbf{X}$ berechnen lassen [169]:

$$
\mathbf{T}=\mathbf{X P}
$$

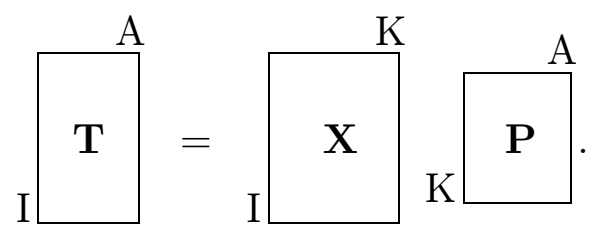

Im zweiten Schritt werden die Faktoren herangezogen, um durch least-square-fit y-Gewichte $\mathbf{q}$ zu bestimmen:

$$
\mathbf{y}=\mathbf{T q}+\mathbf{e}
$$




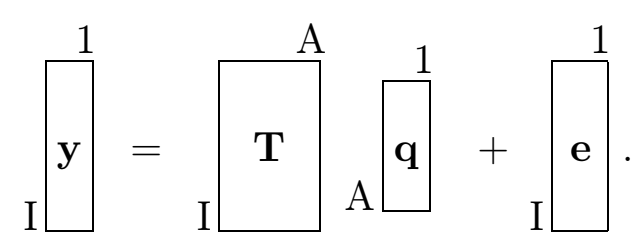

Wobei in der Regel $A<K$ gilt. Lediglich bei unkorrelierten Rohdaten $\mathbf{X}$ kann $A=K$ vorliegen. In diesem Fall wären PCR und OLS äquivalent [163]. Die Wahl eines geeigneten $A$ ist, wie im Abschnitt (6.3.4) beschrieben, von großer Bedeutung. Der Vektor e gibt den zu minimierenden Fehler an. Da die Faktoren $\mathbf{T}$ als Ergebnis der PCA unkorreliert sind, läßt sich $\mathbf{q}$ mit den Eigenwerten $\lambda_{a}(a=1 . . A)$ der in der PCA verwendeten Korrelationsmatrix berechnen:

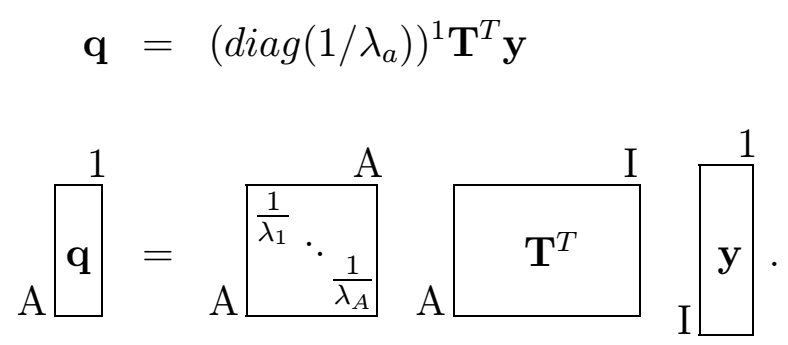

Im dritten Schritt werden diese Gewichte verwendet, um den Koeffizientenvektor b zu berechnen:

$$
\mathbf{b}=\mathbf{P q}
$$

Die zu $J$ einzelnen Hauptkomponentenregressionen gehörenden Vektoren $\mathbf{b}_{j}$ lassen sich nun als Spaltenvektoren der Koeffizientenmatrix B auffassen, womit wieder eine Vorhersage von $J$ Variablen (y) aus einer Messung (x) nach Gleichung (6.14) möglich ist.

Da die $\mathbf{x}$-Werte durch zwei Sätze linearer Parameter $\mathbf{T}$ und $\mathbf{P}$ verbunden werden (Gleichung (6.22)), bezeichnet man das PCR-Verfahren, wie auch das PLSVerfahren, im Gegensatz zur OLS als bilineare Methode.

\subsubsection{Partial Least Squares Regression (PLS)}

Wie auch bei der PCR werden bei der PLS die Ausgangsdaten $\mathbf{X}$ in einem ersten Schritt durch Faktoren T beschrieben. Im Gegensatz zur Hauptkomponentenregression fließen allerdings bereits in dieser Phase die Zielgrößen $\mathbf{Y}$ mit ein. Dies hat besonders dann Vorteile, wenn bei der Hauptkomponentenanalyse Faktoren $\mathbf{T}$ erzeugt würden, die für das Modell nicht von Bedeutung sind, denen aber dennoch große Eigenwerte zugeordnet sind. Bei solchen Faktoren handelt es sich in der Regel um systematische Phänomene (im Gegensatz zu Rauscheffekten, deren kleine Eigenwerte bereits durch die PCR erkannt werden), die zwar durch die Daten 
X beschrieben werden, durch die Analyse aber nicht wiedergegeben werden sollen. Auf diese Weise lassen sich unbekannte Einflußgrößen berücksichtigen. In der Analyse von Fluoreszenzspektren wären das beispielsweise unbekannte und nicht interessierende Fluorophore.

Wie auch bei der Hauptkomponentenregression ist die Zahl $A$ der berücksichtigten Faktoren von kritischer Bedeutung. Werden sowohl PCR als auch PLS auf die gleichen Daten angewendet, ist die Zahl der optimalen Faktoren häufig ähnlich oder gleich [170]. Allerdings tendiert die PLS-Methode stärker als die PCR zum Überlernen (overfit), d.h. zu viele Faktoren können ähnlich schlechte Ergebnisse liefern wie zu wenige [140]. Dadurch ist die Validierung (Abschnitt 6.3.4) von besonderer Bedeutung.

Das Konzept von PLS entstand im Zusammenhang mit der Auswertung von Daten aus den Sozialwissenschaften und wurde um 1975 von H. und S. Wold für chemische Anwendungen erweitert und propagiert [171]. Aufgrund der hohen Leistungsfähigkeit von PLS wurden diverse ähnliche und z.T. äquivalente PLSAlgorithmen entwickelt.

An dieser Stelle sollen zwei Variationen behandelt werden: Der „orthogonale PLS-Algorithmus für eine y-Variable“ (PLS1) und der „orthogonale PLS-Algorithmus für mehrere y-Variablen" (PLS2). „Orthogonal" bezieht sich dabei auf die Faktoren t. Andere, in der Vorhersagegenauigkeit äquivalente PLS-Verfahren, verzichten auf diese Orthogonalität und sind dadurch in der Lage, mit nur einem Satz von Ladungen auszukommen [172].

Im Gegensatz zur PCR, bei der die simultane Regression für mehrere y-Variablen gleichwertig mit mehreren Regressionen für jeweils eine $\mathrm{y}$-Variable ist, ist die PLSKalibration für die beiden Fälle unterschiedlich, da bei der Datenkompression von $\mathbf{X}$ die $\mathbf{y}$-Werte direkt in die Bildung der Faktoren $\mathbf{t}$ mit einfließen. Es läßt sich allerdings nicht a priori sagen, daß bei einer Regression auf mehrere Zielgrößen - also auf eine Matrix Y an Stelle eines Vektors y - der PLS2-Algorithmus der geeignetere ist [140].

\section{PLS1 - eine y-Variable}

Die hier vorgestellte relativ kompakte Variante stammt aus [140] und wurde beschrieben in [173] und [174]. Zuerst wird die Anzahl $A_{\max }$ der zu berechnenden Faktoren gewählt. $A_{\max }$ sollte größer als die Anzahl der erwarteten Phänomene sein, um nicht erwartete oder unbekannte Phänomene berücksichtigen zu können. In der Validierungsphase (Abschnitt 6.3.4) lassen sich anschließend nicht benötigte Faktoren wieder eliminieren. Die folgenden Schritte werden nun für jeden Faktor $a=1,2, \ldots, A_{\max }$ durchgeführt:

1. Es werden durch Regression normierte Ladungsvektoren $\mathbf{w}_{a}$ bestimmt, so daß die Kovarianz zwischen $\mathbf{y}_{a-1}$ und $\mathbf{X}_{a-1} \mathbf{w}_{a}$ maximal ist. Die Berechnung der Vektoren erfolgt durch

$$
\mathbf{w}_{a}=c \mathbf{X}_{a-1}^{T} \mathbf{y}_{a-1}
$$


wobei $c$ ein Skalar ist, der w auf die Länge 1 normiert.

2. Mit diesen Ladungen werden Faktoren $\mathbf{t}$ berechnet, welche die verbleibenden Quelldaten nach dem Modell $\mathbf{X}_{a-1}=\mathbf{t}_{a} \mathbf{w}_{a}^{T}+\mathbf{E}$ möglichst gut approximieren. $\mathbf{E}$ bezeichnet die Residuen. Mit $\mathbf{w}_{a}^{T} \mathbf{w}_{a}=1$, finden sich diese $\mathrm{zu}$

$$
\mathbf{t}_{a}=\mathbf{X}_{a-1} \mathbf{w}_{a}
$$

3. Es werden Ladungen berechnet, die nach dem Modell $\mathbf{X}_{a-1}=\mathbf{t}_{a} \mathbf{p}_{a}^{T}+\mathbf{E}$ ebenfalls $\mathbf{X}$ approximieren. Die least squares Lösung lautet:

$$
\mathbf{p}_{a}=\frac{\mathbf{X}_{a-1}^{T} \mathbf{t}_{a}}{\mathbf{t}_{a}^{T} \mathbf{t}_{a}}
$$

4. Die Ladung $q_{a}$ (genannt „,chemische Ladung“) wird berechnet, die nach dem Modell $\mathbf{y}_{a-1}=\mathbf{t}_{a} q_{a}+\mathbf{f}$ die $\mathrm{y}$-Werte mit den Residuen $\mathbf{f}$ approximiert:

$$
q_{a}=\frac{\mathbf{y}_{a-1}^{T} \mathbf{t}_{a}}{\mathbf{t}_{a}^{T} \mathbf{t}_{a}}
$$

5. Ist $a<A_{\max }$, so wird die Berechnung des nächsten Faktors initialisiert:

$$
\begin{aligned}
\mathbf{X}_{a} & :=\mathbf{X}_{a-1}-\mathbf{t}_{a} \mathbf{p}_{a}^{T}, \\
\mathbf{y}_{a} & :=\mathbf{y}_{a-1}-\mathbf{t}_{a} q_{a} \text { und } \\
a & :=a+1 .
\end{aligned}
$$

Wie bereits erwähnt, wird nun durch die in Abschnitt (6.3.4) beschriebene Validierungen die Anzahl der Faktoren von $A_{\max }$ auf $A$ eingeschränkt. Die auf diese Weise gewonnenen Ladungen $\mathbf{W}=\left\{\mathbf{w}_{a}\right\}$ und Faktoren $\mathbf{T}=\left\{\mathbf{t}_{a}\right\}$ sind orthogonal. Obwohl sich $\mathbf{W}$ und $\mathbf{P}=\left\{\mathbf{p}_{a}\right\}$ ähneln, sind die geschätzten Ladungen $\mathbf{P}$ im Gegensatz dazu in der Regel nicht orthogonal.

Zur Vorhersage von y-Variablen mit $y=\mathbf{x b}$ (entsprechend Gleichung (6.14)) wird abschließend der Vektor

$$
\mathbf{b}=\mathbf{W}\left(\mathbf{P}^{T} \mathbf{W}\right)^{-1} \mathbf{q}
$$

berechnet, wobei $\mathbf{q}=\left(q_{1} . . q_{A}\right)^{T}$ ist.

\section{PLS2 - mehrere y-Variablen}

Die Modifizierung des PLS1-Verfahrens zur Bearbeitung von mehreren y-Variablen gleichzeitig ist verhältnismäßig einfach. An Stelle von $\mathbf{y}, \mathbf{f}$ und $\mathbf{q}$ beim PLS1 treten beim PLS2-Verfahren $\mathbf{Y} \in \mathbb{R}^{I \times J}, \mathbf{F} \in \mathbb{R}^{I \times J}$ und $\mathbf{Q} \in \mathbb{R}^{J \times A}$. Die Maximierung 
der Kovarianz zwischen $\mathbf{X}_{a-1} \mathbf{w}_{a}$ und dem Vektor mit jeweils einer y-Variablen $\mathbf{y}_{a-1}$ in Schritt (1) des Algorithmus' wird durch die Maximierung der Kovarianz zwischen $\mathbf{X}_{a-1} \mathbf{w}_{a}$ und dem Zeilenvektor $\mathbf{u}_{a}=\mathbf{Y}_{a-1} \mathbf{q}_{a}\left(\mathbf{q}_{a}^{T} \mathbf{q}_{a}\right)^{-1}, \mathbf{u}_{a} \in \mathbb{R}^{I}$, ersetzt, einer Linearkombination der y-Variablen. Die Vektoren $\mathbf{q}_{a} \in \mathbb{R}^{J}$ sind die Spalten der Matrix $\mathbf{Q}$. Der Vektor $\mathbf{u}_{a}$ wird durch Iteration gewonnen.

Die Datenvorbereitung und die Wahl von $A_{\max }$ ist analog zum PLS1. Entsprechend werden folgende Schritte für jeden Faktor $a=1,2, \ldots, A_{\max }$ durchgeführt:

1. Es wird ein Startwert für $\mathbf{u}_{a}$ gewählt, beispielsweise der Spaltenvektor von $\mathbf{Y}_{a-1}$ mit dem größten Betrag.

2. Iteration zur Bestimmung von $\mathbf{u}_{a}$ :

a) Die Ladungen für $\mathbf{X}_{a-1}=\mathbf{u}_{a} \mathbf{w}_{a}^{T}+\mathbf{E}$ werden bestimmt ( $c$ normiert $\mathbf{w}_{a}$ auf 1):

$$
\mathbf{w}_{a}=c \mathbf{X}_{a-1}^{T} \mathbf{u}_{a-1} .
$$

b) Die Faktoren für $\mathbf{X}_{a-1}=\mathbf{t}_{a} \mathbf{w}_{a}^{\prime}+\mathbf{E}$ werden berechnet:

$$
\mathbf{t}_{a}=\mathbf{X}_{a-1} \mathbf{w}_{a} .
$$

c) Die Ladungen für $\mathbf{X}_{a-1}=\mathbf{t}_{a} \mathbf{p}_{a}^{\prime}+\mathbf{E}$ werden bestimmt:

$$
\mathbf{p}_{a}=\frac{\mathbf{X}_{a-1}^{T} \mathbf{t}_{a}}{\mathbf{t}_{a}^{T} \mathbf{t}_{a}}
$$

d) Schließlich erfolgt die Berechnung der chemischen Ladungen für $\mathbf{Y}_{a-1}=$ $\mathbf{t}_{a} \mathbf{q}_{a}^{T}+\mathbf{F}$ :

$$
\mathbf{q}_{a}=\frac{\mathbf{Y}_{a-1}^{T} \mathbf{t}_{a}}{\mathbf{t}_{a}^{T} \mathbf{t}_{a}}
$$

e) Konvergenztest: Wurde Konvergenz erreicht - wenn sich z.B. die Faktoren $\mathbf{t}_{a}$ seit dem letzten Iterationsschritt nicht mehr wesentlich verändert haben - dann weiter bei Punkt (3). Wurde noch keine Konvergenz erreicht, so werden die y-Faktoren $\mathbf{u}_{a}$ mit dem Modell $\mathbf{Y}_{a-1}=\mathbf{u}_{a} \mathbf{q}_{a}^{T}+\mathbf{F}$ neu berechnet:

$$
\mathbf{u}_{a}=\frac{\mathbf{Y}_{a-1} \mathbf{q}_{a}}{\mathbf{q}_{a}^{T} \mathbf{q}_{a}}
$$

und die Iteration wird bei Punkt (2.a) fortgesetzt.

3. Ist $a<A_{\max }$, so wird die Berechnung des nächsten Faktors initialisiert:

$$
\begin{aligned}
\mathbf{X}_{a} & :=\mathbf{X}_{a-1}-\mathbf{t}_{a} \mathbf{p}_{a}^{T}, \\
\mathbf{Y}_{a} & :=\mathbf{Y}_{a-1}-\mathbf{t}_{a} \mathbf{q}_{a}^{T} \text { und } \\
a & :=a+1 .
\end{aligned}
$$




\subsubsection{Bestimmung signifikanter Faktoren}

Zur Bestimmung der Zahl signifikanter Faktoren (z.B. der Zahl der Hauptkomponenten in der PCA) einer Faktorzerlegung gibt es zahlreiche heuristische und statistische Kriterien. Typische Methoden für die PCA/PCR sind beispielsweise:

- Anteil der erklärten Varianz: Es werden sukzessive Faktoren aufgenommen, bis ein bestimmter Anteil der Gesamtvarianz erfaßt wurde (z.B. 95\%).

- Eigenwert-Eins-Kriterium: Wird mit standardisierten Daten gearbeitet, so ist der Mittelwert der Eigenwerte Eins. Es werden nur Faktoren aufgenommen, deren Eigenwert größer als Eins ist.

Allgemeiner sind Methoden, die einen direkten Test des Kalibrationsmodells durchführen. Speziell bei spektroskopischen Daten ist der Ansatz „kleine Eigenwerte $=$ geringe Bedeutung für die Kalibration/Analyse" oft nicht haltbar [125]. Eine Validierung mit Testdaten ist, wenn auch rechenintensiv, in der Regel die Methode der Wahl [140]. Das faktorielle Modell wird nicht mit allen zur Verfügung stehenden Daten erstellt, sondern einige Daten werden als Testobjekte zurückbehalten (internal validation). Das Modell wird anschließend zur Vorhersage der ausgelassenen Daten verwendet und es wird der Fehler zwischen den ursprünglichen und den vorhergesagten Werten ermittelt. Das Minimum dieses Fehlers ist meist nicht für die größte Anzahl von Faktoren zu finden, so daß die optimale Anzahl der Faktoren aus diesem Minimum abgeleitet werden kann.

Besondere Bedeutung hat hier die Kreuzvalidierung (cross validation): Bei der vollen Kreuzvalidierung wird bei einem Kalibrationsdatensatz, bestehend aus $I$ Messungen $\mathbf{x}_{i}$ mit bekannten Zielwerten $\mathbf{y}_{i}$, der Kalibrations-Test-Zyklus ( $\left.I-1\right)$ mal durchlaufen. Dabei wird bei jeder Kalibration ein Datenpaar $\left(\mathbf{x}_{i}, \mathbf{y}_{i}\right)$ aus der Kalibration ausgeschlossen und verwendet, um den Wert $\hat{\mathbf{y}}_{i}$ aus $\mathbf{x}_{i}$ vorherzusagen. Der Vorhersagefehler wird durch $\left(\hat{\mathbf{y}}_{i}-\mathbf{y}_{i}\right)^{2}$ berechnet. Die Summe der Fehler gibt die Qualität der gewählten Faktorenzahl an.

Da die vollständige Kreuzvalidierung sehr rechenintensiv sein kann, ist eine wichtige Modifikation bei der Kreuzvalidierung das Aufteilen der Kalibrationsdaten in Teilgruppen. Bei den Kalibrationen wird nun jeweils eine Teilgruppe ausgelassen und zur Vorhersage verwendet, der Rest der Daten dient wieder der Kalibration.

Vorteil der Kreuzvalidierung ist, daß alle zur Verfügung stehenden Daten im ersten Schritt sowohl zur Kalibration als auch zu Testzwecken verwendet werden können, um die optimale Anzahl der Faktoren zu bestimmen. Anschließend, wenn diese Zahl bekannt ist, werden wieder alle Daten zur Erstellung des endgültigen Kalibrationsmodells herangezogen. 


\section{Optimierung und Vergleich verschiedener Auswertemethoden}

\section{1 Überblick}

Die verschiedenen im vorherigen Kapitel vorgestellten Auswertemethoden werden in diesem Kapitel mit Hilfe von acht Datensätzen untersucht und miteinander verglichen. Jede Methode besteht aus zwei Teilen: Der Matrixzerlegung (Dimensionsreduktion einer Matrix auf einen Vektor) und der Kalibration (siehe auch Abb. 6.1). Die Rechnungen wurden mit Hilfe der Chemometrie-Toolbox unter dem Mathematikprogramm MATLAB ${ }^{1}$ durchgeführt.

\section{Vorhersagefehler}

Eine zentrale Rolle bei der Optimierung und dem Vergleich der Methoden nimmt der Begriff des Vorhersagefehlers ein. Zu der Berechnung des Vorhersagefehlers einer Methode werden mit dieser Methode die Konzentrationen der Schadstoffe in einem Satz von Spektren berechnet ${ }^{2}$, deren tatsächliche Konzentrationen bekannt sind. Die genormte Summe der quadratischen Differenzen zwischen den tatsächlichen und den vorhergesagten Konzentrationen ergibt den Vorhersagefehler:

$$
e=\sqrt{\frac{1}{I} \sum_{i=1}^{I}\left(c_{i, i s}-c_{i, p r e d}\right)^{2}} .
$$

Um verläßliche Ergebnisse zu erhalten, wurde mit mehreren Datensätzen gearbeitet. Da es zudem meist sinnvoll ist, die Vorhersagefehler nach Schadstoffen getrennt zu betrachten, wird der direkte Vergleich der Fehler (z.B. in Form einer Tabelle) schnell unübersichtlich. Für einen graphischen Vergleich zweier Methoden $A$ und $B$ wird deswegen mit Hilfe von

$$
e_{\text {vergl }}\left(e_{A}, e_{B}\right)= \begin{cases}e_{A} / e_{B}-1 & , \text { wenn } e_{A} / e_{B}>1 \\ 1-e_{B} / e_{A} & , \quad \text { sonst }\end{cases}
$$

ein Wert $e_{\text {vergl }}$ für den vergleichenden Vorhersagefehler eingeführt. Ist $e_{\text {vergl }}$ größer als Null, so war der Vorhersagefehler von Methode $A$ größer als der von Methode $B$, und zwar um den Faktor $e_{\text {vergl }}$, d.h. die Methode $B$ hatte eine höhere Vorhersagegenauigkeit. Ist $e_{\text {vergl }}$ kleiner als Null, so war die Vorhersagegenauigkeit von Methode $A$ höher. Auf diese Weise lassen sich die Vorhersagegenauigkeiten zweier Methoden auch bei vielen Ergebnissen übersichtlich in einer Graphik darstellen (vergleiche z.B. die Abbildungen auf Seite 70).

1 Matlab, Version 5.3, The MathWorks Inc., Natick (USA)

2 Der Einfachheit halber wird hier von der Schadstoffkonzentration eines Spektrums gesprochen. Gemeint sind damit selbstverständlich die Konzentrationen der Schadstoffe in der Probe, in der das zugehörige Fluoreszenzspektrum aufgezeichnet wurde. 


\section{Datensätze}

Als Datensatz wird in dieser Arbeit eine Serie von zeitaufgelösten Fluoreszenzspektren bezeichnet, die sowohl für die Erstellung als auch für die Überprüfung von Kalibrationsmodellen verwendet werden. Um bei diesen numerischen Versuchen allgemeingültige Aussagen treffen zu können, ist die Verwendung von mehreren möglichst verschiedenen Datensätzen nötig.

Ein Spektrum eines Datensatzes ist eine $W \times Z$-Matrix mit $W$ Kanälen (spektrale Information) zu $Z$ Zeitscheiben (siehe auch Abschnitt 3.5). Jeder Datensatz besteht aus zwei Teilen: Dem Kalibrations- und dem Validationsteil. Der Kalibrationsteil dient zur Erstellung des multivariaten Kalibrationsmodells, das anschließend mit dem Validationsteil optimiert und/oder überprüft werden kann.

Zwei Sorten von Datensätzen wurden erzeugt: Vier Datensätze mit realen Spektren und vier Datensätze mit pseudo-realen (simulierten) Spektren. Handelte es sich um den Vergleich zweier Methoden, wurden in der Regel beide Sorten von Datensätzen verwendet, um zuverlässige Aussagen treffen zu können. Reale Daten können Fehler enthalten, die trotz aller Sorgfalt zu systematischen Abweichungen führen. Zudem ist die Anzahl von realen Spektren durch den Meßaufwand naturgemäß begrenzt. Simulierte Daten, wenn auch entsprechend der Eigenschaften von Probe und Nachweissystem erzeugt und verrauscht, werden dagegen vermutlich nicht alle Eigenschaften und Unterschiede von realen Daten perfekt widerspiegeln.

Die realen Spektren (Datensätze DS1 bis DS4) wurden in natürlichen Wasserproben aufgezeichnet, die im Labor gezielt mit PAK kontaminiert wurden. Jedes Spektrum stellt eine eigene Probenpräparation und Messung dar. Jeder Datensatz besteht aus 225 bis 258 Spektren von Gemischen aus 11 PAK $^{3}$. Jede Probe enthielt zwischen einer und fünf dieser Substanzen in unterschiedlichen Konzentrationen bis zu einer für diesen Datensatz festgelegten Maximalkonzentrationen (im ppb-Bereich). Die Spektren der Proben enthalten zudem unterschiedlich ausgeprägte natürliche Hintergrundfluoreszenz.

Zur Erzeugung der pseudo-realen Spektren (Datensätze DS5 bis DS8) wurden die Spektren der 14 unterscheidbaren EPA-PAK ${ }^{4}$ getrennt in destilliertem Wasser aufgezeichnet. Aus dieser Basis von Spektren wurden entsprechend dem Linear-Mixture-Model (siehe Abschnitt (2.1)) 280 Spektren für die Kalibration durch digitale Konzentrationsänderung (Intensitätsskalierung unter Berücksichtigung der Geräteparameter, z.B. der Auflösung des A/D-Wandlers des Nachweissystems) erzeugt, jeweils 20 verschiedene Konzentrationen für jeden der 14 PAK. Jedes Spektrum des Kalibrationsteils enthält nur einen Schadstoff. Für die Validation wurden 160 weitere Spektren erzeugt, wobei in jedem dieser 160 Spektren alle PAK mit zufälliger Konzentration vertreten sind. Auf alle 440 Spektren eines pseudorealen Datensatzes wurden anschließend diverse Spektren aus einer Sammlung von

3 ACN, ANT, BaA, BkF, BbF, BaP, CHR, FLU, NAP, PHT und PYR.

4 ACN, ANT, BaA, BkF, BbF, BgP, BaP, CHR, DBA, FLU, INP, NAP, PHT und PYR, siehe auch Seite 114. 
ca. 3000 Hintergrundspektren, (siehe Anhang (A.10)) addiert. Abschließend wurde jedes Spektrum mit einem dem System entsprechenden Poisson-Rauschen versehen. Mehr Information zu den Datensätzen DS1 bis DS8 ist im Anhang (A.4) (Seite 117) $\mathrm{zu}$ finden.

\section{Durchführung der Vergleiche}

Zur Berechnung des vergleichenden Vorhersagefehlers zweier Methoden A und B wurden mit dem Kalibrationsteil eines Datensatzes jeweils zwei Kalibrationsmodelle erstellt, eines für Methode A und eines für B. Bei A und B kann es sich auch um zwei Methoden im weiteren Sinne handeln, also z.B. um eine Methode mit zwei verschiedenen Parametereinstellungen. Mit diesen Kalibrationsmodellen wurden für den Validationsteil der Daten die Schadstoffkonzentrationen vorhergesagt. Die nach Schadstoffen getrennten vergleichenden Vorhersagefehler (siehe Gleichung (7.2)) geben Auskunft darüber, welche Methode zur Vorhersage eines bestimmten Schadstoffes besser geeignet ist. Bei Verwendung von acht Datensätzen ergeben sich so acht vergleichende Vorhersagefehler pro Schadstoff.

Zusätzlich zu dieser datensatzinternen Fehlerberechnung wurde z.T. auch ein datensatzübergreifender Vorhersagefehler berechnet. Dazu wurden die Kalibrationsmodelle mit einem ganzen Datensatz (inklusive Validationsteil) erzeugt und dieses Modell zur Vorhersage der Schadstoffkonzentrationen in den anderen Datensätzen verwendet. Beim Kreuztest, ähnlich aber nicht zu verwechseln mit der Methode cross-validation zur Bestimmung der Faktorenzahl, dienen nacheinander alle Datensätze einmal als Kalibrationsdaten zur Vorhersage der Konzentrationen in den restlichen Datensätzen, wodurch sich deutlich mehr relative Vorhersagefehler ergeben.

Da Matrixzerlegung und Kalibration getrennt untersucht wurden, richtete sich die Bezeichnung der einzelnen Methoden nach den Merkmalen, die jeweils von Interesse waren. So wurde eine Analyse mit abstrakter Faktorzerlegung (AFD: abstract factor decomposition) und anschließender PLS-Kalibration wahlweise als AFD-Analyse bezeichnet, wenn alternative Matrixzerlegungen untersucht wurden oder als PLS-Analyse, wenn auch andere Kalibrationen Verwendung fanden.

\subsection{Untersuchungen zur Matrixzerlegung}

Die abstrakte Faktorzerlegung dient zur Zerlegung oder Umformung einer Datenmatrix eines zeitaufgelösten Spektrums in einen Vektor. Besondere Bedeutung kommt dabei der Wahl der Abklingzeiten $\tau_{1} \ldots \tau_{n}$ zu, die zusammengefaßt als Tauvektor mit der Dimension $N_{\tau}$ bezeichnet werden. Mit Hilfe von Gleichung (6.11) (Seite 54) wird aus dem Tauvektor die Matrix $\mathbf{Z}$ mit den abstrakten Abklingkurven berechnet, die zur Zerlegung der zeitaufgelösten Spektren Verwendung findet. 
Da es nicht sinnvoll ist, die AFD an Hand von Substanzen zu untersuchen, die eine kurze Abklingzeit oder eine geringe Fluoreszenzausbeute im Verhältnis zur Systemaufösung haben, wurden für die folgenden Untersuchungen nur die sechs Schadstoffe ACN, BaA, BaP, CHR, PHT und PYR herangezogen. Die zugehörigen Abklingzeiten und weitere Eigenschaften sind im Anhang (A.2) zu finden.

\subsubsection{Abstrakte Faktorzerlegung mit festem Tauvektor (FT-AFD)}

Die FT-AFD (fixed tau abstract factor decomposition) wurde von F. Lewitzka speziell für die zeitaufgelöste laserspektroskopische PAK-Analytik entwickelt (siehe Abschnitt 6.2.3). Der Tauvektor wird dabei für ein bestimmtes System und eine gegebene Anwendung durch eine Mischung aus theoretischen Überlegungen, Experimenten und Erfahrungen („Expertenwissen“) festgelegt. Die Kalibration wird mit Hilfe des PLS-Algorithmus' durchgeführt.

In der Praxis hat sich die Entfaltung der Gerätefunktion nach Gleichung (6.9) als unpraktikabel herausgestellt. Es wurden diverse Versuche mit und ohne digitaler Entfaltung durchgeführt und es hat sich gezeigt, daß bereits kleine Veränderungen im zeitlichen Verhalten des Systems zu starken Veränderungen in den entfalteten Daten führen. Solche Veränderungen, wie z.B. eine kleine Änderung der Laserpulslänge, sind aber gerade im Feldeinsatz oft unvermeidlich. Anstelle der Entfaltung wird daher nur der Teil der Daten für die abstrakte Faktorzerlegung verwendet, für den die Laseranregung bereits vollständig abgeklungen ist. Gleichung (6.11) wird dann zu:

$$
Z_{n z}=\exp \left(-z \Delta t_{0} / \tau_{n}\right)
$$

Mit Hilfe der Pseudoinversen der Matrix $\mathbf{Z}$ lassen sich die abstrakten Spektren $\mathbf{S}$ wieder durch Gleichung (6.12) berechnen: $\mathbf{S}=\mathbf{M} \mathbf{Z}^{\dagger}$.

Als Ausgangspunkt bei der Festlegung eines Tauvektors diente die Überlegung, daß zumindest jeweils eine Komponente des Tauvektors in der Nähe der Abklingzeiten der Analyten liegen sollte. Neben der guten Vorhersage von Schadstoffkonzentrationen in Kontrollproben galt bei der Wahl des Tauvektors die Robustheit der Kalibration und die Vermeidung von negativen Werten in den abstrakten Spektren als wünschenswert, ohne allerdings genau quantifiziert worden zu sein. Mit einem gewissen Maß an Intuition wurden diverse Konfigurationen der AFD durchgespielt [175].

Werden die EPA-PAK entsprechend ihrer Abklingzeiten geordnet, so bilden sich deutlich drei Gruppen heraus (vergleiche auch Anhang A.2): Die „schnellen“ Substanzen mit Abklingzeiten bis $10 \mathrm{~ns}$, die „mittleren“ mit Abklingzeiten zwischen 25 und $37 \mathrm{~ns}$ und das „langsame“ Pyren mit einer Abklingzeit um 120 ns. Dieser Gruppierung als Orientierung folgend, wurden für die PAK-Analytik der Daten des CCD-Laserfluorimeters mit der FT-AFD-Analyse folgende Tauvektoren festgelegt 
(alle Werte in Nanosekunden): $(5 ; 27 ; 125),(7 ; 27 ; 125)$ und $(10 ; 27 ; 125)$. Je nach Art der Datenvorbereitung und Schwerpunkt der Analyse fand einer dieser drei Vektoren Anwendung. Für die Datensätze DS1 bis DS8 wurde der Tauvektor (7; 27 ; 125) verwendet.

Diese Erfahrungswerte gelten allerdings nur für die PAK-Analyse mit dem CCDLaserfluorimeter oder vergleichbaren Systemen. Im folgenden werden Methoden untersucht, die ohne das Expertenwissen auskommen, welches für die Konfiguration der FT-AFD notwendig ist. Vielmehr soll die Entwicklung und Anwendung dieses Wissens systematisiert und automatisiert werden. Es kann dabei davon ausgegangen werden, daß die FT-AFD in Verbindung mit einer PLS-Kalibration für das bestehende Meßsystem bereits sehr leistungsfähig ist und damit einen guten Vergleichsstandard bildet.

\subsubsection{Nicht-negative Faktorzerlegung und Aufnahme des integralen Spektrums}

Eine Modifikation der abstrakten Faktorzerlegung ist die nicht-negative abstrakte Faktorzerlegung (NNFD: non-negative factor decomposition), bei der keine negativen Werte in $\mathbf{S}$ zugelassen werden. Dazu wird in der Gleichung (6.10):

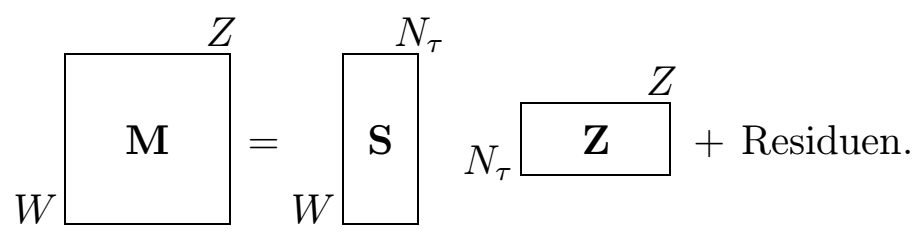

die Matrix $\mathbf{S}$ durch einen iterativen least-squares-fit zur Minimierung der Residuen bestimmt, der nur positive Werte für die Elemente von $\mathbf{S}$ zuläßt.

Bei dieser Zerlegung steht dem Vorteil der besseren physikalischen Beschreibung (eine Fluoreszenzintensität kleiner Null kann es nicht geben) der Nachteil der schlechteren mathematischen Beschreibung der Matrix $\mathbf{M}$ gegenüber. Ein weiterer Nachteil ist die um Größenordnungen höhere Rechenzeit, die zur Bestimmung von $\mathbf{S}$ nötig ist.

Eine weitere Modifikation ist die Aufnahme des über die Zeitachse integrierten Spektrums (IS) in den Kalibrationsvektor, dessen Dimension $K$ sich dadurch von $W \cdot N_{\tau}$ auf $W \cdot\left(N_{\tau}+1\right)$ erhöht.

Für die Datensätze DS1 bis DS4 wurden jeweils vier Kalibrations-ValidierungsZyklen mit der FT-AFD-Analyse durchgeführt. Bei den ersten beiden Zyklen fand die ANFD-Tauzerlegung, bei den anderen beiden die NNFD-Tauzerlegung Anwendung. Im ersten und im dritten Zyklus wurden die abstrakten Spektren um das integrale Spektrum erweitert, im zweiten und vierten nicht.

Wie aus den Abbildungen (7.1) und (7.2) deutlich wird, gibt es eine leichte Überlegenheit der ANFD-Zerlegung gegenüber der NNFD-Zerlegung. Vermutlich 


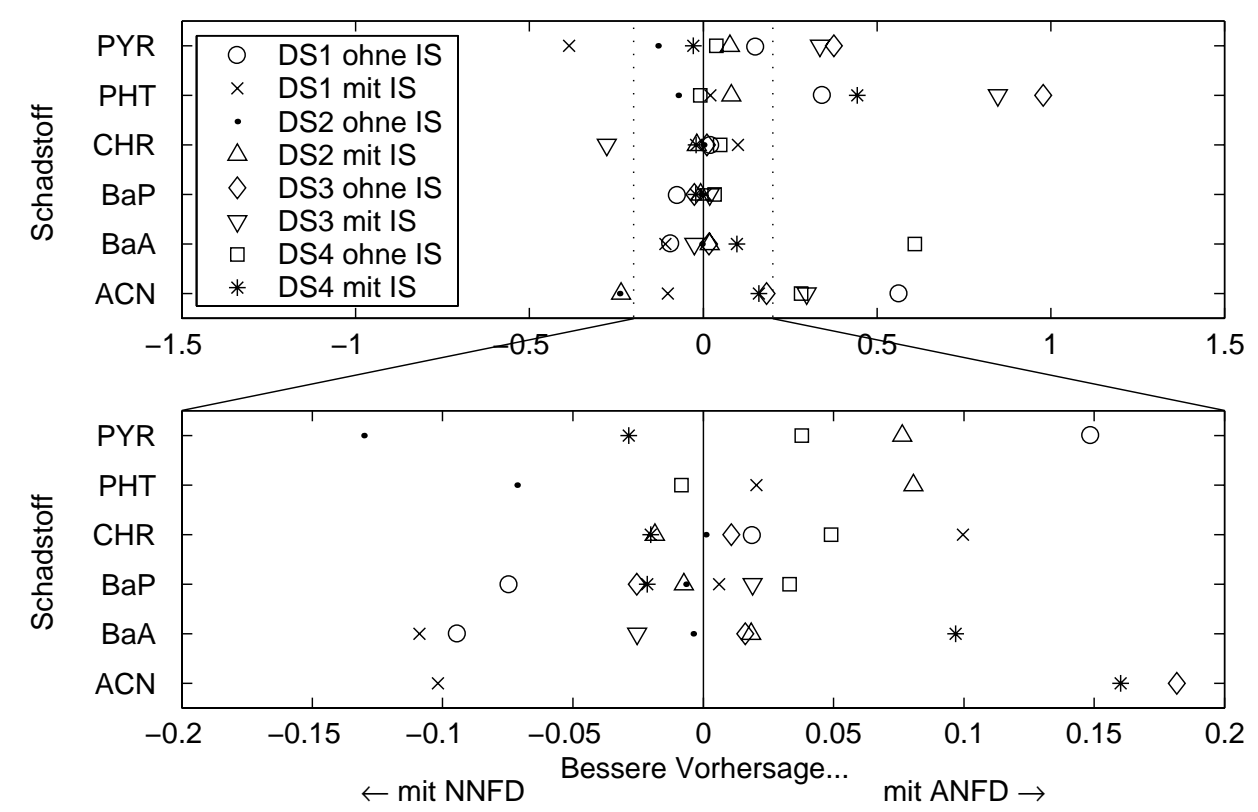

Abbildung 7.1: Vorhersagegenauigkeit der AFD-Analyse bei abstrakter Faktorzerlegung mit (ANFD) und ohne (NNFD) negative Werte in den abstrakten Spektren mit und ohne Aufnahme integraler Spektren (IS) in die Kalibrationsvektoren für sechs PAK in vier Datensätzen mit Realdaten.

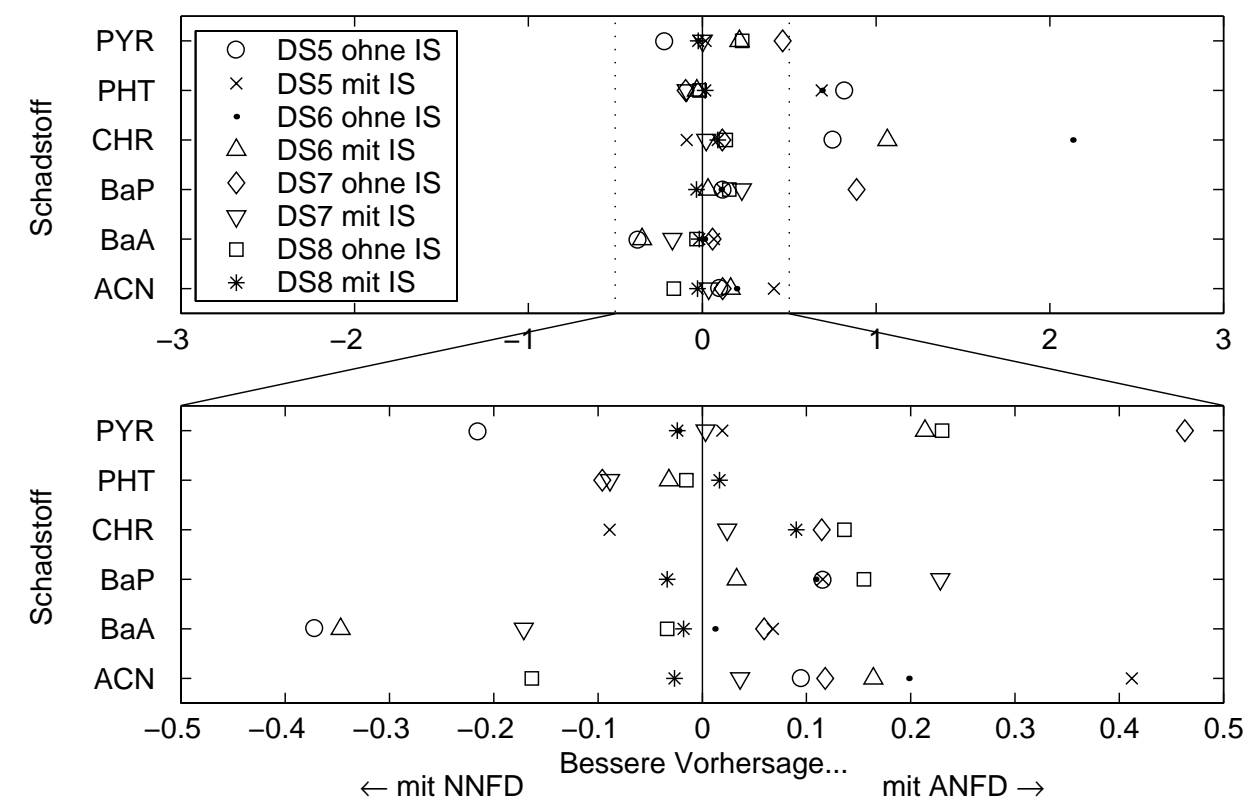

Abbildung 7.2: Vorhersagegenauigkeit der AFD-Analyse bei abstrakter Faktorzerlegung mit (ANFD) und ohne (NNFD) negative Werte in den abstrakten Spektren mit und ohne Aufnahme integraler Spektren (IS) für sechs PAK in vier Datensätzen mit simulierten Daten. 
überwiegt die bessere Beschreibbarkeit (kleineren Residuen) der zeitaufgelösten Spektren die von der Physik her erwartete Verschlechterung der Vorhersage durch Verwendung negativer Spektren.

Die Abbildungen (7.3) und (7.4) zeigen den relativen Vorhersagefehler unter Aufnahme oder Ausschluß des integralen Spektrums (IS) in den Kalibrationsvektor. Auch hier ist der Einfluß des Parameters nicht sehr hoch aber sichtbar. Bei den Substanzen mit einer Fluoreszenzlebensdauer deutlich über der Systemauflösung ist die Aufnahme des integralen Spektrums von Nachteil.

Anders sieht es bei Substanzen mit kurzer Lebensdauer aus (z.B. Anthracen oder Fluoren), hier haben Untersuchungen gezeigt, daß die Aufnahme des integralen Spektrums in den Kalibrationsvektor von Vorteil ist. Das ist nicht überraschend: Da die abstrakte Faktorzerlegung nur auf den Teil des zeitaufgelösten Spektrums angewendet wurde, für den die Anregung bereits beendet war, enthielt das integrale Spektrum über die kurzlebigen Fluorophore deutlich mehr Information als die abstrakten Spektren.

\subsubsection{Residuen-minimierende Zerlegung (RM-AFD)}

Die RM-Zerlegung ist eine Möglichkeit, mit Hilfe der Kalibrationsdaten einen Tauvektor zu bestimmen, ohne daß ein Validationsdatensatz benötigt wird. Zudem erfordert die RM-AFD zur Bestimmung des Tauvektors keinen Kalibrations-Validations-Zyklus und erfordert dadurch vergleichsweise wenig Rechenzeit. Die RMZerlegung basiert auf dem Ansatz, daß kleine Residuen ein Merkmal einer guten Faktorzerlegung sind. Wieder wird nach einem Tauvektor für alle zeitaufgelösten Fluoreszenzspektren eines Datensatzes gesucht. Dieser Tauvektor erzeugt das (idealerweise globale) Minimum der Summe der Residuen, die durch die AFD-Zerlegung des Kalibrationsdatensatzes erhalten werden.

Mit Hilfe einer Fehlerfunktion $f_{R M}\left(\tau_{1}, . ., \tau_{A}\right)$ wird durch ein Extremwertverfahren ein Satz $\left\{\tau_{1} . . \tau_{A}\right\}$ von Abklingzeiten bestimmt, der eine möglichst gute Beschreibung der Kalibrationsdaten erlaubt. Sind die $I$ zur Kalibration gedachten zeitaufgelösten Fluoreszenzspektren in $\mathbf{M}_{i} \in \mathbb{R}^{I \times K}$ enthalten, so lassen sich mit den Abklingzeiten $\tau_{a}$ entsprechend Gleichung (6.11) und (6.12) die Matrix $\mathbf{Z}$ und die Matrizen $\mathbf{S}_{i}$ bestimmen.

Die Fehlerfunktion wird dann durch

$$
f_{R M}\left(\tau_{1}, . ., \tau_{A}\right)=\sum_{i=1}^{I}\left\|\mathbf{S}_{i} \mathbf{Z}-\mathbf{M}_{i}\right\|
$$

berechnet. Zwar können abstrakte Spektren in der Regel nicht einzelnen Analyten zugeordnet werden, sie sind aber als Linearkombination der Basisspektren deutbar [176].

Sind die Abklingzeiten bestimmt, kann die weitere Kalibration und Analyse der Daten wie beim AFD durchgeführt werden. 


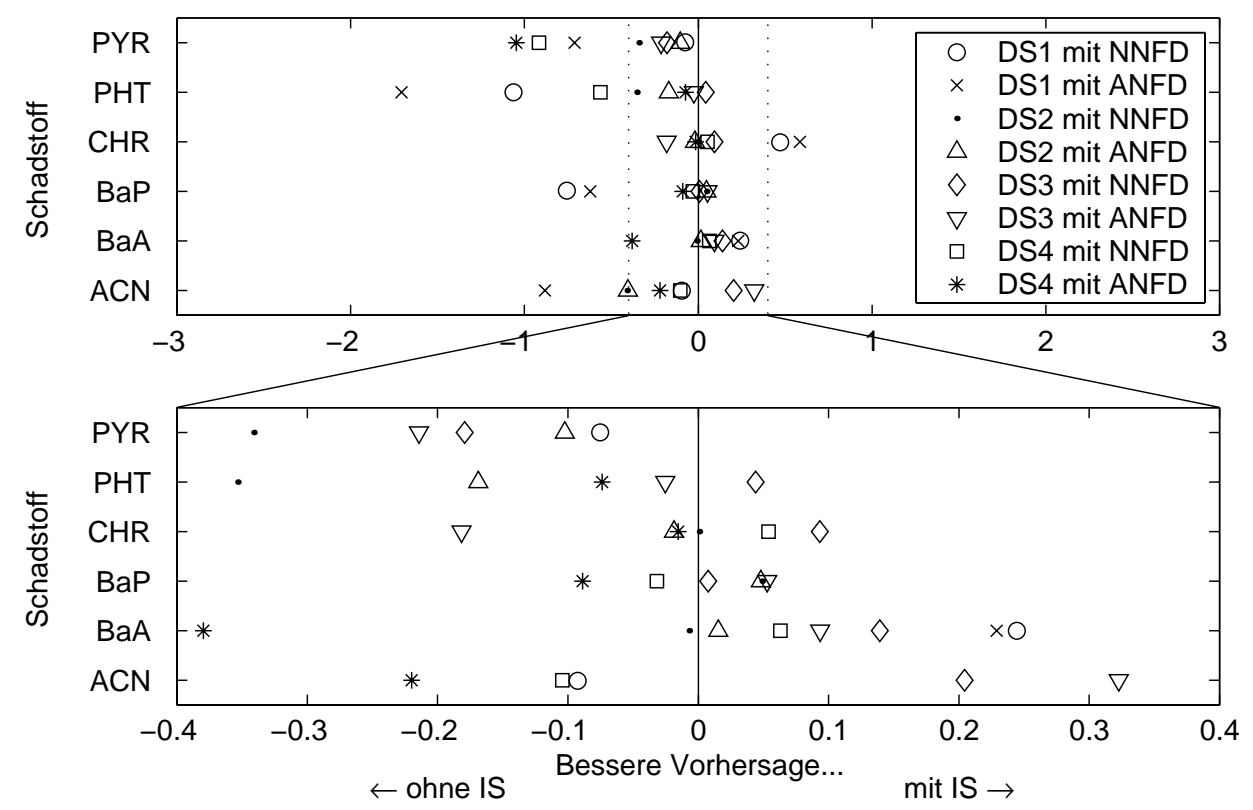

Abbildung 7.3: Vorhersagegenauigkeit der AFD-Analyse ohne und mit Aufnahme integraler Spektren (IS) in die Kalibrationsvektoren für sechs PAK in vier Datensätzen mit Realdaten.

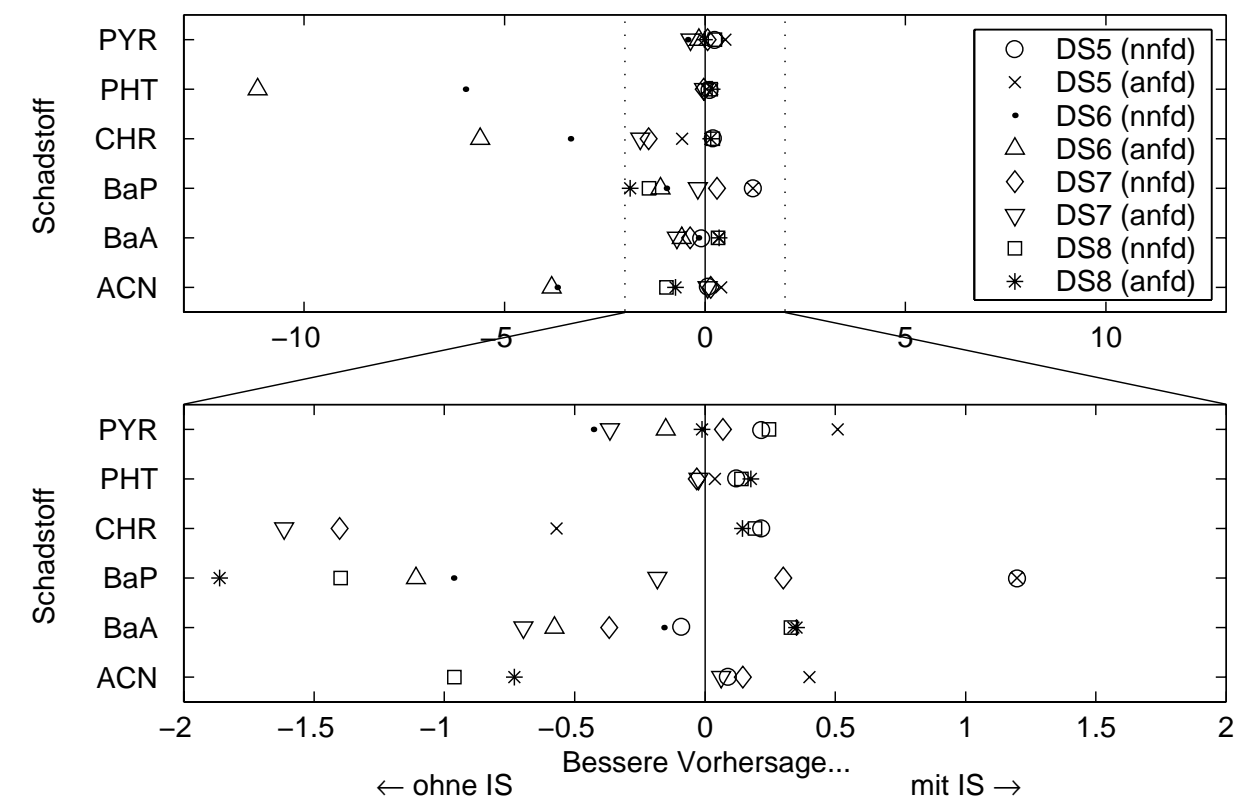

Abbildung 7.4: Vorhersagegenauigkeit der AFD-Analyse ohne und mit Aufnahme integraler Spektren (IS) in die Kalibrationsvektoren für sechs PAK in vier simulierten Datensätzen. 
Zur Minimierung der Fehlerfunktion wurde ein SimPLEX-Algorithmus eingesetzt. Um das Risiko zu minimieren, in einem lokalen Minimum zu landen, wurden 80 Startpunkte für den Simplex im Suchraum gewählt, unter anderem auch den Standardwert der FT-AFD. Interessanterweise führte jede der 80 Simplex-Rechnungen für jeden Datensatz zum gleichen Ergebnis (die Resultate sind in Tabelle (7.1) aufgeführt).

\section{Tabelle 7.1: Ergebnisse der RM-AFD}

Tauvektoren, die zur Minimierung der Residuenmatrix bei der abstrakten Faktorzerlegung führen, errechnet mit RM-AFD.

\begin{tabular}{|c|c|c|c|}
\hline Datensatz & $\begin{array}{c}\text { RM-Tauvektor } \\
\text { (in ns) }\end{array}$ & $\begin{array}{c}\text { Summe der } \\
\text { Residuen }\end{array}$ & $\begin{array}{c}\text { Summe der Residuen bei Ver- } \\
\text { wendung von } \tau=(7 ; 27 ; 125)\end{array}$ \\
\hline DS1 & $(15 ; 17 ; 20)$ & $1.47 \cdot 10^{5}$ & $1.80 \cdot 10^{5}$ \\
DS2 & $(5 ; 10 ; 20)$ & $1.13 \cdot 10^{5}$ & $1.42 \cdot 10^{5}$ \\
DS3 & $(9 ; 10 ; 20)$ & $1.25 \cdot 10^{5}$ & $1.50 \cdot 10^{5}$ \\
DS4 & $(5 ; 10 ; 20)$ & $2.28 \cdot 10^{5}$ & $3.03 \cdot 10^{5}$ \\
\hline
\end{tabular}

Obwohl die mit der RM-AFD gefundenen Tauvektoren zu einer deutlichen Minimierung der Residuen im Vergleich zur FT-AFD führen, sind die Abklingkonstanten physikalisch nicht nachvollziehbar. Der Vergleich beider Methoden (Abb. 7.5) zeigt dann auch die deutliche Überlegenheit der FT-AFD.

Der Grund für diese Unterlegenheit der RM-AFD wird deutlich, wenn die abstrakten Spektren betrachtet werden, die von der RM-AFD für die Kalibration verwendet werden. In Abbildung 7.6 sind die abstrakten Spektren des EPA-

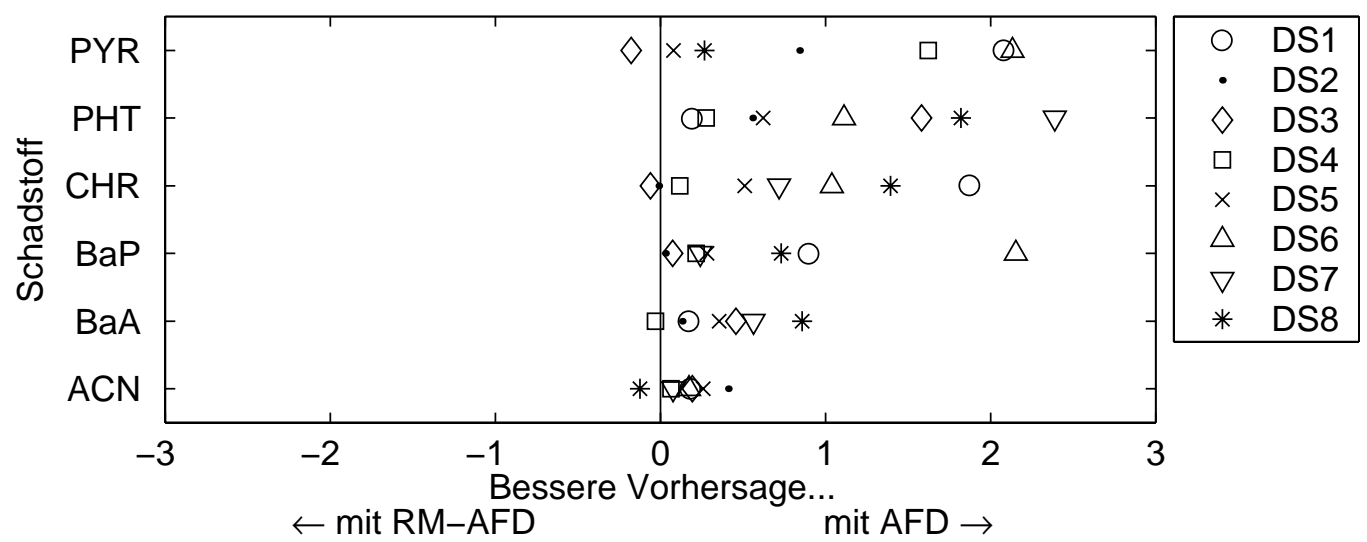

Abbildung 7.5: Vergleich der Vorhersagefehler der abstrakten Faktorzerlegung (AFD) und der Residuen-minimierenden abstrakten Faktorzerlegung (RM-AFD) (beide Methoden mit PLS-Kalibration). 
Standardgemisches ${ }^{5}$ für den Tauvektor der FT-AFD und die drei Tauvektoren der RM-AFD gezeigt. Die Problematik negativer abstrakter Spektren wurde bereits diskutiert (siehe Abschnitt (7.2.2)). Offensichtlich kommt diese Problematik der physikalisch nicht möglichen negativen Spektren hier massiv zum Tragen.

\section{Residuen-minimierende NNFD-Zerlegung}

Eine Möglichkeit, die RM-AFD zu verwenden ohne die Kalibration durch negative Spektren zu belasten, ist die Verwendung der NNFD-Zerlegung. Doch auch hier zeigt sich die Analyse mit NNFD-Zerlegung der FT-AFD unterlegen (Abb. 7.7).

\section{Gewichtete Residuen-minimierende Zerlegung (BRM-AFD)}

Eine weitere Möglichkeit, Tauvektoren durch Minimierung der Residuen zu erhalten, ohne die Kalibration durch negative Spektren zu belasten, ist die Einführung einer Straffunktion $p\left(\mathbf{S}_{i}\right)$ für negative Werte in den abstrakten Spektren ( $\mathrm{p}$ für penalty). Aus Gleichung (7.4) wird dann:

$$
f_{B R M}\left(\tau_{1}, . ., \tau_{A}\right)=\sum_{i=1}^{I}\left(\left\|\mathbf{S}_{i} \mathbf{Z}-\mathbf{M}_{i}\right\|+p\left(\mathbf{S}_{i}\right)\right) .
$$

Ist $\operatorname{sum}_{+}(\mathbf{S})$ die Summe der positiven Elemente von $\mathbf{S}$ und sum $-(\mathbf{S})$ entsprechend die Summe der negativen Elemente, so ist eine mögliche Straffunktion:

$$
p(\mathbf{S})=\left|\frac{b \operatorname{sum}_{-}(\mathbf{S})}{\operatorname{sum}_{+}(\mathbf{S})}\right|
$$

mit einer Wichtung (bias) $b \in \mathbb{R}$.

Versuche mit verschiedenen Werten für $b$ zeigen, daß die BRM-AFD bereits deutlich bessere Ergebnisse liefert als die RM-AFD, allerdings wird die Leistung der FT-AFD noch immer nicht erreicht (siehe Abb. 7.8).

\subsubsection{Vorhersagefehler-minimierende Zerlegung (PEM- AFD)}

Wieder wird der Tauvektor optimiert, hier allerdings in Hinblick auf den Vorhersagefehler der Analytkonzentrationen. Bei der PEM-AFD (PEM = prediction error minimizing) wird das Konzept „ein Tauvektor für alle Schadstoffe“ aufgegeben und für jeden Schadstoff ein eigener Tauvektor gesucht. Das Kriterium für die Qualität eines Tauvektors ist dabei die Vorhersagegenauigkeit einer AFD-PLS-Analyse mit diesem Tauvektor, berechnet nach Gleichung (7.1) für den Validationsteil des jeweiligen Datensatzes.

5 Alle 16 EPA-PAK in den Konzentration 10 ppb in destilliertem Wasser. 

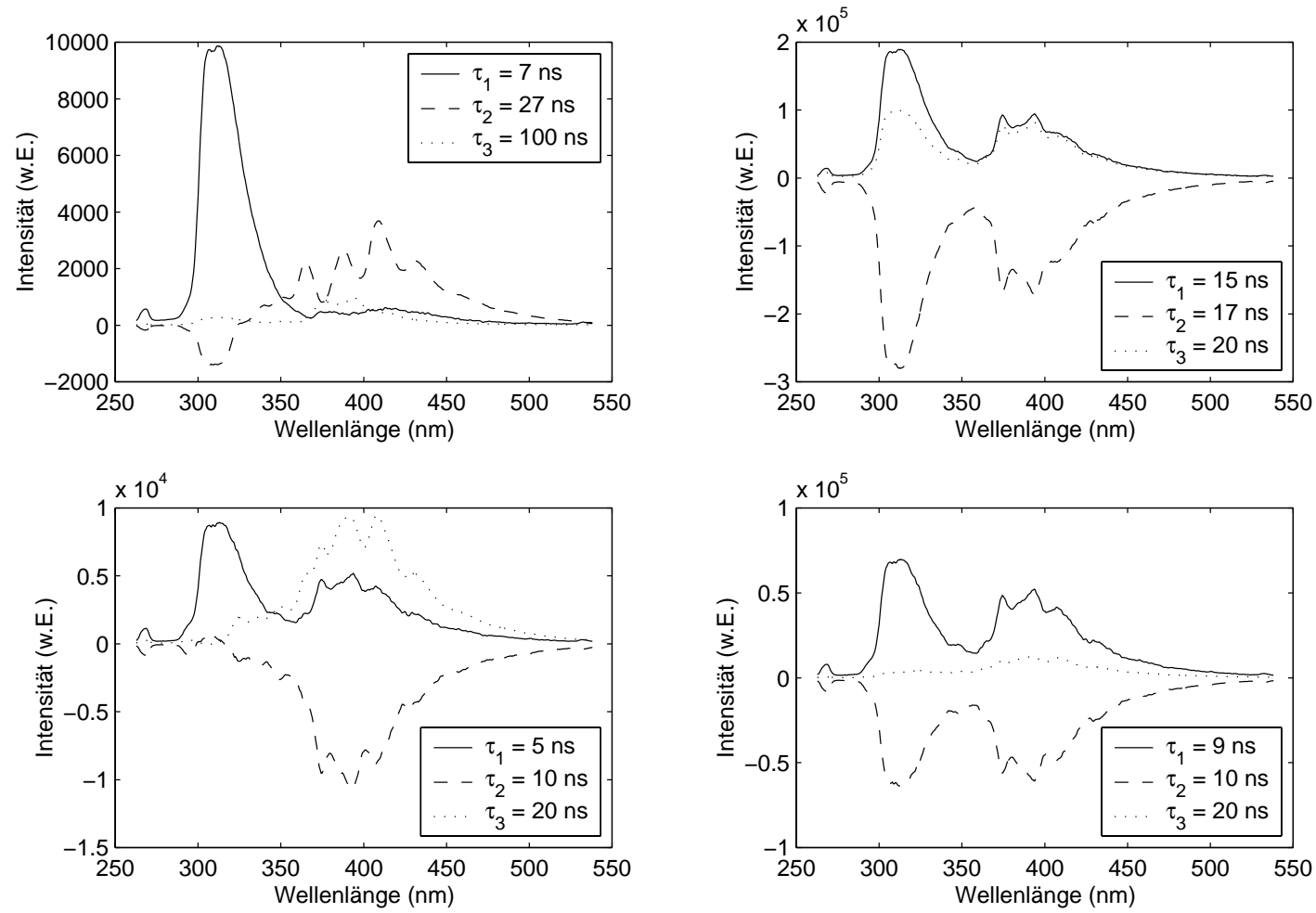

Abbildung 7.6: Die abstrakten Spektren des EPA-Standardgemisches (die $16 \mathrm{im} \mathrm{An-}$ hang aufgeführten „EPA-PAK“ mit den Konzentrationen $10 \mathrm{ppb}$ ) für die Zerlegung mit den FT- und den RM-AFD-Tauvektoren.

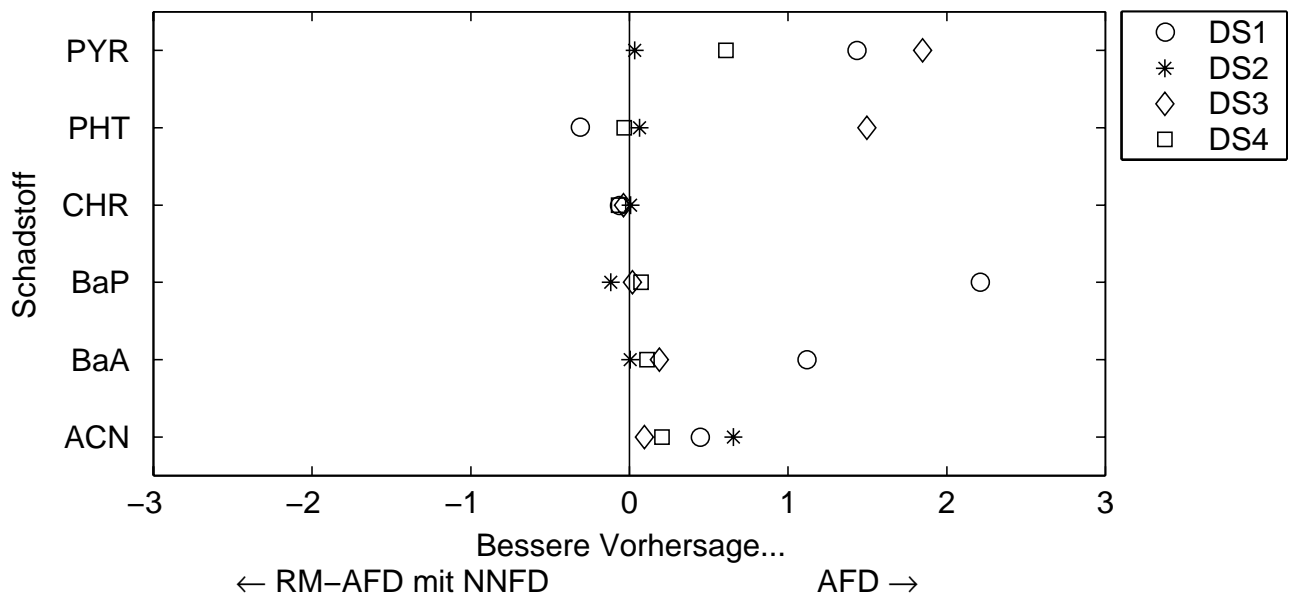

Abbildung 7.7: Vergleich der Vorhersagefehler der Residuen-minimierenden abstrakten Faktorzerlegung mit nicht-negativer Faktorzerlegung (RM-AFD mit NNFD) und der normalen abstrakten Faktorzerlegung (FT-AFD) (beide Methoden mit PLS-Kalibration). 

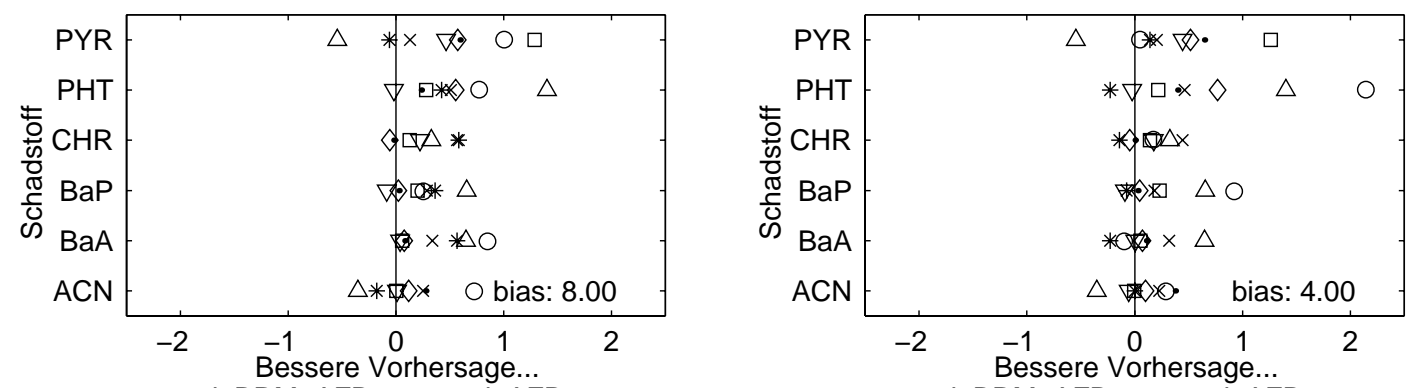

$\leftarrow$ mit BRM-AFD

mit AFD $\rightarrow$

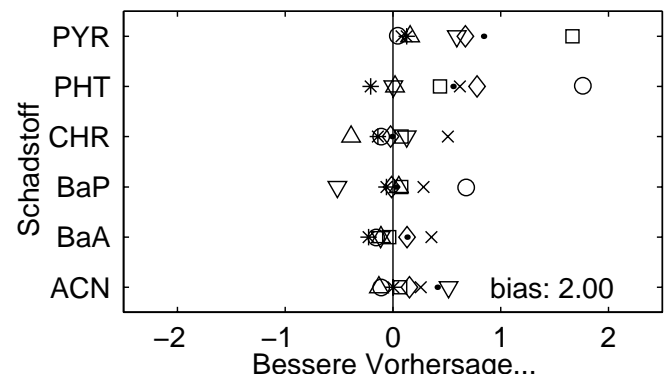

$\leftarrow$ mit BRM-AFD mit AFD $\rightarrow$

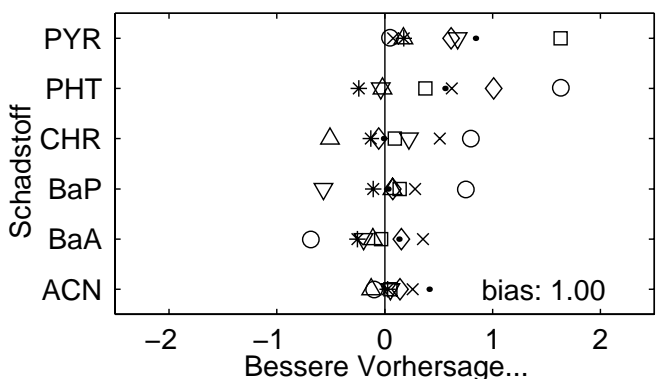

$\leftarrow$ mit BRM-AFD mit AFD $\rightarrow$
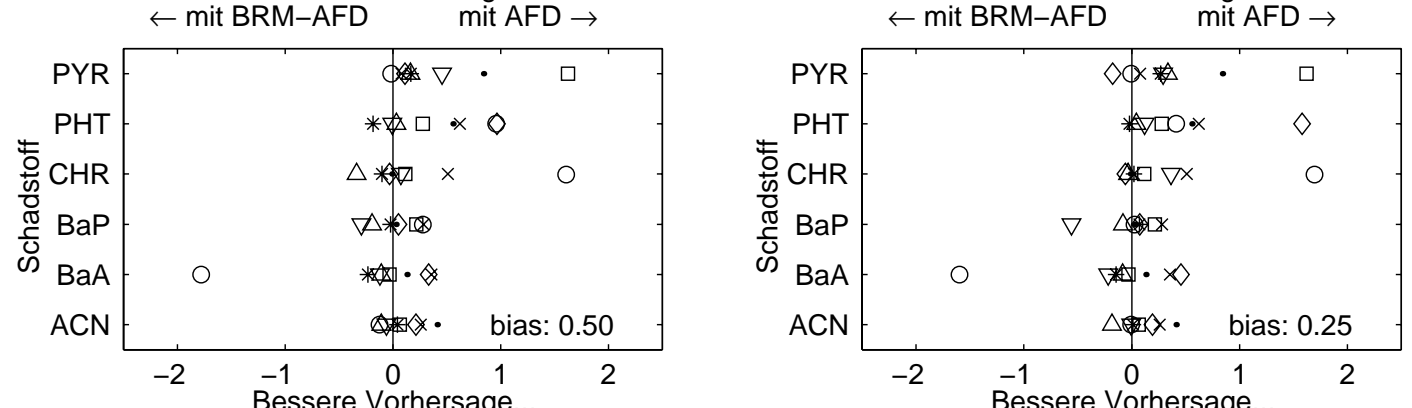

$\leftarrow$ mit BRM-AFD

mit AFD $\rightarrow$
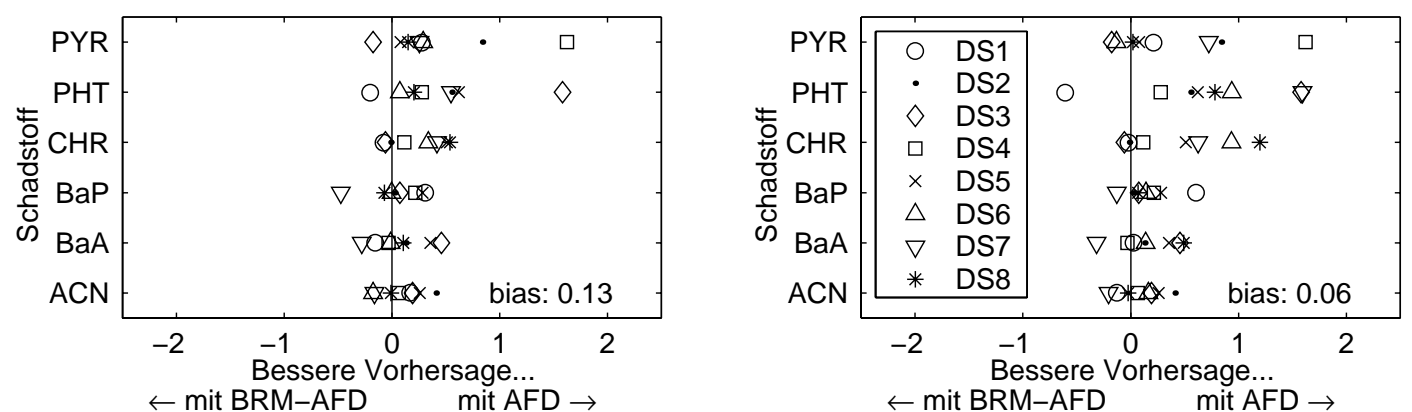

Abbildung 7.8: Vergleich der Vorhersagefehler der gewichteten Residuen-minimierenden abstrakten Faktorzerlegung (BRM-AFD) und der abstrakten Faktorzerlegung (AFD) für acht verschiedene Wichtungen (bias) zwischen 8.0 und 0.06 . Unterhalb von bias $=0.06$ geht die gewichtete Residuen-Minimierung in die ungewichtete über. 
Zur numerischen Durchführung wurde wieder ein lokaler Minimierer auf Basis des SimpleX-Algorithmus' mit verschiedenen Startpunkten eingesetzt. Da jeder Rechenschritt einen vollständigen Kalibrations-Validierungs-Zyklus erfordert, ist die PEM-AFD sehr rechenaufwendig. Eine Reihe von Techniken wurden angewendet, um die Berechnungen effektiver und schneller zu gestalten, u.a. problemspezifische Simplex-Schrittweiten und mehrere look-up tables auf verschiedenen Ebenen zur Vermeidung von Doppelrechnungen. Dennoch lag der Rechenaufwand zur Bestimmung eines Vorhersagefehler-minimierenden Tauvektors typischerweise in der Größenordnung von einigen Teraflops ${ }^{6}$ pro Datensatz.

\section{Tabelle 7.2: Tauvektoren der PEM-AFD}

Die aufgeführten Tauvektoren sind das Ergebnis der Minimierung der Vorhersagefehler bei der PEM-AFD mit $N_{\tau}=3$.

\begin{tabular}{|c|c||c|c|}
\hline Datensatz & $\begin{array}{c}\text { PEM-Tauvektor } \\
\text { (in ns) }\end{array}$ & Datensatz & $\begin{array}{c}\text { PEM-Tauvektor } \\
\text { (in ns) }\end{array}$ \\
\hline DS1 & $(10 ; 19 ; 80)$ & DS5 & $(10 ; 40 ; 103)$ \\
DS2 & $(4 ; 40 ; 150)$ & DS6 & $(10 ; 17 ; 150)$ \\
DS3 & $(10 ; 32 ; 72)$ & DS7 & $(4 ; 16 ; 72)$ \\
DS4 & $(3 ; 23 ; 70)$ & DS8 & $(7 ; 40 ; 150)$ \\
\hline
\end{tabular}

\section{Dimension des Tauvektors}

Neben $N_{\tau}=3$, dem Wert der FT-AFD, wurden auch andere Dimensionen des Tauvektors untersucht. Abbildung 7.9 zeigt die Summe der absoluten Vorhersagefehler für verschiedene Werte von $N_{\tau}$ im Kreuztest der Datensätze DS1 bis DS4.

Für jeden der Datensätze wurde im ersten Schritt (dem PEM-Schritt) der Tauvektor bestimmt, der den Vorhersagefehler dieses Datensatzes minimiert. Kalibriert wurde mit dem jeweiligen Kalibrationsteil und validiert entsprechend mit dem Validationsteil der Datensätze. Anschließend wurden die absoluten Vorhersagefehler aller vier Datensätze für jeden dieser vier Tauvektoren berechnet. Offensichtlich nimmt der Fehler für Werte $N_{\tau}>3$ deutlich zu, Aussagen über $N_{\tau} \leq 3$ lassen sich dagegen an Hand dieser Darstellung nicht treffen. Zu beachten ist, daß die Maximal- und die Durchschnittskonzentrationen der Datensätze verschieden sind, wodurch z. B. der Vorhersagefehler von DS3 innerhalb einer Rechnung immer deutlich unter dem von DS4 liegt.

Für eine genauere Betrachtung wurde wieder der relative Vorhersagefehler nach Gleichung (7.2) bestimmt und in Abbildung 7.10 paarweise dargestellt. Auch hier ist die deutliche Unterlegenheit für Werte $N_{\tau}>3$ klar zu erkennen. Während sich

$6 \quad$ Flop $=$ floating point operation. Die verwendeten Rechner hatten Rechenleistungen zwischen 15 und 30 Megaflops pro Sekunde, ein Teraflop entsprach also einer Rechenzeit von 10 bis 20 Stunden pro Computer. 

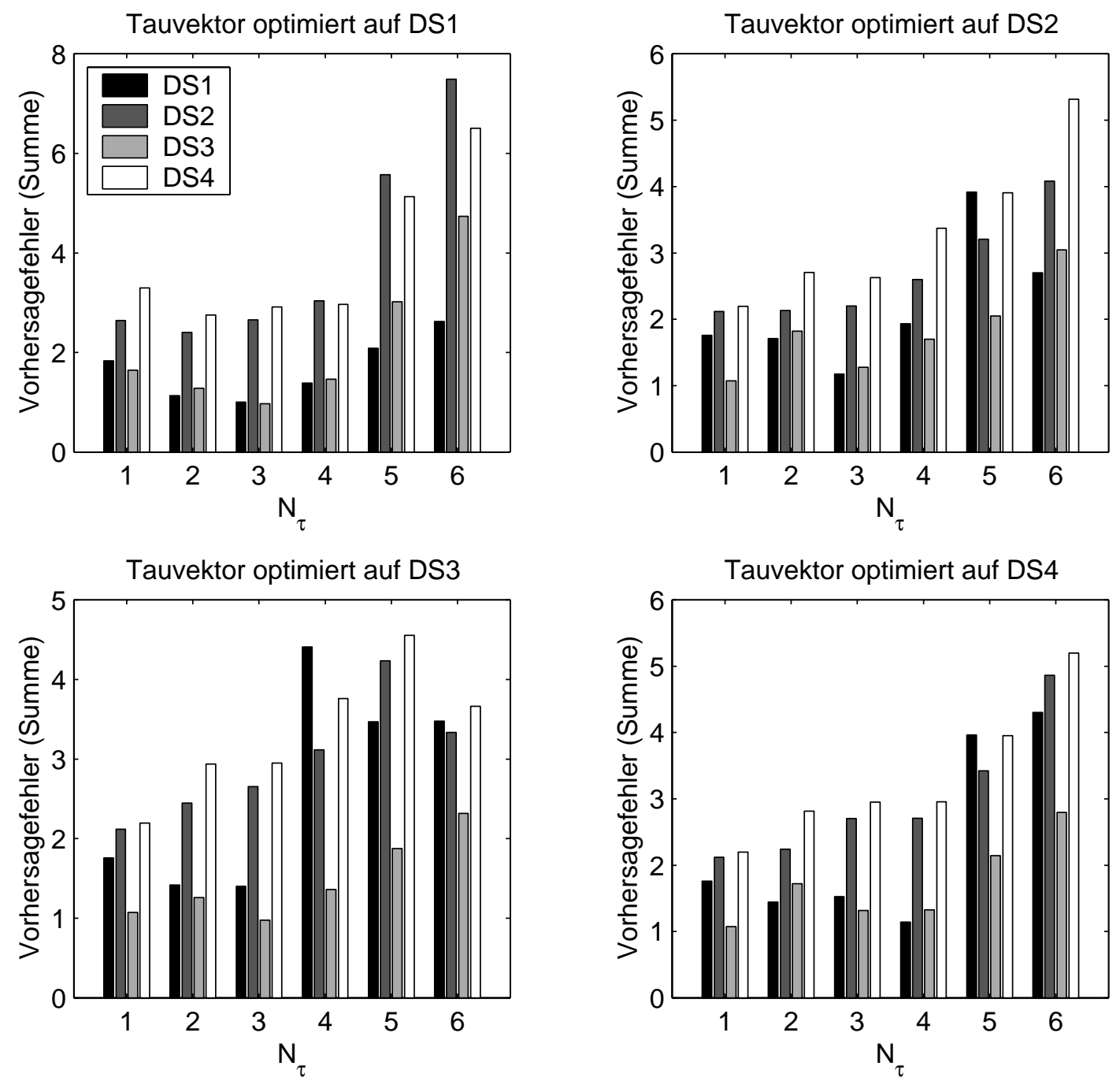

Abbildung 7.9: Summe der Vorhersagefehler der AFD-Analyse für die Schadstoffe ACN, BaA, BaP, CHR, PHT und PYR in Abhängigkeit der Anzahl der $\tau$ 's für DS1 bis DS4 für die vier verschiedenen $\tau$ 's, die mit Hilfe der PEM-AFD-Optimierung gefunden wurden (Kreuztest).

die Vorhersagefehler für $N_{\tau}=2$ und $N_{\tau}=3$ offensichtlich kaum unterscheiden, ist eine Tendenz für die Unterlegenheit von $N_{\tau}=1$ sichtbar.

\section{Vergleich von PEM-AFD und FT-AFD}

Zum Vergleich der PEM-AFD mit der FT-AFD wurden die Ergebnisse der PEMAFD mit $N_{\tau}=3$ verwendet. Da einer der Startpunkte des Optimierers bei der Minimierung des Vorhersagefehlers der Standardtauvektor der FT-AFD war, er- 

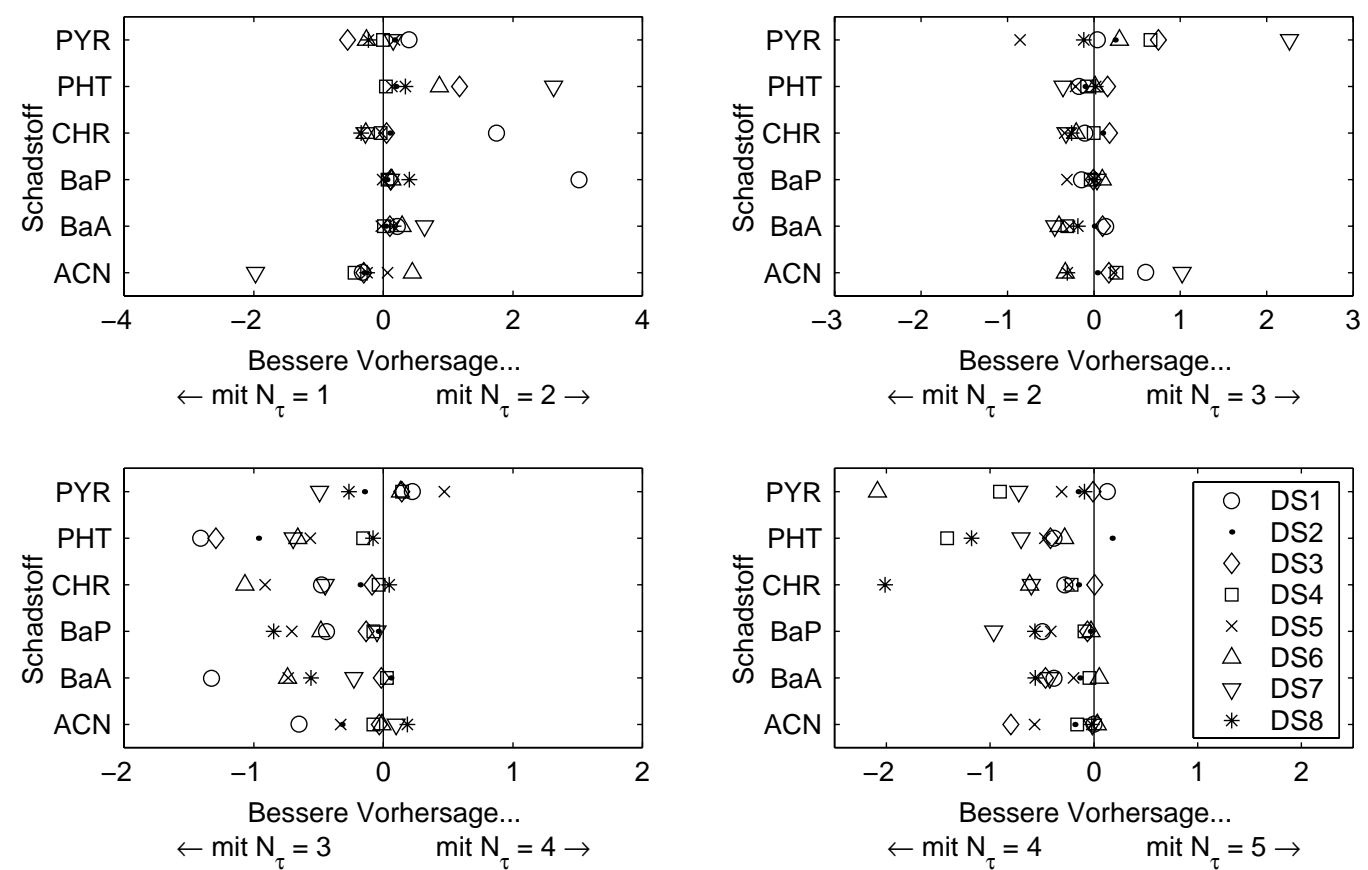

Abbildung 7.10: Vorhersagegenauigkeit der PEM-AFD in Abhängigkeit der Dimension des Tauvektors.

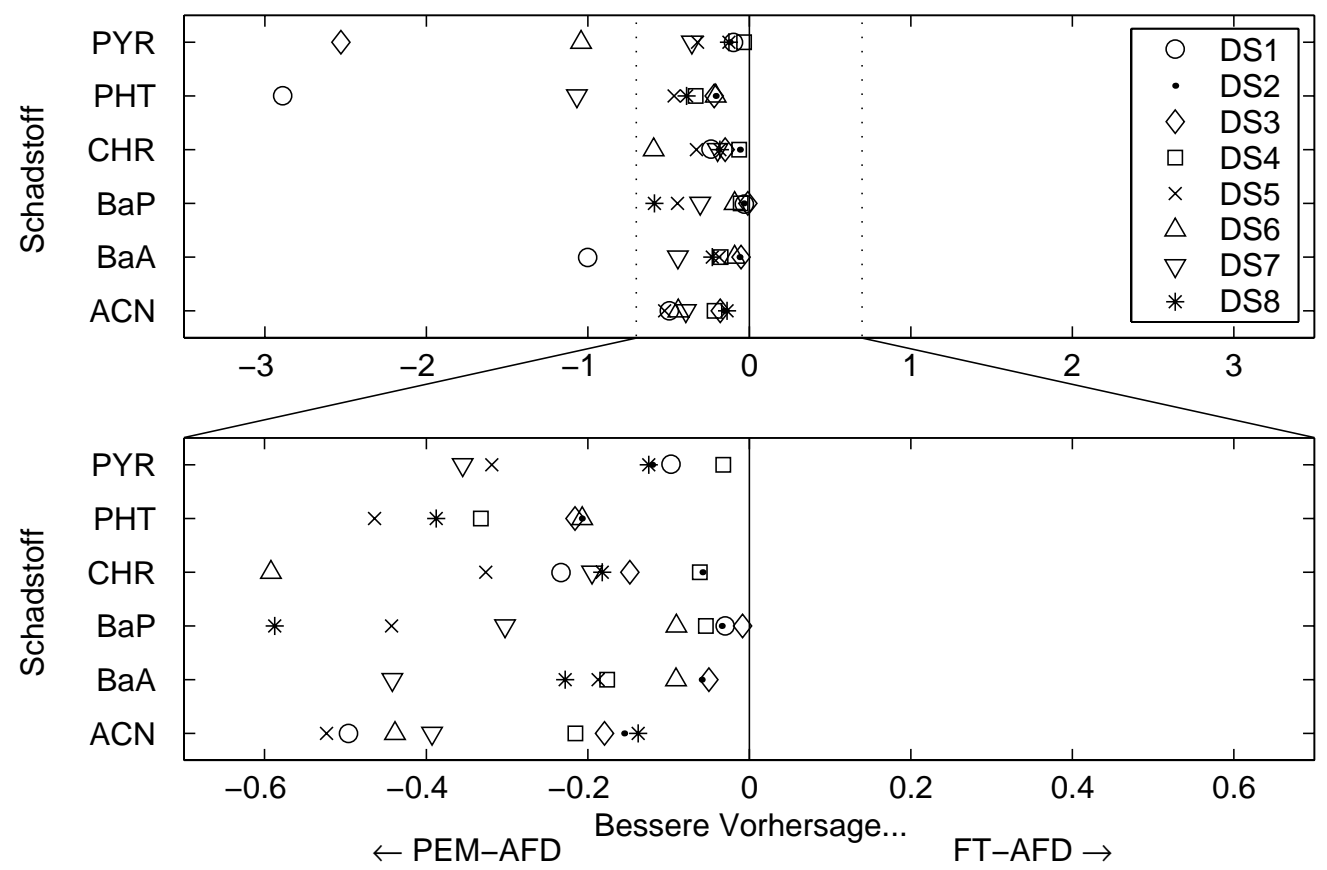

Abbildung 7.11: Vergleich der Vorhersagegenauigkeit von PEM-AFD und FT-AFDAnalyse (beide: $N_{\tau}=3$ ) für die realen Spektren, wobei für jeden Datensatz die für diesen Datensatz optimierten $\tau$ 's verwendet wurden (datensatzinterner Test). 
zielt die PEM-AFD beim datensatzinternen Test für jeden Vergleich mindestens genau so gute Ergebnisse wie die FT-AFD (Abb. 7.11). Der eigentliche „Härtetest" ist der Kreuztest, bei dem die mit der PEM-AFD für einen Datensatz gewonnen Tauvektoren für die Vorhersage der Konzentrationen in anderen Datensätzen verwendet werden. Die Abbildungen (7.12) und (7.13) zeigen dies für die realen Datensätze DS1-4 und die pseudo-realen Daten DS5-8 getrennt. Tatsächlich zeigt sich die PEM-AFD der FT-AFD leicht überlegen. Die zugehörigen Tauvektoren sind in Tabelle (7.2) zu finden.

\subsubsection{Wählerische abstrakte Faktorzerlegung (C-AFD)}

Bei der C (choosy)-AFD werden nicht mehr alle Daten der abstrakten Zerlegung für Kalibration und Validation verwendet, sondern nur eines der abstrakten Spektren.

Die Schadstoffe werden entsprechend ihrer Abklingzeit in $N_{\tau}$ verschiedene Gruppen aufgeteilt. Ein Beispiel: Bei einer Aufteilung in "schnell“ $(<15 \mathrm{~ns})$, „mittel" (15-40 ns) und „langsam“ (> $40 \mathrm{ns)} \mathrm{teilen} \mathrm{sich} \mathrm{die} \mathrm{hier} \mathrm{nachweisbaren} \mathrm{EPA-PAK} \mathrm{in}$ folgende Gruppen:

- „schnell": ANT, BkF und FLU;

- „mittel“: ACE, BaA, BbF, BgP, BaP, CHR, DBA, FLA, NAP und PHT;

- „langsam“: PYR.

Nach der abstrakten Zerlegung mit den der Gruppen entsprechenden Abklingzeiten wird für jede Gruppe ein Kalibrationsmodell erstellt. In dem Beispiel verwendet das erste Modell nur die zur „schnellen“ Abklingzeit gehörenden abstrakten Spektren und Schadstoffe, das zweite und dritte entsprechend die „mittleren“ und die „langsamen“. Jedes Modell wird nur zur Vorhersage der zugehörigen Analyten verwendet. Die Wahl des Tauvektors ist zwar wie bei der FT-AFD ein manueller Vorgang, erfordert aber abgesehen von der groben Klassifizierung der Analyten entsprechend ihrer Abklingzeiten keine aufwendigen Untersuchungen oder problemspezifisches Wissen. Eine Automatisierung dieser Klassifizierung wäre mit Hilfe der Clusteranalyse durchführbar (siehe z. B. [177, 178, 179]).

Wie schon bei der PEM-AFD wurden verschiedene Werte für $N_{\tau}$ untersucht. In den Datensätzen befinden sich auch Spektren von Substanzen mit Abklingzeiten, die sich in Gruppen um 5 ns und um 10 ns zuordnen lassen. Obwohl bei diesen Experimenten keine Kalibration auf diese Substanzen durchgeführt wurde, ist es denkbar, daß eine Zerlegung in diese Gruppen zu einer besseren Trennung der einzelnen Spektren führt. Folgende Gruppen wurden gebildet: 


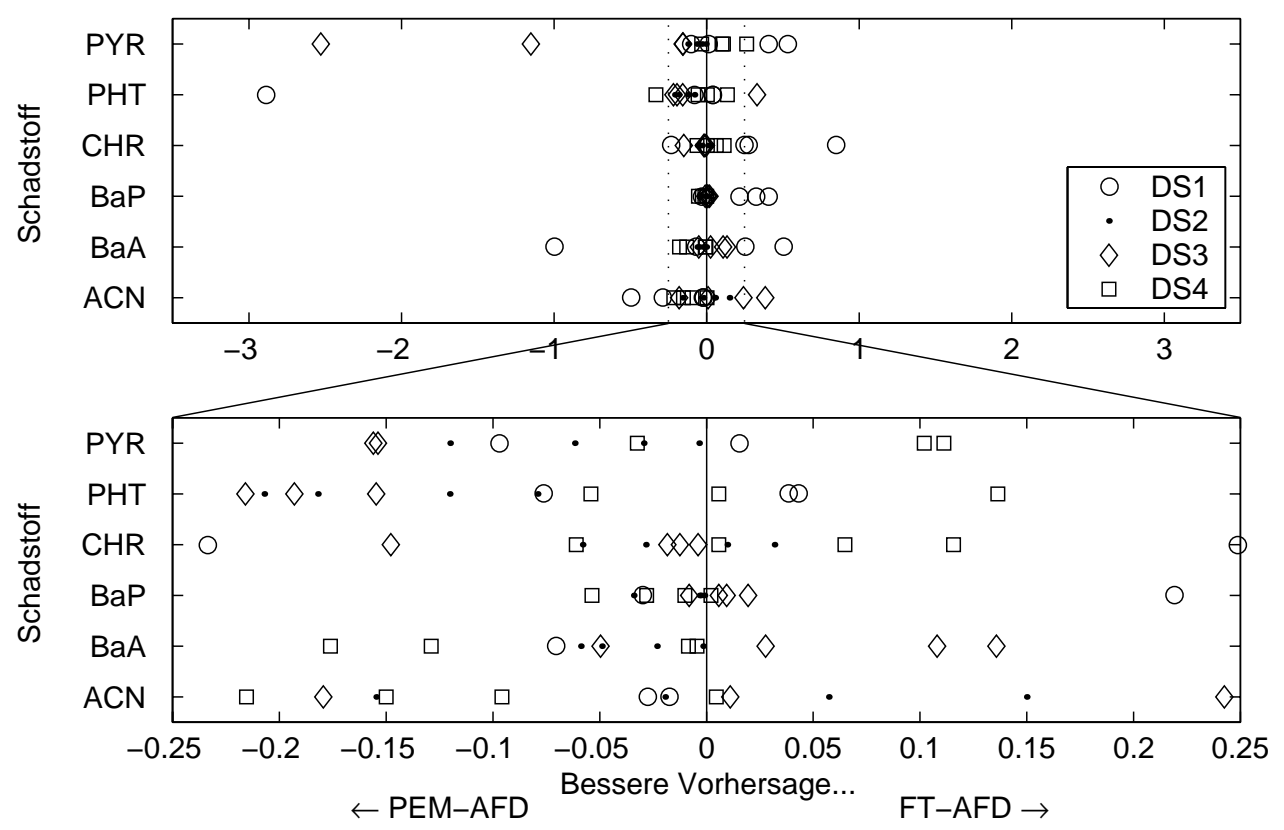

Abbildung 7.12: Vergleich der Vorhersagegenauigkeit von PEM-AFD und FT-AFDAnalyse für die realen Spektren mit Hilfe des Kreuztestes: Jeder Datensatz wurde mit jedem Tauvektor bearbeitet.

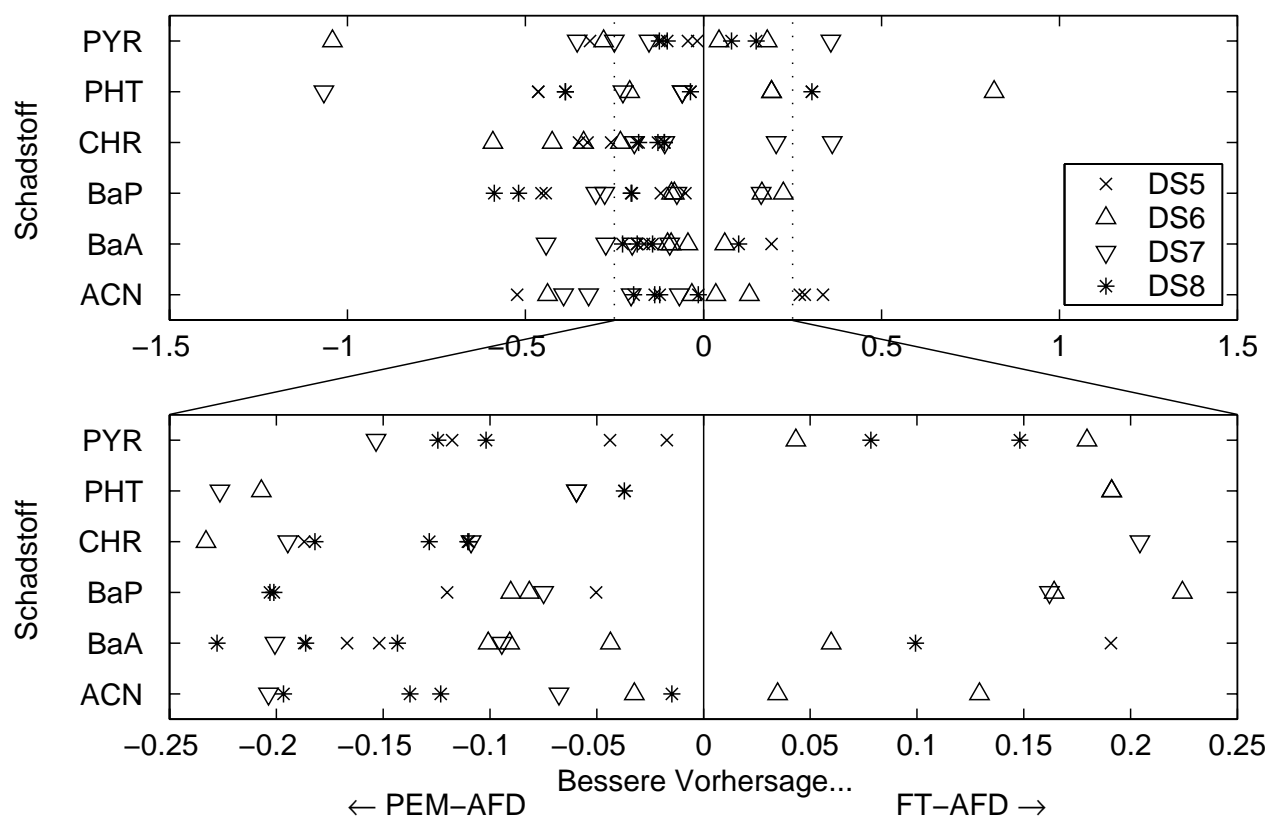

Abbildung 7.13: Vergleich der Vorhersagegenauigkeit von PEM-AFD und FT-AFDAnalyse für die pseudo-realen Spektren mit dem Kreuztest. 


\begin{tabular}{l|l|l}
$N_{\tau}$ & Tauvektor (in ns) & Gruppen \\
\hline 1 & $(80)$ & eine Gruppe mit allen Substanzen \\
2 & $(27 ; 125)$ & $1:$ alle bis auf PYR / 2: PYR \\
3 & $(7 ; 27 ; 125)$ & $1:-/ 2:$ alle bis auf PYR / 3: PYR \\
4 & $(5 ; 27 ; 37 ; 125)$ & $1:-/ 2:$ ACN,BaA,BaP,CHR / 3: PHT / 4: PYR \\
5 & $(5 ; 10 ; 27 ; 37 ; 125)$ & $1:-/ 2:-/ 3:$ ACN,BaA,BaP,CHR / 4: PHT /5: PYR
\end{tabular}

Die vergleichende Darstellung der Vorhersagefehler dieser Einteilungen ist in Abbildung 7.14 zu sehen. Ganz deutlich ist die Einteilung in zwei Gruppen der Einteilung mit $N_{\tau}=3$ überlegen. Erstaunlich gut ist auch der Vorhersagefehler für $N_{\tau}=1$ für die Analyten ACN und PHT.

Abbildung 7.15 zeigt den Vergleich der C-AFD $\left(N_{\tau}=2\right)$ mit der FT-AFD. Interessant ist, daß die Vorhersage der Stoffe in der ersten Gruppe (alle bis auf Pyren) mit der C-AFD durchweg besser als mit der FT-AFD ist während die Vorhersage von Pyren schlechter ist. Offensichtlich enthält auch die erste Gruppe noch wichtige Kalibrationsinformationen über Pyren, die von der FT-AFD genutzt werden können. Das könnte auch das schlechte Abschneiden der C-AFD mit $N_{\tau}=3$ erklären, bei der die Information der ersten Gruppe für keinen der untersuchten Stoffe mit in die Kalibration einfließt.
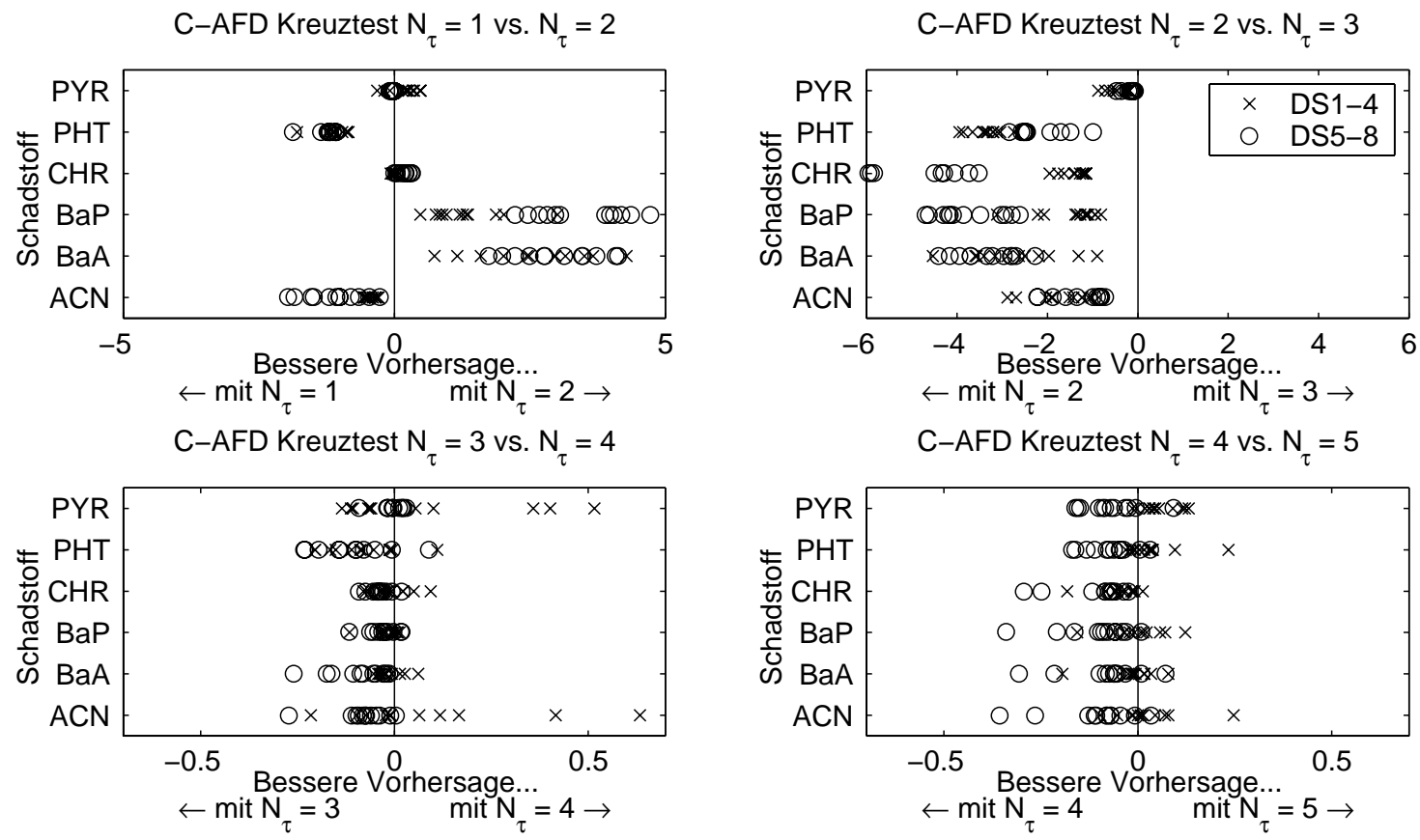

Abbildung 7.14: Vergleich der Vorhersagefehler der „wählerischen“ AFD-Analyse (CAFD) für die Schadstoffe ACN, BaA, BaP, CHR, PHT und PYR in den Datensätzen DS1 bis DS8 für unterschiedliche Dimensionen des Tauvektors. 


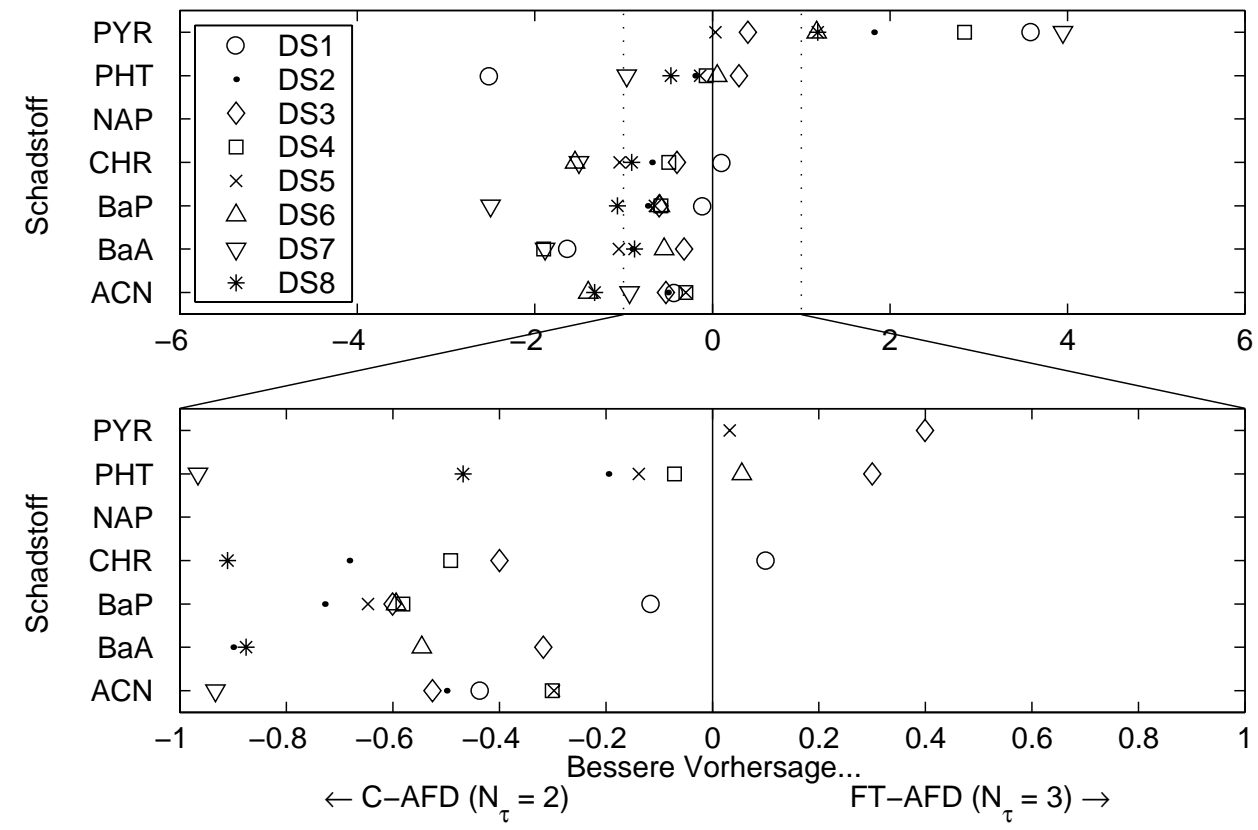

Abbildung 7.15: Vergleich der Vorhersagefehler der „wählerischen“ AFD-Analyse (CAFD) mit der FT-AFD.

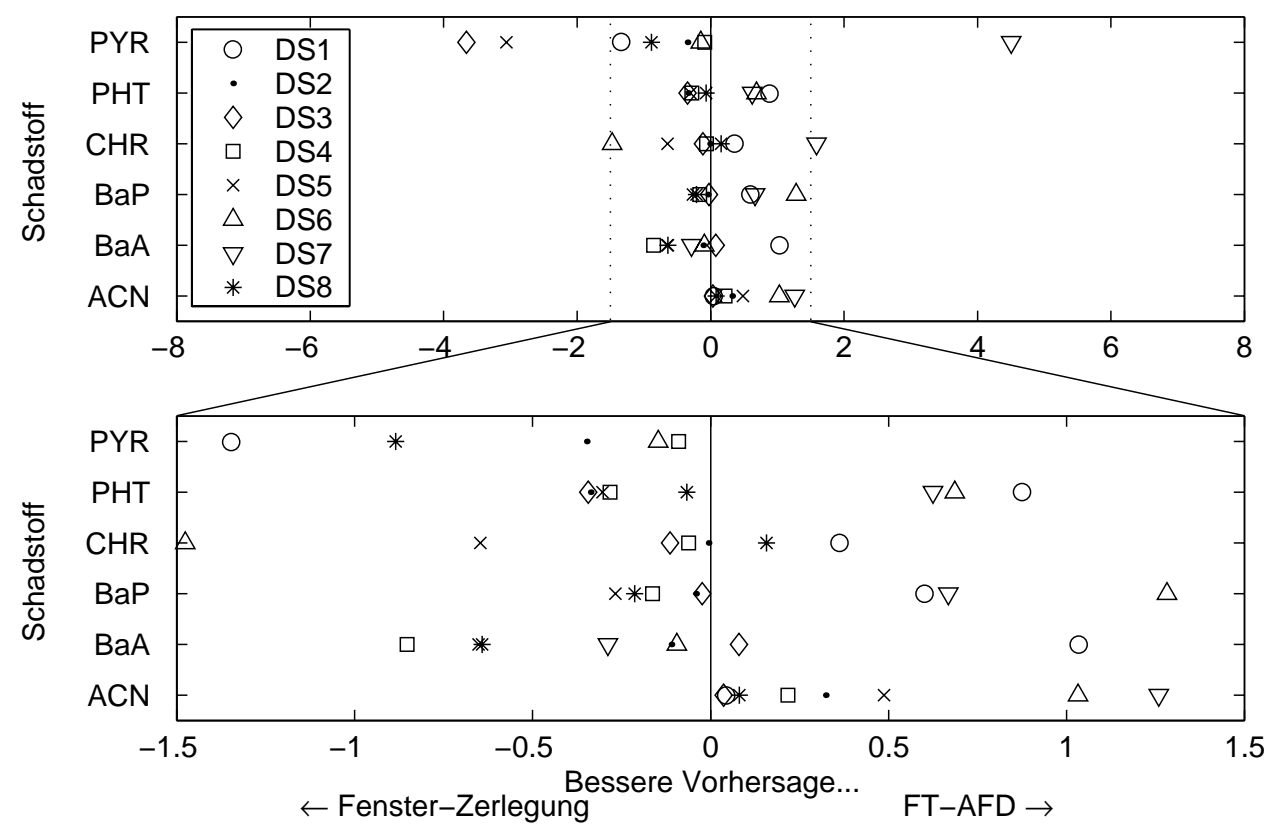

Abbildung 7.16: Vergleich der Vorhersagegenauigkeit von Fensterzerlegung (2 Fenster) und normaler AFD-Analyse. 


\subsubsection{Alternative zur AFD: Fensterzerlegung}

Im ersten Schritt wurden für 1 bis 6 Fenster Optimierungen durchgeführt. Die Fensterbreiten wurden variabel, aber für alle Fenster gleich gewählt. Die einzelnen Fenster wurden zwischen dem jeweils früheren und dem späteren Fenster frei verschoben, eine Überlagerung einzelner Fenster wurde ausgeschlossen.

Während die Zerlegung mit einem Fenster der Zerlegung mit zwei Fenstern unterlegen ist, ändert sich interessanterweise die Vorhersagegenauigkeit für mehr als zwei Zeitfenster bei den untersuchten Analyten nicht mehr wesentlich, im Gegensatz zur AFD, bei der die Zerlegung mit zunehmendem $N_{\tau}$ nach einem Optimum deutlich schlechter wird. Folgende Zerlegung mit zwei und drei Fenstern ergaben die besten Kalibrationen:

\begin{tabular}{c|l} 
Anzahl der Fenster & Fensterposition (in ns) \\
\hline 2 & $0-20 / 25-150$ \\
3 & $0-15 / 20-35 / 40-150$
\end{tabular}

Für diese beiden Zerlegungen wurden Vergleiche mit der FT-AFD berechnet (siehe Abbildungen (7.16) und (7.17)). Die Fensterzerlegung zeigt sich der FTAFD demnach als etwa gleichwertig. Im Vergleich zur C-AFD (Abb. 7.18), die sich der FT-AFD ja bereits überlegen gezeigt hat, schneidet die Fensterzerlegung signifikant schlechter ab.

\subsection{Untersuchungen zur Kalibration}

Im folgenden werden drei Regressionsmethoden untersucht, eine Koeffizientenmatrix B für eine Kalibration entsprechend Gleichung (6.14) zu bestimmen, die ausführlich in Abschnitt (6.3) vorgestellt wurden: Die ordinary least squares regression (OLS), die principal component regression (PCR) und die partial least square regression (PLS).

Während bei dem OLS-Verfahren unkorrelierte Eingangsdaten erforderlich sind, führen die faktoriellen Methoden PCR und PLS eine „Rangreduktion" der Quelldaten durch. Korrelationen werden aufgedeckt und beseitigt. Aus diesem Grund ist bei Vorliegen von Multikollinearität die OLS den Verfahren PCR und PLS meist deutlich unterlegen (z.B. [180]).

Die Anzahl $K$ der Faktoren wurde bei der PCR und der PLS durch Minimierung des Vorhersagefehlers der Validationsteile der Datensätze bestimmt und lag bei Festlegung eines Wertes für $K$ je nach Datensatz zwischen 10 und 20.

Abbildung 7.19 zeigt den Vergleich von OLS und PCR, wobei für beide Methoden natürlich die gleiche Matrixzerlegung (FT-AFD) verwendet wurde. Da die einzelnen Kanäle der PAK-Spektren stark korreliert sind, ist das bessere Abschneiden der PCR gegenüber der OLS nicht erstaunlich. Das gleiche gilt für den Vergleich von OLS und PLS (Abb. 7.20), der auf die gleiche Weise durchgeführt wurde. 


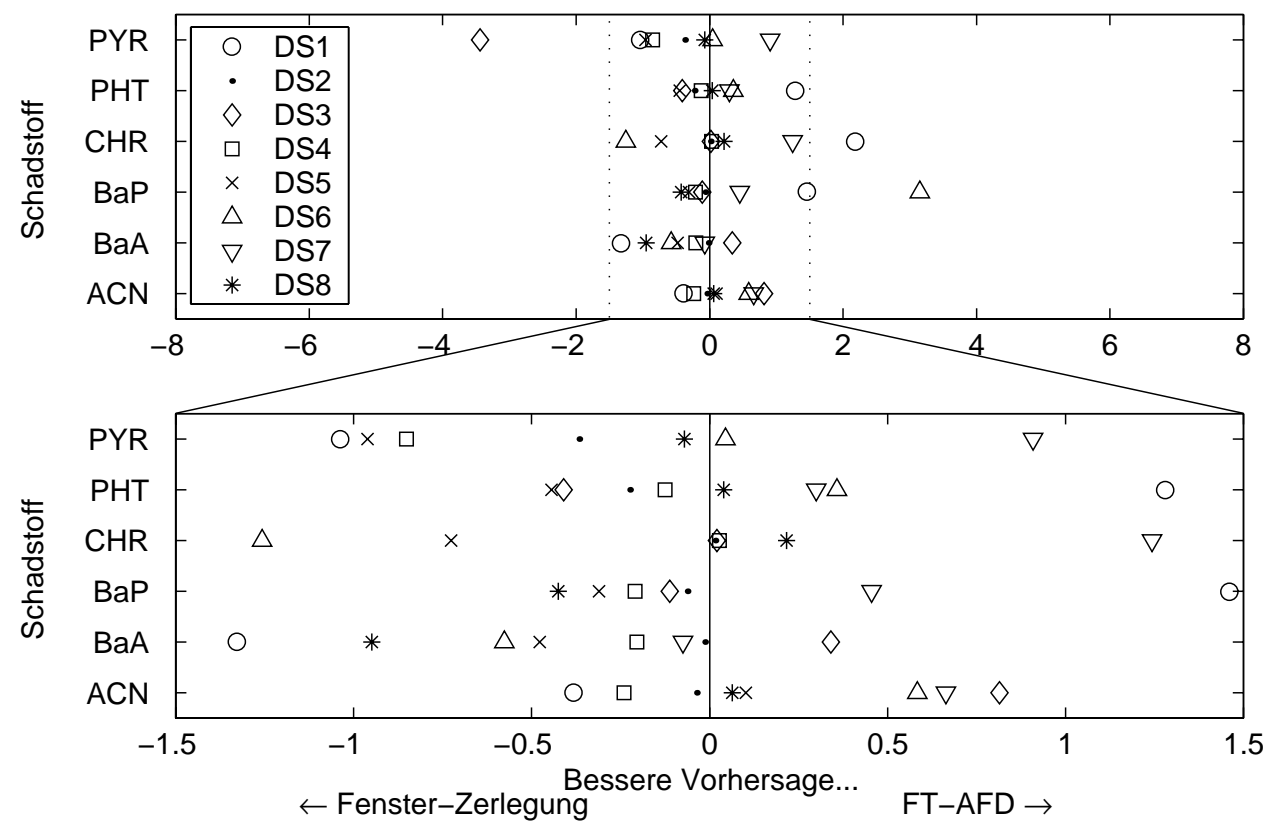

Abbildung 7.17: Vergleich der Vorhersagegenauigkeit von Fensterzerlegung (3 Fenster) und normaler AFD-Analyse.

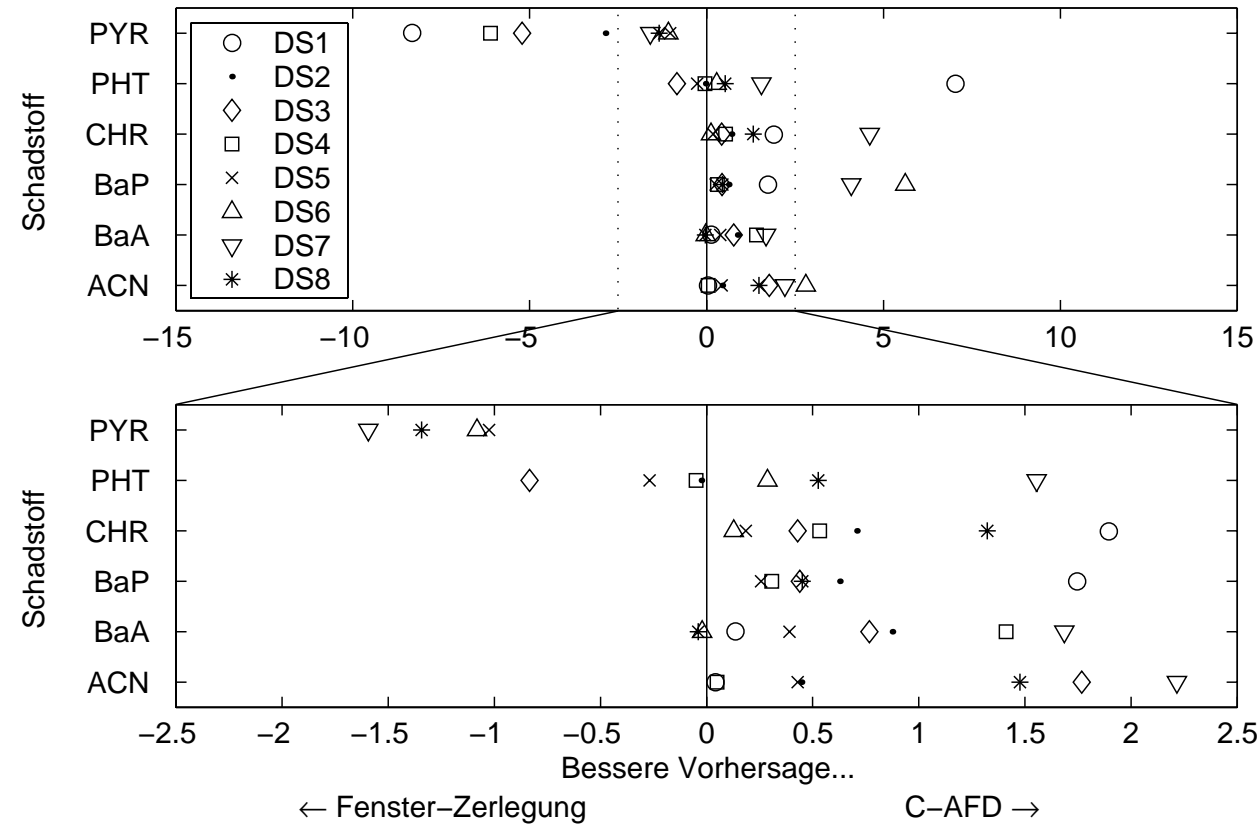

Abbildung 7.18: Vergleich der Vorhersagefehler von Fensterzerlegung (3 Fenster) und C-AFD. 


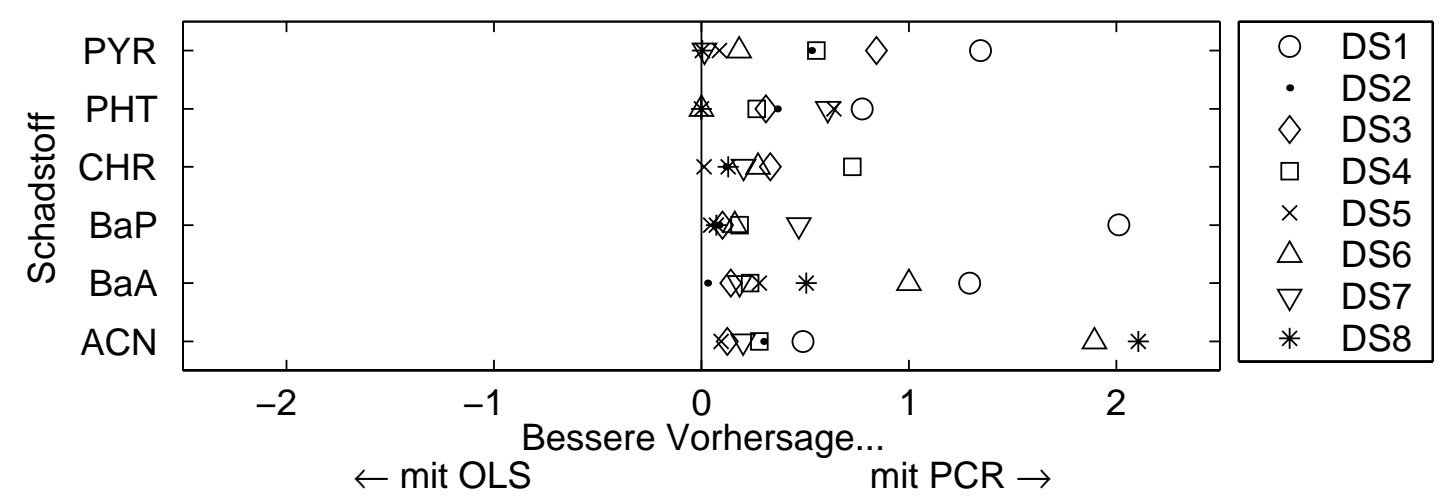

Abbildung 7.19: Vorhersagegenauigkeit der AFD-Analyse mit den Kalibrationen ordenary least squares regression (OLS) und principal component regression (PCR).

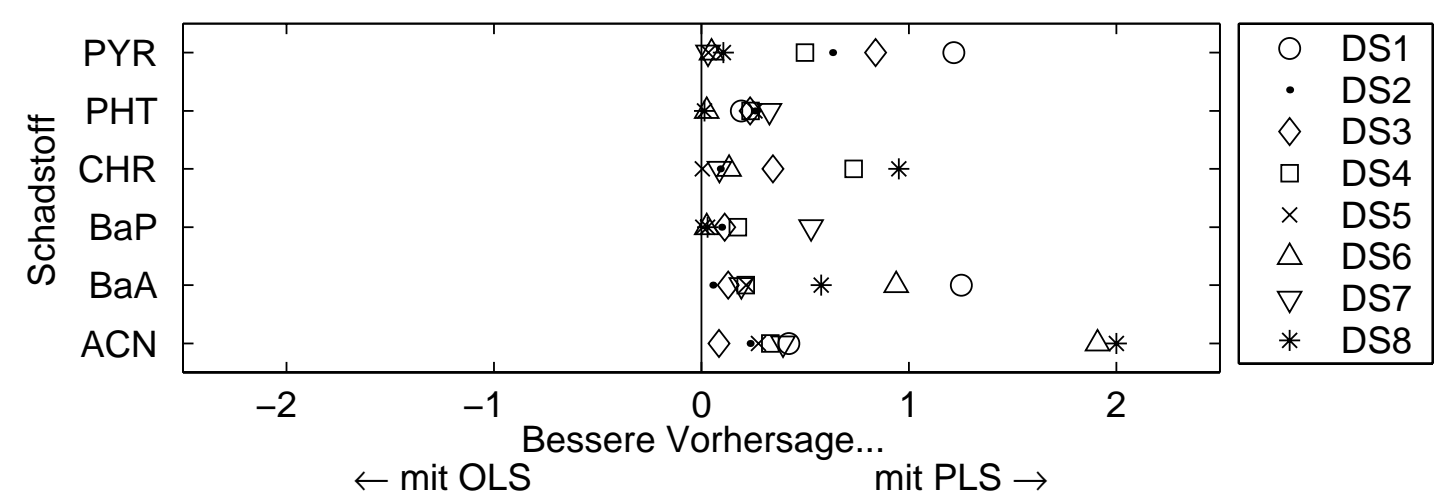

Abbildung 7.20: Vorhersagegenauigkeit der AFD-Analyse mit den Kalibrationen ordenary least squares regression (OLS) und partial least squares regression (PLS).

Für den Vergleich von PCR und PLS wurde die Anzahl der Faktorenwerte für beide Methoden auf $K=15$ festgesetzt, dem Wert, bei dem die Summe der Vorhersagefehler beider Methoden zusammengenommen ein Minimum erreicht. Abbildung 7.21 zeigt das Ergebnis der Rechnungen. PLS zeigt eine leichte Überlegenheit gegenüber PCR. Die Unterschiede in den Vorhersagen mit den drei Methoden ist am Beispiel Chrysen aus dem Validationsteil von DS2 gezeigt (Abb. 7.22).

Zur experimentellen Überprüfung der Behauptung, daß OLS, PCR und PLS bei maximaler Anzahl von Faktoren ineinander übergehen (und als zusätzlicher Integritätstest der Programme), wurden die PCR und die PLS mit der Faktorenzahl $=K$ (Anzahl der Kanäle) durchgeführt und mit der OLS verglichen. Wie erwartet entstanden Vorhersagemodelle, die für alle Daten die gleichen Vorhersagen lieferten. 


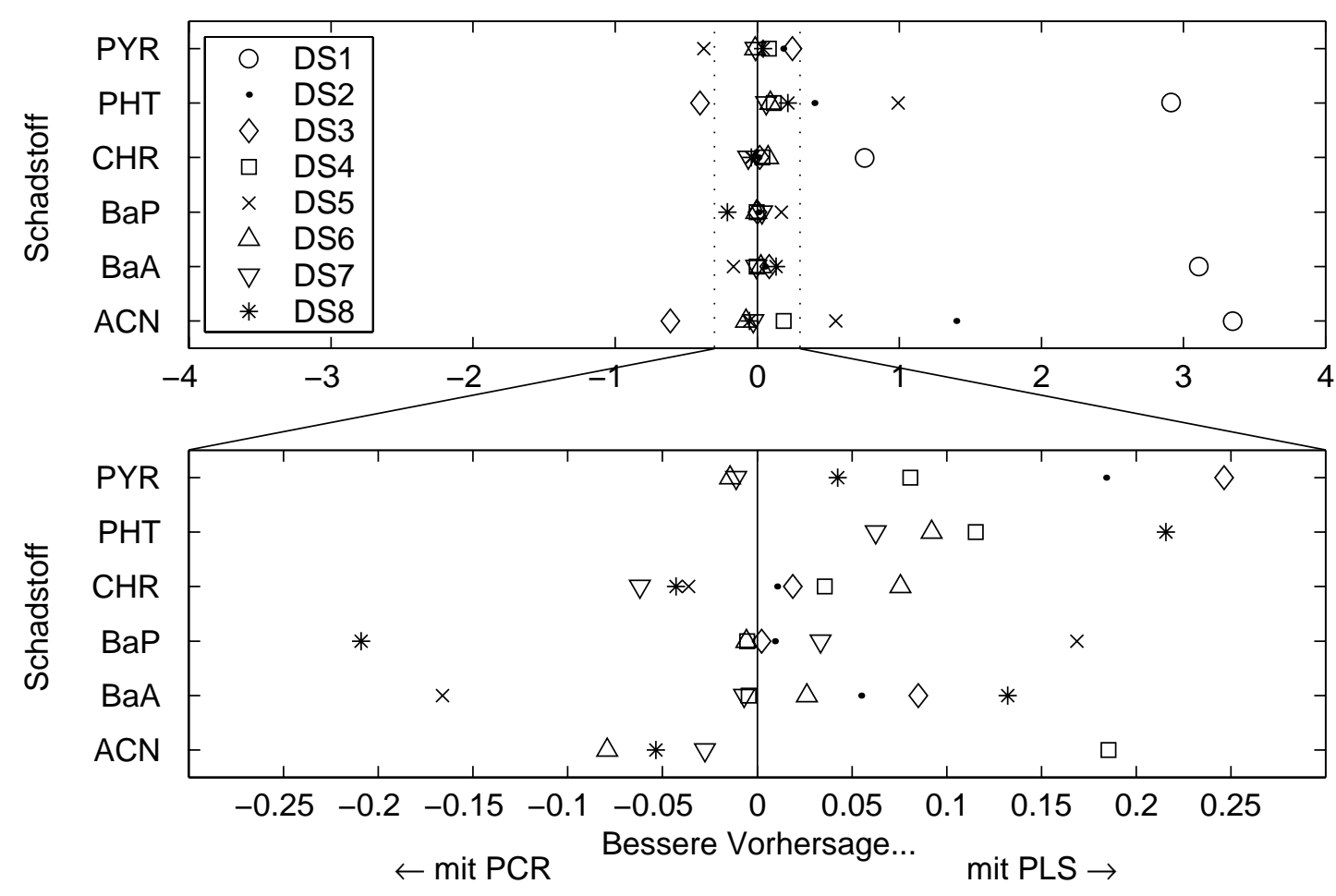

Abbildung 7.21: Vorhersagegenauigkeit der AFD-Analyse mit den Kalibrationen principal component regression (PCR) und partial least squares regression (PLS) (beide mit Faktorenzahl $=15)$.
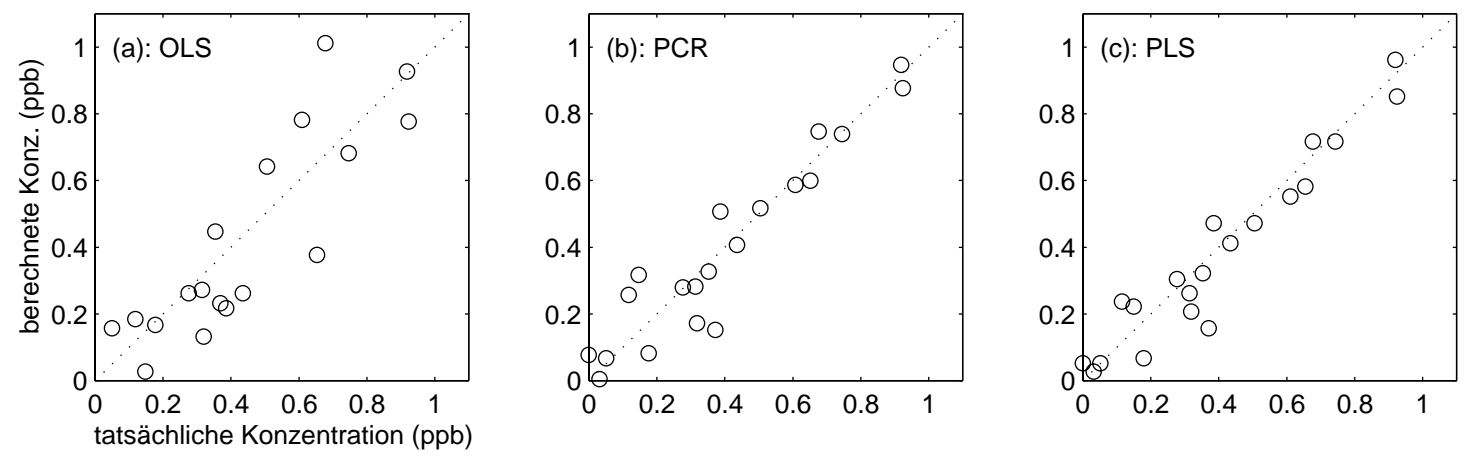

Abbildung 7.22: Vergleich von tatsächlichen und vorhergesagten Konzentrationen von Chrysen (CHR) im Validierungsteil des Datensatzes DS2 für die Kalibrationstechniken (a) ordenary least squares regression (OLS), (b) principal component regression (PCR) und (c) partial least squares regression (PLS). 


\subsection{Nachweisgrenzen}

Mit der FT-AFD-Matrixzerlegung und der PLS-Kalibration wurden für die EPAPAK Nachweisgrenzen berechnet (siehe Tabelle 7.3).

Tabelle 7.3: Nachweisgrenzen der EPA-PAK in natürlichem Wasser

\begin{tabular}{|l|c||l|c|}
\hline $\begin{array}{l}\text { PAK-Index und } \\
\text { Abkürzung }\end{array}$ & $\begin{array}{c}\text { Nachweisgrenze } \\
\text { (in ppb) }\end{array}$ & $\begin{array}{l}\text { PAK-Index und } \\
\text { Abkürzung }\end{array}$ & $\begin{array}{c}\text { Nachweisgrenze } \\
\text { (in ppb) }\end{array}$ \\
\hline \hline 1. ACN & 2 & 9. CHR & 0.03 \\
\hline $2 . \mathrm{ACY}$ &.$/$. & 10. DBA &.$/$. \\
\hline $3 . \mathrm{ANT}$ & 6 & 11. FLA & 3 \\
\hline $4 . \mathrm{BaA}$ & 0.1 & 12. FLU & 1 \\
\hline $5 . \mathrm{BkF}$ & 1.5 & 13. INP &.$/$ \\
\hline $6 . \mathrm{BbF}^{*}$ & 0.8 & 14. NAP & 5 \\
\hline $7 . \mathrm{BgP}$ &.$/$. & 15. PHT & 0.4 \\
\hline $8 . \mathrm{BaP}$ & 0.08 & 16. PYR & 0.2 \\
\hline
\end{tabular}

*BbF und FLA zeigen, abgesehen von der Fluoreszenzintensität, das gleiche spektrale und temporale Fluoreszenzverhalten und können nur gemeinsam bestimmt werden.

Die Werte wurden als gerundete dreifache Standardabweichung des Nullsignals (vorhergesagte Konzentration in unkontaminierten natürlichen Gewässerproben) bestimmt. Für BgP, DBA und INP wurden zwar durch Herstellung stark übersättigter Lösungen Fluoreszenzspektren aufgezeichnet und theoretische Werte für die Nachweisgrenzen berechnet, solch starke Übersättigungen sind in der Praxis aber nicht zu erwarten. Die Nachweisgrenzen wurden daher nicht in die Tabelle mit aufgenommen (zu den Löslichkeiten der PAK in Wasser siehe Anhang, S. 115). ACY zeigte keine meßbare Fluoreszenz.

\subsection{Querempfindlichkeiten}

Die Querempfindlichkeit ist ein Wert, der die Beeinflussung der Vorhersage der Konzentration eines Stoffes A bei variierenden Konzentrationen des Stoffes B angibt. Das Prinzip der Berechnung wird in Abbildung 7.23 verdeutlicht: In diversen Proben wird die Konzentration von ACN gemessen. Befindet sich außer den natürlichen Hintergrundfluorophoren kein Schadstoff in der Probe, schwankt der gemessene ACN-Wert (im Rahmen der Nachweisgrenze) um Null. Befindet sich nun in weiteren Proben die Substanz BaP, ändert sich der mittlere gemessene Wert für ACN, obwohl nach wie vor kein $\mathrm{ACN}$ in den Proben vorhanden ist. Mit zunehmender BaP-Konzentration steigt auch die fälschlicherweise gemessenen ACN- 
Konzentration. Die Steigung der Ausgleichsgrade gibt die Querempfindlichkeit von ACN gegenüber BaP: 0.51.

Für die 12 mit einem Nachweisgrenzwert angegebenen PAK aus Tabelle (7.3) wurden die Querempfindlichkeiten gemessen und die spektralen Ähnlichkeiten berechnet (zur Definition der spektralen Ähnlichkeit siehe nächste Seite). Für die Matrixzerlegung der zeitaufgelösten Spektren wurde die FT-AFD verwendet. Für die Stoffe ANT, BkF und FLU wurden wegen der kurzen Abklingzeiten die integralen Spektren in die Kalibrationsvektoren mit aufgenommen. Die multivariate Regression wurde mit dem PLS-Verfahren durchgeführt. Das Ergebnis der Bestimmungen ist in Tabelle (7.4) zu finden, der Übersichtlichkeit halber als Prozentangabe, der Wert 100 in der Tabelle entspricht also einer Querempfindlichkeit von 1.

Mehr Strukturen erkennt man aus der Tabelle, wenn alle Querempfindlichkeiten weggelassen werden, die betragsmäßig kleiner als $20 \%$ sind (Tabelle (7.5)). Aus der Tabelle wird der Vorteil der Zeitauflösung deutlich: Der Nachweis des schnellabklingenden ANT beispielsweise wird durch das Vorhandensein der länger fluoreszierenden Substanzen BaA, CHR, FLU und PYR gestört, der Nachweis dieser Substanzen im Gegenzug aber nicht durch das Vorhandensein von ANT. Ebenfalls auf die Zeitauflösung zurückzuführen ist die Stabilität von Pyren, dem Stoff mit der (mit großem Abstand) längsten Fluoreszenzlebensdauer. Interessant ist der Einfluß von $\mathrm{BbF}$ und FLA, die sich nicht nur gegenseitig stören sondern auch massiv den Nachweis der anderen Substanzen.

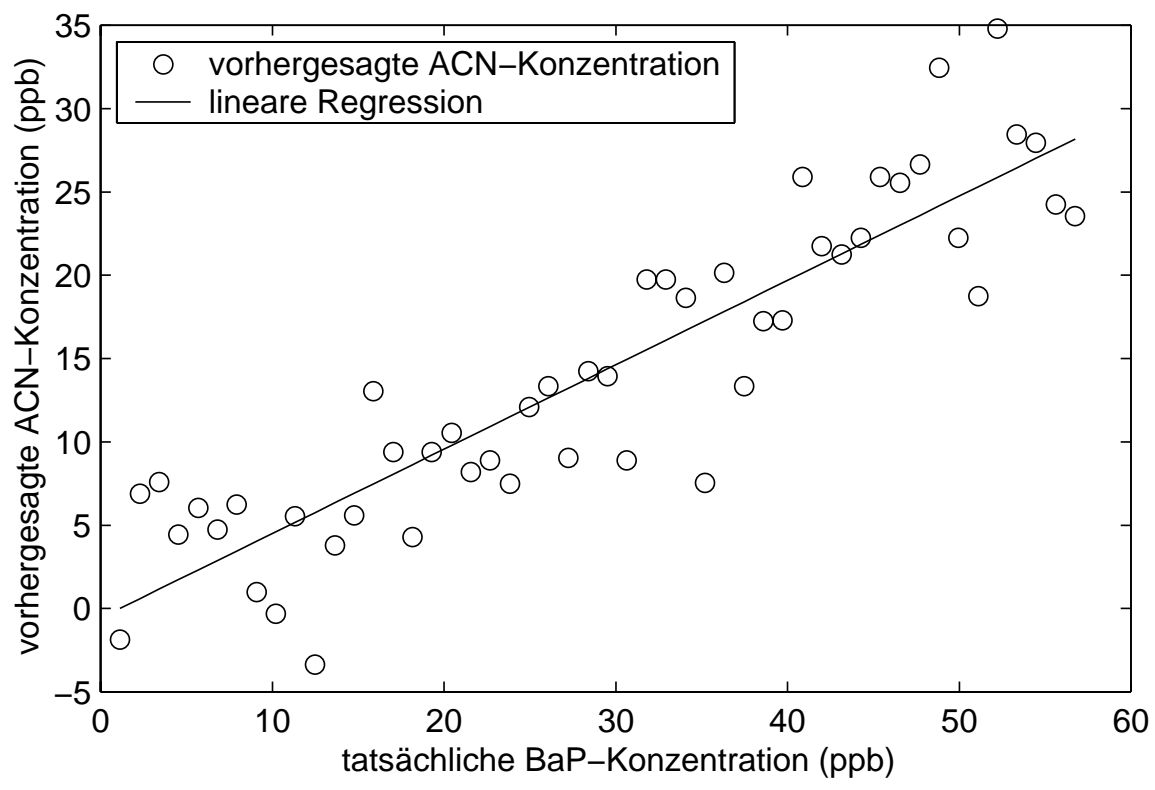

Abbildung 7.23: Vorhergesagte ACN-Konzentration in einer Probe, in der nur der Schadstoff $\mathrm{BaP}$ (in unterschiedlichen Konzentrationen) vorhanden ist. Die Steigung der Ausgleichsgraden gibt die Querempfindlichkeit, in diesem Fall den Wert $0.51(+51 \%)$. 


\section{Tabelle 7.4: Querempfindlichkeiten}

Die gemessenen Querempfindlichkeiten der 12 im ppb-Bereich nachweisbaren PAK in Prozent.

\begin{tabular}{|l||c|c|c|c|c|c|c|c|c|c|c|c|}
\hline \multicolumn{1}{|c||}{} & \multicolumn{10}{c|}{ zugegebener (störender) Schadstoff } \\
& ACN & ANT & BaA & BkF & BbF & BaP & CHR & FLA & FLU & NAP & PHT & PYR \\
\hline \hline ACN & $\bullet$ & -0.5 & -18 & 13 & 15 & 51 & -83 & 18 & 9.7 & 6.9 & -4.2 & 5.1 \\
\hline ANT & 14 & $\bullet$ & -37 & 2.8 & 15 & 6.2 & -168 & 15 & -21 & 5.8 & -8.9 & 52 \\
\hline BaA & -2.4 & -0.8 & $\bullet$ & 8.1 & 35 & -2.5 & 8.9 & 41 & 1.5 & -0.4 & -0.8 & 15 \\
\hline BkF & -1.5 & 0.7 & -11 & $\bullet$ & 56 & 6.6 & 6.2 & 57 & 28 & 0.1 & 0.4 & 18 \\
\hline BbF & -1.6 & -0.2 & -8.5 & -2.3 & $\bullet$ & 0.1 & -12 & 107 & -0.8 & -0.3 & -1.7 & 3.6 \\
\hline BaP & -4.1 & -1.0 & -15 & 2.9 & 65 & $\bullet$ & -25 & 68 & 0.3 & -0.6 & -0.4 & 2.1 \\
\hline CHR & -6.4 & -0.6 & -21 & 7.7 & 51 & 3.9 & $\bullet$ & 61 & 0.8 & -1.4 & -0.5 & 14 \\
\hline FLA & -4.7 & -0.9 & -15 & 7.9 & 91 & 12 & -18 & $\bullet$ & -0.1 & -0.9 & -0.6 & 7.1 \\
\hline FLU & -1.1 & -0.1 & -3.1 & -0.8 & 1.8 & -2.4 & 3.3 & 2.0 & $\bullet$ & -0.4 & 0.6 & 3.3 \\
\hline NAP & 12 & -1.8 & 9.0 & 7.0 & 22 & -29 & 94 & 25 & -26 & $\bullet$ & 1.4 & 17 \\
\hline PHT & -1.1 & -0.1 & -12 & 6.0 & 9.6 & 22 & 25 & 15 & 4.1 & -0.3 & $\bullet$ & -0.6 \\
\hline PYR & -2.6 & 0.4 & -2.6 & 1.4 & 13 & -2.4 & -0.1 & 14 & 1.1 & -1.2 & -0.2 & $\bullet$ \\
\hline
\end{tabular}

\section{Spektrale Ähnlichkeiten}

Sind $\mathbf{s}_{\mathbf{1}}$ und $\mathbf{s}_{\mathbf{2}} \in \mathbb{R}^{W}$ zwei integrale Spektren, so läßt sich mit Hilfe der Korrelation eine spektrale Ähnlichkeit durch:

$$
\operatorname{corr}\left(\mathbf{s}_{\mathbf{1}}, \mathbf{s}_{\mathbf{2}}\right)=\frac{<\mathbf{s}_{\mathbf{1}} \mid \mathbf{s}_{\mathbf{2}}>}{\left\|\mathbf{s}_{\mathbf{1}}\right\||| \mathbf{s}_{\mathbf{2}} \|}
$$

berechnen, wobei $<. . \mid . .>$ das Skalarprodukt und $\| . .||$ die 2-Norm ist.

Vergleicht man die auf diese Weise bestimmten spektralen Ähnlichkeiten (Tabelle (7.6)) mit den Querempfindlichkeiten in Tabelle (7.5) und den Abklingzeiten in Tabelle (A.2), so lassen sich folgende Schlußfolgerungen ziehen:

1. Eine hohe spektrale Ähnlichkeit bei ähnlicher oder gleicher Abklingzeit führt zu einer hohen beidseitigen Querempfindlichkeit (Beispiel: BbF und FLA).

2. Unterschiedliche Abklingzeiten ermöglichen selbst bei hoher spektraler Ähnlichkeit niedrige Querempfindlichkeiten, wenn beide Abklingzeiten deutlich über der Systemauflösung liegen (Beispiel: ACN (26 ns) und NAP (37 ns)). Ist nur die Abklingzeit einer der Substanzen deutlich über der Systemauflösung, so ist auch nur dieser stabil gegenüber dem Einfluß des anderen, nicht aber umgekehrt (Beispiel: ANT (<5 ns) und PYR (122ns)).

3. Niedrige spektrale Ähnlichkeiten können zu relativ hohen Querempfindlichkeiten führen, wenn die Substanzen ähnliche oder gleiche Abklingzeiten haben 
Tabelle 7.5: Querempfindlichkeiten größer 20\%

\begin{tabular}{|l||c|c|c|c|c|c|c|c|c|c|c|c|}
\hline \multicolumn{1}{|c||}{} & \multicolumn{10}{|c|}{ zugegebener (störender) Schadstoff } \\
& ACN & ANT & BaA & BkF & BbF & BaP & CHR & FLA & FLU & NAP & PHT & PYR \\
\hline \hline ACN & $\bullet$ & & & & & 51 & -83 & & & & & \\
\hline ANT & & $\bullet$ & -37 & & & & -168 & & -21 & & & 52 \\
\hline BaA & & & $\bullet$ & & 35 & & & 41 & & & & \\
\hline BkF & & & & $\bullet$ & 56 & & & 57 & 28 & & & \\
\hline BbF & & & & & $\bullet$ & & & 107 & & & & \\
\hline BaP & & & & & 65 & $\bullet$ & -25 & 68 & & & & \\
\hline CHR & & & -21 & & 51 & & $\bullet$ & 61 & & & & \\
\hline FLA & & & & & 91 & & & $\bullet$ & & & & \\
\hline FLU & & & & & & & & & $\bullet$ & & & \\
\hline NAP & & & & & 22 & -29 & 94 & 25 & -26 & $\bullet$ & & \\
\hline PHT & & & & & & 22 & 25 & & & & $\bullet$ & \\
\hline PYR & & & & & & & & & & & & $\bullet$ \\
\hline
\end{tabular}

Tabelle 7.6: Spektrale Ähnlichkeiten

Berechnet als Korrelation zwischen den integralen Spektren der jeweiligen Substanzen.

\begin{tabular}{|l||c|c|c|c|c|c|c|c|c|c|c|c|}
\hline & ACN & ANT & BaA & BkF & BbF & BaP & CHR & FLA & FLU & NAP & PHT & PYR \\
\hline \hline ACN & 1.00 & & & & & & & & & & & \\
\hline ANT & 0.08 & 1.00 & & & & & & & & & & \\
\hline BaA & 0.05 & 0.88 & 1.00 & & & & & & & & & \\
\hline BkF & 0.08 & 0.62 & 0.66 & 1.00 & & & & & & & & \\
\hline BbF & 0.01 & 0.45 & 0.46 & 0.89 & 1.00 & & & & & & & \\
\hline BaP & 0.02 & 0.76 & 0.77 & 0.85 & 0.64 & 1.00 & & & & & & \\
\hline CHR & 0.21 & 0.71 & 0.58 & 0.26 & 0.15 & 0.32 & 1.00 & & & & & \\
\hline FLA & 0.01 & 0.37 & 0.38 & 0.80 & 0.98 & 0.52 & 0.12 & 1.00 & & & & \\
\hline FLU & 0.48 & 0.03 & 0.02 & 0.06 & 0.01 & 0.01 & 0.05 & 0.01 & 1.00 & & & \\
\hline NAP & 0.99 & 0.07 & 0.04 & 0.08 & 0.01 & 0.02 & 0.18 & 0.01 & 0.56 & 1.00 & & \\
\hline PHT & 0.41 & 0.42 & 0.34 & 0.17 & 0.07 & 0.16 & 0.82 & 0.07 & 0.09 & 0.38 & 1.00 & \\
\hline PYR & 0.11 & 0.83 & 0.77 & 0.35 & 0.22 & 0.43 & 0.81 & 0.19 & 0.03 & 0.10 & 0.59 & 1.00 \\
\hline
\end{tabular}


(Beispiel: BbF und CHR, beide um $30 \mathrm{~ns}$ ), dies ist aber die Ausnahme.

4. Niedrige spektrale Ähnlichkeiten und deutlich verschiedene Abklingzeiten (oberhalb der Systemauflösung) führen zu niedrigen Querempfindlichkeiten.

\subsection{Diskussion der Ergebnisse}

Im wesentlichen stehen sich zwei Methoden zur Matrixzerlegung gegenüber: Die abstrakte Faktorzerlegung (AFD) und die Fensterzerlegung. In Verbindung mit einer PLS-Kalibration führen beide Zerlegungen zu akzeptablen Ergebnissen. Die leistungsfähigste abstrakte Faktorzerlegung in dieser Arbeit, die C-AFD, zeigte sich etwas stärker als die Fensterzerlegung (Abb. 7.18). Allerdings reagieren die Faktorzerlegungen sehr viel sensibler auf schlecht gewählte Parameter, vor allem auf ungünstige abstrakte Abklingkonstanten (Tauvektor). Die Fensterzerlegung ist gegenüber Parameterveränderungen sehr viel stabiler. Dies scheint auch aus theoretischer Sicht plausibel: Während die abstrakte Faktorzerlegung prinzipiell mehr temporale Information als eine Fensterzerlegung (mit wenigen Fenstern) enthält, so ist sie doch gleichzeitig anfällig für die typische Ambivalenz multiexponetieller Entfaltungen, die in einer Vielzahl von Publikationen behandelt wird [181]-[197].

Letztlich wird es von der Anwendung abhängen, welche der beiden Methoden verwendet werden sollte. Ist eine hohe Vorhersagegenauigkeit verlangt und sind die verschiedenen Einflußparameter gut bekannt, wenn z.B. sehr viele ähnliche Proben unter ähnlichen Bedingungen vermessen werden, so ist die C-AFD den anderen Methoden vorzuziehen. Liegen zudem sehr viele Kalibrationswerte vor, kann auch die PEM-AFD die Methode der Wahl sein, von der zu erwarten steht, daß sie mit zunehmender Anzahl von Referenzdaten stetig leistungsfähiger wird. Sind dagegen viele Einflußparameter nicht bekannt, wie das bei Feldmessungen häufig der Fall ist, scheint die Fensterzerlegung aufgrund ihrer Robustheit den anderen Methoden überlegen.

Bei den Kalibrationen hat sich die PLS als stärkste Methode erwiesen. Dieses Ergebnis spiegelt die Erfahrungen einer Reihe von Arbeiten wieder, die zum Thema PLS-Kalibration für spektroskopische Daten existieren (siehe Literaturzitate zur PLS auf Seite 56). 


\section{Umweltproben und Feldversuche}

Während dieser Arbeit wurden mit dem CCD-Laserfluorimeter eine Reihe von Proben mit realen Umweltverschmutzungen im Labor sowie drei Feldversuche zur Analyse von Fließgewässern durchgeführt:

- Analyse einer durch einen Tankstellenunfall verunreinigten Grundwasserprobe auf aromatische Bestandteile,

- Xylol-Nachweis in diversen Wasserproben,

- Nachweis von DOC (dissolved organic compounds) in der Leine im Rahmen eines gemeinsamen Einsatzes mit der Berufsfeuerwehr Göttingen,

- Tracerversuche auf Havel und Elbe.

\subsection{Tankstellenunfall}

Abbildung (8.1) zeigt das Spektrum einer Grundwasserprobe, die im Oktober 1997 nach einem Tankstellenunfall unterhalb der Tankstelle in einem Bohrloch entnommen wurde. Dies war einer der ersten Realproben, die mit dem zu diesem Zeitpunkt erst als Laboraufbau bestehenden CCD-Laserfluorimeter untersucht wurden.

Eine Analyse des Spektrums ergab eine Benzolkonzentration von 200 ppm und eine Naphthalinkonzentration von 200 ppb (Aufgrund der hohen Querempfindlichkeit zwischen Naphthalin und Acenaphthen kann es sich auch um 100 ppb Acenaphthen oder einem Gemisch aus beidem handeln). Neben den polyzyklischen aromatischen
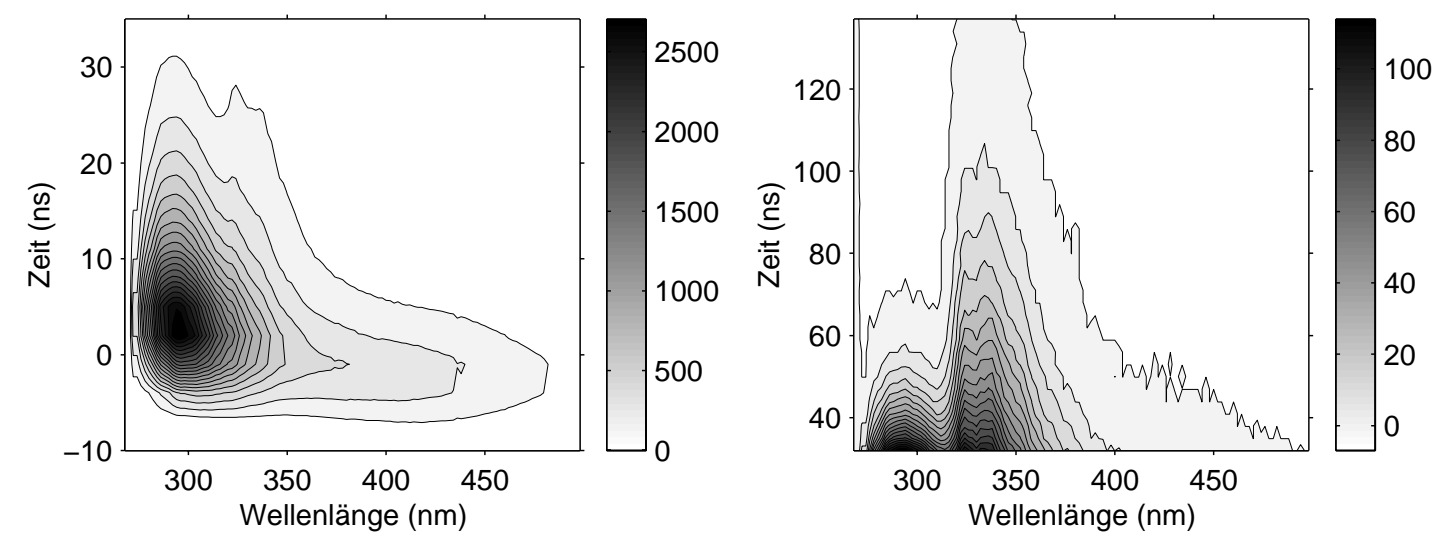

Abbildung 8.1: Zeitaufgelöstes Fluoreszenzspektrum einer Grundwasserprobe nach einem Tankstellenunfall. Intensitätseinheiten in counts (Zähleinheiten des Nachweissystems). Rechts ist der „spätere“ Teil des Spektrums zu sehen. 
Kohlenwasserstoffen bilden die BTXE-Aromaten (Benzol, Toluol, Xylol und EthylBenzol) eine bedeutende Gruppe von Umweltschadstoffen. Die Fluoreszenz dieser Aromaten liegt sehr nahe bei der hier verwendeten Anregungswellenlänge und überlagert sich stark mit dem Ramansignal von Wasser, wodurch eine Analyse erschwert wird. Ergebnisse einer naßchemischen Analyse liegen nicht vor.

\subsection{Xylol-Verschmutzungen}

Mit Hilfe des CCD-Laserspektrometers wurde von F. LEwITZKA die Möglichkeit zum Nachweis von Xylol in Wasser untersucht [198]. Innerhalb der Gruppe der BTXE-Aromaten ist Xylol der Analyt mit der höchsten Fluoreszenzintensität (bei Anregung mit $266 \mathrm{~nm}$ ) und der längsten Fluoreszenzabklingzeit. Besonders die vergleichsweise lange Abklingzeit erlaubt daher einen guten Nachweis von Xylol.

Da nur eine begrenzte Anzahl von Wasserproben mit realen Xylol-Verschmutzungen zur Verfügung standen, wurden weitere Proben durch Zugabe von Xylol in unverschmutzten Wasserproben im Labor hergestellt. Die Messung der XylolKonzentrationen der realen Proben fand auf naßchemischem Wege statt. Die Spektren der realen und der künstlichen Proben wurden zusammengenommen und in einen Kalibrations- und eine Validationsteil aufgeteilt. Mit dem Kalibrationsteil wurde ein multivariates Kalibrationsmodell für die AFD/PLS-Analyse erstellt. Abbildung (8.2) zeigt das Ergebnis der Kalibration sowohl für die Kalibrations- als auch für die Validationsdaten. Mit dem Kalibrationsteil der Spektren wurde eine Nachweisgrenze von $10 \mu \mathrm{g} / \mathrm{l}$ für Xylol berechnet [198].

\subsection{Feuerwehreinsatz Leineverschmutzung}

Im Oktober 1998 kam es auf der Leine in Höhe Göttingen zu einer Verschmutzung, deren Art und Ursache anfangs nicht bestimmt werden konnte. Da die Feuerwehr Göttingen über das mobile Laserfluorimeter informiert war, wurde bereits eine halbe Stunde nach Entdeckung der Verschmutzung das Meßsystem des LLGs zur Schadstoffbestimmung und Lokalisation der Schadstoffquelle herangezogen.

Die ersten Messungen ergaben eine Verschmutzung mit DOC (dissolved organic compounds) im hohen ppm-Bereich. Das starke Fluoreszenzsignal erforderte eine Reduktion der Systemempfindlichkeit auf ein Hundertstel (gain=0.3). Als Einzelsubstanz konnte Pyren (PYR) mit einer Konzentration von 50 ppb $\pm 30 \%$ bestimmt werden. Zum Zeitpunkt der ersten fluorimetrischen Messungen auf der Leine wurde die Schadstoffquelle von der Feuerwehr lokalisiert, so daß hier kein Handlungsbedarf mehr bestand. Prinzipiell wäre es aber mit Hilfe des Spektrums der Verschmutzung 


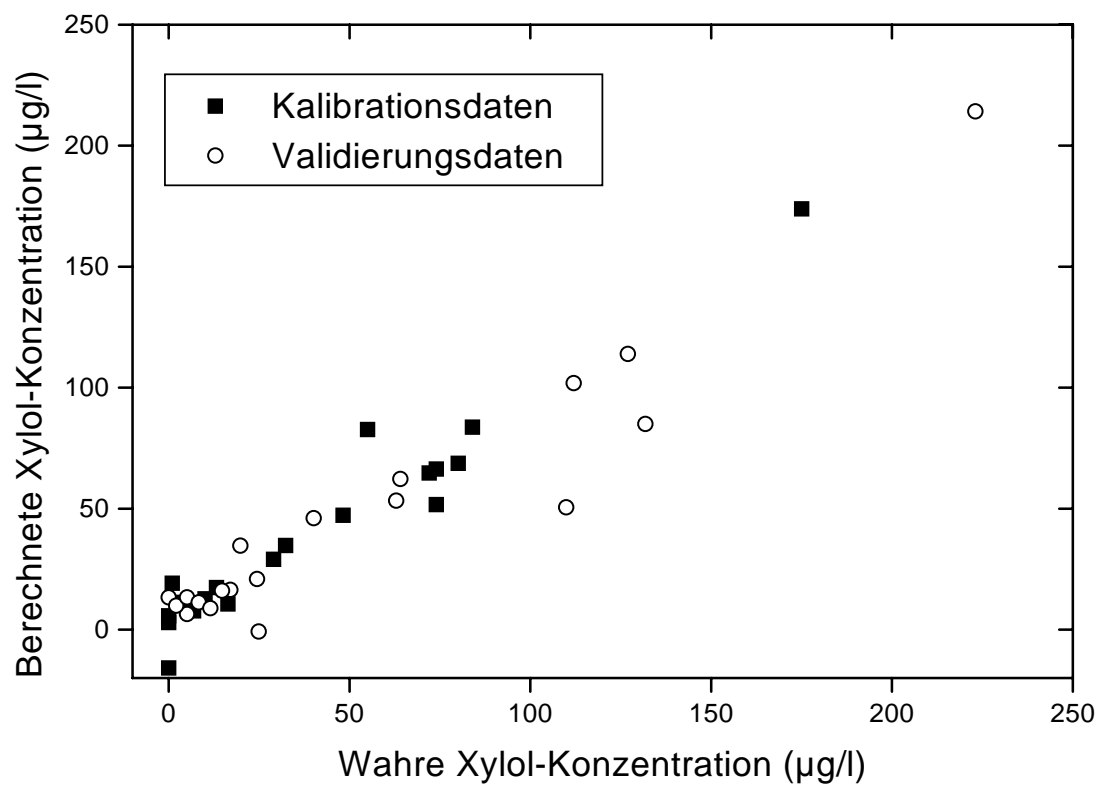

Abbildung 8.2: Xylol-Kalibration mit realen und künstlich erstellten Proben.

(siehe Abb. (8.3)) im fingerprint-Verfahren ${ }^{1}$ möglich gewesen, den Schadstoffherd auszumachen. Selbst nach Ende der Schadstoffeinleitung hätte die Restverschmutzung ein Zurückverfolgen der Verschmutzung vermutlich ermöglicht.

Die Verschmutzung stellte sich schließlich als ausgelaufenes Bohröl einer Göttinger Firma heraus. Ein großer Teil des verschmutzen Leinewasser konnte von der Feuerwehr in ein Auffangbecken des nahen Göttinger Klärwerkes abgepumpt werden.

\subsection{Tracerversuch Potsdamer Havel (Mai 98)}

Bei Tracerversuchen in Flüssen wird eine kleine Menge (z.B. ein Kilogramm) umweltneutraler Fluoreszenzfarbstoff - der Tracer - im Oberlauf eines Flusses eingeleitet und über die nächsten Tage verfolgt. Da der Farbstoff sich mit dem Wasser bewegt, können aus der Art der Ausbreitung und den Bewegungen der sich bildenden Tracerwolke die Strömungsverhältnisse eines Flusses gemessen werden. Diese

1 Bei dem fingerprint-Verfahren wird an einigen Stellen mit (z.B. durch naßchemische Analyse) bekannter Verschmutzung das Spektrum dieser Verschmutzung aufgezeichnet und ggf. mit unkontaminierten Proben verglichen. Durch eine Kalibration auf diese Referenzspektren kann nun relativ zuverlässig diese konkrete Verschmutzung wiedererkannt werden. 
(a)

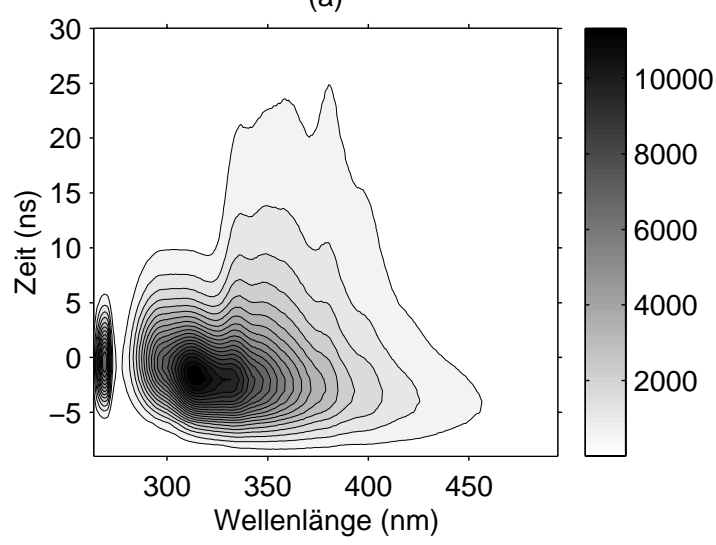

(c)

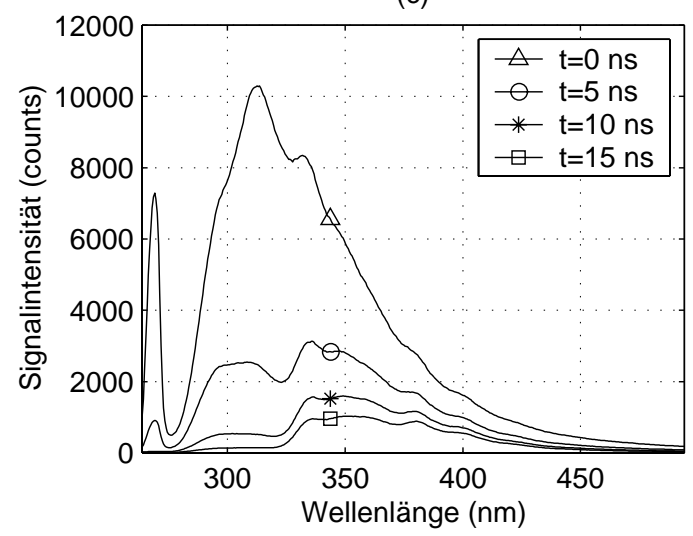

(b)

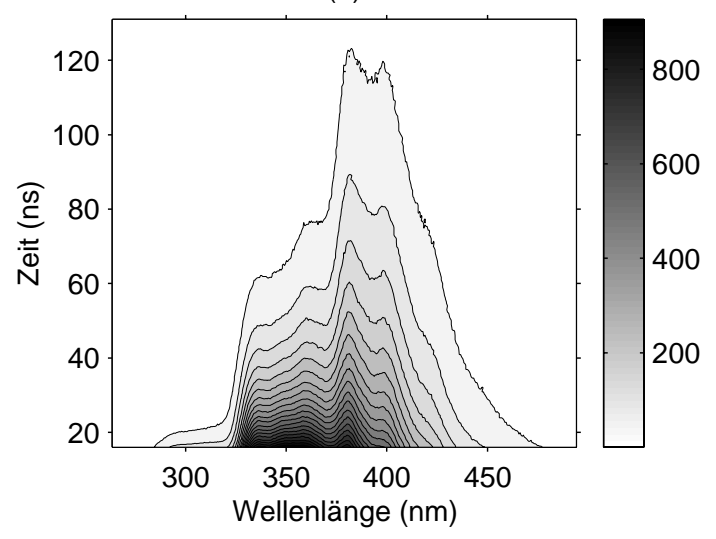

(d)

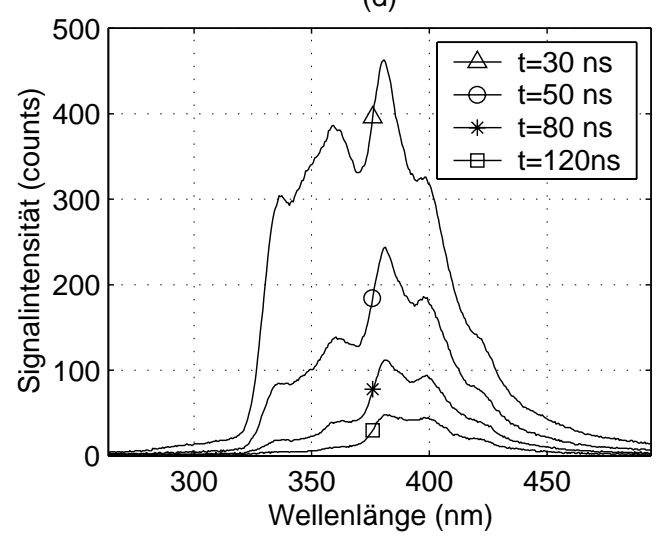

Abbildung 8.3: Spektrum der Leineverschmutzung. (a): Das sehr intensive Spektrum im Zeitbereich der Anregung. (b): Der hintere Teil des Spektrums (ab 20 ns nach Anregung). (c) und (d): Zeitscheiben, Zeiten relativ zur Anregung. Deutlich ist das Spektrum von Pyren zu erkennen. Die Intensität ist in counts bei einem gain von 0.3 gegeben.

Informationen bilden die notwendige Basis für ein mathematisches Modell zur Beschreibung der Strömungsverhältnisse dieses Flusses. Ein solches Modell kann von großer Bedeutung sein: Seit für den Rhein ein solches Modell existiert, konnte die von Hochwasser ausgehende Gefährdung deutlich reduziert werden. Durch gezielten Einsatz von strömungsbeeinflussenden Maßnahmen (z. B. Rückhaltebecken) können Hochwasserwellen wirksam manipuliert und z. T. vermieden werden. Je genauer das mathematische Modell ist, desto effektiver sind diese Maßnahmen. Ähnlich wichtig ist ein mathematisches Flußmodell für den Um- und Ausbau von Wasserstraßen. Sind die bestehenden Strömungsverhältnisse bekannt, so lassen sich die Auswirkungen der geplanten Veränderungen deutlich genauer vorhersagen.

Die Verfolgung einer Tracerwolke über einen längeren Zeitraum ist allerdings gerade in größeren Flüssen mit den klassischen Methoden schwierig und kosten- 
aufwendig. Die Gründe dafür sind ähnlich gelagert wie bei der Umweltanalytik. Bereits nach verhältnismäßig kurzer Zeit ist der Tracer so stark verdünnt, daß er (bisher) nur noch mit Probenahme und Analyse im Labor nachgewiesen werden konnte. Um die Ausdehnung und Position einer Tracerwolke mit Hilfe der Probenahme ausreichend genau bestimmen zu können, ist dabei die Anzahl der nötigen Proben sehr hoch. Zudem liegt das Ergebnis erst Tage bis Wochen später vor.

Als Tracersubstanz diente der Fluoreszenzfarbstoff Sulforhodamin G (SRG) ${ }^{2}$, der bei Anregung mit $532 \mathrm{~nm}$ ein sehr gutes Fluoresenzverhalten zeigt. Durch Herausnahme des zweiten frequenzverdoppelnden Kristalls wurde der Laser auf $532 \mathrm{~nm}$ umgerüstet. Das Spektrometer wurde so justiert, das der spektrale Bereich bis $620 \mathrm{~nm}$ erfaßbar war. Für die Positionsbestimmung diente ein handelsübliches Satellitenpositionierungssystem ${ }^{3}$. Für die Auswertung der Spektren wurde eine einfache PLS-Kalibration auf einen kleinen Teil des Spektrums ohne Berücksichtigung der Hintergrundfluoreszenz eingesetzt.

\subsubsection{Havel bei Phöben (4. Mai 98)}

Nach der SRG-Einleitung um ca. 10 Uhr am Montag, den 4. Mai 1998, in die Havel zwischen den Orten Phöben und Töplitz bei Flußkilometer 4.5 wurden nach einer groben Lokalisierung der SRG-Verteilung vier Profile mit einer Sensortiefe von ca. 10 bis $20 \mathrm{~cm}$ aufgezeichnet (Profile M1 bis M4, siehe Kartenskizze Abb. (8.4)). Es zeigte sich, daß bereits um 13.15 Uhr eine wesentliche Menge des Tracers flußaufwärts an der Landzunge (Südwestufer) bei Flußkilometer $5 \mathrm{zu}$ finden war (siehe Profil M1, Abb. (8.5)). Die folgenden Profile zeigen keine weiterer Verlagerung dieser Wolke, lediglich eine Abnahme der Tracerkonzentration bis 15.40 Uhr auf ein Viertel (Vergleiche Profile M1 und M4). Zu diesem Zeitpunkt findet sich der Tracer entlang eines etwa 500 Meter langen Uferstreifens am Südwestufer zwischen Flußkilometer 4.5 und 5 (siehe Profil M4).

Als Grund für die Tracerverteilung darf der starke Nordwind (etwa Stärke 4 Beaufort) angenommen werden, der vermutlich das Oberflächenwasser in die Südwestbucht von Phöben gedrückt hat und die Tracerverteilung stärker als die sehr geringe Strömung der Havel in diesem Bereich beeinflußt hat. Die Ergebnisse dieser Messung bei Phöben sind daher für die mathematische Beschreibung der Havel kaum verwertbar.

\subsubsection{Havel „Tiefer See“ bei Potsdam (5. Mai 98)}

Nach der SRG-Einleitung um ca. 10:50 Uhr an Position 52 24'36.1" Nord, $13^{\circ} 05^{\prime}$ 17.9" Ost (siehe Abb. (8.6)) wurde um 12:00 Uhr das erste Oberflächenprofil D1 mit

2 Summenformel: $\mathrm{C}_{25} \mathrm{H}_{25} \mathrm{~N}_{2} \mathrm{NaO}_{7} \mathrm{~S}_{2}$, Molmasse: $552.59 \mathrm{~g} / \mathrm{mol}$ [199]

3 GARMIN GPS 128, Ungenauigkeit durch Selective Availability bis zu 100 Meter. 


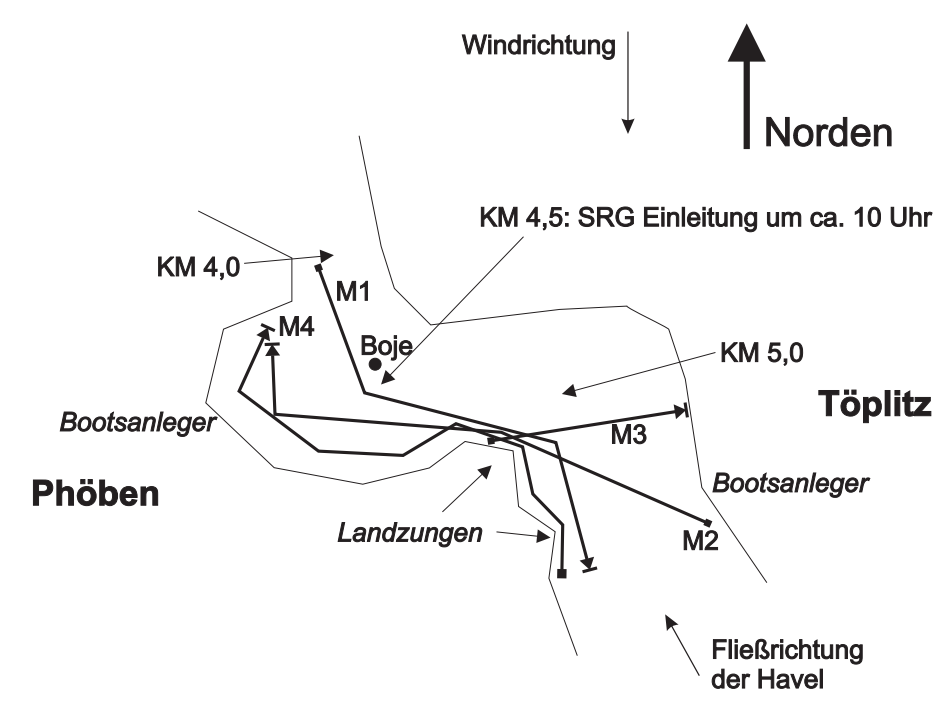

Abbildung 8.4: Kartenskizze zum Tracerversuch Havel/Phöben mit den Routen der Meßprofile M1 bis M4.
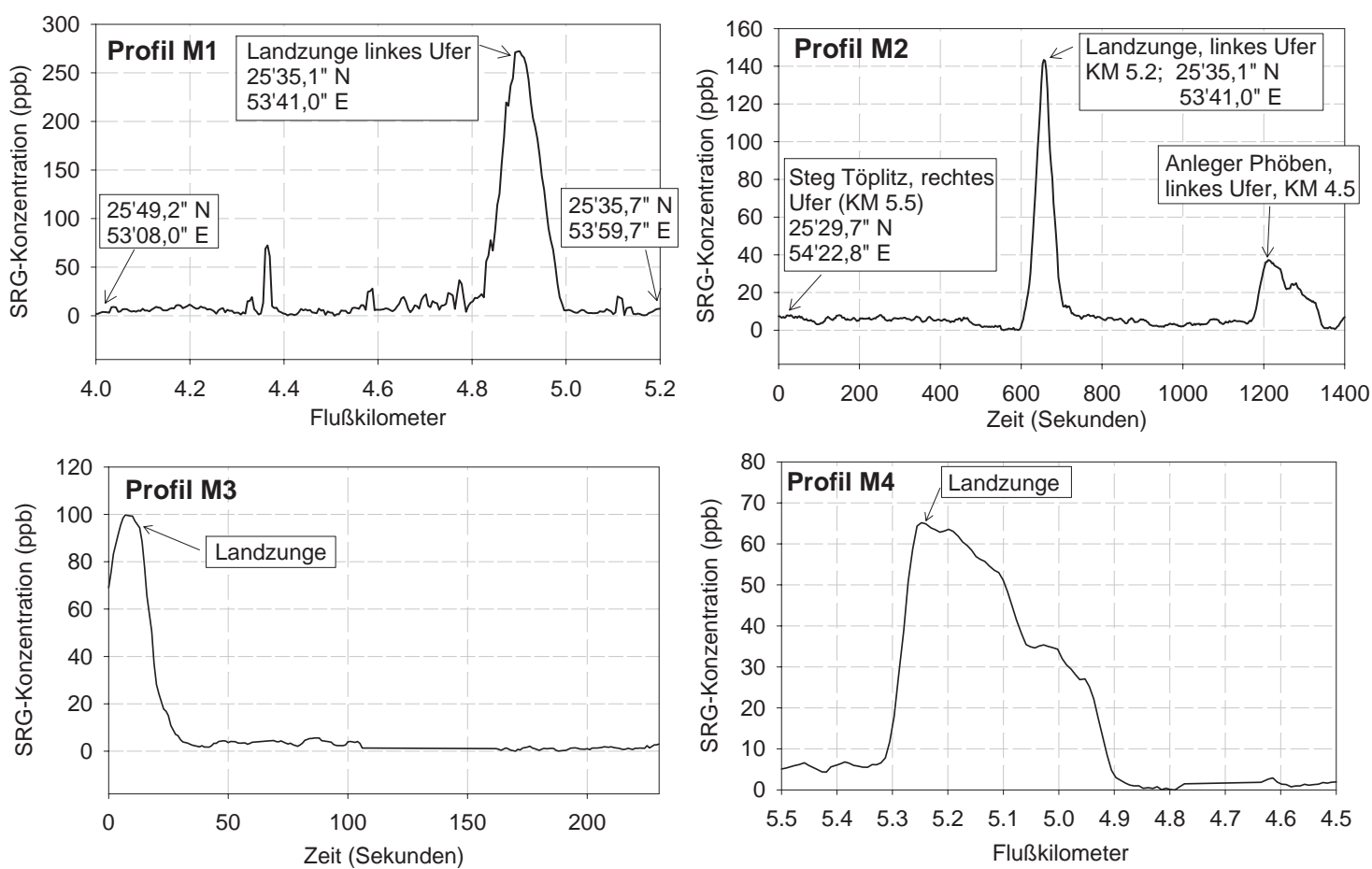

Abbildung 8.5: Die Ergebnisse der Meßprofile M1 bis M4. M1: Längsprofil 13.15 bis 13.27 Uhr. M2: Quer-/Längsprofil 13.50 bis 14.15 Uhr. M3: Querprofil 15.25 bis 15.29 Uhr. M4: Uferprofil 15.34 bis 15.47 Uhr. 
einer Tauchtiefe von $1 \mathrm{~m}$ an Position 52 24'26.7" Nord, $13^{\circ} 05^{\prime} 05.7^{\prime \prime}$ Ost gestartet. Das Profil zeigt eine deutliche Wanderung des Tracers nach Südwest (Abb. (8.7)).

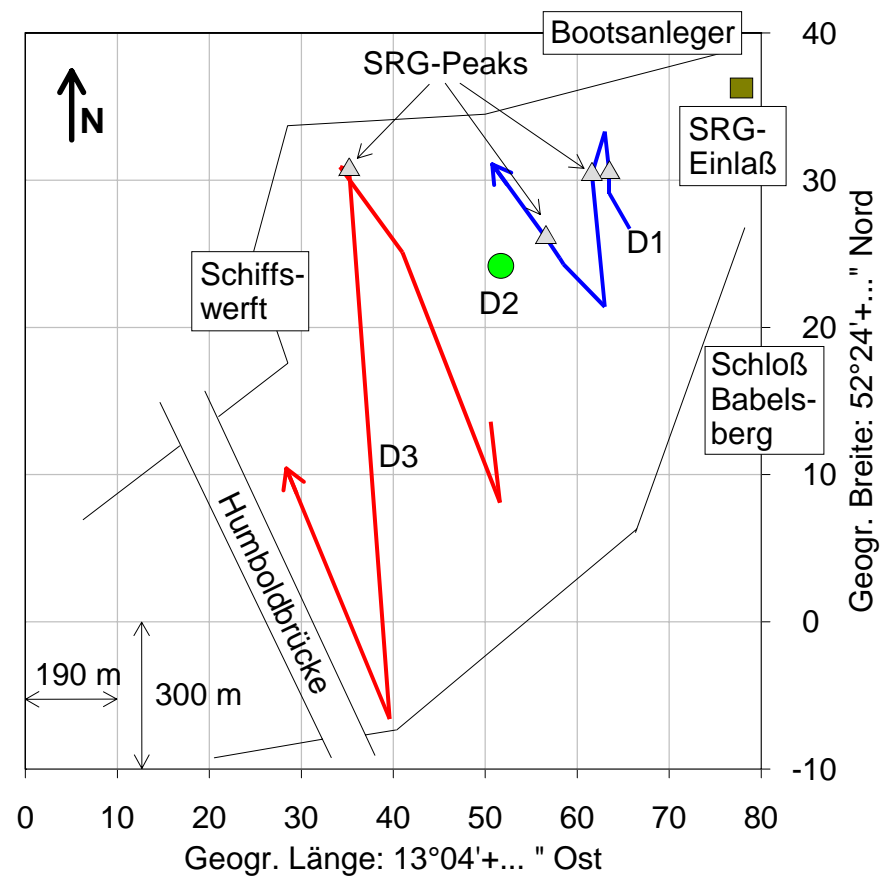

Abbildung 8.6: Kartenskizze zum Tracerversuch Havel/Potsdam mit den Meßprofilen D1 bis D3.

Um 12:51 Uhr wurden an der Position 52 24'24.4" Nord, $13^{\circ} 04^{\prime} 51.7^{\prime \prime}$ Ost Tiefenprofile (D2) zwischen 0 und 9 Metern aufgezeichnet. Die Profile zeigen eine annähernd gleichmäßige Verteilung des Tracers bis etwa 5 Meter Tiefe. Unterhalb von 5 Metern sank die Tracerkonzentration unter die Nachweisgrenze.

Abschließend wurde ab 13:33 Uhr und Position 52 24'13,6" Nord, $13^{\circ} 04^{\prime} 50.6^{\prime \prime}$ Ost ein weiteres Oberflächenprofil (D3) mit einer Sensortiefe von 1 Meter aufgezeichnet. Eine signifikante Tracerwolke fand sich nun vor allem in der Nähe des Nordufers.

Da das aufgenommene Signal auch den Anregungsbereich mit einschließt und wegen der kurzen Fluoreszenzlebensdauer des SRGs eine zeitliche Trennung von Fluoreszenz und Streulicht nicht möglich war, wurde aufgrund des starken Streusignals während der gesamten Messungen das Laserfluorimeter nur mit einem Bruchteil der maximal möglichen Empfindlichkeit betrieben. Durch Einsatz eines Kantenfilters zur Unterdrückung des Streusignals sollte sich demnach die Nachweisempfindlichkeit für SRG um mehrere Größenordnungen erhöhen lassen. 

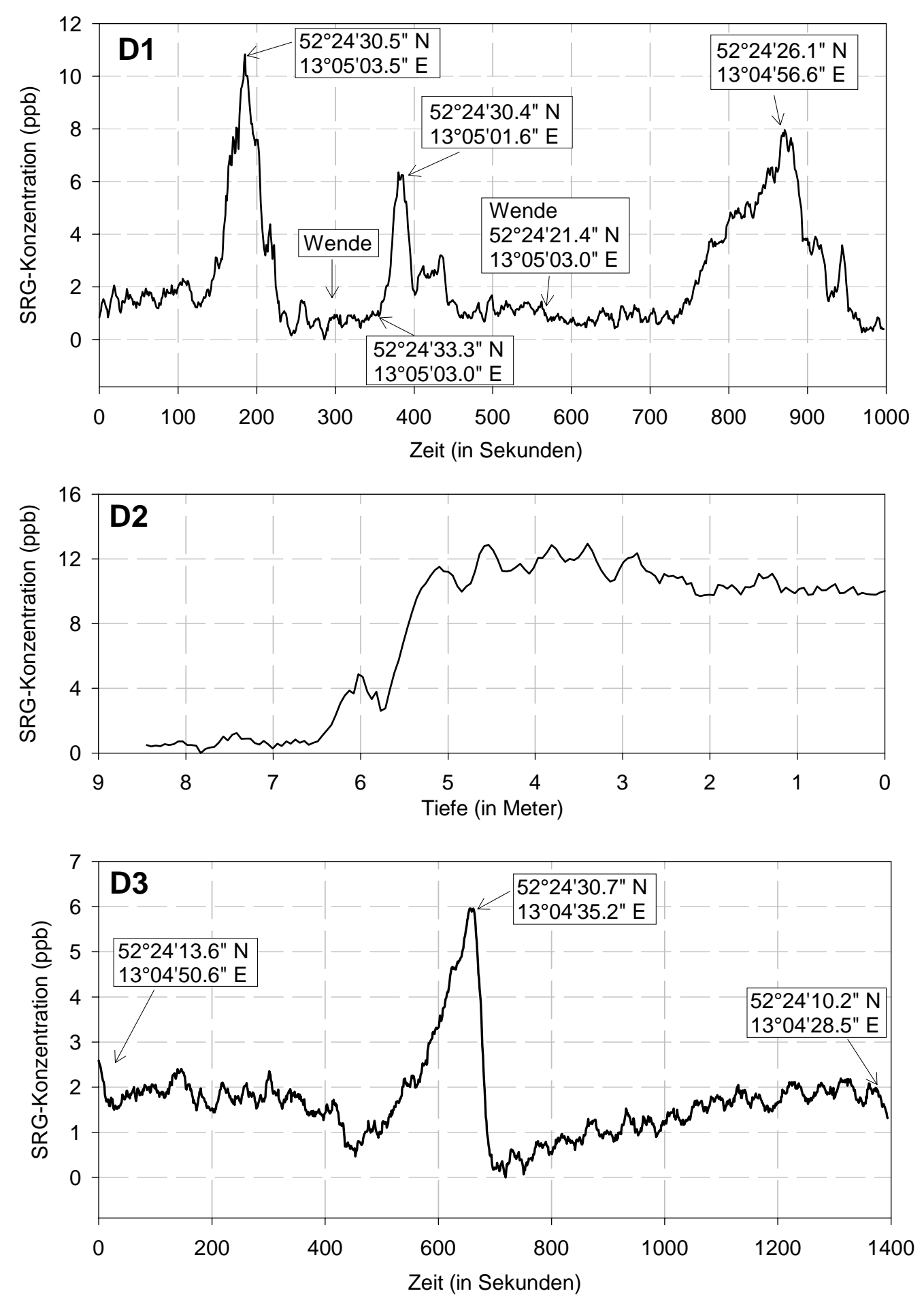

Abbildung 8.7: Die Ergebnisse der Meßprofile D1 bis D3 entsprechend Abb. (8.6). Profil D2 (Mitte) ist ein Tiefenprofil. 


\subsection{Tracerversuch Elbe bei Dresden (April 99)}

Nach den Erfahrungen auf der Havel wurde für den Tracerversuch auf der Elbe im April 1999 das Laserfluorimeter mit einem holographischen 532-nm-Notch-Filter ausgestattet, der das Streusignal des Anregungslichtes um mehrere Größenordnungen scharfkantig abschwächt. In Abbildung (8.8) ist ein mit dem System aufgezeichnetes zeitaufgelöstes Spektrum der Tracersubstanz SRG in Leitungswasser dargestellt.

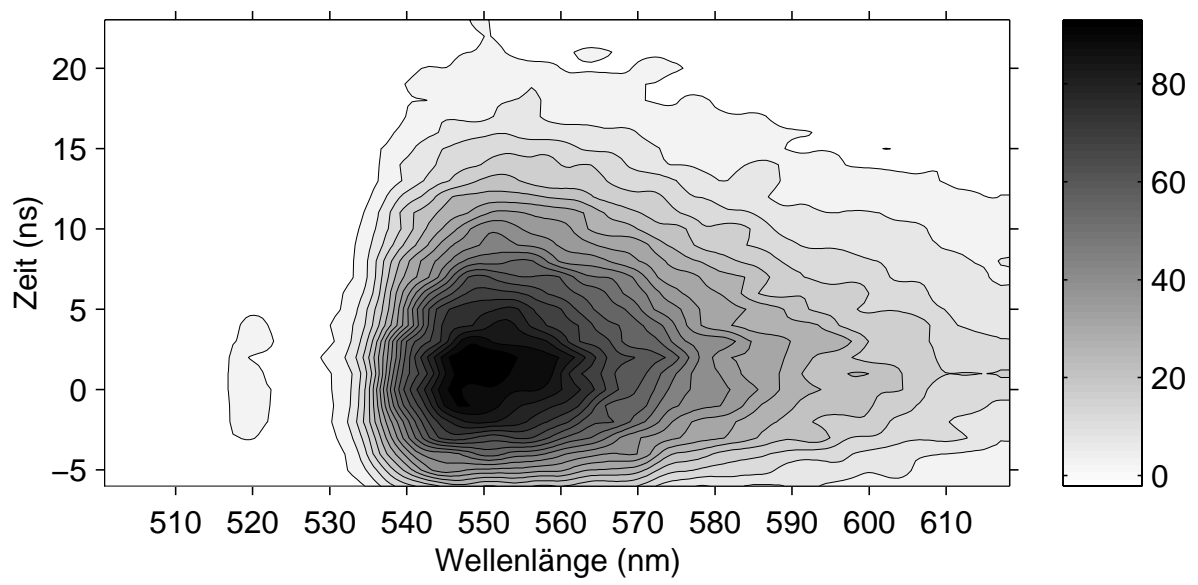

Abbildung 8.8: Zeitaufgelöstes Fluoreszenzspektrum von $100 \mathrm{ng} / \mathrm{l}$ (0.1 ppb) SRG in Leitungswasser bei Anregung mit $532 \mathrm{~nm}$. Intensitätseinheiten in counts.

\subsubsection{Erstellung des Kalibrationsmodells für die Tracer- substanz}

Für die Erstellung des Modells wurden SRG-Konzentrationsreihen in vier verschiedenen Wasserproben hergestellt. Die Wasserproben wurden dem Göttinger Leitungswassernetz, dem Graben "Lutter" und dem Kiessee Göttingen entnommen. Aus der Lutter stammen sowohl verhältnismäßig klare als auch sehr trübe Proben. Die ebenfalls trüben Kiesseeproben nehmen eine gewisse Sonderstellung ein, da hier die Hintergrundfluoreszenz durch Huminsäuren besonders stark ist.

Voruntersuchungen haben gezeigt, daß für den Nachweis der Tracersubstanz SRG aufgrund der kurzen Fluoreszenzlebensdauer die Aufnahme von zeitaufgelösten Fluoreszenzspektren nicht notwendig ist. Für die Kalibration und den Nachweis sowohl bei den weiteren Vorversuchen in Göttingen als auch während der Messungen auf der Elbe selbst wurden daher nur zeitlich integrierte zweidimensionale Spektren (Intensität als Funktion der Wellenlänge) aufgezeichnet.

Da der Anzahl von PLS-Faktoren eine besondere Bedeutung zukommt und zudem bei der PLS-Kalibrierung die Gefahr des overfittings besteht, wurde das Ergeb- 

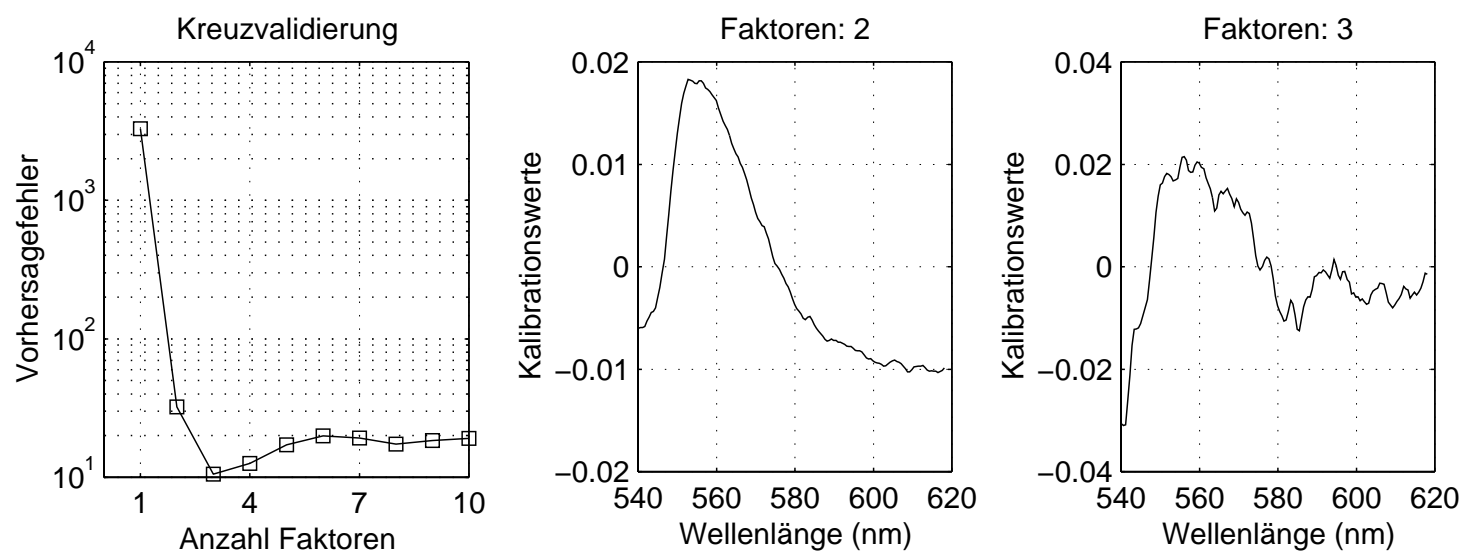

Abbildung 8.9: Links: Vorhersagefehler berechnet als Summe der quadratischen Abstände zwischen Ist- und Sollkonzentration der Validierungsdaten als Funktion der PLS-Faktorenanzahl. Mitte: Kalibrationsvektor bei Verwendung von 2 PLS-Faktoren, Rechts: Kalibrationsvektor bei Verwendung von 3 PLS-Faktoren.

nis der Kreuzvalidierung (Abb. (8.9) links) näher untersucht. Die Kreuzvalidierung gibt als optimale Faktorenanzahl den Wert 3 an (Minimum des Vorhersagefehlers). Betrachtet man allerdings die Vorhersage der Validierungsdaten (Abbildungen (8.10) und (8.11)), so entspricht die Faktorenzahl 2 mehr dem gewünschten Ergebnis. Zwar ist hier im Gegensatz zu 3 Faktoren ein systematischer Fehler bei hohen Konzentrationen für die Kiesseedaten zu beobachten (wodurch sich der deutlich höhere quadratische Fehler erklärt), dafür ist die Kalibration im unteren Bereich deutlich stabiler. Für die Kalibrierung wurde daher die Faktorenzahl 2 mit dem in Abbildung (8.9) (Mitte) dargestellten Kalibrationsvektor verwendet.

\subsubsection{Durchführung der Messungen}

Nach der Einleitung des Tracers am Montag (25.4.1999) im Oberlauf der Elbe wurde der Durchgang des Tracers am Mittwoch (27.4.) in Höhe von Pirna bei Dresden verfolgt. Entsprechend den Beobachtungen der anderen Meßstationen oberhalb Pirna wurde mit der Messung am Mittwochmorgen um 5:45 Uhr begonnen. In regelmäßigen Abständen wurden bis 22 Uhr des selben Tages Konzentrationsquerprofile aufgezeichnet. Die Messungen wurden auf einer Motorschaluppe durchgeführt, die freundlicherweise vom Wasser- und Schiffahrtsamt (WSA) Dresden, Außenstelle Pirna, zur Verfügung gestellt wurde. Die Optrode wurde mit Hilfe des dafür vorgesehen Optrodenhalters in 60 Zentimeter Wassertiefe an der linken Bootsseite ca. 2 Meter hinter dem Bug mit einem Abstand von etwa 40 Zentimetern von der Bootsaußenwand befestigt. Die Transportkiste des Meßsystems (Laser, Nachweiseinheit, Laptop-PC) wurde im Führerhaus der Schaluppe aufgestellt. Die 

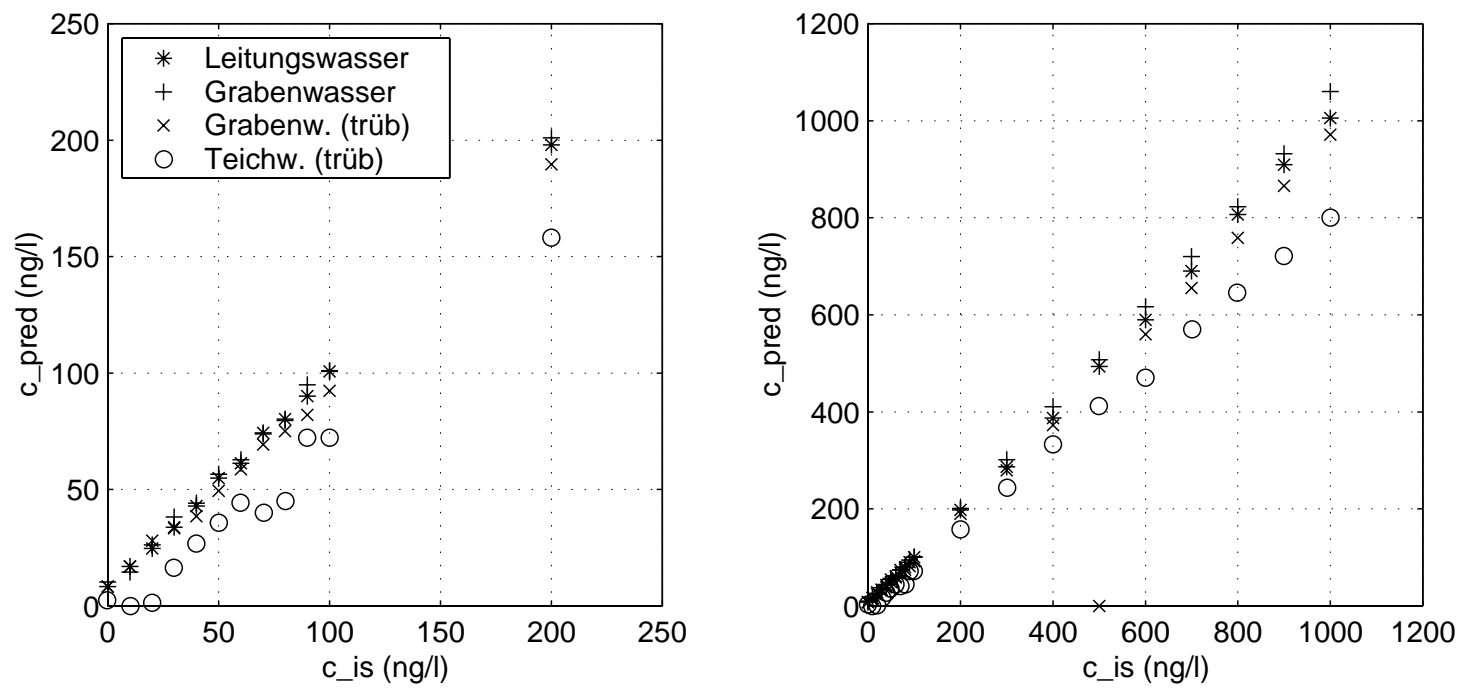

Abbildung 8.10: Validierungs-Kalibration mit 2 PLS-Faktoren: Soll-Konzentration aufgetragen gegen die Ist-Konzentration (links: Ausschnittsvergrößerung).
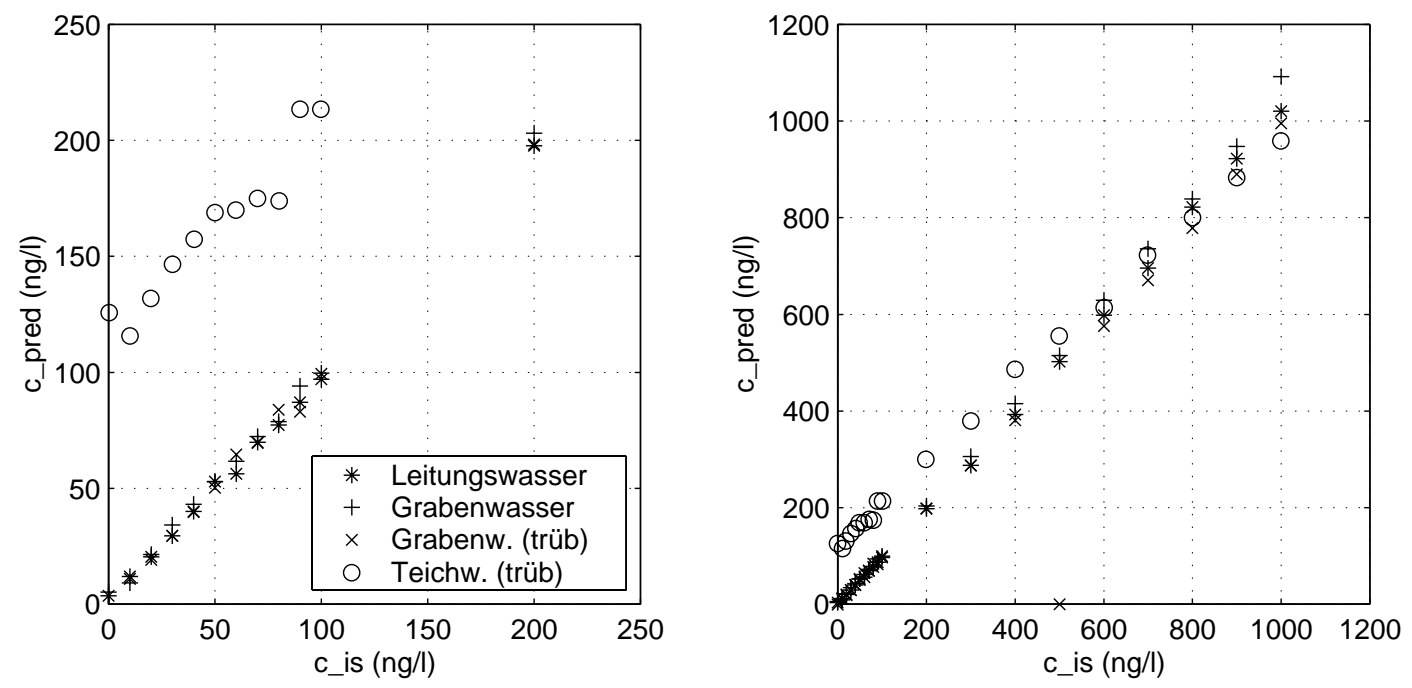

Abbildung 8.11: Validierungs-Kalibration mit 3 PLS-Faktoren (links: Ausschnittsvergrößerung).

GPS-Antenne wurde in 3 Meter Höhe über dem Führerhaus auf der Spitze einer Kunststoffstange angebracht. Das System war ab Dienstag, 27.4., 21:15 Uhr meßbereit. Das erste Querprofil wurde am 27.4. um 21:28 Uhr aufgezeichnet. Da zu dieser Zeit noch keine Tracerkonzentration zu erwarten war, wurde der gemesse- 
ne Konzentrationswert (22 ng/l) als Bezugs-Nullwert für die weiteren Messungen verwendet.

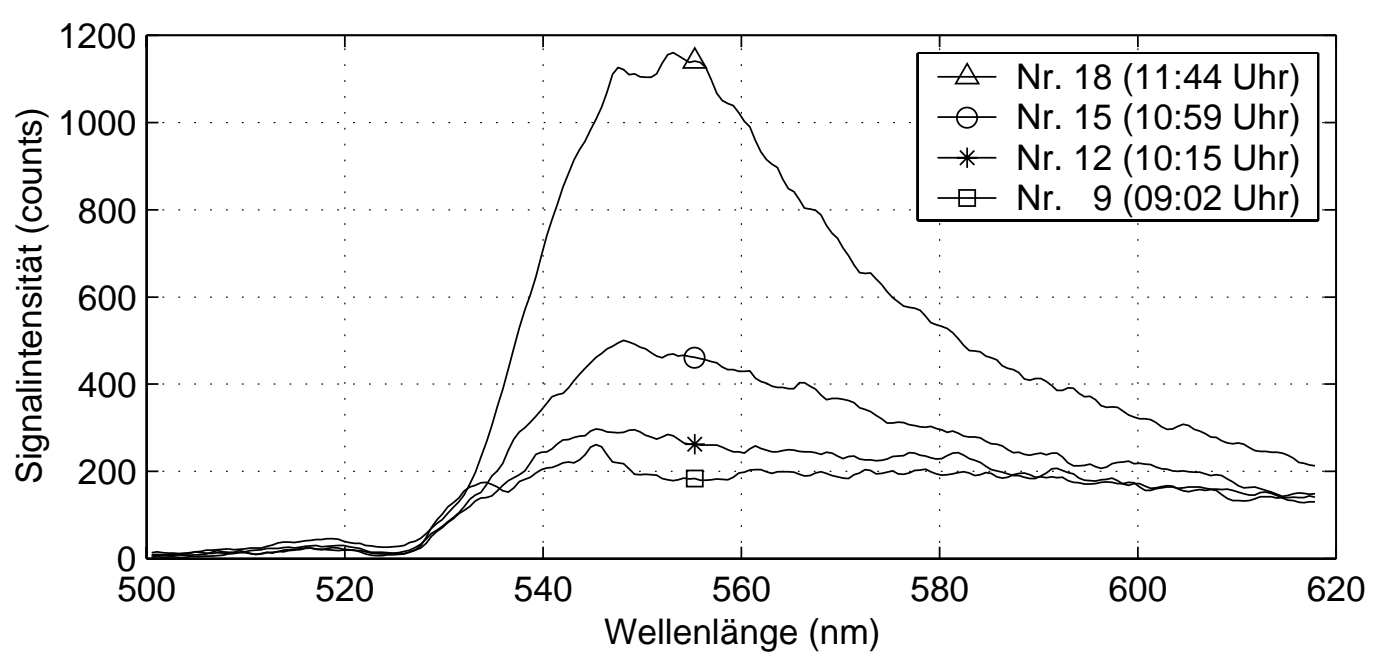

Abbildung 8.12: Einzelne Fluoreszenzspektren aus vier Querprofilen, mit denen die SRG-Konzentrationen berechnet wurde.

Ein Querprofil wurde wie folgt aufgezeichnet: Während des Ablegens der Motorschaluppe vom Anleger des WSA in Pirna auf der linken Uferseite wurde die automatische Messung gestartet. Dabei wurden im Abstand von 2 Sekunden jeweils 30 2D-Fluoreszenzspektren (zeitlicher Mittlungsbereich: 150 Nanosekunden) aufgezeichnet (siehe Abb. 8.12), gemittelt und aus dem gemittelten Spektrum mit Hilfe des im Voraus erstellten Kalibrationsmodells (Abschnitt 8.5.1) die Konzentration des Tracers SRG bestimmt. Uhrzeit, GPS-Position, Laserenergie, Tracerkonzentration und gemitteltes Spektrum wurden automatisch in Dateien abgespeichert.

Vom Anleger des WSA fuhr die Schaluppe mit annähernd konstanter Geschwindigkeit (etwa 0.5 bis $1 \mathrm{~m} / \mathrm{s}$ ) lateral über den Fluß bis ca. 5 Meter an das gegenüberliegende (rechte) Ufer heran. Hier wurde die Aufzeichnung gestoppt und ein neues Querprofil für die Rückfahrt gestartet. Die Rückfahrt wurde mit etwa der doppelten Geschwindigkeit der Hinfahrt durchgeführt und die Aufzeichnung des RückfahrtQuerprofils wurde direkt am Anleger beendet.

Ab Mittwoch, 28.4., 5:44 Uhr, wurden im Viertel- bzw. Halbstundentakt Querprofile aufgezeichnet, bis um 10 Uhr das Eintreffen der Tracerwolke (signifikanter Konzentrationsanstieg, siehe Tabelle (8.1)) beobachtet wurde. Ab 10 Uhr wurden bis 17 Uhr (eine Stunde nach Durchgang des Konzentrationsmaxiums) Querprofile im 15-Minuten-Takt aufgezeichnet. Ab 17 Uhr wurden die Profile im Halbstundentakt (ab 21 Uhr: Stundentakt) aufgezeichnet. Obwohl eine Fortführung der Messungen bis ca. 10 Uhr des nächsten Tages wünschenswert gewesen wäre, mußten die Messungen aus organisatorischen Gründen um 22 Uhr beendet werden. 
Tabelle 8.1: Tracerversuch Elbe: SRG-Konzentrationen Gemittelt über die Flußbreite zwischen 06:29 und 10:31 Uhr.

\begin{tabular}{|c|c||c|c|}
\hline $\begin{array}{c}\text { Messbe- } \\
\text { ginn }\end{array}$ & $\begin{array}{c}\text { SRG-Konzentration } \\
(\mathrm{ng} / \mathrm{l})\end{array}$ & $\begin{array}{c}\text { Messbe- } \\
\text { ginn }\end{array}$ & $\begin{array}{c}\text { SRG-Konzentration } \\
(\mathrm{ng} / \mathrm{l})\end{array}$ \\
\hline \hline $06: 29$ & 2.6 & $09: 02$ & 0.4 \\
\hline $07: 00$ & 1.0 & $09: 29$ & 3.7 \\
\hline $07: 30$ & 1.3 & $09: 57$ & 11.9 \\
\hline $08: 00$ & 1.5 & $10: 15$ & 27.4 \\
\hline $08: 29$ & 2.9 & $10: 31$ & 47.9 \\
\hline
\end{tabular}

\subsubsection{Ergebnisse}

Die Positionierung, d.h. die Zuordnung der einzelnen Konzentrationsmeßpunkte zum Abstand vom Anleger, sollte mittels GPS erfolgen. Eine kritische Betrachtung der aufgezeichneten GPS-Daten zeigte allerdings, daß die GPS-Daten größeren Schwankungen unterlegen sind als die Positionierung durch die Annahme, daß sich das Boot mit konstanter Geschwindigkeit vom Anleger bis zum anderen Flußufer bewegt hat. Aus diesem Grund wurde die Ortsbestimmung durch eine lineare Umrechnung der Aufnahmezeit auf die Flußbreite durchgeführt (bzw. auf das Teilstück von etwa 90 Metern, auf dem gemessen wurde). Generell bleibt allerdings festzuhalten, daß eine Ortsbestimmung mittels DGPS ${ }^{4}$ oder GPS und eigener Referenzstation sinnvoller gewesen wäre.

Von den einzelnen Querprofilen werden an dieser Stelle exemplarisch nur vier gezeigt (Abb. (8.13)). Der Ausgleichsfit der Rohdaten $r(i)$ wurde mit Hilfe eines digitalen Tiefpaßfilters nach der Formel:

$$
\mathrm{fit}(i)=\sum_{j=-b}^{j=b} w_{j} r(i+j)
$$

mit der Filterbreite $\mathrm{b}=5$ (spektrale Achse) bzw. $\mathrm{b}=3$ (temporale Achse) erzeugt. Die Wichtungen $w_{j}\left(\right.$ mit $\left.\sum w_{j}=1\right)$ wurden entsprechend der Filterbreite als Dreiecksprofil mit Maximum bei $w_{0}$ gewählt. In den Querprofilen Nr. 9 und 12 (1. und 2. Grafik) ist diese Fitkurve zusätzlich um den Faktor 5 verstärkt eingezeichnet.

Durch entsprechendes Zusammenfügen der einzelnen Querprofile wurde eine dreidimensionale Darstellung der Konzentration als Funktion von lateraler Flußposition und Uhrzeit erstellt (siehe Abb. (8.14)).

4 DGPS: differential global positioning system, GPS-Satellitenpositionierung, bei der per Funk übermittelte Korrekturwerte einer Referenzstation zu deutlich höherer Genauigkeit führen. 

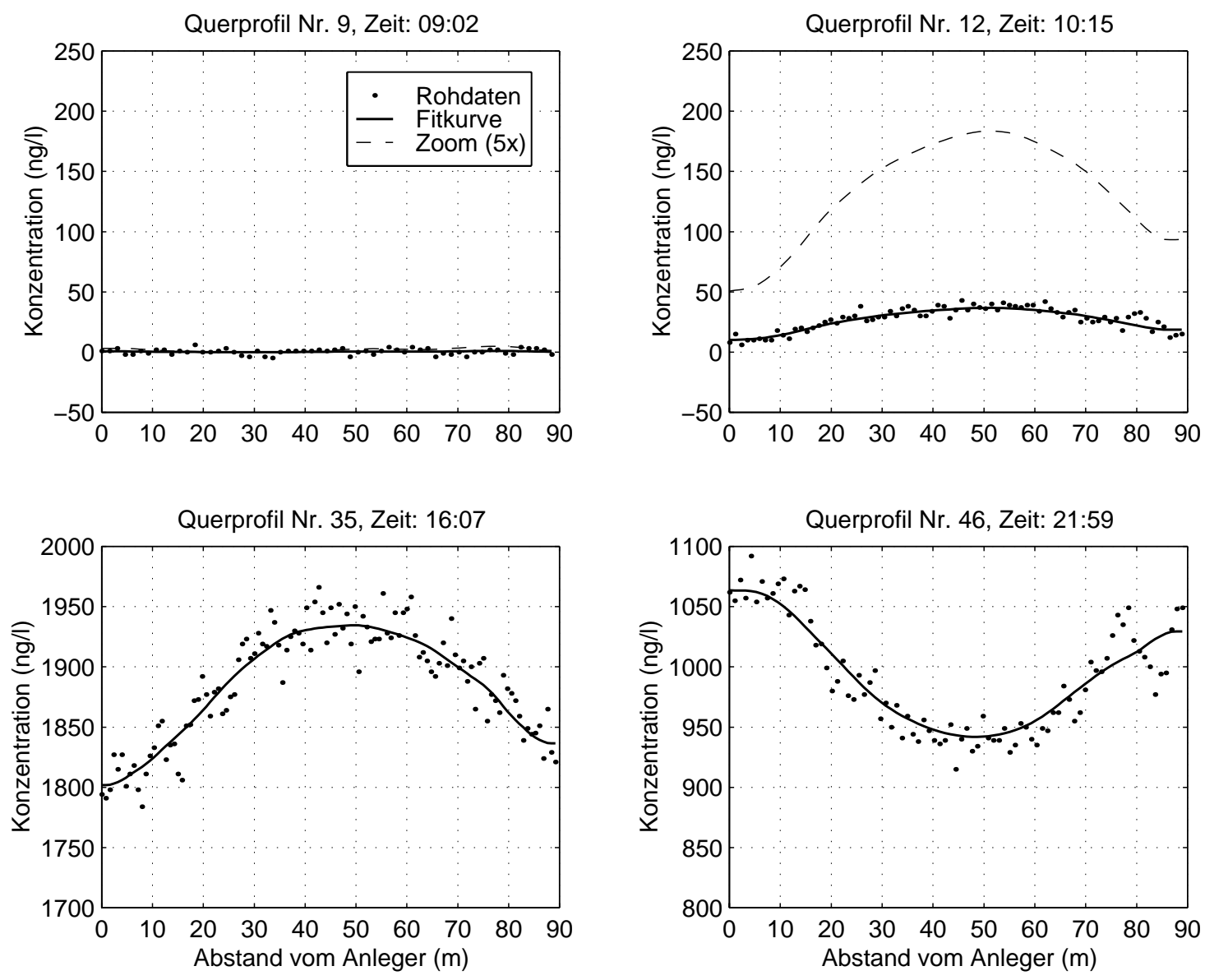

Abbildung 8.13: Querprofile: Tracerkonzentration als Funktion des Ortes (lateraler Abstand vom Anleger des WSA Pirna) zu vier verschiedenen Zeiten.

\section{Referenzmessungen}

Parallel zu den Messungen des Laser-Laboratoriums fanden im Auftrag der BfG Messungen am linken Flußufer mit Hilfe eines Probenehmers statt [200]. Dieses Gerät hat halbstündig Wasserproben aus der Elbe entnommen, die anschließend naßchemisch analysiert wurden. Die Ergebnisse im direkten Vergleich zu den Daten des Laserfluorimeters sind in Abbildung (8.15) zu sehen. Berechnet man die relativen Unterschiede zwischen den fluorimetrischen Daten $f(t)$ und den Werten des Probenehmers p(t) nach der Formel

$$
u(t)=\frac{|f(t)-p(t)|}{0.5(f(t)+p(t))}
$$

so erhält man für den zeitlichen Bereich mit starkem Signal (13 bis 19 Uhr) einen durchschnittlichen relativen Meßunterschied von 1.6\% zwischen den beiden Meß- 


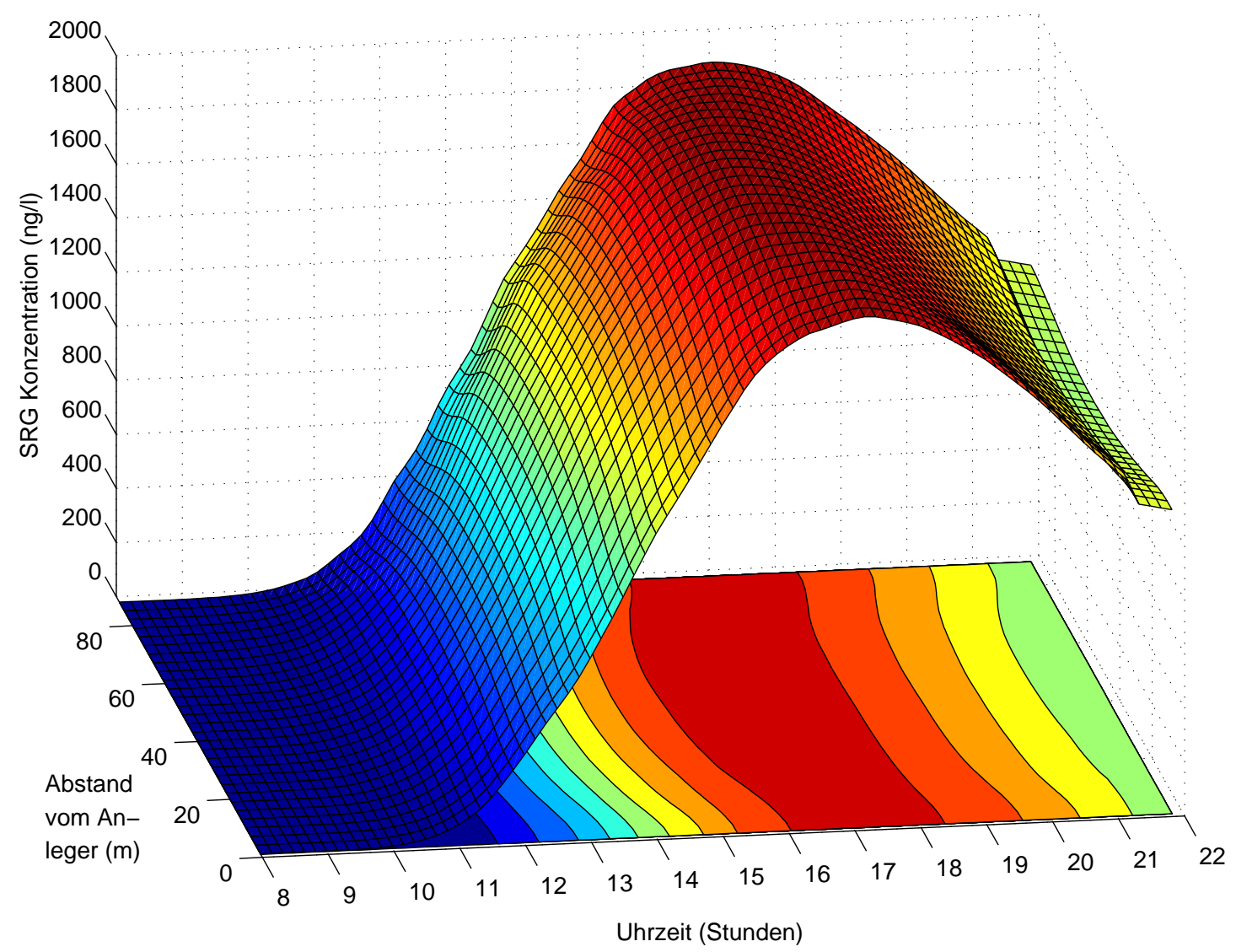

Abbildung 8.14: Die Querprofile der Hinfahrten (Anleger bis rechtes Ufer) als 3DDarstellung. Für die Darstellung wurde ein digitaler Tiefpaßfilter der Filterbreite 5 (entlang der Ortsachse) bzw. 3 (Zeitachse) verwendet.

methoden.

\subsection{Diskussion der Ergebnisse}

Die Messungen der Grundwasserverunreinigung durch einen Tankstellenunfall und der Leineverschmutzung mit Bohröl haben gezeigt, daß für reale Verschmutzungen die Sensitivität des Meßsystems mehr als ausreicht. Bei beiden Messungen war das Fluoreszenzsignal derart stark, daß über das gain des Bildverstärkers die Empfindlichkeit des Systems um eine Größenordnung reduziert werden mußte. Ebenso zeigten diese Versuche, daß auch bei realen Verschmutzungen die Spektren deutliche Charakteristiken besitzen. Es steht daher zu erwarten, daß die fingerprintMethode zur Untersuchung der Ausbreitung einer Verschmutzung große Aussicht 


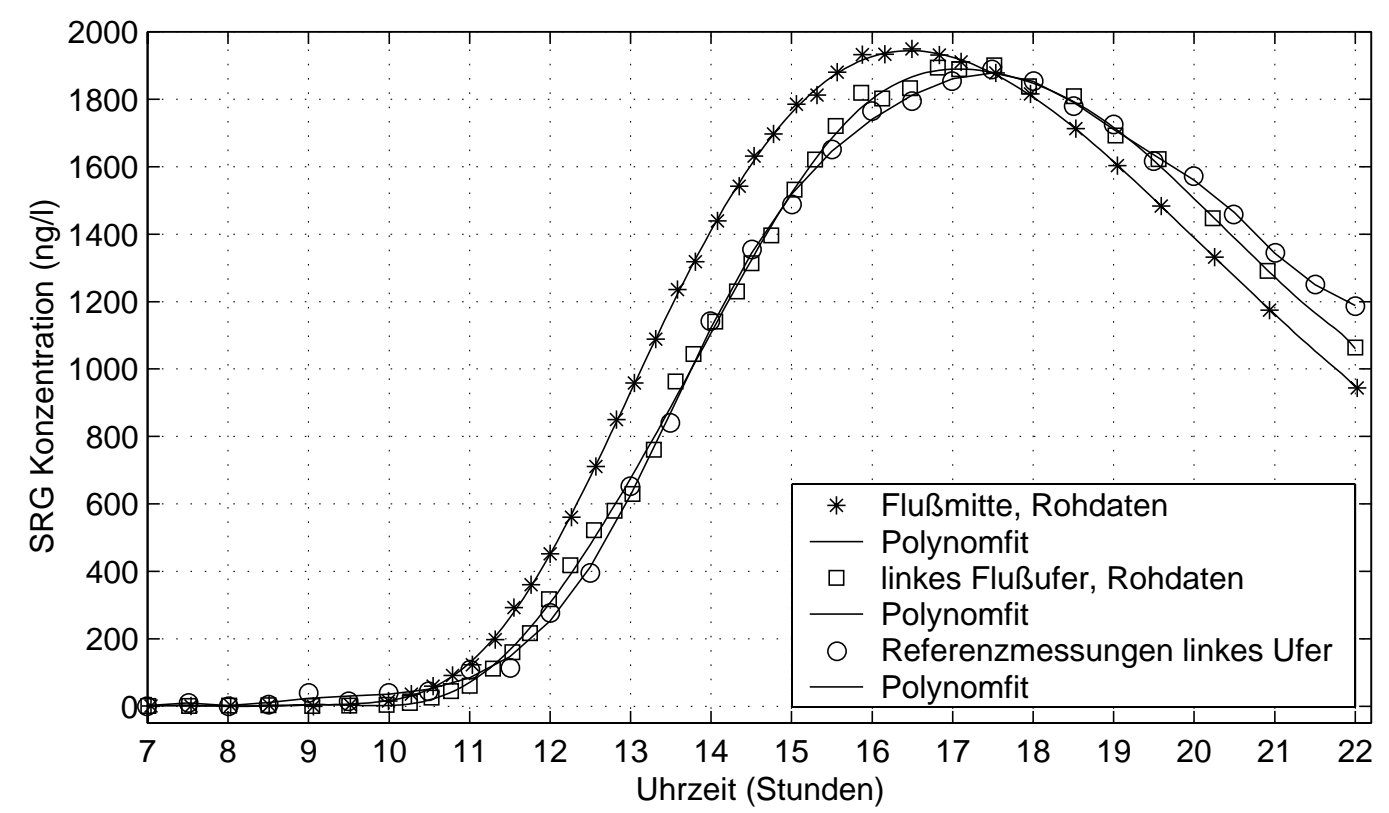

Abbildung 8.15: Fluorimetrisch gemessene Tracerkonzentration als Funktion der Zeit in der Flußmitte und am linken Ufer und mit Hilfe eines Probenehmers naßchemisch bestimmte Konzentration als Referenzwert gemessen am linken Ufer.

auf Erfolg hat, selbst wenn die genaue Art der Verschmutzung nicht bekannt ist. Die Analyse der Spektren konnte in diesen beiden Fällen mangels Referenzwerte nicht überprüft werden. Anders bei der Xylol-Verschmutzung: Obwohl die Proben an verschiedenen Orten entnommen wurden und die Ursachen der Verschmutzung unterschiedlich waren, konnte mit Hilfe der Referenzmessungen eine hohe Nachweisgenauigkeit für Xylol festgestellt werden.

Der erste Tracerversuch (Havel) war zugleich der erste Feldversuch mit dem CCD-Laserfluorimeter. Bei diesem Versuch wurden eine Reihe von „Kinderkrankheiten" des Meßsystems entdeckt (und anschließend beseitigt). Auch wurde für diesen Versuch noch kein Notch-Filter eingesetzt. Aus diesem Grund lag die Nachweisempfindlichkeit noch mehrere Größenordnungen unter der des späteren Tracerversuches auf der Elbe. Bei den Tracermessungen auf der Elbe zeigte das System eine Nachweisgenauigkeit und Empfindlichkeit, die alle Erwartungen an das Laserfluorimeter übertroffen hat. Da zudem Meßgeschwindigkeit und Preis pro Messung um mehrere Größenordnungen unter der Alternative - der naßchemischen Analyse - liegen, ist es wohl angebracht zu sagen, daß das CCD-Meßsystem die derzeit beste Möglichkeit zur Verfolgung des Farbstofftracers SRG in Flüssen ist. Neben der Demonstration der Leistungsfähigkeit des Systems und der Verwendung der Resultate für die Erstellung eines mathematischen Modells zur Strömungsbeschreibung der Elbe im Oberlauf zeigen die Querprofile eine deutliche Ausprägung der erwarteten 
„Herzform" von Tracerwolken in Flüssen [201]. So betrug die am Rande des Flusses gemessene SRG-Konzentration während des Anstieges zwischen 10 und 15 Uhr bis zu $350 \mathrm{ng} / \mathrm{l}$ weniger als in der Mitte. Während des Konzentrationsabfalls ab 17 Uhr konnte der gegenteilige Effekt beobachtet werden: Die Konzentration in der Flußmitte lag deutlich unter der SRG-Konzentration am Rand. Diese Beobachtungen konnten bisher mangels Meßmethode im sub-ppb-Bereich nicht durchgeführt werden (ebenfalls [201]). 


\section{Zusammenfassung und Ausblick}

Drei Aspekte der zeitaufgelösten in-situ-Fluoreszenzspektroskopie wurden bearbeitet: Die mathematische Modellierung der Sensorkopfgeometrie für ein Laserspektrometer, die Entwicklung und Untersuchung von Auswertemethoden für zeitaufgelöste Fluoreszenzspektren und die Systemvalidierung durch Labor- und Feldversuche.

Für die Charakterisierung und Optimierung einer Glasfaser-Optrode wurde ein mathematisches Modell entwickelt. Auf Basis dieses Modells wurde ein Computerprogramm zur Berechnung der Optrodeneffizienz als Integral über das bewertete Beobachtungsgebiet bei vorgegebenem Optrodendesign erstellt. Es wurde gezeigt, daß die Verwendung eines bezüglich des Ortes bewerteten Beobachtungsgebietes notwendig für die Berechnung der Qualität eines Optrodendesigns ist, indem die Unterschiede zwischen dem unbewerteten und dem bewerteten Beobachtungsgebiet dargestellt wurden. Die Optrodeneffizienz wurde für diverse Entwürfe bestimmt, wobei in der Regel jeweils zwei Parameter des Designs variiert wurden. Die Ergebnisse der Rechnungen fanden bei der Herstellung mehrerer Optroden Anwendung.

Das vorgestellte mathematische Modell läßt sich relativ leicht auf andere Konzepte für faseroptische Optroden anpassen. Dadurch ist die Entwicklung von faseroptischen Sensoren von den Problemen der experimentellen Charakterisierung und Optimierung zumindest zum Teil entkoppelt. Eine weitere mögliche Anwendung des Modells ist z.B. die mathematische Modellierung eines optischen Mikrofons.

Für die Auswertung von zeitaufgelösten Fluoreszenzspektren wurden eine Reihe von verschiedenen Methoden vorgestellt und diskutiert. Eine Auswertung besteht aus drei Teilschritten: Der Datenvorbereitung, der Matrixzerlegung in Kalibrationsvektoren und der Kalibration. Da für Datenvorbereitung und Kalibration bereits eine Vielzahl von Untersuchungen vorhanden waren, lag das Schwergewicht der Arbeit auf der Matrixzerlegung, der Umformung eines zeitaufgelösten Fluoreszenzspektrums in einen Vektor. Ziel der Zerlegung war die Entwicklung einer leistungsfähigen Datenreduktion unter Beibehaltung wichtiger temporaler Informationen. Als leistungsfähigste, allerdings auch wenig robuste Methoden der Matrixzerlegung haben sich die Vorhersagefehler-minimierende abstrakte Faktorzerlegung (PEM-AFD) und die „wählerische“ abstrakte Faktorzerlegung (C-AFD) erwiesen. Nicht ganz so leistungsfähig, dafür robuster, zeigte sich die Zerlegung der Datenmatrix in Zeitfenster. Für weitere Arbeiten auf diesem Gebiet wäre es wünschenswert, wenn für reale Daten eine theoretische Grenze für die Vorhersagegenauigkeit bestimmt werden könnte. Es ist interessant, daß viele der behandelten Methoden ähnlich gute Ergebnisse liefern. Selbst für grundverschiedenen Methoden zur Matrixzerlegung sind die Unterschiede in der Leistungsfähigkeit nicht sehr groß. Das legt die Vermutung nahe, daß bereits ein Großteil der Informationen eines zeitaufgelösten Spektrums für die Vorhersage genutzt wird und diese hypothetische 
theoretische Grenze nicht mehr allzuweit entfernt ist. Falls dem so ist, so würde auch für die Auswertung zeitaufgelöster Fluoreszenzspektren gelten, was LANCZOS bereits 1956 zum Thema Multiexponentialfit schrieb [181]: „It would be idle to hope that some other modified mathematical procedure could give better results, since the difficulty lies not with the manner of evaluation ... The only remedy would be an increase of accuracy to limits which are far beyond the possibilities of our present measuring devices."

Durch Experimente mit Proben realer Umweltverschmutzungen und durch Feldversuche hat sich das Laserspektrometer und die im Meßprogramm eingebundenen Auswertemethoden als feldtauglich und leistungsfähig erwiesen.

Es wurden Spektren von Grundwasser, das durch einen Tankstellenunfall verschmutzt war, und durch ausgelaufenes Bohröl verschmutztes Wasser des Flußes Leine aufgezeichnet und mit den Spektren eine Schadstoffbestimmung vorgenommen. In beiden Fällen zeigte sich die Empfindlichkeit des Meßsystems als sehr hoch.

Durch Aufnahme von Konzentrationsquerprofilen wurde der Durchgang einer Tracerwolke in der Elbe bei Pirna/Dresden beobachtet. Dabei konnte für das Meßsystem eine Nachweisempfindlichkeit für SRG in Elbewasser unterhalb $10 \mathrm{ng} / \mathrm{l}$ (entsprechend $0.01 \mu \mathrm{g} / \mathrm{l}$ bzw. $0.01 \mathrm{ppb}$ ) festgestellt werden. Durch Referenzmessungen mit Probenahme und naßchemischer Analyse konnte der Nachweisfehler des Systems auf unter $2 \%$ abgeschätzt werden. Durch die (für ein on-line System) ausgesprochen hohe Empfindlichkeit konnte das Eintreffen der Tracerwolke - der Beginn des "Anstiegs“ - und der Durchgang des Maximums bis auf wenige Minuten genau beobachtet werden.

Das wohl größte Manko des bestehenden CCD-Laserfluorimeters scheinen die Herstellungskosten zu sein. Durch eine Weiterentwicklung auf Basis eines Photomultipliers (PMT - Photo Multiplier Tube) konnten die Herstellungskosten bereits deutlich gesenkt werden. Der erste Prototyp des PMT-Systems wurde vor kurzem fertiggestellt. Noch weiter reduzieren lassen sich Preis und auch Gewicht durch Verwendung eines Mikrochiplasers in Verbindung mit einer Photonenzähltechnik. Ein solches System befindet sich derzeit in der Planungsphase. 


\section{A. Anhang}

\section{A.1 Symbole und allgemeine Abkürzungen}

\section{A.1.1 Mathematische Symbole}

Einer gängigen Konvention folgend werden Matrizen mit fett gedruckten Großbuchstaben, Vektoren mit fett gedruckten Kleinbuchstaben, Konstanten mit normalen Großbuchstaben und Variablen mit normalen kleinen Buchstaben bezeichnet.

M Ein zeitaufgelöstes Fluoreszenzspektrum als Matrix aus $\mathbb{R}^{W \times Z}$

$\mathbf{M}^{T} \quad$ Transponierte von $\mathbf{M}$

$\mathbf{M}^{\dagger} \quad$ Pseudoinverse von $\mathbf{M}$

$\mathbf{M}^{-1} \quad$ Inverse von $\mathbf{M}$ (Voraussetzung: $\mathbf{M}$ ist quadratisch)

$W \quad$ Anzahl der Kanäle (Wellenlängen) von $\mathbf{M}$

Z Anzahl der Zeitscheiben von $\mathbf{M}$

s Spaltenvektor aus $\mathbb{R}^{W}$ mit spektralen Informationen, ein 2D-Spektrum

S $\quad W \times F$-Matrix aus den Spaltenvektoren $\mathbf{s}$

z Zeilenvektor aus $\mathbb{R}^{Z}$ mit zeitabhängigen Informationen

$\mathbf{Z} \quad F \times Z$-Matrix aus den Zeilenvektoren $\mathbf{z}$

$F \quad$ Anzahl der 2D-Spektren, die durch eine Faktorzerlegung nach $\mathbf{M}=$ $\mathbf{S Z}+\mathbf{E}$ erhalten wird

E Residuenmatrix

x Zeilenvektor aus $\mathbb{R}^{K}$ mit den Variablen einer Messung

X $\in \mathbb{R}^{I \times K}$, Matrix für die multivariate Kalibration (Kalibrations- oder Regressormatrix)

I Anzahl der Messungen, z.B. Anzahl der verschiedenen Spektren

$J \quad$ Anzahl Zielvariablen, d.h. der verschiedenen Analyten

$K \quad$ Anzahl der für eine Kalibration verwendeten Variablen einer Messung

B $\in \mathbb{R}^{K \times J}$, Koeffizientenmatrix des multivariaten Modells $\mathbf{Y}=\mathbf{X B}+\mathbf{E}$

y $\in \mathbb{R}^{J}$, Zeilenvektor mit den $J$ Konzentrationen einer Messung

$\mathbf{Y} \in \mathbb{R}^{I \times J}$, Konzentrations- oder Regressandenmatrix mit den $J$ Konzentrationen von $I$ Messungen 


\section{A.1.2 Allgemeine Abkürzungen}

$\begin{array}{ll}\text { AFD } & \text { abstract factor decomposition } \\ \text { ANFD } & \text { allow negatives factor decomposition } \\ \text { BRM-AFD } & \text { biased residual minimizing abstract factor decomposition } \\ \text { C-AFD } & \text { choosy abstract factor decomposition } \\ \text { CCD } & \text { charge coupled device } \\ \text { CLS } & \text { classical least square regression } \\ \text { DFT } & \text { diskrete Fouriertransformation } \\ \text { DGPS } & \text { Differential Global Positioning System } \\ \text { DOC } & \text { dissolved organic compounds } \\ \text { EPA } & \text { Environmental Protection Agency } \\ \text { FFT } & \text { Fast Fourier Transform } \\ \text { FT-AFD } & \text { fixed-tau abstract factor decomposition } \\ \text { GC } & \text { Gas-Chromatographie } \\ \text { GPS } & \text { Global Positioning System } \\ \text { HPLC } & \text { high pressure liquid chromatography } \\ \text { ISO } & \text { International Standard Organization } \\ \text { LIF } & \text { laser induced fluorescence } \\ \text { LMM } & \text { linear mixture model } \\ \text { OLS } & \text { ordinary least squares regression } \\ \text { OMA } & \text { optical multichannel analyzer } \\ \text { MKW } & \text { Mineralölkohlenwasserstoffe } \\ \text { MLR } & \text { multiple linear regression } \\ \text { NNFD } & \text { non-negative factor decomposition } \\ \text { PAK } & \text { polycyklische aromatische Kohlenwasserstoffe } \\ \text { PCR } & \text { principle component analysis } \\ \text { PCR } & \text { principle component regression } \\ \text { PEM-AFD } & \text { prediction error minimizing abstract factor decomposition } \\ \text { PLS } & \text { partial least squares regression } \\ \text { PMT } & \text { Photo Multiplier Tube } \\ \text { RM-AFD } & \text { residual minimizing abstract factor decomposition } \\ \text { SVD } & \text { singular value decomposition } \\ \text { UV } & \text { Ultraviolett(es Licht) } \\ \text { WSA } & \text { Wasser- und Schiffahrtsamt } \\ & \end{array}$




\section{A.2 Abkürzungen und Eigenschaften der Schad- stoffe}

Tabelle A.1: Eigenschaften der EPA-PAK (1)

Die Abklingzeiten wurden in dest. Wasser mit Sauerstoffgleichgewicht unter Raumtemperatur bestimmt. (aus [56, 202, 203]).

\begin{tabular}{|l|c|r|r|c|}
\hline Index und Name & Abkürzung & $\begin{array}{c}\text { Abklingzeit } \\
\text { (in ns) }\end{array}$ & Ringe & Summenformel \\
\hline \hline 1. Acenaphthen & ACN & $25.5 \pm 0.5$ & 3 & $\mathrm{C}_{11} \mathrm{H}_{8}$ \\
\hline 2. Acenaphthylen & ACY &.$/$. & 3 & $\mathrm{C}_{12} \mathrm{H}_{10}$ \\
\hline 3. Anthracen & ANT & $<5$ & 3 & $\mathrm{C}_{14} \mathrm{H}_{10}$ \\
\hline 4. Benzo[a]anthracen & BaA & $26.5 \pm 1.0$ & 4 & $\mathrm{C}_{18} \mathrm{H}_{12}$ \\
\hline 5. Benzo[k]fluoranthen & BkF & $9.9 \pm 0.6$ & 5 & $\mathrm{C}_{20} \mathrm{H}_{12}$ \\
\hline 6. Benzo[b]fluoranthen & BbF & $31.4 \pm 0.9$ & 5 & $\mathrm{C}_{20} \mathrm{H}_{12}$ \\
\hline 7. Benzo[g,h,i]perylen & BgP &.$/$. & 6 & $\mathrm{C}_{22} \mathrm{H}_{12}$ \\
\hline 8. Benzo[a]pyren & BaP & $29.0 \pm 0.6$ & 5 & $\mathrm{C}_{20} \mathrm{H}_{12}$ \\
\hline 9. Chrysen & CHR & $29.7 \pm 0.8$ & 4 & $\mathrm{C}_{18} \mathrm{H}_{12}$ \\
\hline 10. Dibenz[a,h]anthracen & DBA &.$/$. & 5 & $\mathrm{C}_{22} \mathrm{H}_{14}$ \\
\hline 11. Fluoranthen & FLA & $32.6 \pm 0.4$ & 4 & $\mathrm{C}_{16} \mathrm{H}_{10}$ \\
\hline 12. Fluoren & FLU & $5.2 \pm 0.3$ & 3 & $\mathrm{C}_{13} \mathrm{H}_{10}$ \\
\hline 13. Indeno[1,2,3,c,d]pyren & INP &.$/$. & 6 & $\mathrm{C}_{22} \mathrm{H}_{12}$ \\
\hline 14. Naphthalin & NAP & $37.0 \pm 0.5$ & 2 & $\mathrm{C}_{10} \mathrm{H}_{8}$ \\
\hline 15. Phenanthren & PHT & $37.1 \pm 0.9$ & 3 & $\mathrm{C}_{14} \mathrm{H}_{10}$ \\
\hline 16. Pyren & PYR & $122.3 \pm 5.5$ & 4 & $\mathrm{C}_{16} \mathrm{H}_{10}$ \\
\hline
\end{tabular}

In Tabelle A.1 sind die 16 polyzyklischen aromatischen Kohlenwasserstoffe (PAK) aufgeführt, die in der Liste der besonders unerwünschten Schadstoffe der US-Environment Protection Agency (EPA) aufgeführt werden. Tabelle A.2 enthält weitere Eigenschaften und Bewertungskriterien der PAK. 
Tabelle A.2: Eigenschaften der EPA-PAK (2)

Löslichkeit: bei $25^{\circ} \mathrm{C}$ (aus $[204,205,206,207]$ ). Gesundheitsschädigung (a): akute Toxizität (letale Dosis für 50\% Mäuse oder Ratten bei oraler Applikation, $\mathrm{LD}_{50}$ oral) in $\mathrm{mg} / \mathrm{kg}$ Körpergewicht, aus [208]; (b): Karzinogenität bei Tieren in mg/kg Körpergewicht (-: keine Wirkung), aus [207]; (c): Mutagenität nach dem Ames Assay (-: negativ, +: positiv), aus [208]. Grenzwert: Entsprechend der deutschen Trinkwasserverordnung (TVO), aus [131].

\begin{tabular}{|c|c|c|c|c|c|}
\hline Index und & Löslichkeit & \multicolumn{3}{|c|}{ Gesundheitsschädigung } & Grenzwert \\
\hline Abkürzung & in Wasser & (a) & (b) & (c) & nach TVO \\
\hline 1. $\mathrm{ACN}$ & $3.93 \mathrm{mg} / \mathrm{l}$ & n.b. & n.b. & n.b. & - \\
\hline 2. ACY & $16.1 \mathrm{mg} / \mathrm{l}$ & k.A. & n.b. & n.b. & - \\
\hline 3. ANT & $73 \mu \mathrm{g} / \mathrm{l}$ & n.b. & 3300 & n.b. & - \\
\hline 4. $\mathrm{BaA}$ & $14 \mu \mathrm{g} / \mathrm{l}$ & n.b. & 2 & + & - \\
\hline 5. BkF & $0.55 \mu \mathrm{g} / \mathrm{l}$ & k.A. & 72 & n.b. & $0.2 \mu \mathrm{g} / 1$ \\
\hline 6. $\mathrm{BbF}$ & $1.2 \mu \mathrm{g} / \mathrm{l}$ & k.A. & 40 & n.b. & $0.2 \mu \mathrm{g} / \mathrm{l}$ \\
\hline 7. BgP & $0.26 \mu \mathrm{g} / \mathrm{l}$ & k.A. & n.b. & n.b. & $0.2 \mu \mathrm{g} / 1$ \\
\hline 8. $\mathrm{BaP}$ & $3.8 \mu \mathrm{g} / \mathrm{l}$ & 250 & 0.002 & + & $0.2 \mu \mathrm{g} / \mathrm{l}$ \\
\hline 9. CHR & $2.0 \mu \mathrm{g} / 1$ & 320 & 99 & + & - \\
\hline 10. DBA & $0.5 \mu \mathrm{g} / \mathrm{l}$ & n.b. & 0.006 & + & - \\
\hline 11. FLA & $260 \mu \mathrm{g} / 1$ & 500 & n.b. & + & $0.2 \mu \mathrm{g} / 1$ \\
\hline 12. FLU & $1.98 \mathrm{mg} / \mathrm{l}$ & n.b. & n.b. & n.b. & - \\
\hline 13. INP & $62 \mu \mathrm{g} / \mathrm{l}$ & n.b. & 72 & n.b. & $0.2 \mu \mathrm{g} / 1$ \\
\hline 14. NAP & $31.7 \mathrm{mg} / \mathrm{l}$ & 310 & - & - & - \\
\hline 15. PHT & $1.29 \mathrm{mg} / \mathrm{l}$ & 700 & - & - & - \\
\hline 16. PYR & $135 \mu \mathrm{g} / 1$ & 510 & - & - & - \\
\hline
\end{tabular}




\section{A.3 Das Meßprogramm FAP-CONTROL}

Auf der Softwareseite wurden folgende drei Komponenten benötigt:

- Hardwareansteuerung mit (mindestens) Millisekundengenauigkeit,

- Benutzeroberfläche für den Laboreinsatz (Kontrolle über alle Meßparameter), den Feldeinsatz (u.a. automatische Einbindung von GPS-Daten zur Positionsbestimmung) und den Routineeinsatz (Simple-User-Interface) und

- automatisierte Datenanalyse.

Für die Realisierung des Programms wurden die Compiler Borland $\mathrm{C}++^{1}$ und Borland Delphi ${ }^{2}$ verwendet.

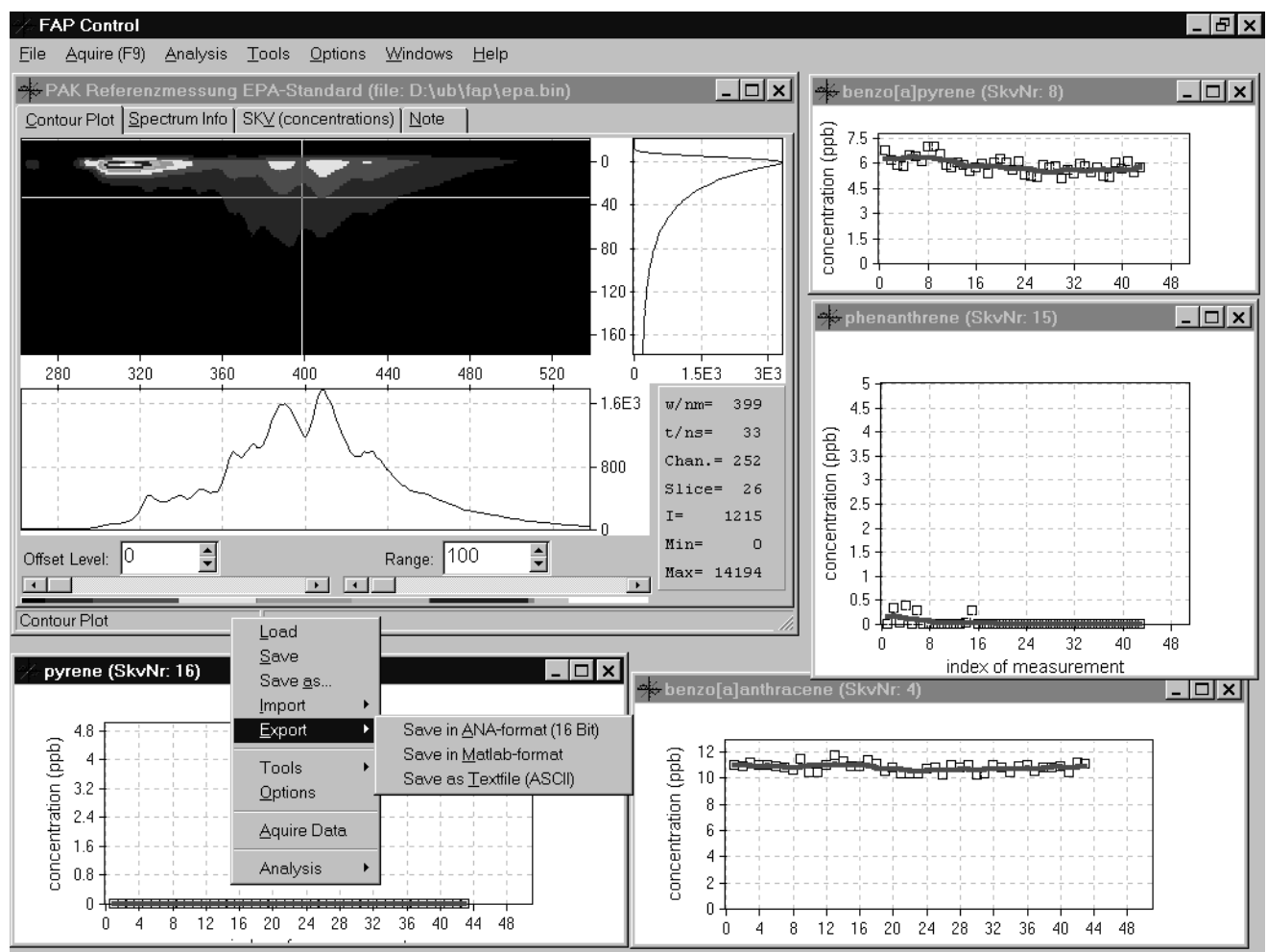

Abbildung A.1: Die Oberfläche des Meß- und Auswerteprogramms FAP-CONTROL.

Die Hardwareansteuerung erfolgt durch Assemblerroutinen, die so ausgelegt sind, daß sie auch unter Windows $95^{3}$ ein zeitkritisches Timing im Mikrosekundenbereich erlauben (Auflösung: $0.8 \mu \mathrm{s}$ ). Die Assemblerbefehle sind von Delphi-Funktionen

1 Borland $\mathrm{C}++$, Vers. 4.52, Borland GmbH, Langen.

2 Borland Delphi, Vers. 2.01, Borland GmbH, Langen.

3 Betriebssystem Windows $95 b$ (Sep. 1997), Microsoft Corp., Seattle. 
eingekapselt und werden durch den Delphi-Compiler übersetzt. Sie bilden damit die Schnittstelle zwischen dem Laserfluorimeter und der in Delphi entwickelten Benutzeroberfläche.

Die Benutzeroberfläche unter Windows 95 wurde als MDI-Programm (Multiple Document Interface, siehe Abb. (A.1)) realisiert und erlaubt die vollständige Kontrolle über die Aufnahmeparameter. In das Programm integriert ist ein Assistent für eine einfache Bedienbarkeit (Simple User Interface). Zur näheren Betrachtung können die 3D-Daten (zeitaufgelöste Fluoreszenzspektren) in Niveaulinienplots dargestellt werden. Der Benutzer hat die Möglichkeit, beliebige 2D-Schnitte durch Wellenlängen und Zeit für nähere Betrachtungen auszuwählen.

Für die Auswertung der Daten stehen mehrere Methoden parallel zur Verfügung. Einige Methoden, wie z.B. die „Maximalabschätzung“ und die „Kompositanalyse“ (ein OLS-Verfahren), wurden C++ implementiert und über eine DLL-Schnittstelle mit der Benutzeroberfläche verbunden. Die leistungsfähigsten Auswertemethoden basieren auf einer multivariaten Kalibration mit wahlweise abstrakter Faktorzerlegung oder Fensterzerlegung und sind direkt in das Programm integriert.

\section{A.4 Eigenschaften der Datensätze DS1 bis DS8}

Die einzelnen Spektren aller Datensätze wurde auf das gleiche Matrixformat gebracht, mit $W=35$ Kanälen (302 bis $506 \mathrm{~nm}$ ) und $Z=39$ Zeitscheiben (0 bis 152 ns, gemessen ab Maximum der Anregung).

- DS1 Maximalkonzentrationen (in $\mu \mathrm{g} / \mathrm{l}$ ): ACN: 2.5, ANT: 5.0, BaA: 1.3, BkF: 1.3, BbF: 0.25, BaP: 0.75, CHR: 1.3, FLU: 1.3, NAP: 5.0, PHT: 5.0 und PYR: 2.5. Hintergrundspektren des Kalibrationsteils aus WP1 und WP3; Hintergrundspektren des Validationsteils aus WP2, WP4 und WP5.

- DS2 Maximalkonzentrationen (in $\mu \mathrm{g} / \mathrm{l}$ ): ACN: 13.7, ANT: 18.7, BaA: 4.2, BkF: 2.4, BbF: 0.50, BaP: 3.9, CHR: 3.9, FLU: 3.9, NAP: 20.4, PHT: 15.9 und PYR: 4.9. Hintergrundspektren des Kalibrationsteils aus WP1 bis WP12; Hintergrundspektren des Validationsteils aus WP13 bis WP24.

- DS3 Maximalkonzentrationen (in $\mu \mathrm{g} / \mathrm{l}$ ): ACN: 3.8, ANT: 7.5, BaA: 1.3, BkF: 1.00, BbF: 0.20, BaP: 1.3, CHR: 1.3, FLU: 1.3, NAP: 6.3, PHT: 5.0 und PYR: 2.5. Hintergrundspektren des Kalibrationsteils aus WP1 bis WP5; Hintergrundspektren des Validationsteils aus WP6 bis WP12.

- DS4 Maximalkonzentrationen (in $\mu \mathrm{g} / \mathrm{l}$ ): ACN: 6.0, ANT: 12.0, BaA: 2.0, BkF: 1.7, BbF: 0.33, BaP: 2.0, CHR: 2.0, FLU: 2.0, NAP: 10.0, PHT: 8.0 und PYR: 4.0. Hintergrundspektren des Kalibrationsteils aus WP1 bis WP10; Hintergrundspektren des Validationsteils aus WP11 bis WP20. 
- DS5 Maximalkonzentrationen (in $\mu \mathrm{g} / \mathrm{l}$ ): ACN: 1.6, ANT: 7.1, BaA: 0.59, BkF: 0.43, BbF: 0.86, BgP: 28.0, BaP: 0.29, CHR: 0.23, DBA: 17.5, FLU: 0.67, INP: 332.3, NAP: 5.3, PHT: 2.0 und PYR: 0.85. Hintergrundspektren des Kalibrationsteils aus WP1 bis WP10; Hintergrundspektren des Validationsteils aus WP11 bis WP24.

- DS6 Maximalkonzentrationen (in $\mu \mathrm{g} / \mathrm{l}$ ): ACN: 3.1, ANT: 14.3, BaA: 1.2, BkF: 0.85, BbF: 1.7, BgP: 56.0, BaP: 0.57, CHR: 0.45, DBA: 34.9, FLU: 1.3, INP: 664.6, NAP: 10.6, PHT: 3.9 und PYR: 1.7. Hintergrundspektren des Kalibrationsteils nur aus WP10 (kurzwellige Fluoreszenz); Hintergrundspektren des Validationsteils aus WP1-9 und WP11-24 .

- DS7 Maximalkonzentrationen (in $\mu \mathrm{g} / \mathrm{l}$ ): ACN: 1.6, ANT: 7.1, BaA: 0.59, BkF: 0.43, BbF: 0.86, BgP: 28.0, BaP: 0.29, CHR: 0.23, DBA: 17.5, FLU: 0.67, INP: 332.3, NAP: 5.3, PHT: 2.0 und PYR: 0.85. Keine Hintergrundspektren im Kalibrationsteil; Hintergrundspektren des Validationsteils aus WP1 bis WP24.

- DS8 Maximalkonzentrationen (in $\mu \mathrm{g} / \mathrm{l}$ ): ACN: 3.1, ANT: 14.3, BaA: 1.2, BkF: 0.85, BbF: 1.7, BgP: 56.0, BaP: 0.57, CHR: 0.45, DBA: 34.9, FLU: 1.3, INP: 664.6, NAP: 10.6, PHT: 3.9 und PYR: 1.7. Hintergrundspektren des Kalibrationsteils nur aus WP1 und WP2 (langwellige Fluoreszenz); Hintergrundspektren des Validationsteils aus WP3 bis WP24. 


\section{A.5 Spektren}

Im folgenden finden sich die Fluoreszenzspektren der 15 fluoreszierenden EPAPAK und des EPA-Standards (die 16 EPA-PAK in destilliertem Wasser in den Konzentrationen $10 \mu \mathrm{g} / \mathrm{l}$ ), aufgezeichnet mit dem CCD-Laserfluorimeter.

Die für die Erstellung von Labordaten verwendeten Hintergrundspektren (Spektren natürlicher Proben ohne PAK-Kontamination) befinden sich in - nach Herkunft der Proben geordnet - 24 Datensätzen WP1 bis WP24 mit jeweils 129 Spektren. Die Fluoreszenz in den natürlichen Proben wird durch diverse natürliche fluoreszierende Bestandteile verursacht. Ab Seite 128 werden jeweils drei Zeitscheiben eines der 129 Spektren aus jedem der 24 Datensätze gezeigt. 
PAK Nr. 1: ACN
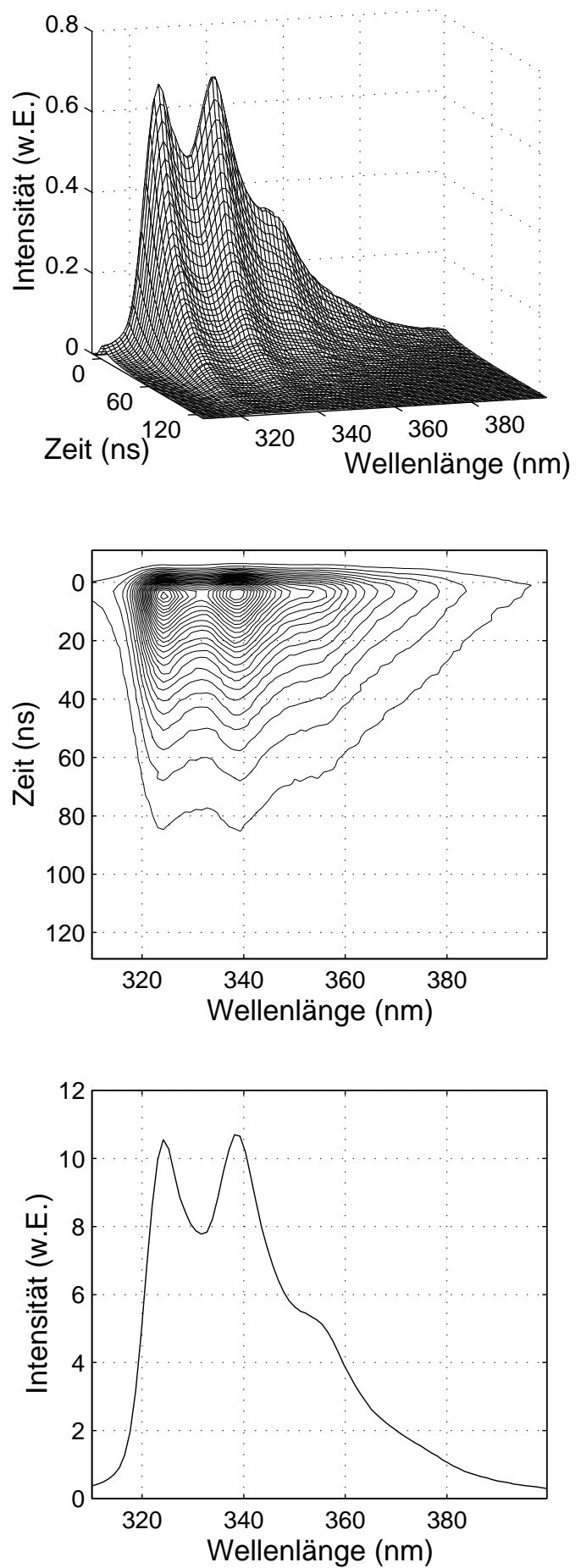

PAK Nr. 3: ANT
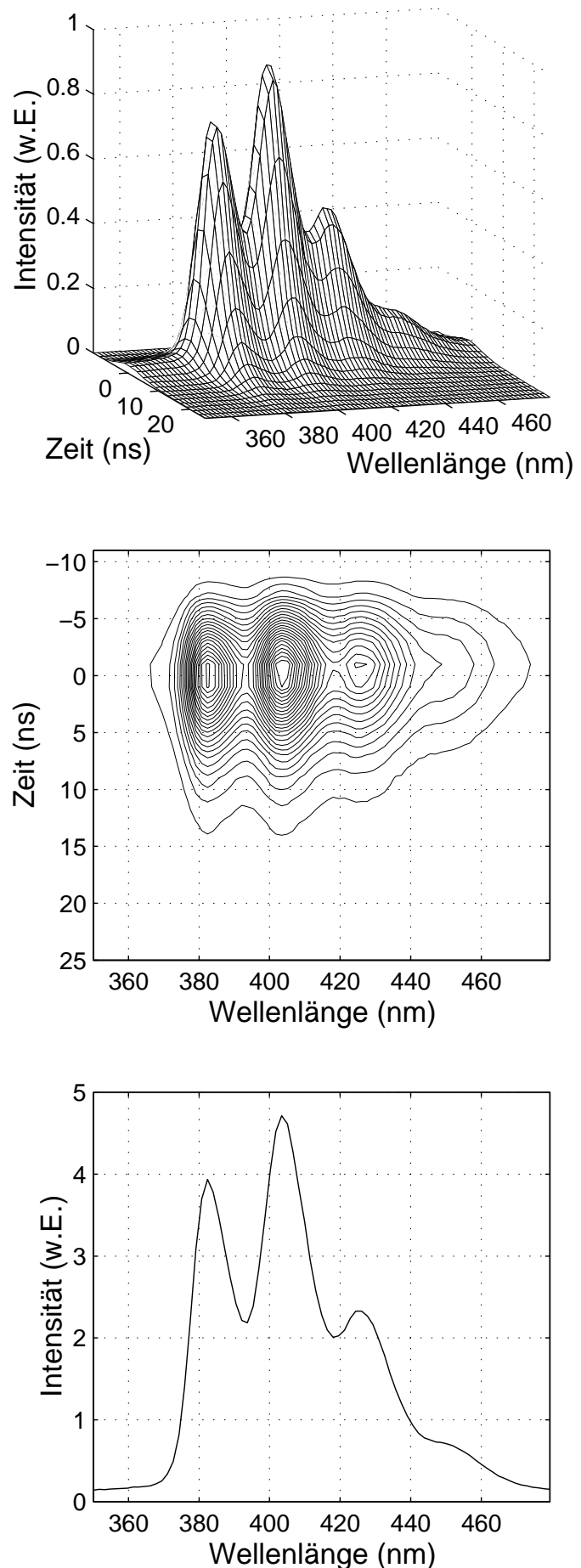

Abbildung A.2: Die zeitaufgelösten Spektren von Acenaphthen (ACN, links) und Anthracen (ANT, rechts), normiert auf das Ramansignal. Oben: Perspektivische 3DDarstellung; Mitte: Kontourendarstellung; Unten: Integrales Spektrum (Summe der Zeitscheiben). 
PAK Nr. 4: BaA
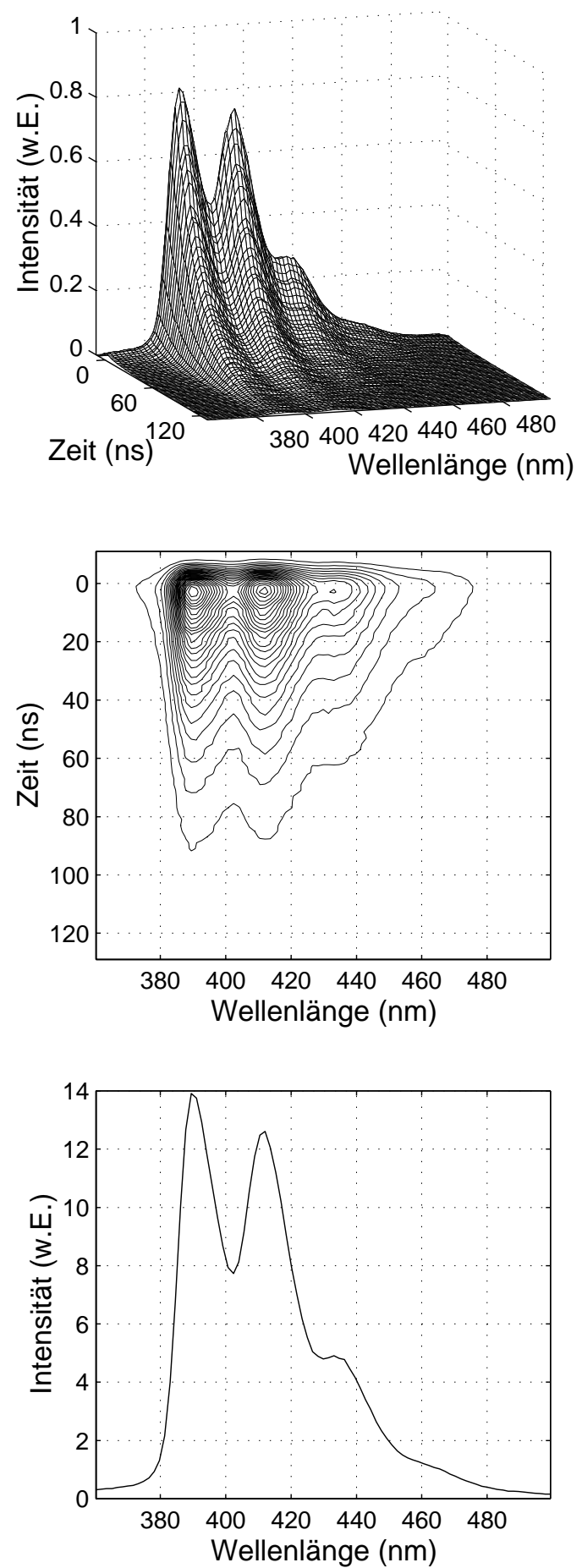

PAK Nr. 5: BkF
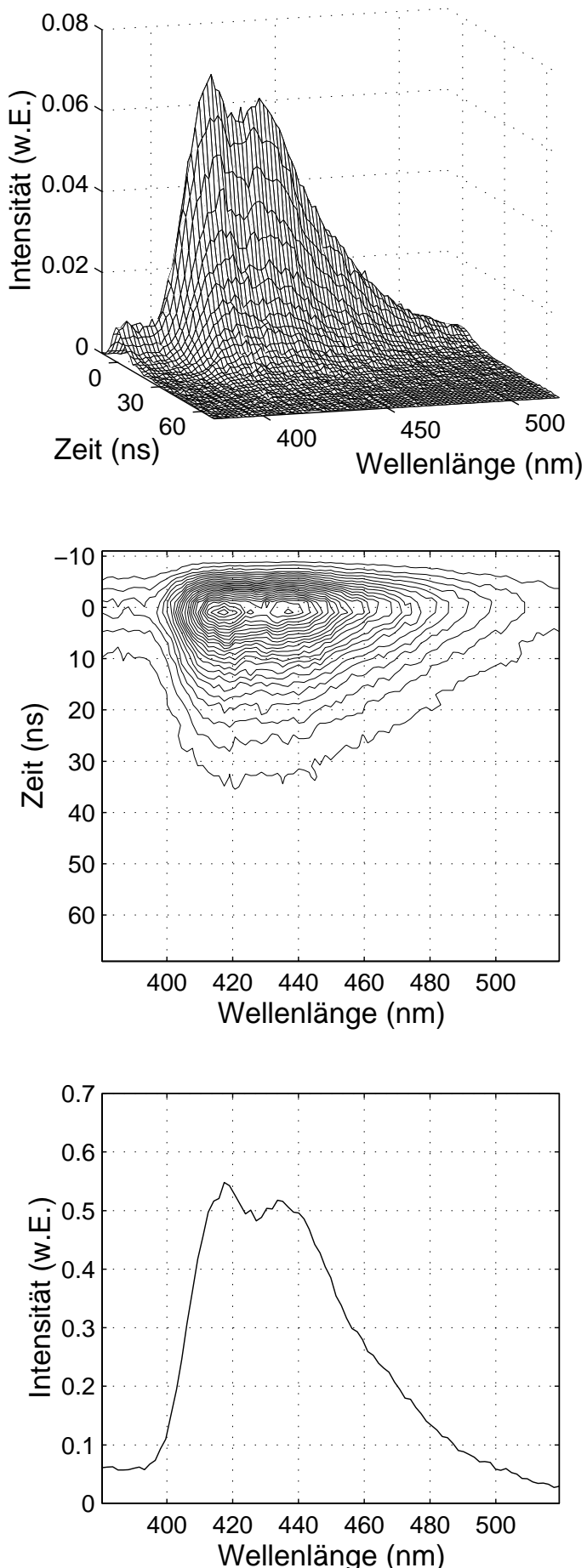

Abbildung A.3: Die zeitaufgelösten Spektren von Benzo[a]anthracen (BaA, links) und Benzo[k]fluoranthen (BkF, rechts), normiert auf das Ramansignal. Oben: Perspektivische 3D-Darstellung; Mitte: Kontourendarstellung; Unten: Integrales Spektrum (Summe der Zeitscheiben). 
PAK Nr. 6: BbF
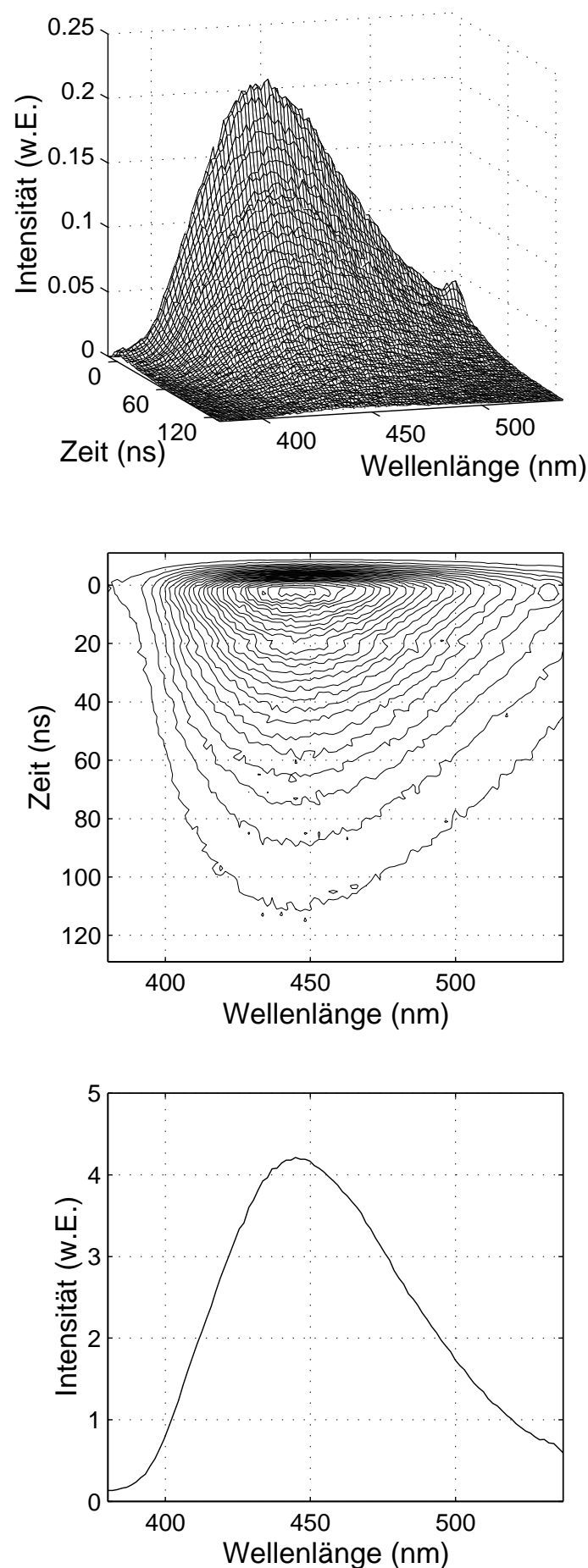

PAK Nr. 7: BgP
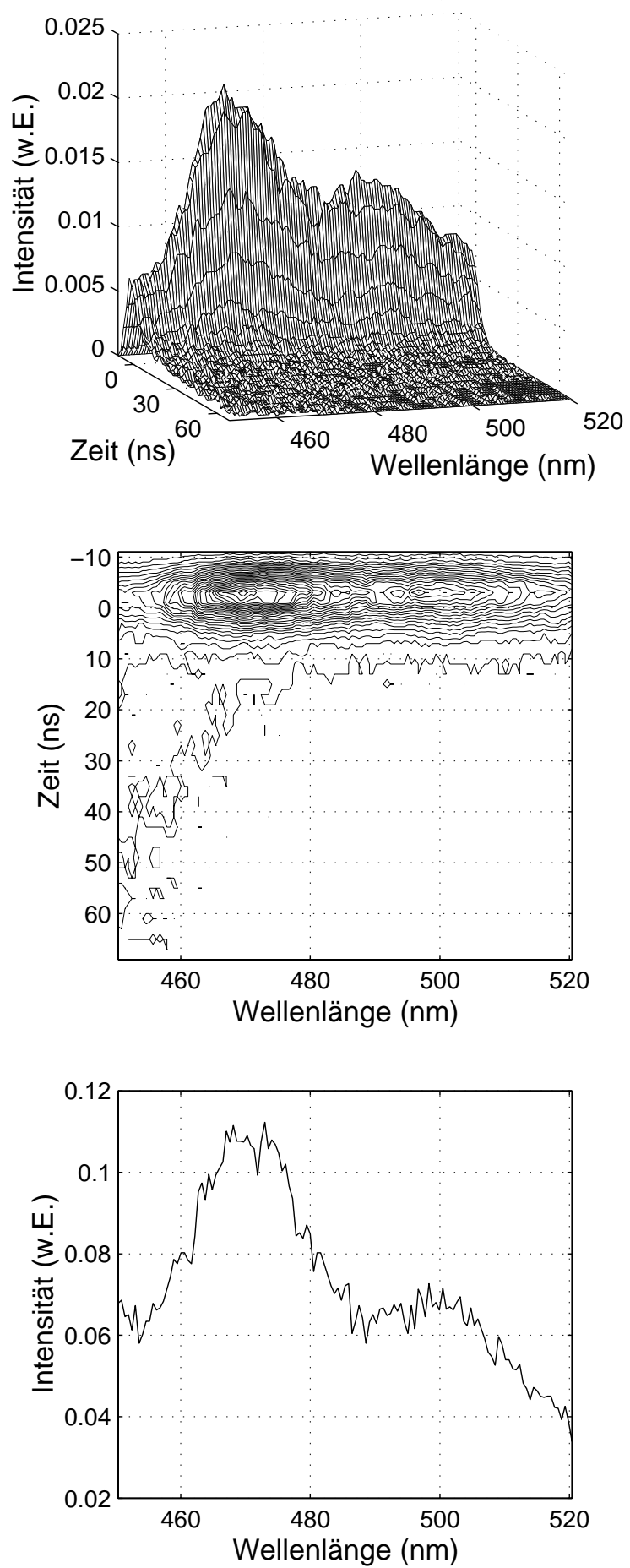

Abbildung A.4: Die zeitaufgelösten Spektren von Benzo[b]fluoranthen (BbF, links) und Benzo[g,h,i]perylen (BgP, rechts), normiert auf das Ramansignal. Oben: Perspektivische 3D-Darstellung; Mitte: Kontourendarstellung; Unten: Integrales Spektrum (Summe der Zeitscheiben). 
PAK Nr. 8: BaP
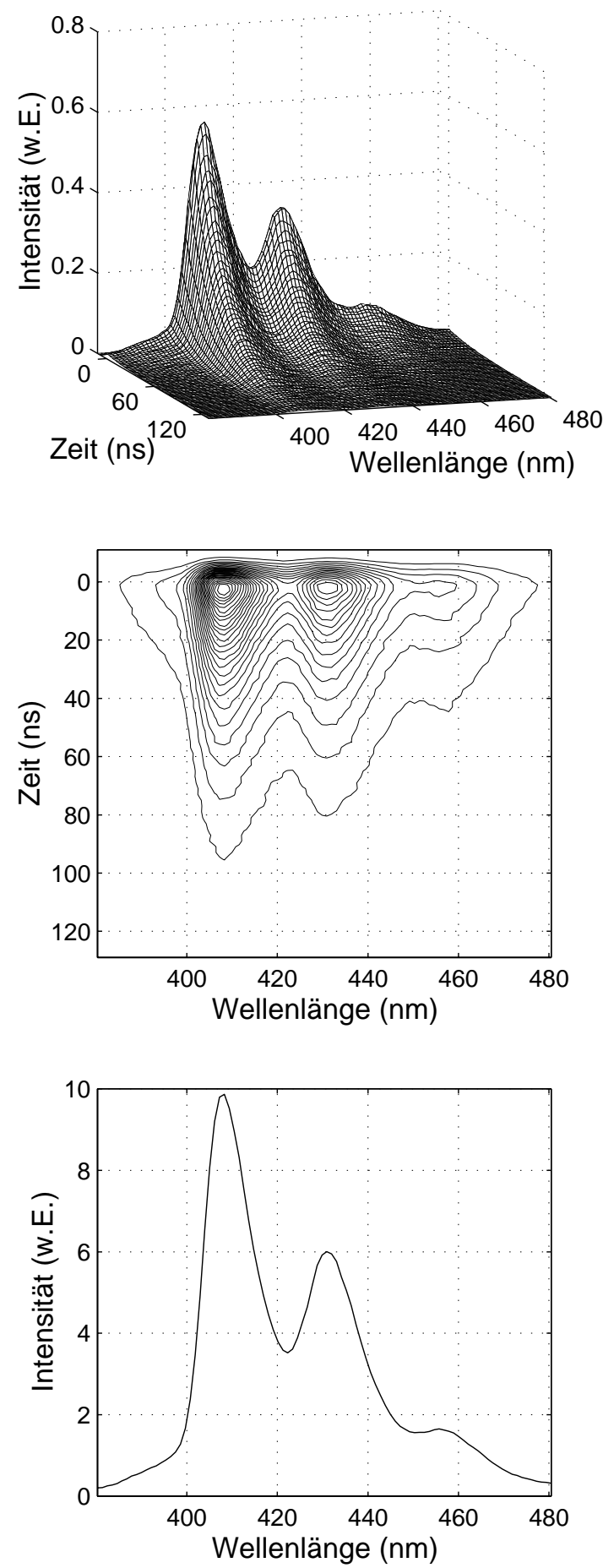

PAK Nr. 9: CHR
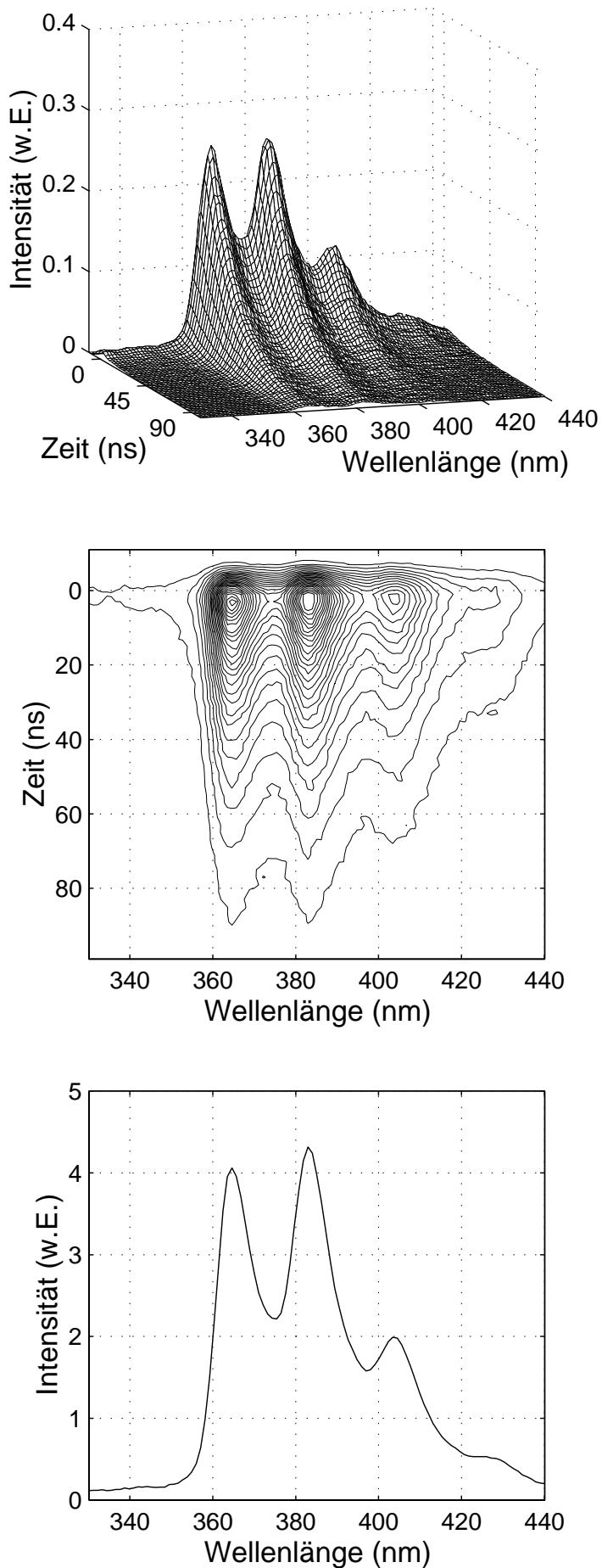

Abbildung A.5: Die zeitaufgelösten Spektren von Benzo[a]pyren (BaP, links) und Chrysen (CHR, rechts), normiert auf das Ramansignal. Oben: Perspektivische 3DDarstellung; Mitte: Kontourendarstellung; Unten: Integrales Spektrum (Summe der Zeitscheiben). 
PAK Nr. 10: DBA
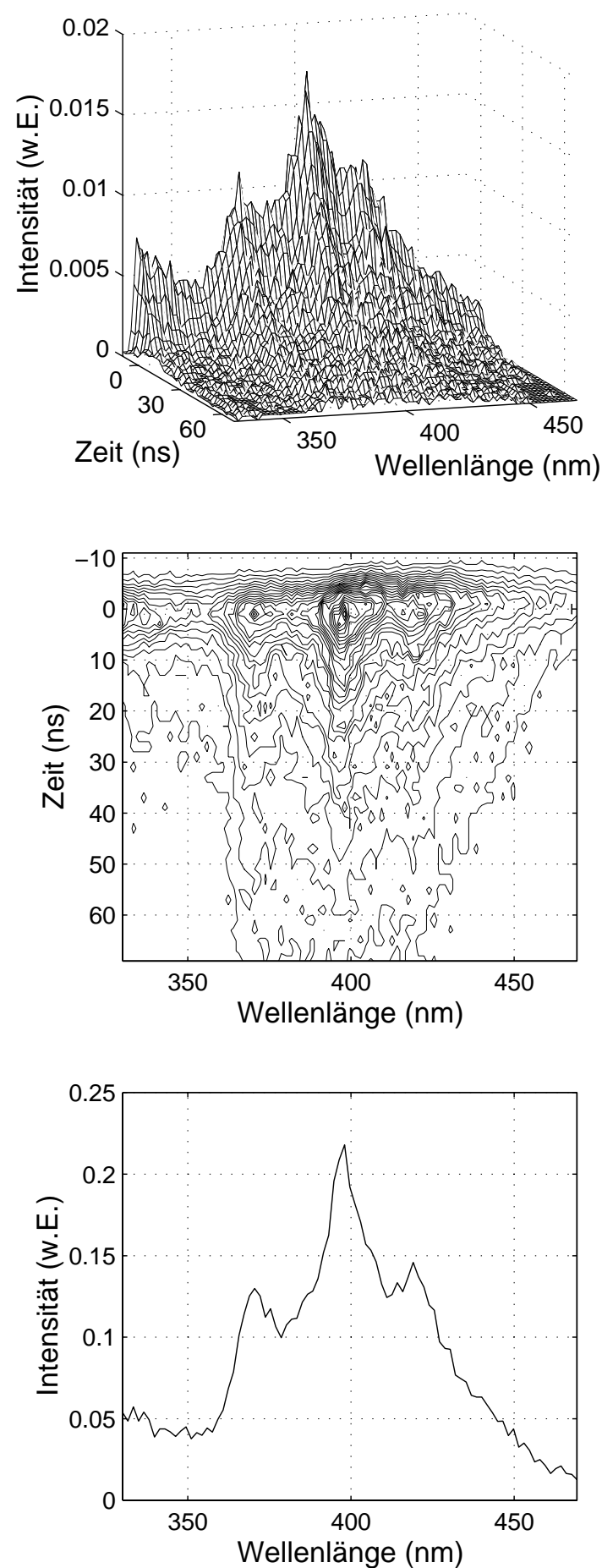

PAK Nr. 11: FLA
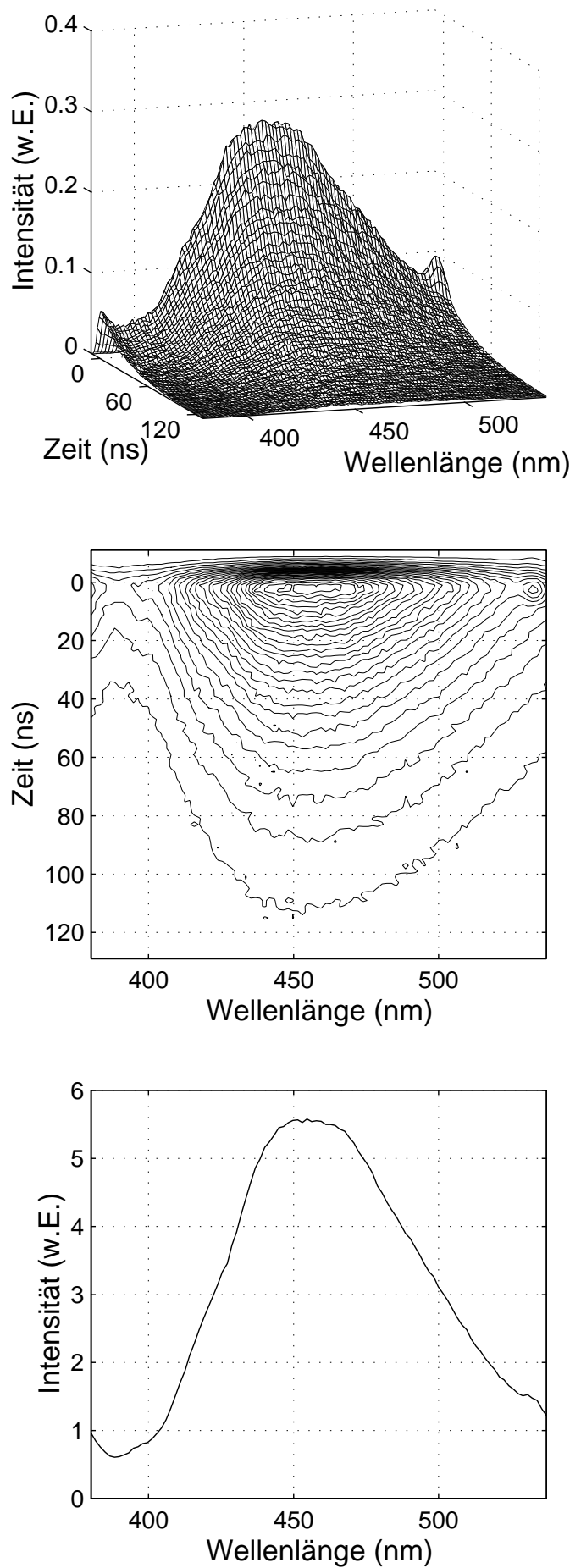

Abbildung A.6: Die zeitaufgelösten Spektren von Dibenz[a,h]anthracen (DBA, links) und Fluoranthen (FLA, rechts), normiert auf das Ramansignal. Oben: Perspektivische 3D-Darstellung; Mitte: Kontourendarstellung; Unten: Integrales Spektrum (Summe der Zeitscheiben). 
PAK Nr. 12: FLU
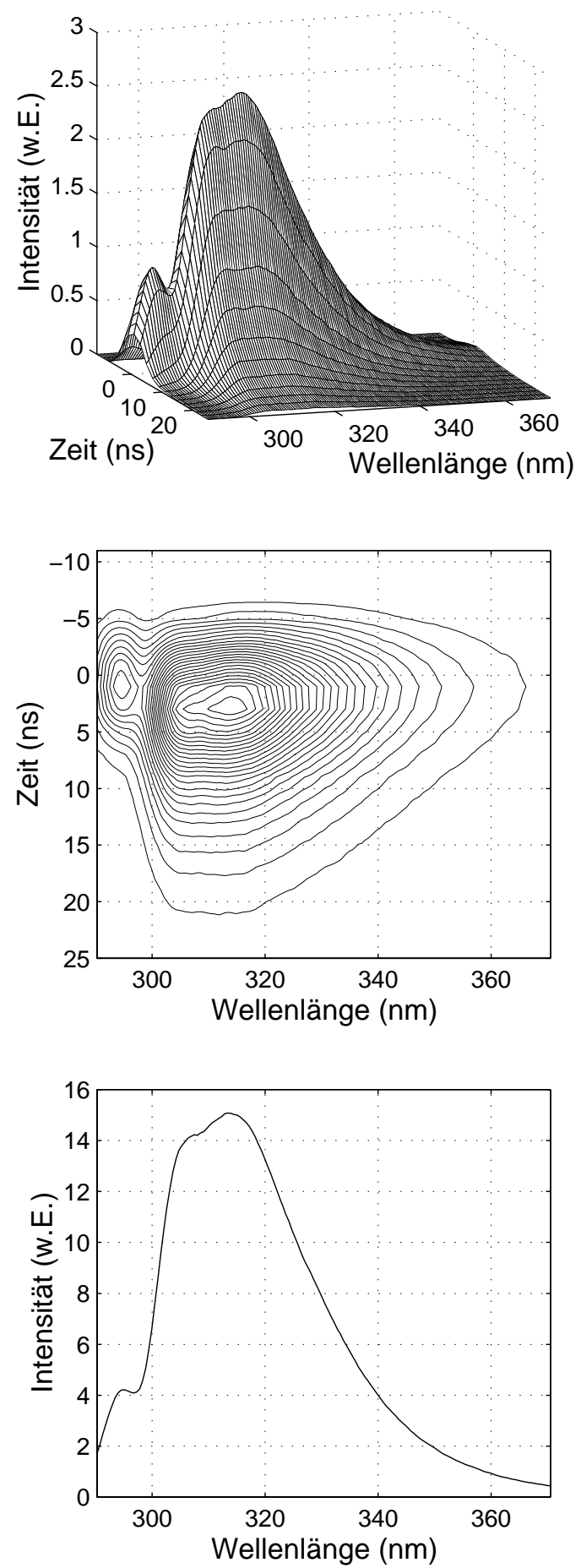

PAK Nr. 13: INP
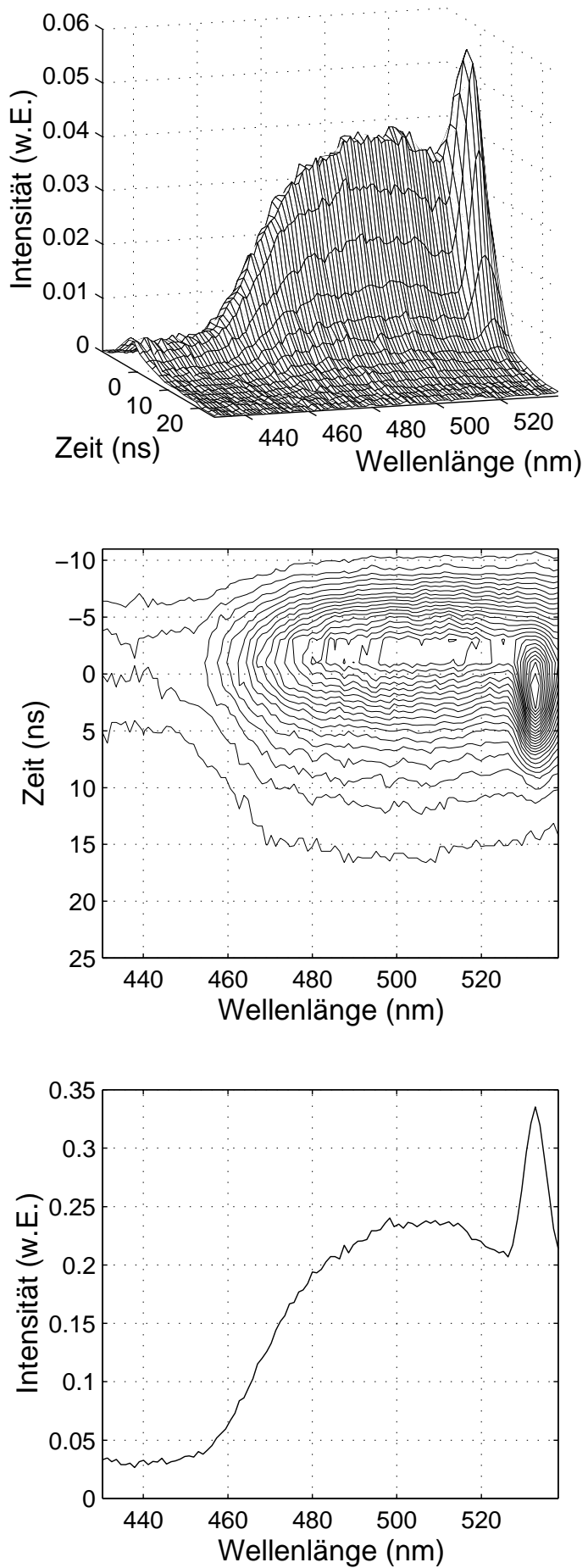

Abbildung A.7: Die zeitaufgelösten Spektren von Fluoren (FLU, links) und Indeno[1,2,3,c,d]pyren (INP, rechts), normiert auf das Ramansignal. Oben: Perspektivische 3D-Darstellung; Mitte: Kontourendarstellung; Unten: Integrales Spektrum (Summe der Zeitscheiben). Im INP-Spektrum ist bei $532 \mathrm{~nm}$ das Anregungsscheinsignal (2. Gitterordung des 266-nm-Signals) zu sehen. Die Verspätung relativ zur Fluoreszenz kommt durch die intramodale Dispersion zustande (siehe Abschnitt 6.1.1) 
PAK Nr. 14: NAP
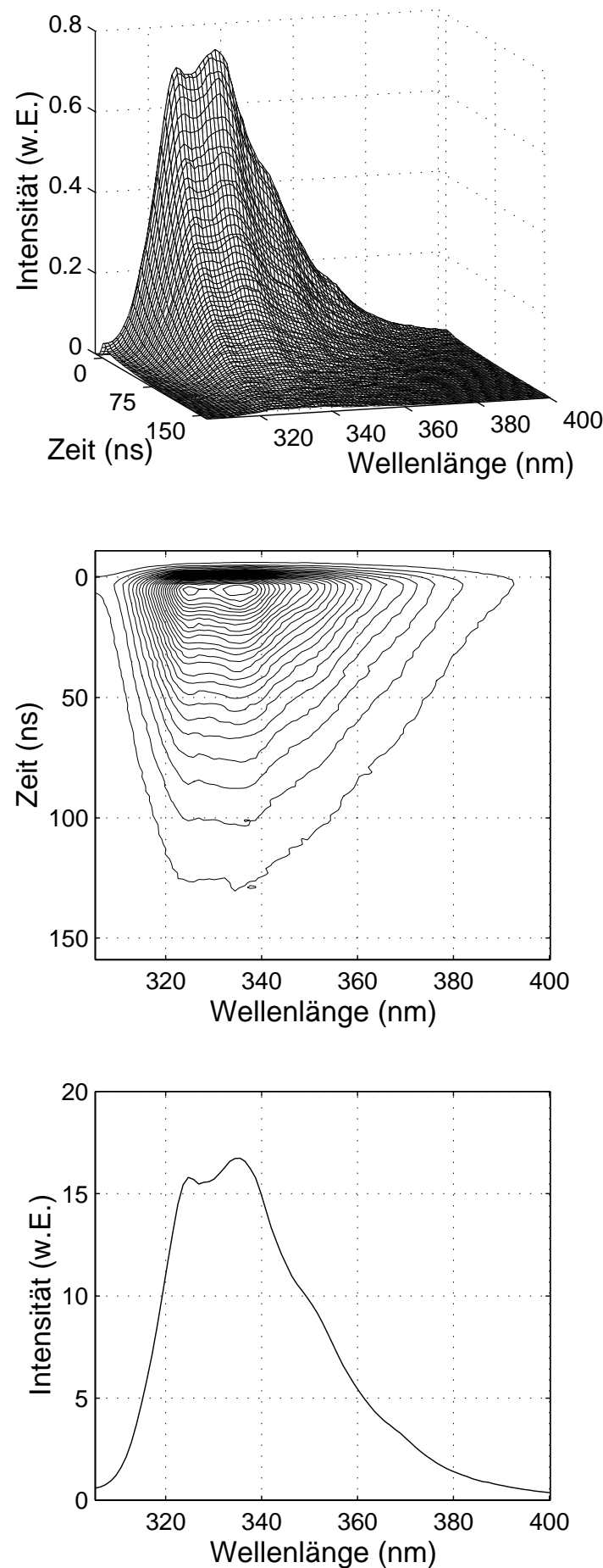

PAK Nr. 15: PHT
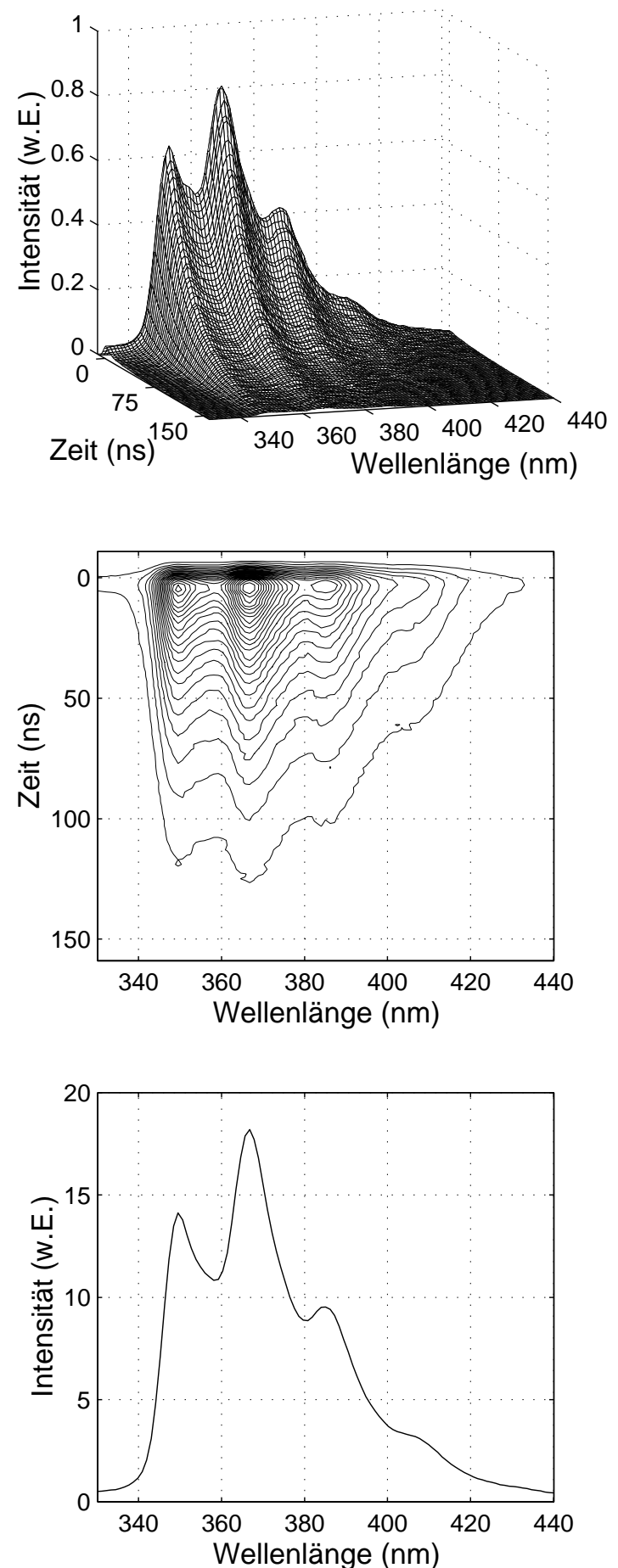

Abbildung A.8: Die zeitaufgelösten Spektren von Naphthalin (NAP, links) und Phenanthren (PHT, rechts), normiert auf das Ramansignal. Oben: Perspektivische 3DDarstellung; Mitte: Kontourendarstellung; Unten: Integrales Spektrum (Summe der Zeitscheiben). 
PAK Nr. 16: PYR
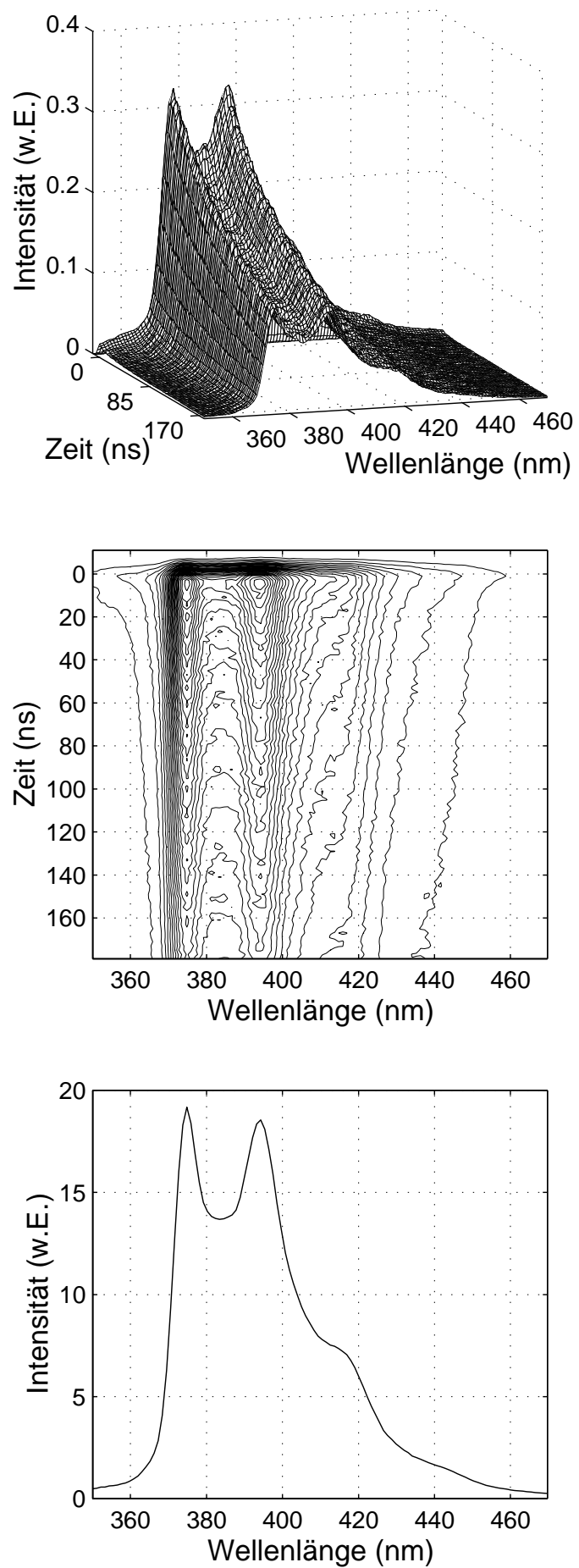

EPA-Standard
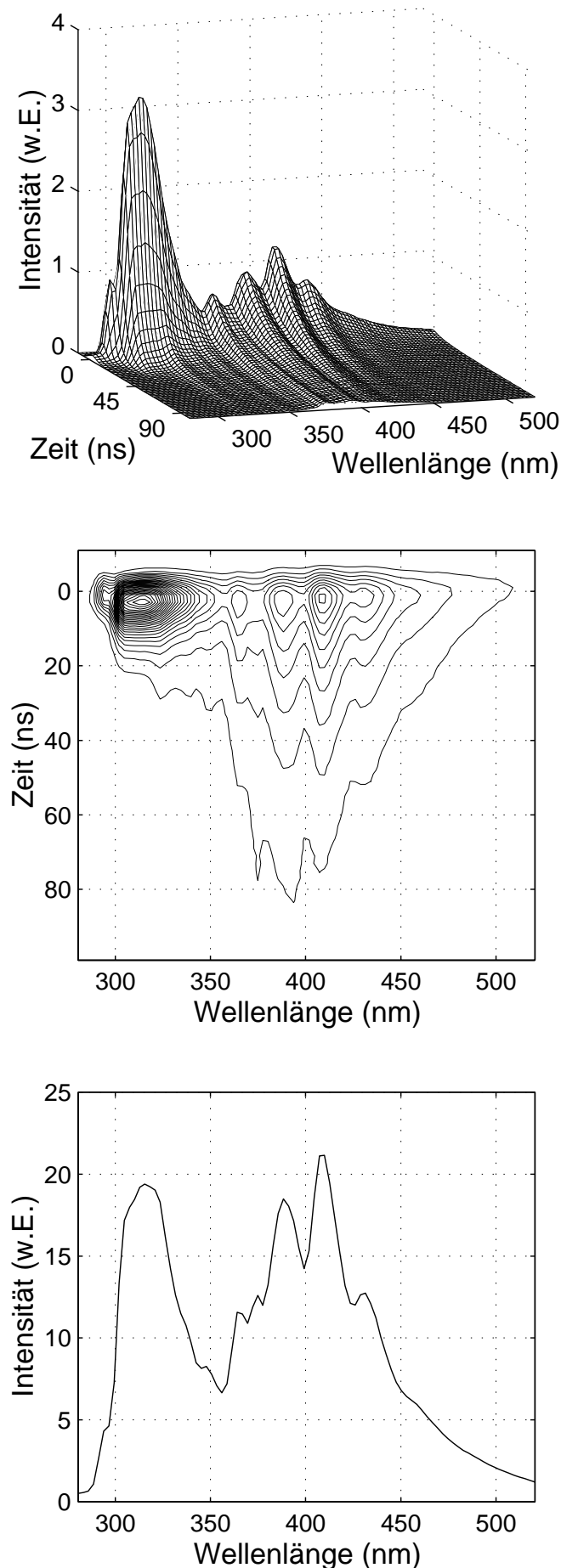

Abbildung A.9: Die zeitaufgelösten Spektren von Pyren (PYR, links) und des EPAStandardgemisches (rechts), normiert auf das Ramansignal. Oben: Perspektivische 3DDarstellung; Mitte: Kontourendarstellung; Unten: Integrales Spektrum (Summe der Zeitscheiben). 

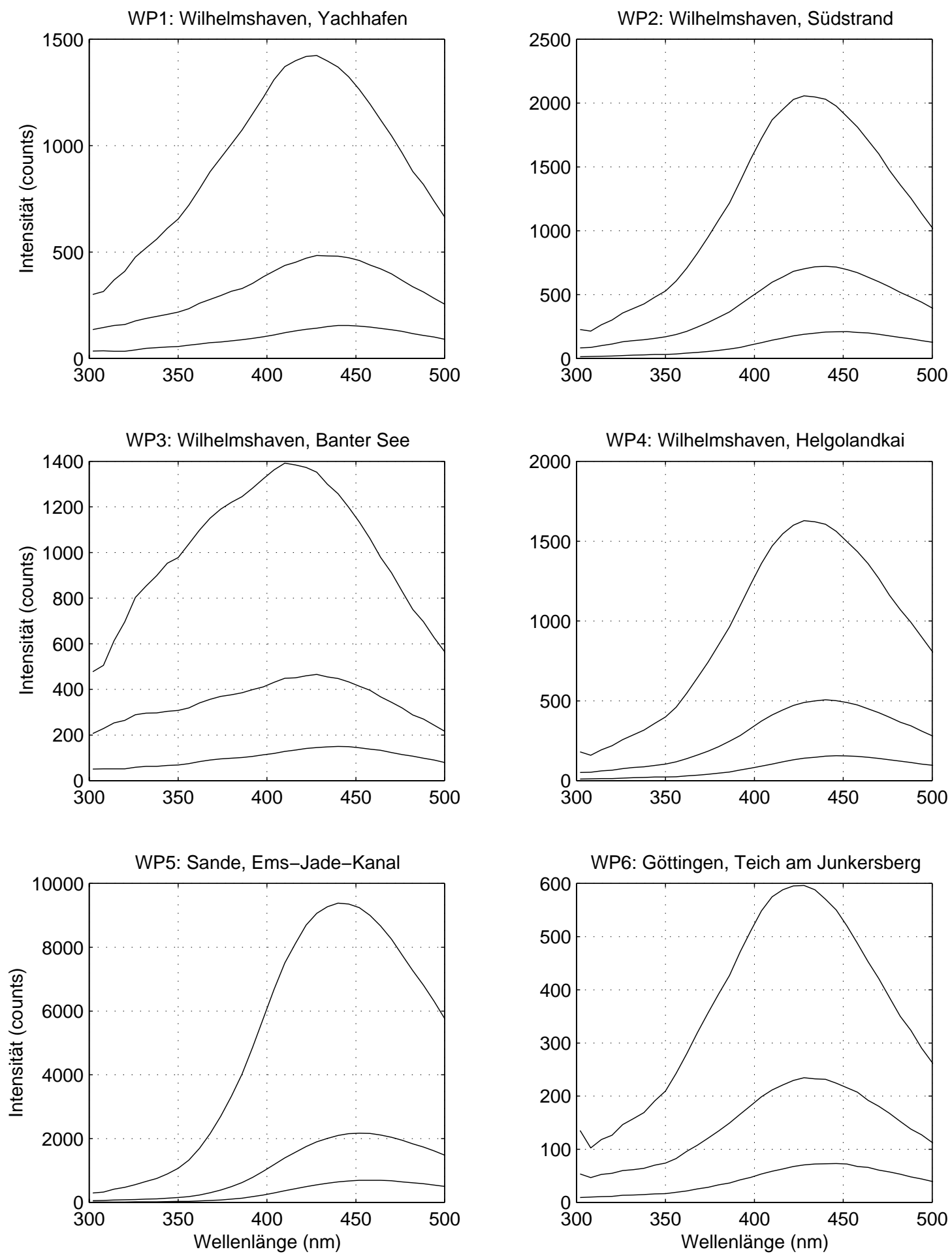

Abbildung A.10: Spektren von Wasserproben, drei Zeitscheiben: 0-8 ns, 8-16 ns und 16-22 ns relativ zum Maximum der Anregung. 

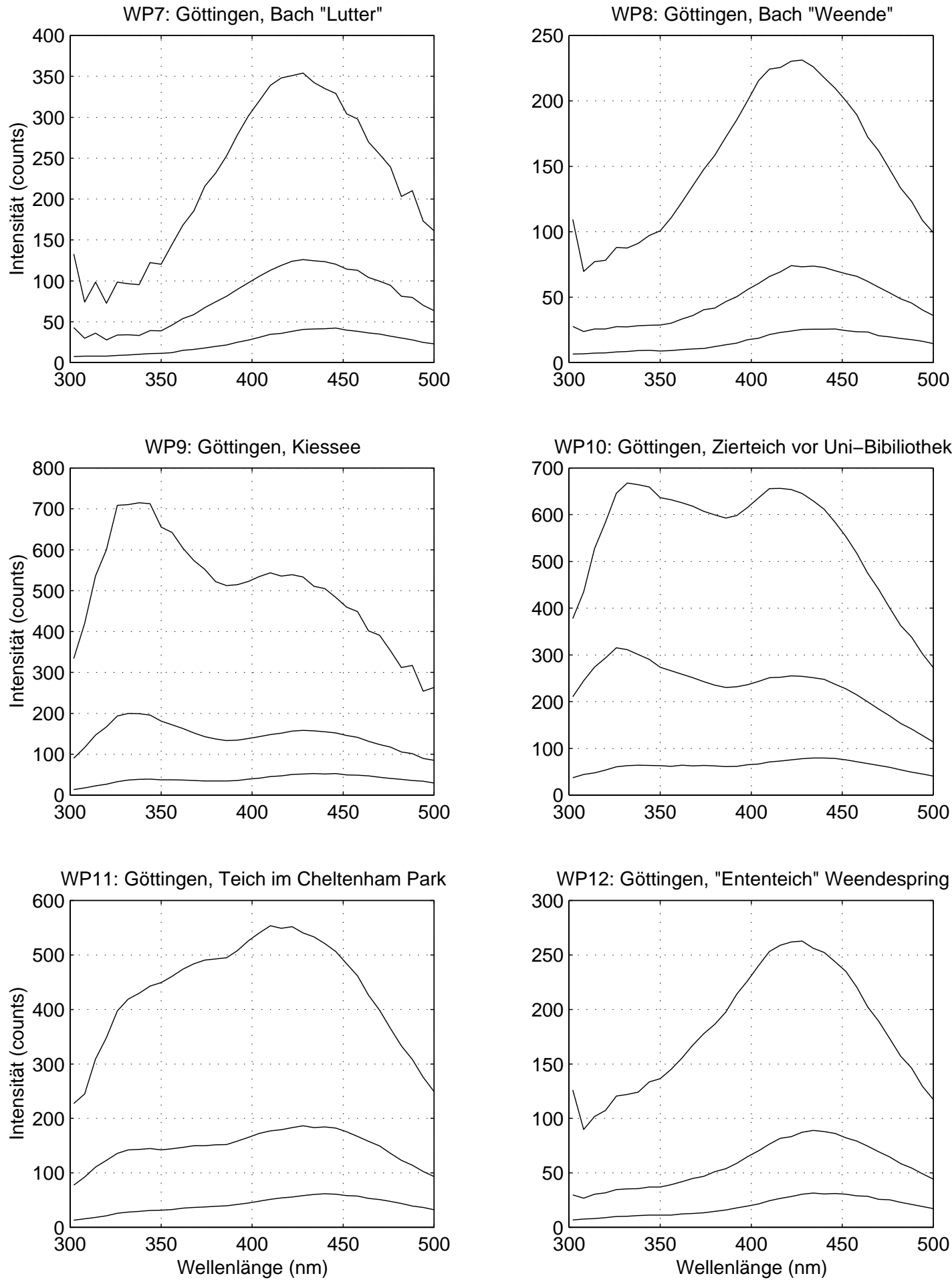

Abbildung A.11: Spektren von Wasserproben, drei Zeitscheiben: 0-8 ns, 8-16 ns und 16-22 ns relativ zum Maximum der Anregung. 

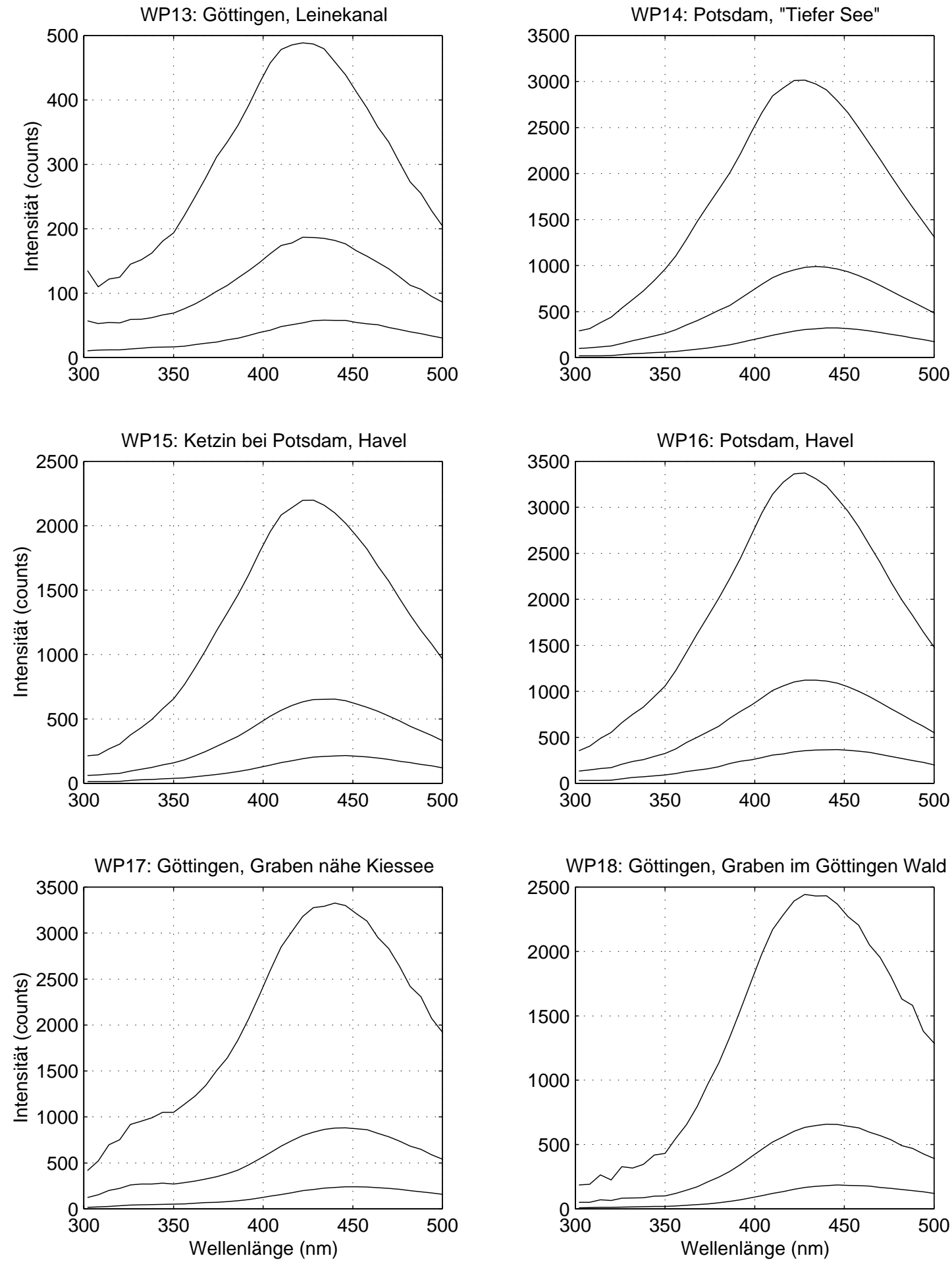

Abbildung A.12: Spektren von Wasserproben, drei Zeitscheiben: 0-8 ns, 8-16 ns und 16-22 ns relativ zum Maximum der Anregung. 

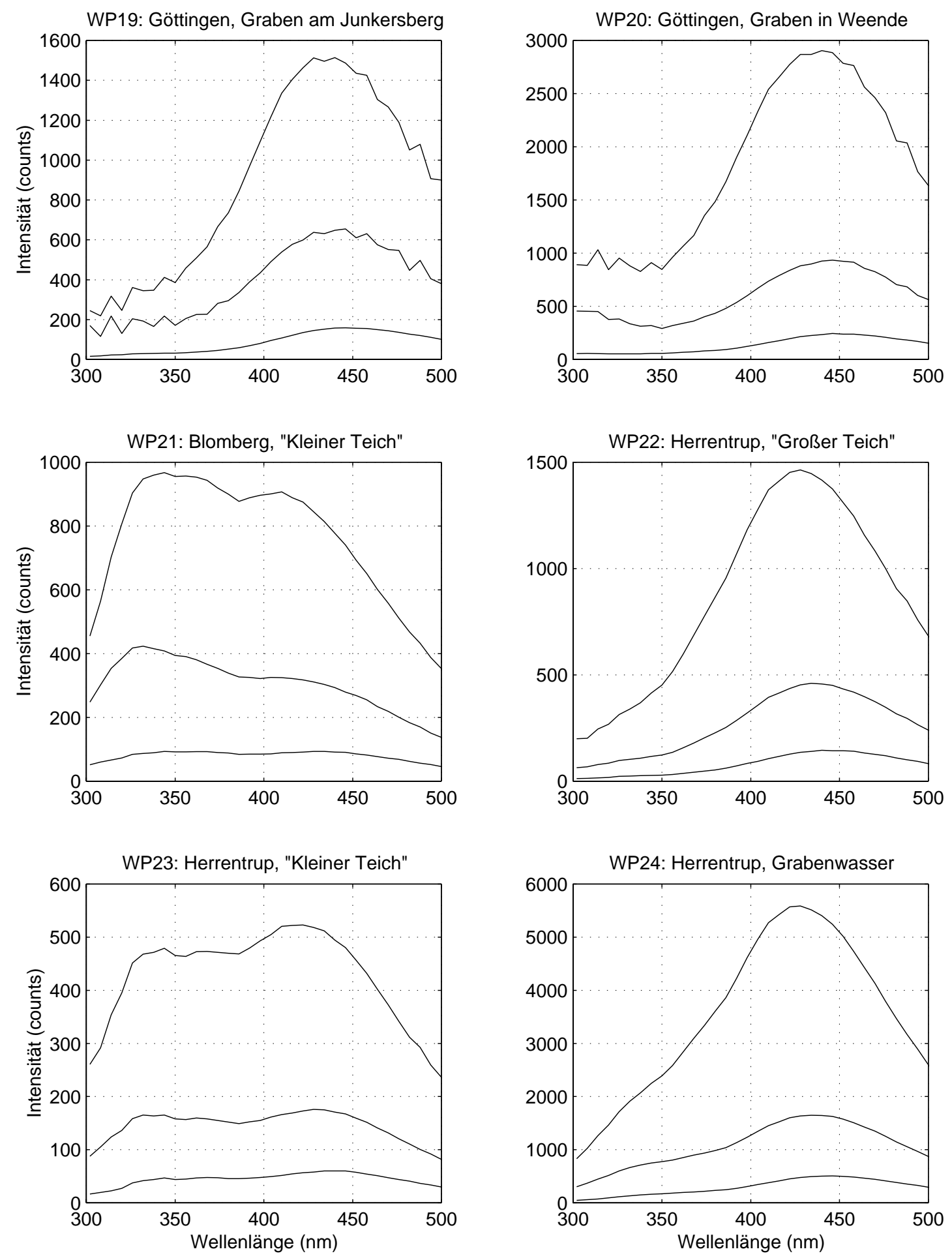

Abbildung A.13: Spektren von Wasserproben, drei Zeitscheiben: 0-8 ns, 8-16 ns und 16-22 ns relativ zum Maximum der Anregung. 


\section{Abbildungsverzeichnis}

2.1 Strukturformel des Benzols . . . . . . . . . . . . . . . . 5

2.2 Strukturformeln für Naphthalin und Anthracen . . . . . . . . . . 5

2.3 Zur Ableitung des Lambert-Beerschen Gesetzes . . . . . . . . . . . . 7

2.4 Jablonski-Diagramm . . . . . . . . . . . . . . . . . . . . 8

2.5 Zur Erläuterung des Franck-Condon-Prinzips . . . . . . . . . . . . . 10

2.6 Schematischer Aufbau eines Lichtwellenleiters . . . . . . . . . . . . 11

2.7 Wellenlängenabhängiger Brechungsindex von Quarz . . . . . . . . . 12

3.1 Ein Foto des CCD-Laserfluorimeters. . . . . . . . . . . . . . . . 13

3.2 Schematischer Aufbau des Meßsystems . . . . . . . . . . . . . . 14

3.3 Schematische Aufbau des Lasers . . . . . . . . . . . . . . . . . . . . . 16

3.4 Der Vielkanalanalysator . . . . . . . . . . . . . . . . 16

3.5 Zeitfenster . . . . . . . . . . . . . . . . . . 17

3.6 Die Wasser-Optrode . . . . . . . . . . . . . . . . . . . . . 19

3.7 Ein zeitaufgelöstes Spektrum . . . . . . . . . . . . . 20

4.1 Die Geometrie des Bodensensors . . . . . . . . . . . . . . . . 24

4.2 Definition der Winkel $\omega$ und $\varphi \ldots \ldots . \ldots . \ldots . \ldots 24$

4.3 Die Einhüllende einer Punktmenge . . . . . . . . . . . . . . . . . . 29

4.4 Die Bewertungsfunktion für $z_{w i n}=1 \mathrm{~mm} \ldots \ldots . \ldots . . \ldots 33$

4.5 Die Bewertungsfunktion für $z_{w i n}=0.6 \mathrm{~mm} \ldots \ldots . \ldots . . \ldots 34$

4.6 Die unbewertete Beobachtungsfläche $T$ für ein Quarz-Schutzfenster 35

$4.7 C E$ als Funktion von $z_{w i n}$ und $\gamma_{D F}$ für ein Quarzfenster . . . . . . . 36

$4.8 C E$ als Funktion von $z_{w i n}$ und $\gamma_{D F}$ für ein Saphirfenster . . . . . . 37

$4.9 C E$ als Funktion der Kippwinkel . . . . . . . . . . . . . 38

$4.10 C E$ als Funktion von $\vec{c}_{D F}$ und $\gamma_{D F} \ldots \ldots \ldots . \ldots . \ldots . \ldots 39$

$4.11 C E, T$ und $T_{E F}$ als Funktion von $N A \ldots \ldots . \ldots . \ldots 40$

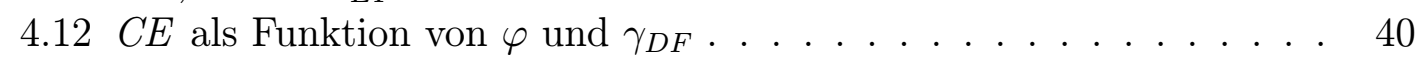

5.1 Bodenkalibrationen ...................... 44

6.1 Elemente einer Analysemethode . . . . . . . . . . . . . . . . . . 45

6.2 Beispiel zur intramodalen Dispersion . . . . . . . . . . . . . . . 47

6.3 Wellenlängenabhängige Laufzeit des Lichtes in einer Quarzfaser . . 47

6.4 Zeitverhalten des Ramansignals . . . . . . . . . . . . . . . . . 49

6.5 Datenreduktion durch FFT . . . . . . . . . . . . . . 50

6.6 Datenreduktion durch FFT: Residuen . . . . . . . . . . . . . . 51

6.7 Prinzip der Fensterzerlegung . . . . . . . . . . . . . 54

7.1 ANFD versus NNFD bei Realdaten . . . . . . . . . . . . . . 70

7.2 ANFD versus NNFD bei simulierten Daten . . . . . . . . . . . . . 70

7.3 „Ohne IS" versus „mit IS" bei Realdaten . . . . . . . . . . . . . . . . 72

7.4 „Ohne IS" versus „mit IS" bei simulierten Daten . . . . . . . . . . . 72 
7.5 RM-AFD versus FT-AFD . . . . . . . . . . . . . . . . 73

7.6 Abstrakte Spektren der AFD . . . . . . . . . . . . . . 75

7.7 RM-AFD mit NNFD versus FT-AFD . . . . . . . . . . . . . . 75

7.8 BRM-AFD versus FT-AFD . . . . . . . . . . . 76

7.9 PEM-AFD: Absoluter Vorhersagefehler beim Kreuztest . . . . . . . 78

7.10 PEM-AFD: Dimension des Tauvektors im Vergleichstest . . . . . . 79

7.11 PEM-AFD versus FT-AFD (interner Test) . . . . . . . . . . . . . 79

7.12 PEM-AFD versus FT-AFD (Kreuztest DS1 bis DS4) . . . . . . . . 81

7.13 PEM-AFD versus FT-AFD (Kreuztest DS5 bis DS8) . . . . . . . . 81

7.14 C-AFD für verschiedene Dimensionen des Tauvektors . . . . . . . . 82

7.15 C-AFD versus FT-AFD . . . . . . . . . . . . . . 83

7.16 Fensterzerlegung (2 Fenster) versus FT-AFD . . . . . . . . . 83

7.17 Fensterzerlegung (3 Fenster) versus FT-AFD . . . . . . . . . . . 85

7.18 Fensterzerlegung versus C-AFD . . . . . . . . . . . . . . . . . 85

7.19 OLS versus PCR . . . . . . . . . . . . . 86

7.20 OLS versus PLS . . . . . . . . . . . . . . . 86

7.21 PCR versus PLS . . . . . . . . . . . . . . . 87

7.22 Vorhersagekurven für Chrysen . . . . . . . . . . . . . . . . . . 87

7.23 Querempfindlichkeit ACN/BaP . . . . . . . . . . . 89

8.1 Spektrum Tankstellenunfall _. . . . . . . . . . . . . . . . . . . . 93

8.2 Xylol-Kalibration . . . . . . . . . . . . . . . . . . . . . . . . . . 95

8.3 Leineverschmutzung in Göttingen . . . . . . . . . . . . . . . . . . 96

8.4 Karte zum Tracerversuch Havel/Phöben . . . . . . . . . . . . . . . 98

8.5 Tracerversuch Havel: Profile M1 bis M4 . . . . . . . . . . . . . . . . 98

8.6 Kartenskizze zum Tracerversuch Havel/Potsdam . . . . . . . . . . . 99

8.7 Tracerversuch Havel: Profile D1 bis D3 . . . . . . . . . . . . . . . . 100

8.8 Spektrum des Tracers . . . . . . . . . . . . . . . . . . 101

8.9 Anzahl der PLS-Faktoren . . . . . . . . . . . . . . . . . 102

8.10 SRG-Kalibrationstest mit 2 Faktoren . . . . . . . . . . . . . . 103

8.11 SRG-Kalibrationstest mit 3 Faktoren . . . . . . . . . . . . . . . 103

8.12 Vier Spektren zu unterschiedlichen Zeiten . . . . . . . . . . . . . . 104

8.13 Vier Querprofile . . . . . . . . . . . . . . . . . . . 106

8.14 Querprofile in der 3D-Darstellung . . . . . . . . . . . . . . . 107

8.15 Tracerkonzentration am Ufer und in der Flußmitte. . . . . . . . . . 108

A.1 Meßprogramm FAP-CONTROL . . . . . . . . . . . . . . . . 116

A.2 Spektren ACN und ANT . . . . . . . . . . . . . . . . . . 120

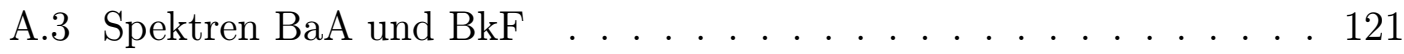

A.4 Spektren BbF und BgP . . . . . . . . . . . . . . . . . . . . 122

A.5 Spektren BaP und CHR . . . . . . . . . . . . . . . 123

A.6 Spektren DBA und FLA . . . . . . . . . . . . . . . . . . . . . . . . . . . . . . . . . . . . . . . . 124

A.7 Spektren FLU und INP . . . . . . . . . . . . . . . . . . 125 
A.8 Spektren NAP und PHT . . . . . . . . . . . . . . . . 126

A.9 Spektren PYR und EPA-Standard . . . . . . . . . . . . . . . . 127

A.10 Spektren von Wasserproben (1) . . . . . . . . . . . . . 128

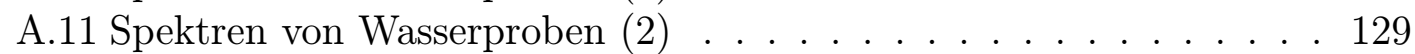

A.12 Spektren von Wasserproben (3) . . . . . . . . . . . . . . . . 130

A.13 Spektren von Wasserproben (4) . . . . . . . . . . . . . 131 


\section{Tabellenverzeichnis}

4.1 Symbole und Funktionen, die für die mathematische Modellierung der Bodenoptrode verwendet wurden. . . . . . . . . . . . 25

7.1 Ergebnisse der RM-AFD . . . . . . . . . . . . . . . . 73

7.2 Tauvektoren der PEM-AFD . . . . . . . . . . . . . . . . . . 77

7.3 Nachweisgrenzen der EPA-PAK in natürlichem Wasser . . . . . 88

7.4 Querempfindlichkeiten . . . . . . . . . . . . . . . 90

7.5 Querempfindlichkeiten größer $20 \%$. . . . . . . . . . . . 91

7.6 Spektrale Ähnlichkeiten . . . . . . . . . . . . . . . . . . . . . 91

8.1 Tracerversuch Elbe: SRG-Konzentrationen . . . . . . . . . . . . . 105

A.1 Eigenschaften der EPA-PAK (1) . . . . . . . . . . . . . . 114

A.2 Eigenschaften der EPA-PAK $(2) \ldots \ldots . \ldots . \ldots . \ldots 115$ 


\section{Literaturverzeichnis}

[1] J. Bundt. Bestimmung von Mineralölinhaltsstoffen und deren Abbauprodukten im Boden unter besonderer Berücksichtigung aromatischer Verbindungen. Dissertation, Universität Hamburg, 1991.

[2] H.G. Kicinski, S. Adamek, A. Kettrup. Festphasenextraktion und HPLCBestimmung von PAH's aus Trinkwasser-, Boden- und Altölproben. CLB Chemie für Labor und Betrieb, 40, S. 537-541, 1989.

[3] R. Ciupe, J. Spangenberg, G. Wild, J. Woelke, T. Meyer. Gaschromatographische Simultanbestimmung von PAKs mit FID und ITD in Boden- und Mineralölproben. GIT Spezial - Chromatographie, S. 34-37, 1994.

[4] R. Reupert, G. Brausen. Trennung von PAKs durch HPLC und Nachweis durch Fluoreszendetektion. GIT Fachz. Lab., S. 1219-1221, 1991.

[5] J. Kinkeldei, W. Hausotter, K.H. Bareiß. Bestimmung von PAKs mit HPLC und UV/FL-Detektion. Chromatographie-Spektroskopie, S. 37-42, 1990.

[6] F. Fanzius. Stand der Bodenreinigungsverfahren bei der Altlastensanierung. Umwelt Technolgie Aktuell, S. 463-473, 1993.

[7] T. M. Roch. Fluoreszenzspektroskopische in-situ Analyse von polycyclischen aromatischen Verbindungen in mineralölkontaminierten Böden. Dissertation, TU Braunschweig, 1994.

[8] H. Hulpke, H.A. Koch, R. Wagner. Römpp Lexikon Umwelt. Thieme, Stuttgart, 1993.

[9] J.B. Birks. Photophysics of Aromatic Molecules. Wiley Interscience, London, 1970.

[10] R.S. Becker. Theory and Interpretation of Fluorescence and Phosphorescence. Wiley Interscience, New York, 1968.

[11] M. Zander. Fluorometrie. Springer Verlag, Berlin, 1981.

[12] V. Brückner, K.H. Feller, U.W. Grummt. Applications of Time-Resolved Optical Spectroscopy. Elsevier, Amsterdam, 1990.

[13] M. Klessinger, J. Michl. Lichtabsorption und Photochemie organischer Moleküle. Verlag Chemie, Weinheim, 1990.

[14] J. R. Lakowicz. Principles of Fluorescence Spectroscopy. Plenum Press, New York, 1983.

[15] J.A. Miller. Carcinogenesis by chemicals: An overview. Cancer Res., 30, S. 559-576, 1970.

[16] O.G. Widlocki, A.Y.H. Lu. Carcinogenicity and Mutagenicity of Proximate and Ultimate Cacinogens of Polycyclic Aromatic Hydrocarbons. In S.K. Yang, B.D. Silverman, Editoren, Polycyclic Aromatic Hydrocarbons: Structure-Activity Relationsships, S. 2-30. CRC Press, Boca Raton, 1988. 
[17] A. Borgen, H. Darvey, N. Castagnoli, R.E. Rasmussen, I.Y. Wang. Metabolic conversion of benzo(a)pyrene by syrian hamster liver microsomes and binding of metabolites to deoxyribonucleic acid. J. Med. Chem., 16, S. 502-506, 1973.

[18] P. Sims, P.L. Grover, A. Swaisland, K. Pal, H. Hewer. Metabolic activiation of benzo(a)pyrene by a diol-epoxide. Nature, 252, S. 326-328, 1974.

[19] M. Hall, P.L. Grover. Polycyclic Aromatic Hydrocarbons: Metabolism, Activation and Tumor Initation. In C.S. Cooper, P.L. Groover, Editoren, Chemical Carcinogenesis and Mutagenesis, S. 285-319. Springer Verlag, Berlin, 1990.

[20] D.H. Philips. Fifty years of benzo(a)pyrene. Nature, 309, S. 468-472, 1983.

[21] A. Bjoerseth, G. Becher. PAH in Work Atmospheres: Occurrence and Determination. CRC Press, Boca Raton, 1986.

[22] C.E. Cearle, O.J. Teale. Occupational Carcinogens. In C.S. Cooper, P.L. Grover, Editoren, Chemical Carcinogenesis and Mutagenesis. Springer Verlag, Berlin, 1990.

[23] G. Grimmer. Environmental Carcinogens: Polycyclic Aromatic Hydrocarbons. CRC Press, Boca Raton, 1983.

[24] S.S. Miller. In a faraway state. Environ. Sci. Technol., 24, S. 1286-1289, 1990.

[25] B.A. Brenner, N.P. Bryner, S.A. Wise, G.W. Mulholland. Polycyclic aromatic hydrocarbon emissions from the combustion of cure oil on water. Environ. Sci. Technol., 24, S. 1418-1427, 1990.

[26] J. König, E. Balfanz, G. Brechtloff. Zusammensetzung von PAH-Gemischen am Arbeitsplatz. Erich Schmidt Verlag, Berlin, 1985.

[27] H. Hellmann. Kohlenwasserstoffe in Luftstaub und Niederschlag - Mineralöle oder Naturstoffe. Staub-Reinhaltung der Luft, 52, S. 157-161, 1992.

[28] K. Hemminki. Environmental Cacinogens. In C.S. Cooper, P.L. Grover, Editoren, Chemical Carcinogenesis and Mutagenesis, S. 33-61. Springer Verlag, Berlin, 1990.

[29] C.A. Menzie, B.B. Potocki, J. Santodonato. Exposure to carcinogenic PAHs in the environment. Environ. Sci. Technol., 26, S. 1278-1284, 1992.

[30] J. M. Neff. Polycyclic Aromatic Hydrocarbons in the Aquatic Environment. Applied Science Publishers LTD, London, 1979.

[31] W. Chudyk, K. Pohlig. Dynamic range limits in field determination of fluorescence using fiber optic sensors. SPIE-Proceedings, 1368, S. 105-114, 1990.

[32] G.A. Theriault, R. Newberry, J.M. Andrews, S.E. Apitz, S.H. Lieberman. Fiber optic fluorometer based on a dual wavelength laser excitation source. SPIEProceedings, 1796, S. 115-123, 1992. 
[33] S.M. Inman, P. Thibado, G. Theriault, S.H. Lieberman. Development of a pulsedlaser, fiber-optic-based fluorimeter: determination of fluorescence decay times of polycylic aromatic hydrocarbons in sea water. Anal. Chim. Acta, 239, S. 45-51, 1990.

[34] R. Niessner, U. Panne, H. Schröder. Fibre-optic sensor for the determination of polynuclear aromatic hydrocarbons with time-resolved, laser-induced fluorescence. Anal. Chim. Acta, 225, S. 213-243, 1991.

[35] W. Schade, J. Bublitz. Trace analysis of oil pollution by time-resolved laser spectroscopy - first results of field measurements. Inst. Phys. Conf. Ser., 9, S. 317-320, 1992.

[36] R.M. Measures, W.R. Houston. Laser induced fluorescent decay spectra - a new form of environmental signature. Opt. Eng., 13(6), S. 494-501, 1974.

[37] T.F. van Geel, J.D. Winefordner. Pulsed nitrogen laser in analytical spectrometry of molecules in the condensed phase. Anal. Chem., 48(2), S. 335-338, 1976.

[38] J.H. Richardson, M.E. Ando. Sub-part-per-trillion detection of polycylic aromatic hydrocarbons by laser induces molecular fluorescence. Anal. Chem., 49(7), S. 955959, 1977.

[39] W.A. Chudyk, M.M. Carrabba, J.E. Kenny. Remote detection of groundwater contaminants using far-ultraviolet laser-induced-fluorescence. Anal. Chem., 57, S. 1237-1242, 1985.

[40] W. Chudyk, J. Kenny, G. Jarvis, K. Pohlig. Monitoring of groundwater contaminants using laser fluorescence and fiber optics. InTech, Mai, S. 53-57, 1987.

[41] P. Camagni, G. Colombo, C. Koechler, A. Pedrini, N. Omenetto, G. Rossi. Diagnostics of oil pollution by laser-induced fluorescence. IEEE Transact. on Geoscience and Remote Sensing, GE-26(1), S. 22-26, 1988.

[42] U. Panne, R. Niessner. Ein faseroptischer Sensor zur PAK-Bestimmung mit zeitaufgelöster laserinduzierter Fluoreszenz. Vom Wasser, 79, S. 89-99, 1992.

[43] S.E. Apitz, G.A. Theriault, S.H. Lieberman. Optimization of the optical characteristics of a fiber-optic guided laser fluorescence technique for the in situ evaluations of fuels in soils. SPIE-Proceedings, 1637, S. 241-254, 1992.

[44] J. Bublitz. Zeitaufgelöste Laserspektroskopie an Kohlenwasserstoffen. Diplomarbeit, Christian Albrechts Universität, Kiel, 1992.

[45] J. Bublitz, M. Dickenhausen, M. Grätz, S. Todt, W. Schade. Fiber-optic laserinduced fluorescence probe for the detection of environmental pollutants. Appl. Opt., 34(18), S. 3223-3233, 1995.

[46] G. Hillrichs, W. Neu. UV-laser induced fluorescence to determine organic pollutions in water. In C. Werner, W. Waidelich, Editoren, Laser in der Umweltmeßtechnik, S. 109-112, Berlin, 1993. Springer-Verlag. 
[47] W. Schade, J. Bublitz. Neues Laserverfahren für den Spurennachweis von Schadstoffbelastungen im Wasser und im Boden. Laser und Optoelektronik, 25, S. 41-48, 1993.

[48] T.A. Taylor, G.B. Jarvis, H. Xu, A.C. Bevilacqua, J.E. Kenny. Laser-based fluorescence EEM instrument for in-situ groundwater monitoring. Anal. Instr., 21(3\&4), S. $141-162,1993$.

[49] M.U. Kumke, H.-G. Löhmannsröben, T. Roch. Fluorescence Spectroscopy of Polynuclear Aromatic Compounds in Environmental Monitoring. J. Fluorescence, 5(2), S. 139-153, 1995.

[50] H.-G. Löhmannsröben, M.U. Kumke, Th. Meyer, Th. Roch, U. Zimmermann. Laser-induced fluorescence spectroscopy of polynuclear aromatic compounds and model oils in humic acid- and soil-containing compartments. In Field screening methods for hazardous wastes and toxic chemicals, Las Vegas, 1995.

[51] M.U. Kumke, H.-G. Löhmannsröben, T. Roch. Fluoreszenzspektroskopie in der Umweltanalytik. GIT Fachz. Lab., 2, S. 112ff., 1995.

[52] E. Jäger, H. Lucht, A. Weissbach. Laserfluoreszenz zur Bestimmung von PAK in Wasser. LaborPraxis, Nov/Dez, S. 42-53,46-50, 1994.

[53] G. Hillrichs, P. Karlitschek, W. Neu. Fiber optic aspects of UV laser spectroscopic in situ detection of water pollutants. SPIE, 2293, 1994.

[54] U. Bünting. Untersuchungen zum Schadstoffnachweis in Wasser mittels laserinduzierter Fluoreszenz. Diplomarbeit, Universität Göttingen, 1997.

[55] P. Karlitschek. Faseroptische Untersuchungen der UV-Laser-gestützten Schadstoffsensorik. Dissertation, Georg August Universität, Göttingen, 1996.

[56] H. Beyer, W. Walter. Lehrbuch der Organischen Chemie. S. Hirzel, Stuttgart, 22. Auflage, 1991.

[57] C.E. Mortimer. Chemie. G. Thieme Verlag, Stuttgart, 5. Auflage, 1987.

[58] H.R. Christen, F. Vögtle. Grundlagen der Organischen Chemie. Verlag Sauerländer, 1989.

[59] T. Förster. Fluoreszenz Organischer Verbindungen. Vandenhoeck und Ruprecht, Göttingen, 1982.

[60] G.N. Lewis, M. Kasha. Phosphorescence and the triplet state. J. Am. Chem. Soc., 1944.

[61] I.B. Berlman. Handbook of Fluorescence Spectra of Aromatic Molecules. Academic Press, New York, 2. Auflage, 1971.

[62] G. Wedler. Lehrbuch der Physikalischen Chemie. VCH, Weinheim, 3. Auflage, 1987. 
[63] H. Martens, T. Naes. Multivariate Calibration, Kapitel: 3.6 Multivariate calibration based on the linear mixture model. John Wiley and Sons, 1998.

[64] H.G.Calvert, J.N. Pitts. Photochemistry. Wiley \& Sons, New York, 1967.

[65] M. Zander. Handbook of Polycyclic Aromatic Hydrocarbons, Kapitel: Physical and Chemical Properties of Polycyclic Aromatic Hydrocarbons, S. 1-25. Marcel Dekker, New York, 1983.

[66] J.B. Birks. Photophysics of Aromatic Molecules. John Wiley \& Sons, London, 1972.

[67] G.V. Bünau, T. Wolff. Photochemie. VCH, Weinheim, 1987.

[68] C. Gerthsen, H.O. Kneser, H. Vogel. Physik. Springer, Berlin, 16. Auflage, 1989.

[69] G. Mahlke, P. Gössing. Lichtwellenleiterkabel. Siemens, Berlin, 2. Auflage, 1988.

[70] H. Fabian, U. Grzesik, K.-H. Wörner, K.F. Klein. Optical fibers for UVapplications. SPIE, 1513, S. 168, 1991.

[71] S. Hayashi, K. Awazu, H. Kawazoe. The formation mechanisms of oxygen deficient defects in synthetic silica glasses. J. Non-Cryst. Solids, 179, S. 235-242, 1994.

[72] N. Leclerc, C. Pfleiderer, J. Wolfrum, K. Greulich, W.P. Leung, M. Kulkarni, A.C. Tam. Transient absorption and fluorescence spectroscopy in fused silica induced by pulsed KrF excimer laser irradiation. Appl. Phys. Lett., 59, S. 3369, 1991.

[73] H. Nishikawa, E. Watanabe, D. Ito, Y. Ohki. Kinetics of enhanced photogeneration of E' centers in oxygen-deficient silica. J. Non-Cryst. Solids, 179, S. 179-184, 1994.

[74] H. Nishikawa, R. Nakamura, R. Tohmon. Y. Ohki, Y. Sakurai. K. Nagasawa, Y. Hama. Generation mechanism of photoinduced paramagnetic centers from preexisting precursors in high-purity silicas. Phys. Rev. B, 41(11), S. 7828-7834, 1990.

[75] T.E. Tsai, D.L. Griscom, E.J. Friebele. Mechanism of intrinsic Si E'-center photogeneration in high-purity silica. Phys. Rev. Lett., 61(4), S. 444-446, 1988.

[76] K. Arai, H. Imai, H. Hosono, Y. Abe, H. Imagawa. Two-Photon processes in defect formation by excimer lasers in synthetic silica glass. Appl. Phys. Lett, 53(20), S. 1891, 1988.

[77] H. Imai, K. Arai, H. Imagawa, H. Hosono, Y. Abe. Two types of oxygen-deficient centers in synthetic silica glass. Phys. Rev. B, 38(17), S. 12772-12775, 1988.

[78] J.H. Stathis, M.A. Kastner. Photoinduced paramagnetic defects in amorphous silicon dioxide. Phys. Rev. B, 29(12), S. 7079-7081, 1984.

[79] G.C. Escher. KrF laser induced color centers in commercial fused silicas. SPIE Proc., 998(30), 1988. 
[80] N. Kuzuu, M. Murahara. Effects of synthesis conditions on existence and nonexistence of the ArF excimer laser and x-ray induced $B_{2} \alpha$ band in type-III fused silicas. Phys. Rev. B, 32(5), S. 3241-3246, 1995.

[81] N. Kuzuu. OH-dependence of ArF-excimer-laser-induced absorption in type-III fused silica. SPIE-Proc., 2714, S. 71-79, 1996.

[82] R. A. Brimacombe, R.S.Taylor, K.E. Leopold. Dependence of the nonlinear transmission properties of fused silica fibers on excimer laser wavelength. J.Appl.Phys., 66, S. 4035-4039, 1989.

[83] H. Hitzler, Ch. Pfleiderer, N. Leclerc, J. Wolfrum, K.O. Greulich, H. Fabian. KrFLaser Irradiation Induced Defects in All Silica Optical Fibers. Riga Conference on Point Defects in Glasses, 1991.

[84] J. Li, S. Kannan, R.L. Lehman, G.H. Sigel Jr. Drawing-enhanced defect precursors in low-OH content, oxygen-deficient synthetic silica optical fibers. Appl. Phys. Lett., 64(16), S. 2090-2092, 1994.

[85] G. Hillrichs, M. Dressel, H. Hack, R. Kunstmann, W. Neu. Transmission of XeCl Excimer laser pulses through optical fibers: dependence on fiber and laser parameters. Appl. Phys. B, 54, S. 208, 1992.

[86] C. Whitehurst, M.R. Dickinson, T.A. King. Ultraviolet pulse transmission in optical fibers. Journal of Modern Optic, 35, S. 371, 1988.

[87] P. Liu, W.L. Smith, H. Lotem, J.H. Bechtel, N. Bloembergen. Absolute two-photon absorption coefficients at 355 and $266 \mathrm{~nm}$. Phys. Rev. B, 17(12), S. 4620-4632, 1978.

[88] P. Liu, R.Yen, N. Bloembergen. Two-Photon absorption coefficients in UV window and coating materials. Applied Optics, 18(7), S. 1015, 1979.

[89] P. Karlitschek, G. Hillrichs, K.-F. Klein. Photodegradation and nonlinear effects in optical fibers induced by pulsed UV-laser radiation. Opt. Commun., 116, S. 219-230, 1995.

[90] J. Dijon, E. van Oost, C. Pelle, P. Lyan. Laser induced absorption at $355 \mathrm{~nm}$ in silica studied by calorimetry and photothermal deflection. SPIE, 2714, S. 61-70, 1996.

[91] Tingye Li. Fiber Fabrication, Band 1 von Optical Fiber Communications. Academic Press, Orlando, 1985.

[92] R. Brückner. J. Non-Cryst. Solids, 5, S. 123, 1970.

[93] K. Rau, A. Mühlich, N. Treber. Progress in silica fibers with fluorine dopant. In Proc. OFC Williamsburg, 1977. Paper TuC4.

[94] J. Stone. Interactions of hydrogen and deuterium with silica optical fibers: a review. J. Lightwave Techn., LT-5, S. 712-732, 1987. 
[95] R.W. Lee. Diffusion of hydrogen in natural and synthetic fused quartz. J. Chem. Phys., 38(2), S. 448-455, 1963.

[96] J.E. Shelby. Molecular diffusion and solubility of hydrogen isotopes in vitreous silica. J. Appl. Phys., 48, S. 3387-3394, 1977.

[97] J.E. Shelby. Reaction of hydrogen with hydroxyl-free vitreous silica. J. Appl. Phys., 51(5), S. 2589-2593, 1980.

[98] P. Karlitschek, U. Bünting, T. Nörthemann, G. Hillrichs. Fluorimetric detection of water pollutants with a fiber coupled solid-state UV-laser. In Laser methods for biological and environmental applications, Heraklion, 1996. SPIE.

[99] U. Bünting, P. Karlitschek, F. Lewitzka, M. Niederkrüger, G. Marowsky. Environmental monitoring using micro-optical sensors. In H. Reichel, E. Obermeier, Editoren, Micro System Technologies 98, S. 219-224, Berlin, 1998. VDE Verlag.

[100] M.U. Kumke, H.-G. Löhmannsröben, T. Roch. Fluorescence Quenching of polycylic aromatic compounds by humic acids. Analyst, 119, S. 997-1001, 1994.

[101] U. Panne. Mehrdimensionale Fluoreszenzspektroskopie. Nachr. Chem. Tech. Lab., 44, S. 282-287, 1996.

[102] W. Chudyk, C. Botteron, K. Pohlig. Vapor phase analysis of aromatic organic compounds using laser-induced fluorescence and fiber optics. SPIE-Proceedings, 1587, S. 242-249, 1991.

[103] E.M. Filippova, V.V. Chubarov, V.V. Fadeev. New possibilities of laser fluorescence spectroscopy for diagnostics of petroleum hydrocarbons in natural water. Canadian J. Appl. Spec., 38(5), S. 139-144, 1993.

[104] D.S. Knowles, S.H. Lieberman. Field results form the SCAPS laser-induced fluorescence LIF sensor for in-situ subsurface detection of petroleum hydrocarbons. SPIE-Proceedings, 2504, S. 297-309, 1995.

[105] T.Y. Fan, R.L. Byer. Diode laser-pumped solid-state lasers. IEEE J. Quantum Electron., 24(6), S. 895-912, 1988.

[106] R.L. Byer. Diode-pumped solid-state lasers. Science, 239, S. 742-747, 1988.

[107] D. Botez, D.R. Scifres. Diode Laser Arrays. Cambridge University Press, Cambridge, 1994.

[108] P. Karlitschek, G. Hillrichs. Active and passive Q-switching of a diode-pumped Nd:KGW-laser. Appl. Phys. B, 64, S. 21-24, 1997.

[109] J.R. Shen. The Principles of Nonlinear Optics. John Wiley \& Sons, New York, 1984.

[110] V.G. Dmitriev, G.G. Gurzadyan, D.N. Nikogosyan. Handbook of Nonlinear Optical Crystals. Springer Verlag, Berlin, 1990. 
[111] W.M. Grossman, M. Gifford, R.W. Wallace. Short-pulse Q-switched 1.3- and 1- $\mu \mathrm{m}$ diode-pumped lasers. Optics Letters, 15(11), S. 622-624, 1990.

[112] H.R. Verdun, T. Chuang. Efficient TEM ${ }_{00}$-mode operation of a Nd:YAG laser end pumped by a three-bar high-power diode-laser array. Optics Letters, 17(14), S. 1000-1002, 1992.

[113] Th. Graf, J.E. Balmer. High-power Nd:YLF laser end pumped by a diode-laser bar. Opt. Lett., 18(16), S. 1371-1373, 1993.

[114] M. Niederkrüger. Untersuchungen von Einflußfaktoren in der fluoreszenzspektroskopischen in-situ Analyse von wassergleösten aromatischen Kohlenwasserstoffen. Diplomarbeit, Georg-August-Unversität zu Göttingen, 1999.

[115] M.A. Leugers, R.D. McLachlan. Proc. SPIE, 990, S. 88-95, 1988.

[116] C.K.Chong et.al. Raman spectroscopy with fiber-optic probe. Vibrational Spectroscopy, 3, S. 35-45, 1992.

[117] P. Plaza, Nguyen Quy Dao, M. Jouan, H. Fevrier, H. Saisse. Simulation et Optimisation des Capteurs á Fibres Optiques Adjacentes. Appl. Opt., 25(19), S. 3448-3454, 1986.

[118] S. E. Nave, P. E. O'Rourke, W. R. Toole. Sampling probes enhance remote chemical analyses. Laser Focus World, S. 83-88, Dezember 1995.

[119] M.L. Myrick, S.M. Angel, R. Desiderio. Comparison of some fiber optic configurations for measurement of luminescence and Raman scattering. Appl. Spectrosc., 29, S. 1333-1344, 1990.

[120] S. Mottin, C. Tran-Minh, P. Laporte, R. Cespuglio, M. Jouvet. Fiber-Optic, timeresolved fluorescence sensor for in vitro seotonin determination. Appl. Spectrosc., 47, S. 590-597, 1993.

[121] D.N. Modlin, F.P. Milanovich. Instrumentation for Fiber Optic Chemical Sensors. In O.S. Wolfbeis, Editor, Fiber Optic Chemical Sensors and Biosensors, S. 239-302. CRC Press, Boca Raton, 1991.

[122] C. Komives, J.S. Schultz. Fiber-Optic fluorometer signal enhancement and application to biosensor design. Talanta, 39, S. 429-441, 1992.

[123] Z.Y. Zhu, M.C. Yappert. Determination of the effictive depth for double-fiber fluorometric sensors. Appl. Spectrosc., 46, S. 919-924, 1992.

[124] Z.Y. Zhu, M.C. Yappert. Determination of the effictive depth and equivalent pathlength for a single-fiber fluorometric sensor. Appl. Spectrosc., 46, S. 912-918, 1992.

[125] U. Panne. Zeitaufgelöste, faseroptisch geführte, multi-dimensionale Fluoreszenz als Sensorprinzip zum Nachweis wassergelöster Fluorophore. Dissertation, Universität Dortmund, 1994. 
[126] V. Westphal. Orts- und Zeitaufgelöste Untersuchungen zum Laserabtrag von Knochensubstanzen. Diplomarbeit, Georg August Universität, Göttingen, 1995.

[127] A. S. Glassner, Editor. An Introduction to Ray-Tracing. Academic Press, 1990.

[128] I. H. Malitson. Interspecimen comparison of the refractive index of fused silica. J. Opt. Soc. Am, 55, S. 1205-1209, 1963.

[129] I.N. Bronstein, K.A. Semendjajew. Taschenbuch der Mathematik. Teubner, Stuttgart, 25. Auflage, 1991.

[130] F. Lewitzka, P. Karlitschek, U. Bünting. Vergleich zweier Laserspektroskopischer Verfahren zum Nachweis von Mineralölkohlenwasserstoffen. Deutsche Bundesstiftung Umwelt, AZ 12562, September 1998. Abschlußbericht.

[131] H. Hein, G. Schwedt. Richt- und Grenzwerte. Vogel, Würzburg, 4. Auflage, 1995.

[132] W.B. Whitten. Time domain optical spectrometry with fiber optical waveguides. Appl. Spectrosc. Rev., 19, S. 325-362, 1983.

[133] W.B. Whitten, H.H. Ross. Fiber optic waveguides for time-of-flight optical spectrometry. Anal. Chem., 51, S. 417-419, 1979.

[134] R.W. Ramirez. The FFT: Fundamentals and Concepts. Prentice-Hall, London, 1985 .

[135] A.V. Oppenheim, R.W. Schafer. Digital Signal Processing. Prentice-Hall, Englewood Cliffs, New Jersey, 1975.

[136] C.S Burrus, T.W Parks. DFT/FFT and Convolution Algorithms. John Wiley \& Sons, New York, 1985.

[137] H.J. Nussbaumer. Fast Fourier Transform and Convolution Algorithms. Springer, New York, 1981.

[138] J. Zupan. Algorithms for Chemists. Wiley, Chichester, UK, 1989. Chapter 5.

[139] L.R. Rabiner, B. Gold. Theory and Application of Digital Signal Processing. Prentice-Hall, Englewood Cliffs, New Jersey, 1975.

[140] H. Martens, T. Naes. Multivariate Calibration. John Wiley and Sons, 1998.

[141] R. Henrion, G. Henrion. Multivariate Datenanalyse. Springer-Verlag, 1995.

[142] M.B. Seasholtz, B. Kowalski. The parsimony principle applied to multivariate calibration. Anal. Chim. Acta, 227, S. 165-177, 1993.

[143] D.M. Bates. Nonlineare Regression Analysis and its Applications. Wiley, New York, 1988.

[144] T. Naes, H. Martens. Principal component regression in NIR analysis. J. Chemometr., 2, S. 155-167, 1988. 
[145] P.J. Gemperline, A. Salt. Principal components regression for routine multicomponent UV determinations. A validation protocol. J. Chemometr., 3, S. 343-357, 1989.

[146] K. Danzer, M. Wagner. Multisignal calibration in optical emission spectroscopy. Fresenius J. Anal. Chem., 346, S. 794-801, 1993.

[147] W. Lindberg, J.A. Persson, S. Wold. Partial Lest Squares Method for spectrofluorimetric analysis of mixtures of humic acid and ligninsulfonate. Anal. Chem., 55, S. 643-648, 1983.

[148] P. MaxLaurin, P.J. Worsfold, M. Crane, P. Norman. Multicomponent Analysis by Ultraviolet/Visible Spectrophotometry with Multivariate Calibration. Anal. Proc., 29, S. 65-68, 1992.

[149] D.C. Baxter, J. Öhman. Multi-component standard additions and partial least squares modelling - a multivariate calibration approach to the resolution or spectral interferences. Spectrochimica Acta B, 45, S. 481-491, 1990.

[150] F. Chan, S. Compton. Multivariate Calibration of Infrared Spectra for Quantitative Analysis Using Designed Experiments. App. Spectros., 42, S. 865-872, 1988.

[151] D.M. Haaland, K.L. Higgins, D.R. Tallant. Multivariate calibration of carbon Raman spectra for quantitative determination of peak temperature history. Vib. Spec., 1, S. 35-40, 1990.

[152] U. Norinder. Analysis of reversed-phase liquid chromatographic separations using the data reduction methods PCR and PLS. Analytica Chimica Acta, 259, S. 105108, 1992.

[153] E.V. Thomas, D.M. Haaland. Comparison of Multivariate Calibration Methods of Quantitative Spectral Analysis. Anal. Chem., 62, S. 1091-1099, 1990.

[154] R. Marbach, H.M. Heise. Calibration Modeling by Partial Least-Squares and Principal Component Regression and its Optimization Using an Impoved Leverage Correction for Prediction Testing. Chemometrics and Intelligent Laboratory Systems, 9, S. 45-63, 1990.

[155] A. Lorber, B.R. Kowalski. Alternatives to Cross-Validatory Estimation of the Number of Factors in Multivariate Calibration. App. Spec., 44, S. 1464-1470, 1990.

[156] K. Pearson. On lines and planes of closest fit to systems of points in space. Philos. Mag. Series 6, 2, S. 559-572, 1901.

[157] C. Spearman. General intelligence, objectively determined and measured. Am. J. of Psychology, S. 201-293, 1904.

[158] H. Hotelling. The relations of the newer multivariate statistical methods to factor analysis. Brit. Journ. Statis. Psychol., 10, S. 69-79, 1957. 
[159] H. Hotelling. Analysis of a complex of statistical variables into principal components. J. Educ. Psychol., 24, S. 417-441,498-520, 1933.

[160] M. Stone, R.J. Brooks. Continuum Regression: Cross-validated Sequentially Constructed Prediction Embracing Ordinary Least Squares, Partial Least Squares and Principal Components Regression. J. Royal Stat. Society, 52B, S. 237-269, 1990.

[161] J. Hartung, B. Elpelt. Multivariate Statistik - Lehrbuch und Handbuch der angewandten Statistik. Oldenbourg, München, 1992.

[162] R.H. Myers. Classical and Modern Regression With Applications. PWS-Kent, Boston, 1989.

[163] M. Otto. Chemometrie. VCH-Verlag, Weinheim, 1997.

[164] T.W. Anderson. An introduction to multivariate statistical analysis. John Wiley and Sons, 1958.

[165] K.V. Mardia, J.T. Kent, J.M. Bibby. Multivariate analysis. Academic Press, London, 1980.

[166] C.R. Rao. The use and interpretation of principal component analysis in applied research. Sankhya A, S. 392-358, 1965.

[167] R.F. Gunst, R.L. Mason. Some considerations in the evaluation of alternate prediction equations. Technometrics, 21, S. 55-63, 1979.

[168] I.T. Joliffe. Principal component analysis. Springer Verlag, New York, 1986.

[169] J. Mandel. Use of the singular value decomposition in regression analysis. The American Statistican, 36, S. 15-24, 1982.

[170] T. Naes, C. Irgens, H. Martens. Comparison of linear statistical methods for calibration of NIR instruments. Appl. Stat., 35, S. 195-206, 1996.

[171] H. Wold. Soft modelling: The basic design and some extensions. In K.G. Joereskog, H. Wold, Editoren, Systems under indirect observation, causality-structureprediction. North Holland, Amsterdam, 1981.

[172] H. Martens, T. Naes. Multivariate calibration by data compression. In P.C. Williams, K. Norris, Editoren, Near-infrared technology in agricultural and food industries, S. 57-87. Am. Assoc. Cereal Chem., St. Paul, Minnesota, USA, 1987.

[173] I. Frank. Intermediate least squares regression method. J. Chemometr., 23, S. 123-125, 1987.

[174] A. Hoeskuldsson. PLS regression methods. J. Chemometr., 2, S. 211-228, 1988.

[175] F. Lewitzka. Wahl des Tauvektors bei der klassischen AFD. Persönliche Mitteilung, 1999. 
[176] P. Karlitschek, F. Lewitzka, U. Bünting, M. Niederkrüger, G. Marowsky. Detection of aromatic pollutants in the environment using UV-Laser-Induced Fluorescence. Appl. Phy. B, 1998.

[177] M.R. Anderberg. Cluster Analysis for Applications. Academic Press, New York, 1973.

[178] H. Späth. Cluster-Analyse-Algorithmen zur Objektklassififzierung und Datenreduktion. Oldenbourg, München, 1975.

[179] N. Bratchell. Cluster Analysis. Chem. Int. Lab. Sys., 6, S. 105-125, 1989.

[180] W.P. Carey, K.O. Beebe, B.R. Kowalski. Multicomponent Analysis Using an Array of Piezoelectric Crystal Sensors. Anal. Chem., 59, S. 1529-1534, 1987.

[181] C. Lanczos. Applied Analysis. Prentice Hall, Englewood Cliffs, 1956.

[182] I. Isenberg, R.D. Dyson, R. Hanson. Studies on the analysis of fluorescence decay data by the method of moments. Biophys. J., 13, S. 1090-1115, 1973.

[183] I. Isenber, E.W. Small. Exponential depression as a test of estimated decay parameters. J. Chem. Phys, 77, S. 2799-2805, 1982.

[184] I. Isenberg. Robust estimation in pulse-fluorometry, a study of the method of moments and least squares. Biophys. J., 43, S. 141-148, 1983.

[185] A. Ruperez, L. Ayala, J.J. Laserna. Double exponential phase plane method for the decay analysis in room temperature phosphorimetry. Spectrochim. Acta A, 48, S. 569-575, 1992.

[186] J.N. Demas, G.A. Crosby. Photoluminescence decay curves: an analysis of the effects of flash duration and linear instrumental distortions. Anal. Chem., 42, S. 1010-1017, 1970.

[187] F.W. Reed, J.N. Demas. An analysis of errors in the phase-plane method of deconvolution luminescence lifetimes. In R.B. Cundall, R.E. Dale, Editoren, TimeResolved Fluorescence Spectroscopy in Biochemistry and Biology, S. 285-296. Plenum Press, New York, 1983.

[188] U.P. Wild, A.R. Holzwarth, H.P. Good. Measurement and analysis of fluorescence decay curves. Rev. Sci. Instrum., 48, S. 1621-1627, 1977.

[189] Z. Bajzer, J.C. Sharp, S.S. Sedarous, F.G. Prendergast. Pade-Laplace method for the analysis of time-resolved fluorescence decay curves. Eur. Biophys. J., 18, S. 101-115, 1990.

[190] M.F. Quinn, S. Joubian, F. Al-Bahrani, S. Al-Aruri, O. Alameddine. A deconvolution technique for determining the intrinsic fluorescence decay lifetimes of crude oils. Appl. Spectrosc., 42, S. 406-410, 1988. 
[191] F. Moreno, R.J. Lopez, F. Gonzalez. Analysis of multiexponential decays through a sine transformation method in single photon decay spectroscopy experiments. Proc. SPIE, 1204, S. 206-211, 1990.

[192] A.E.W. Knight, B.K. Selinger. The deconvolution of fluorescence decay curves. A non-method for real data. Spectrochim. Acta A, 27, S. 1223-1234, 1971.

[193] J.S.D. Birch, R.E. Imhof. Kinetic interpretation of fluorescence decays. Anal. Instrum., 14, S. 293-329, 1985.

[194] A. Grinvald, I.Z. Steinberg. On the analysis of fluorescence decay kinetics by the method of least squares. Anal. Biochem., 59, S. 583-598, 1974.

[195] J. Eisenfeld, C.C. Ford. A systems-theory approach to the analysis of multiexponential fluorescence decay. Biophys. J., 26, S. 73-84, 1979.

[196] D.F. Eaton. Recommended methods for fluorescence decay analysis. Pure \& Appl. Chem., 62, S. 1631-1648, 1990.

[197] B.K. Selinger, C.M. Harris. A Critical Appraisal of Analytical Methods. In R.B. Cundall, R.E. Dale, Editoren, Time-Resolved Fluorescence Spectroscopy in Biochemistry and Biology, S. 155-168. Plenum Press, New York, 1983.

[198] F. Lewitzka, U. Bünting, P. Karlitschek, M. Niederkrüger, G. Marowsky. Quantitative analysis of aromatic molecules in water by laser induced fluorescence spectroscopy and multivariate calibration techniques. In SPIE-Proceedings, 1999. (im Druck).

[199] Structure for S-6957: Sulforhodamin G. On-line Datenbank, Molecular Probes, http://www.probes.com, März 1999.

[200] U. Barjenbruch. Daten der Probenehmer, Tracerversuch Elbe/Pirna. Persönliche Mitteilung, Bundesamt für Gewässerkunde, Koblenz, April 1999.

[201] Harnisch. Tracerausbreitung in Fließgewässern. Persönliche Mitteilung, Bundesamt für Gewässerkunde, Koblenz, April 1999.

[202] D.R. Lide, Editor. CRC Handbook of Chemistry and Physics. CRC Press, Boca Raton, Florida, USA, 73. Auflage, 1992.

[203] D.J. Futoma. Polycyclic Aromatic Hydrocarbons in Water Systems. CRC Press, Boca Raton, Florida, 1981.

[204] D. Mackay, W.Y. Shiu. Aqueous solubility of polynuclear aromatic compounds. Journ. Chem. Eng. Data, 22, S. 399-402, 1977.

[205] W. Karcher. Spectral Atlas of Polycyclic Aromatic Compounds. Kluwer, Dordrecht, 1985.

[206] R.W. Walters, R.G. Luthy. Equilibrium adsorption of polycyclic aromatic hydrocarbons from water onto activated carbon. Environ. Sci. Technol., 18, S. 395-403, 1984. 
[207] R.C. Sims, M.R. Overcash. Fate of polynuclear aromatic compounds (NAs) in soilplant systems. In F.A. Gunther, J.D. Gunther, Editoren, Residue Reviews: Residues of Pesticides and Other Contaminants in the Total Environment, Band 88, S. 1-68. Springer, New York, 1983.

[208] H. Hofmann-Kamensky. Untersuchungen zum Vorkommen und Verhalten von polyzyklischen aromatischen Kohlenwasserstoffen in Waldböden des Ruhr-Emscher Industrieraumes. Dissertation, Universität GH Paderborn, 1993. 


\section{Index}

BeER, 5

HÜCKEL, E., 4

KASHA, 5

KeKulÉ, 3

LAMBERT, 5

LEWIS, 5

PAUling, L., 4

Abklingdauer, siehe Lebensdauer

Abklingzeiten, 67

Absorptionskoeffizient (linearer), 6

Absorptionskoeffizient (molarer), 5

abstrakte Faktorzerlegung, 66

Akzeptanzwinkel, 10

Altlasten, 1

ANFD-Spektren, 68

Anthracen, 4

Arene, 3

Basisspektren, 70

Benzol, 3, 93

bewertetes Beobachtungsvolumen, 21

Bezeichnung der Auswertemethoden, 66

Brewster-Fenster, 14

BRM-AFD, 73

BTXE, 93

C-AFD, 79

CCD-Kamera, 14

CCD-Meßsystem, 20

CLS, 56

collection efficiency, siehe Optrodeneffizienz

cond, siehe Konditionszahl

cross validation, siehe Kreuzvalidierung

Datensatz, 65

datensatzübergreifender Vorhersagefehler, 66

Deuterierung, 14

DGPS, 104

Diesel, 42

digitale Konzentrationsänderung, 65

Dimension des Tauvektors, 76

Diodenlaser, 13

DOC (dissolved organic compounds), 93

Einheitsspektren, 7
Elektronengrundzustand, 7

Energiemonitor, 13

Ethyl-Benzol, 93

Excimerlaser, 13

Faktorenzahl, 83

FAP-CONTROL, 115

Farbstofflaser, 13

Fasertransmission, 14

Fensterzerlegung, 83

fingerprint-Verfahren, 94

Flop, 76

Fluoreszenz, 5

Franck-Condon-Prinzip, 8

Frequenzkonversion, 13

Frequenzmischung, 15

FT-AFD, 67

gain, 16

Generalisierte Inverse, 54

Glasfaser, 9

GPS, 96

Grenzwinkel, 9

Hauptkomponentenanalyse, siehe PCA

Hauptkomponentenregression, siehe PCR

Herzform, 107

Holländischen Liste, 43

HOMO, 8

integrales Spektrum, 68

Interventionswert, 43

Jablonski-Diagramm, 7

Kalibration, siehe Regression

Kalibrationsteil, 65

Kanal, 65

Kantenfilter, 14

Karzinogene, 3

Koeffizientenmatrix, 54, 55

Konditionszahl, 56

Korrelation, 89

Kreuztest, 79

Kreuzvalidierung, 63

Löslichkeit, 87

Lebensdauer, 5 
Lichtleitkabel, siehe Glasfaser

lineare Regression, 56

lineares Mischungsmodell, siehe LMM

lineares Modell, 54

LMM, 6, 56

Lumineszenz, 5

LUMO, 8

Matrixzerlegung, 66

MKW-Konzentrationen in Böden, 42

MLR, 56

Multikollinearität, 83

Multiplizität, 5

Multivariate ..., siehe Regression

naßchemische Analyse, 1

Nachweisgrenzen, 87

Naphthalin, 4

Nd:YAG-Laser, 13

negative Spektren, 68, 72

Nicht-negative Faktorzerlegung, 68

nichtlinearer Prozesse, 13

NNFD-Spektren, 68, 73

Notch-Filter, 14

Nullsignal, 87

Numerische Apertur, 10

OLS, 55, 56, 83

Optrode, 17, 21

Optrodeneffizienz, 21, 24

ordinary least squares, siehe OLS

OSO-Fraktion, 42

PAK, 3, 4

PAK-Eintrag in die Biosphäre, 3

partial least squares, siehe PLS

PCA, 57

PCR, 55, 57, 58, 83

Peltier-Element, 16

PEM-AFD, 73

Phosphoreszenz, 5

Photolumineszenz, 5

PLS, 55, 59, 83

PLS1, 60

PLS2, 61

PMT-Meßsystem, 20

Pockelszelle, 14
Poisson-Rauschen, 66

polyzyklische aromatische Kohlenwasserstoffe, siehe PAK

principal components, siehe PCA

principal components regression, siehe $\mathrm{PCR}$

pseudo-reale Spektren, 65

Pseudoinverse, 54

Quarzglasfasern, 10

Querempfindlichkeit, 87

Querprofil, 103

Rangreduktion, 83

reale Spektren, 65

Regressandenmatrix, 55

Regression, 54, 83

Regressionskoeffizienten, 56

Regressormatrix, 55

Residuen, 7, 55

RM-AFD, 70

Rotationszustand, 7

Selective Availability, 96

sequentielle Zeitfenster, 18

signifikante Faktoren, 63

Simplex-Verfahren, 72, 76

Singulärwertzerlegung, siehe SVD

Snelliussches Brechungsgesetz, 10

Spektrale Ähnlichkeit, 89

spektrale Informationen, 65

SRG, 96

SRG-Kalibration, 100

Stickstofflaser, 13

SVD, 56

Tauvektor, 67, 76

Toluol, 93

Totalreflexion, 9

Tracer, siehe SRG

Tracerversuch, 94

Triggerung des Bildverstärkers, 13

Übersättigung, 87

Validationsteil, 65

Vergleich von Analysemethoden, 66

vergleichender Vorhersagefehler, 64 
Vibrationszustand, 7

Vielkanalanalysator, 15

Vorhersagefehler, 64, 73

wahlfreie Zeitfenster, 19

wellenlängensequentieller Nachweis, 20

Windsor-Rohöl, 42

Xylol, 93

Zeitfenster, 18

Zeitscheiben, 65

zeitsequentieller Nachweis, 20 


\section{Danke an...}

...Herrn Prof. Dr. Marowsky und Herrn Prof. Dr. Schaback für die Betreuung der Arbeit und Herrn Prof. Dr. Ronneberger für die Übernahme des Korreferats,

...die Lehrer, die mein Leben mehr geprägt haben, als sie vielleicht glauben: P. Burdich, D. Frey und F. Oellrich,

...meine Arbeitsgruppe Peter Karlitschek, Frank Lewitzka, Matthias Niederkrüger, Tobias Nörthemann und Uta Bongenberg für kreatives innovatives zielorientiertes Mitgeforsche. Ganz besonderen Dank an Frank für die vielen Stunden, in denen wir drei alleine waren: Du, ich und die multivariate Kalibration,

...Matthias, Stefan und meiner Mutter für die Hilfe bei Probennahme und Messungen,

...Frank, Matthias, Uta, Eike und Peter für das Korrekturlesen der Arbeit,

...meine treue Mensagruppe Dirk und Stefan dafür, daß sie den Forschungsalltag erträglich gemacht haben und

...Monika, durch die ich in den letzten Monaten selbst in dunklen Stunden vor dem Rechner das Gefühl hatte, daß das Leben doch eigentlich schön ist,

...als letztes und als erstes wieder meinen Eltern!

Diese Arbeit wurde im Laser-Laboratorium Göttingen e.V. angefertigt und vom Bundesministerium für Bildung und Forschung (BMBF) finanziell unterstützt. 